\title{
DURABILITY OF ADVANCED CEMENT-BASED MATERIALS USED AS REPAIRS FOR DETERIORATED CONCRETE
}

\author{
by \\ Keikhosrow Tahmureszadeh \\ B.Eng., Ryerson University, Toronto, Ontario, Canada, 2016
}

A thesis
presented to Ryerson University

in partial fulfillment of the

requirements for the degree of

Master of Applied Science

in the program of

Civil Engineering

Toronto, Ontario, Canada, 2018

(C) Keikhosrow Tahmureszadeh, 2018 


\section{Author's Declaration}

I hereby declare that I am the sole author of this thesis. This is a true copy of the thesis, including any required final revisions, as accepted by my examiners.

I authorize Ryerson University to lend this thesis to other institutions or individuals for the purpose of scholarly research.

I further authorize Ryerson University to reproduce this thesis by photocopying or by other means, in total or in part, at the request of other institutions or individuals for the purpose of scholarly research.

I understand that my thesis may be made electronically available to the public. 


\title{
DURABILITY OF ADVANCED CEMENT-BASED MATERIALS USED AS REPAIRS FOR DETERIORATED CONCRETE
}

\author{
Keikhosrow Tahmureszadeh \\ Master of Applied Science 2018 \\ Civil Engineering \\ Ryerson University
}

\begin{abstract}
With advanced technology, the production of strong construction material becomes more feasible. However, use of such materials as repairs on top of existing concrete is challenging, since repair system relies not only on the quality of repair but also on the interaction and compatibility of such material with the substrate. Studies regarding the durability of bond strength are limited. Therefore, the objective of this research is to compare the bond strength and durability performance of advanced cement-based materials including ultra-high performance concrete (UHPC), engineered cementitious composite with slag (ECC-Slag), specialized repair material with self-consolidating properties (SCC), and normal concrete (NC) under two common deterioration modes in Canada (freeze-thaw cycles with de-icing salt, and volumetric expansion of the substrate). The freeze-thaw cycle results show higher bond strength and durability performance for UHPC and NC, respectively. Under expanding deterioration, NC started with higher bond strength and UHPC revealed the best durability performance.
\end{abstract}




\section{Acknowledgments}

I would like to extend my deepest and sincere gratitude to Dr. Medhat Shehata for his continuous support and dedication throughout my studies at Ryerson University. Without his invaluable guidance, inspirational expertise in concrete materials, and trust I would not have had the opportunity to complete this thesis. It was truly a great honour to work with him and I hope to instill everything he has taught me in my future career.

I would like to extend special thanks to my parents for their love and unwavering support throughout my life. My accomplishments are a result of their constant guidance and encouragement.

I would like to thank the entire research team of Dr. Medhat Shehata, more particularly the Ph.D candidate: Noura Sinno, MASc graduate: Gregory Richards, and undergraduate research assistant: Seyed Saeed Naseri. I also acknowledge the technical help and valuable advice of the Civil Engineering technicians at Ryerson University Nidal Jaalouk, Domenic Valle, and Min Yao (deceased-RIP).

Funding of this research project was provided by the Natural Sciences and Engineering Research Council of Canada (NSERC) through the NSERC ENGAGE Grant between Ryerson University and industry partner $\mathrm{CRH}$ Canada. The author acknowledges the inkind contribution and collaboration of $\mathrm{CRH}$ Canada. Sincere thanks to Dr. Bill Gong from $\mathrm{CRH}$ Canada for his valuable feedback and comments during this research. 


\section{Dedication}

To my parents who scarified for my success and my brothers who always support me 


\section{Table of Contents}

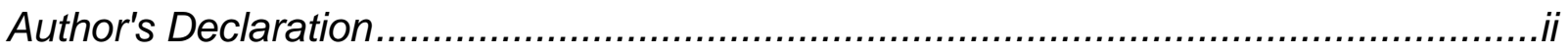

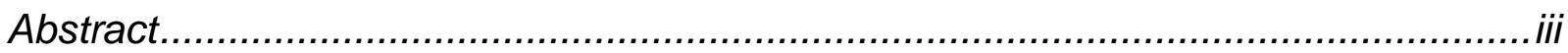

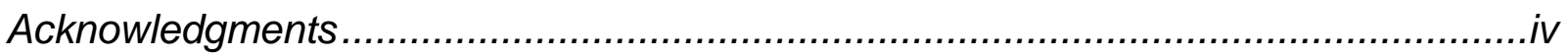

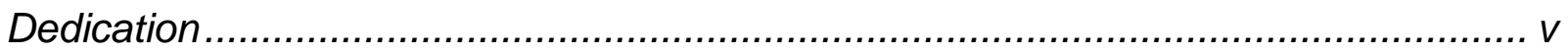

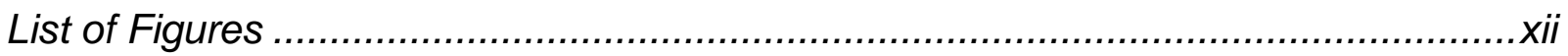

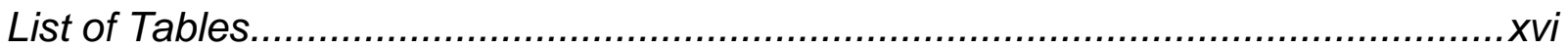

List of Equations ................................................................................................... xviii

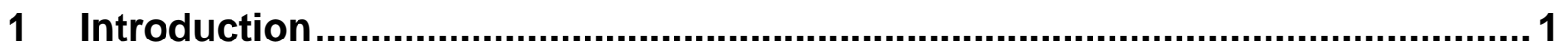

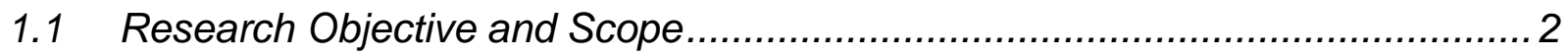

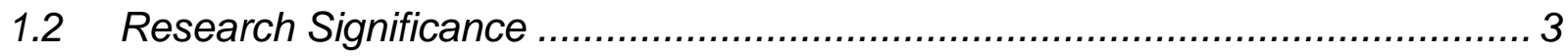

2 Literature Review on Bond Interface Properties for Repair Materials ............... 4

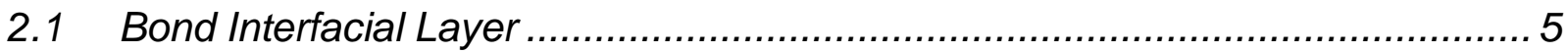

2.2 Type of Material Used as Repairs and Their Requirements............................ 7

2.2.1 Ultra-High Performance Concrete (UHPC) …......................................... 7

2.2.1.1 Background and Fundamental Principles ....................................................... 7

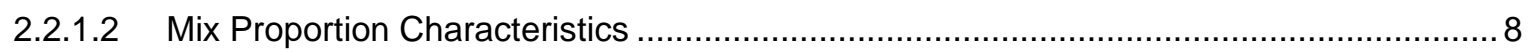

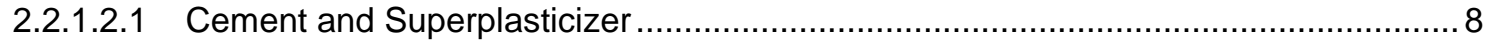

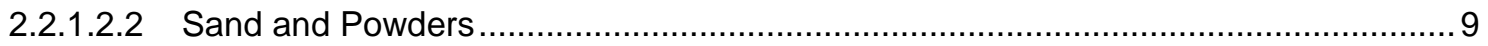

2.2.1.2.3 Supplementary Cementitious Materials (SCMs) …........................................ 10

2.2.1.2.4 Steel Discontinuous Short Fibers .................................................................. 11

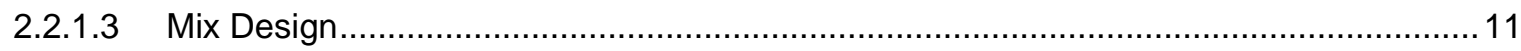

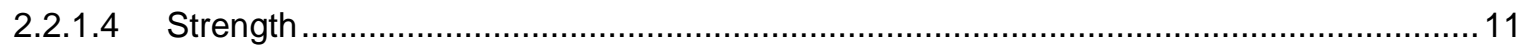

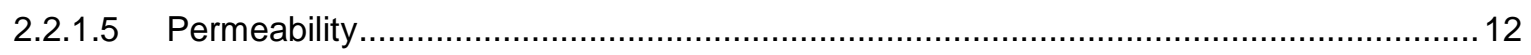




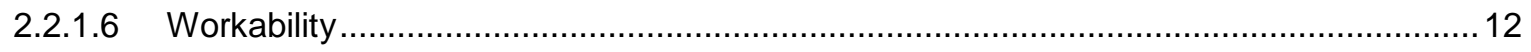

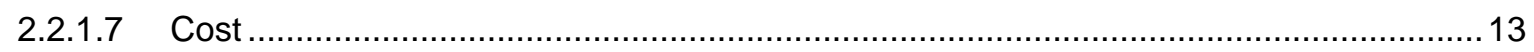

2.2.2 Engineered Cementitious Composites (ECC) ..................................... 14

2.2.2.1 Background and Fundamental Principles .......................................................... 14

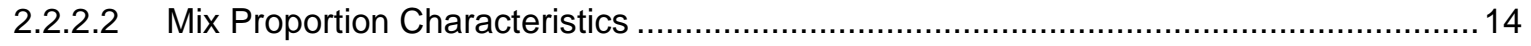

2.2.2.2.1 Discontinuous Short Polymer Fibers ............................................................ 14

2.2.2.2.2 PVA-ECC Mix Design with Fly Ash (Type F) and Silica Sand (PVA-ECC-FS)........ 15

2.2.2.2.3 PVA-ECC Mix Design with Slag and Limestone Powder (PVA-ECC-SL) ...............17

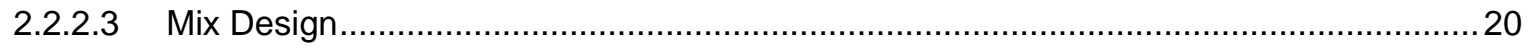

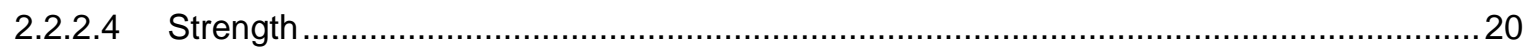

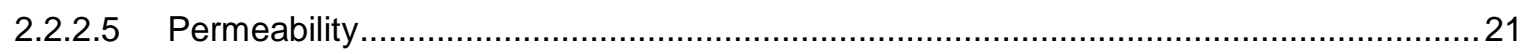

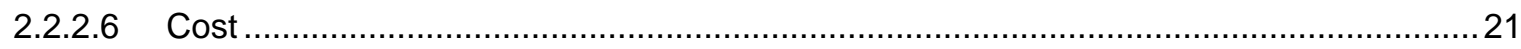

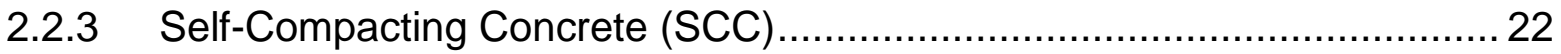

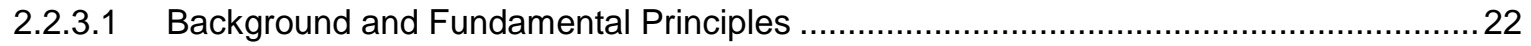

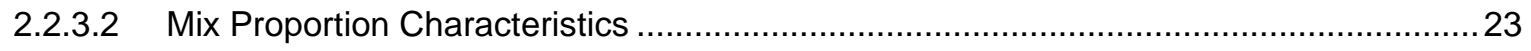

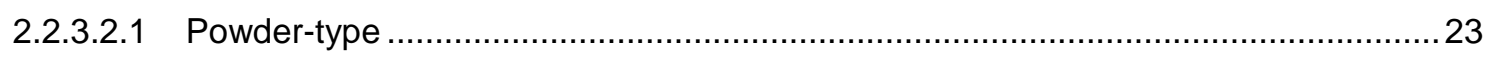

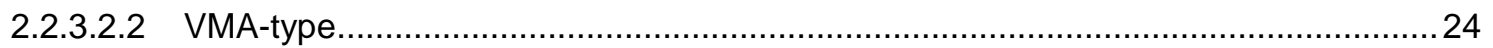

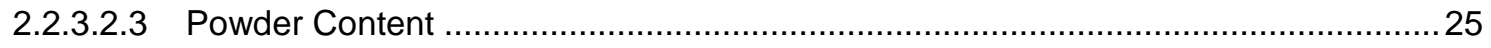

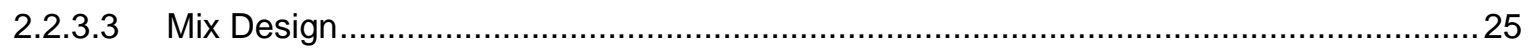

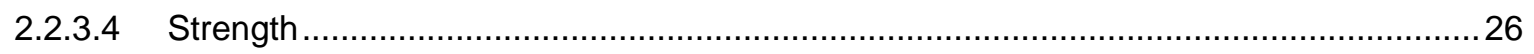

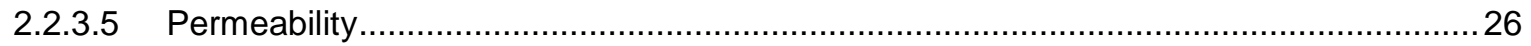

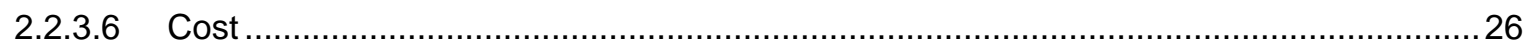

2.3 Materials Properties and Compatibility of Repairs with Substrate.................27

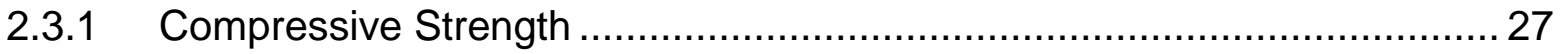

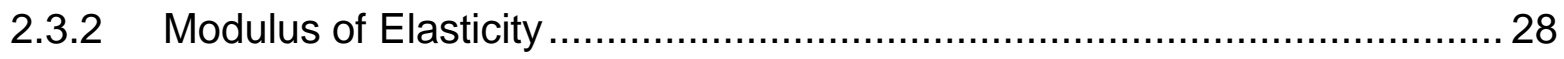

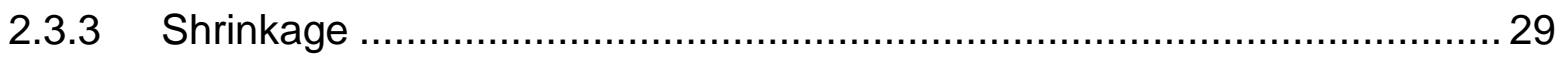




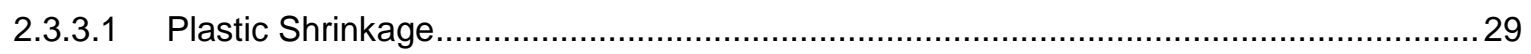

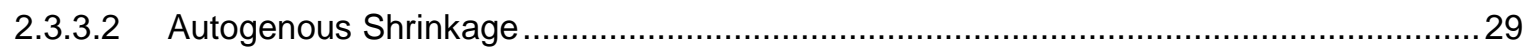

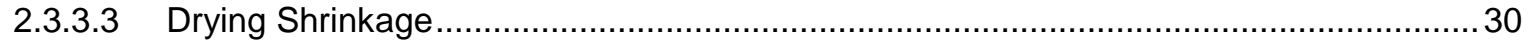

2.4 Substrate Surface Preparation .............................................................. 30

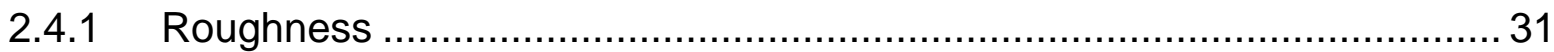

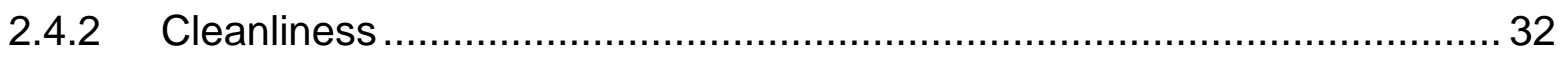

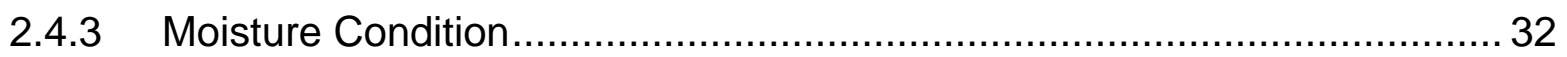

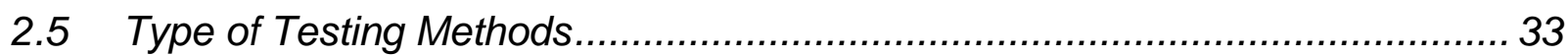

2.5.1 Direct Tensile Stress .................................................................... 33

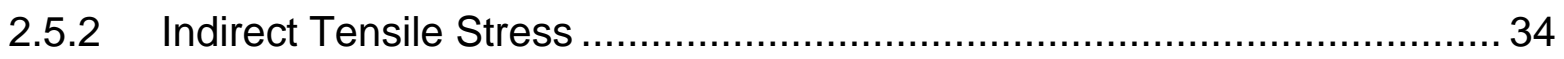

2.5.3 Combined Shear and Compression Stress............................................. 35

3 Materials and Experimental Program ............................................................... 36

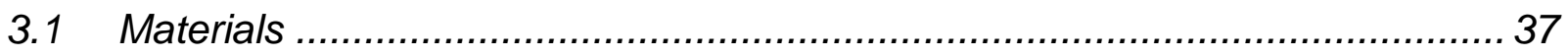

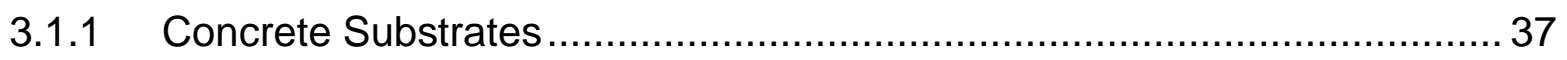

3.1.1.1 Substrate A (Sub-A) - Normal Conventional Concrete (NC) …................................ 37

3.1.1.2 Substrate B (Sub-B) - Alkali-Carbonate Reaction Concrete (ACR) .......................... 38

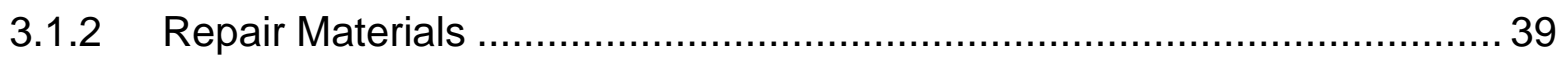

3.1.2.1 Ultra-High Performance Concrete (UHPC) …........................................................ 39

3.1.2.2 Engineered Cementitious Composite (ECC-Slag) ............................................... 40

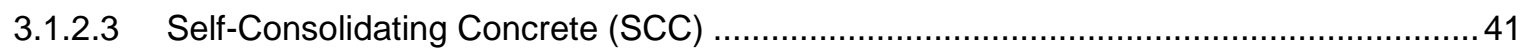

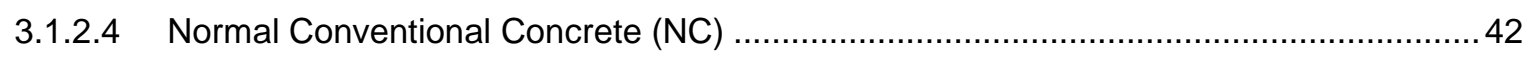

3.2 Materials Properties and Compatibility of Repairs with Substrate (Phase-I) .... 43

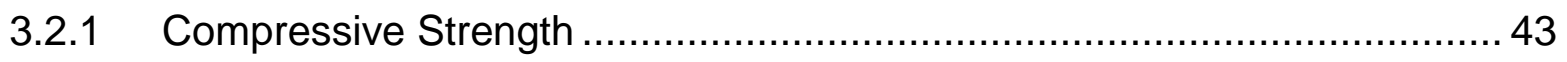

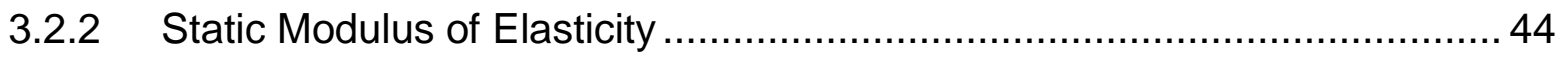

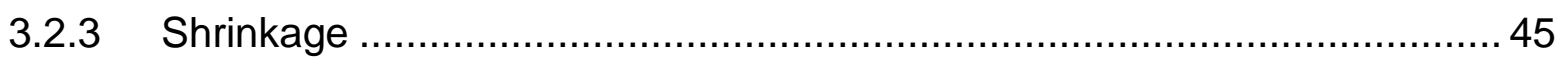




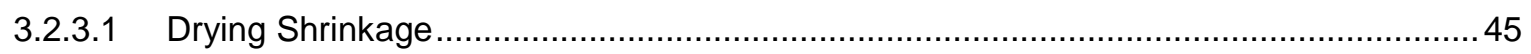

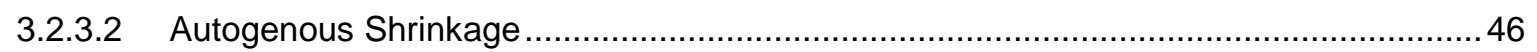

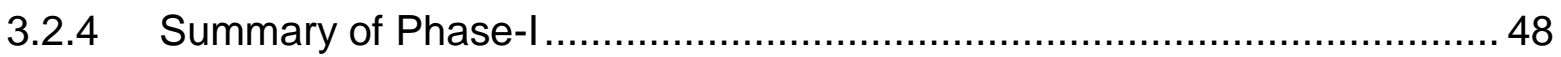

3.3 Repairs under Freeze-Thaw Cycles with De-icing Salt (Phase-II).................. 49

3.3.1 Sub-A Preparation ............................................................................... 49

3.3.1.1 Casting, Surface Roughness, and Curing ............................................................ 49

3.3.1.2 Stabilizing the Substrate (Sub-A) Shrinkage ....................................................... 52

3.3.1.3 Moisture Condition at the Time of Applying Repairs ..................................................5 53

3.3.2 Applying Repairs and Conditioning (Sub-A and Repair Products) ............. 54

3.3.3 Length Change of Concrete Prisms Following the Testing Conditions ...... 56

3.3.4 Bond Strength Testing Methods .......................................................... 58

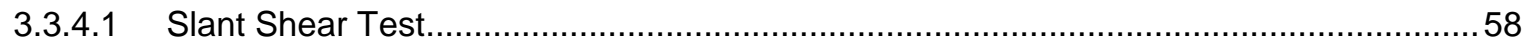

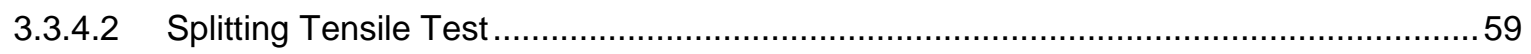

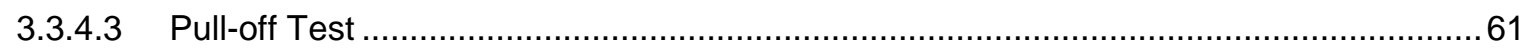

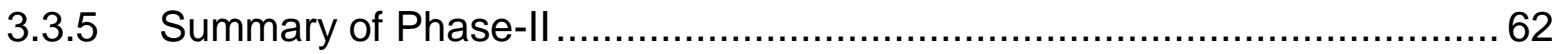

3.4 Repairs Placed on Expanding Substrate - Suffering ACR (Phase-III) .............63

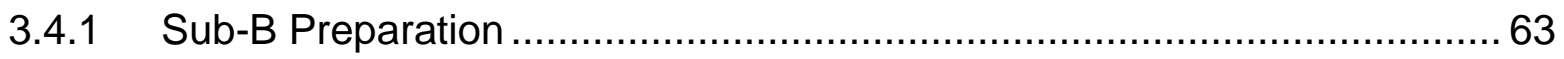

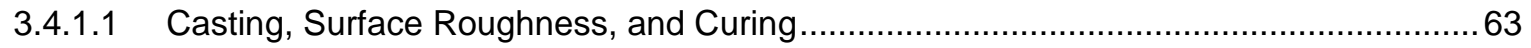

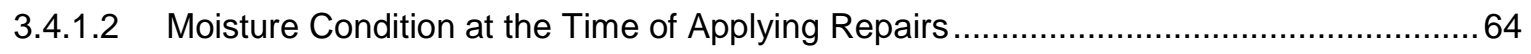

3.4.2 Applying Repairs and Conditioning (Sub-B and Repair Products) ............ 64

3.4.3 Length Change of Concrete Prisms Following the Testing Conditions ....... 65

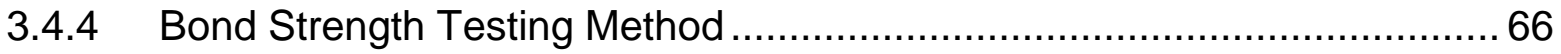

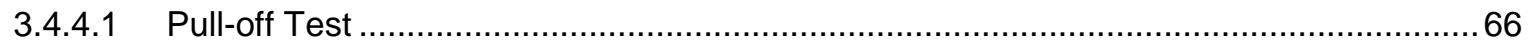

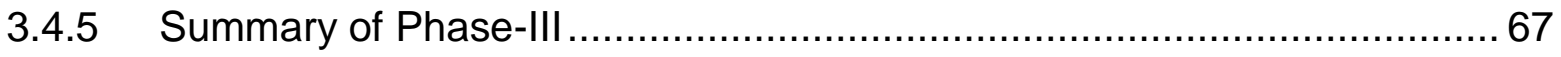

3.5 Summary of the Experimental Program ...................................................6 68 
4 Results and Analysis.

4.1 Materials Properties and Compatibility of Repairs with Substrates (Phase-I) .. 69

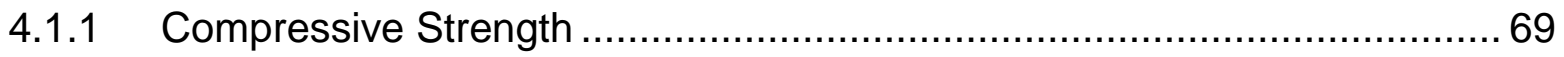

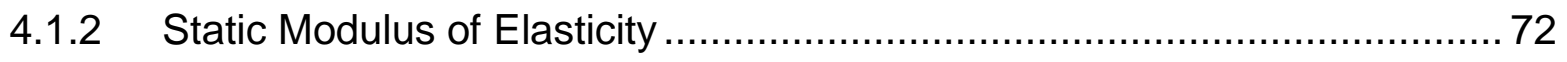

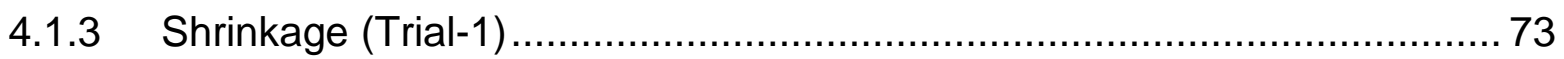

4.1.3.1 Repeatability of the Shrinkage (Trial-2) ………………………………………....75

4.2 Repairs under Freeze-Thaw Cycles with De-icing Salt (Phase-II).................. 77

4.2.1 Length Change of Concrete Prisms Following the Testing Conditions ...... 77

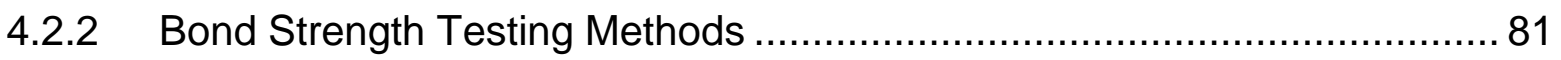

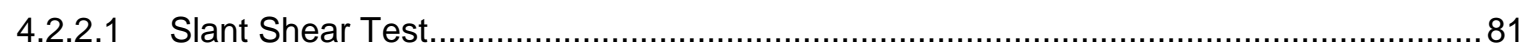

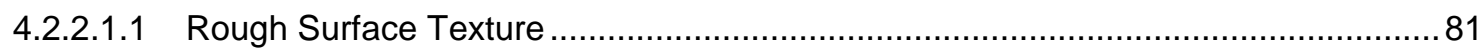

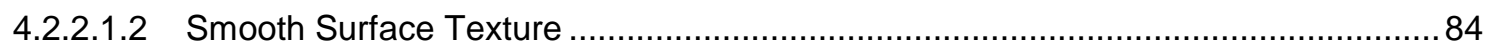

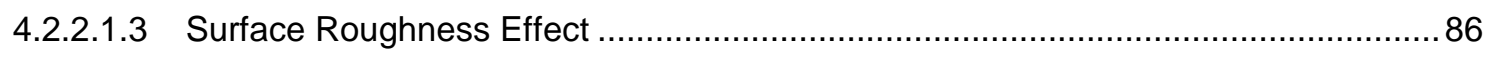

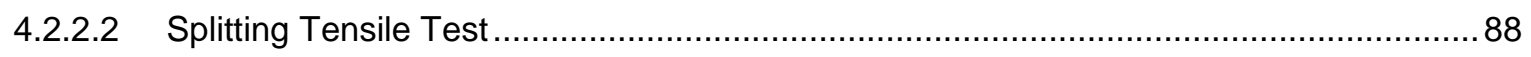

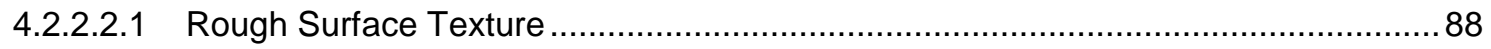

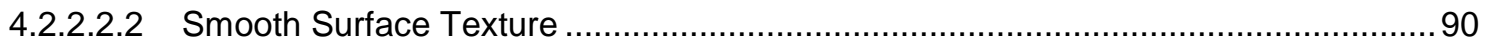

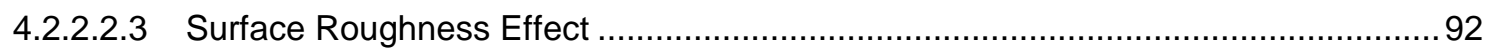

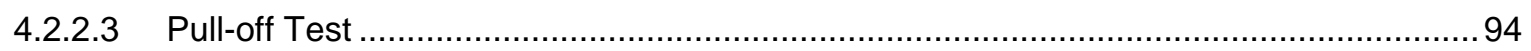

4.3 Repairs Placed on Expanding Substrate - Suffering ACR (Phase-III) ............. 97

4.3.1 Length Change of Concrete Prisms Following the Testing Conditions ...... 97

4.3.2 Bond Strength Testing Method ............................................................ 99

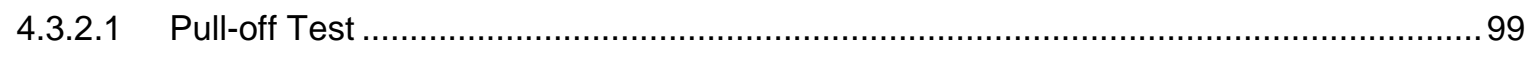

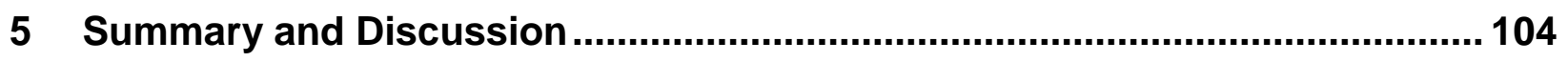

5.1 Materials Properties and Compatibility of Repairs with Substrate (Phase-I) .. 104

5.1.1 Compressive Strength ............................................................. 104 


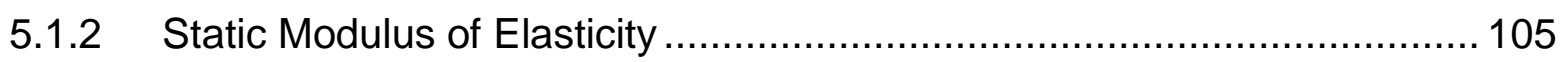

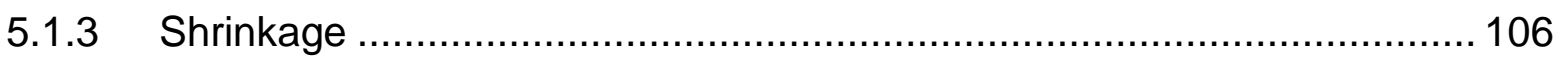

5.2 Repairs under Freeze-Thaw Cycles with De-icing Salt (Phase-II)................. 107

5.2.1 Length Change of Concrete Prisms Following the Testing Conditions .... 107

5.2.2 Bond Strength Testing Methods .................................................... 107

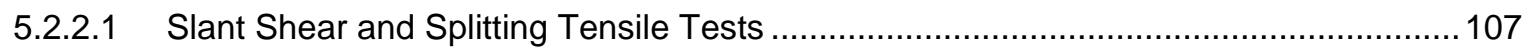

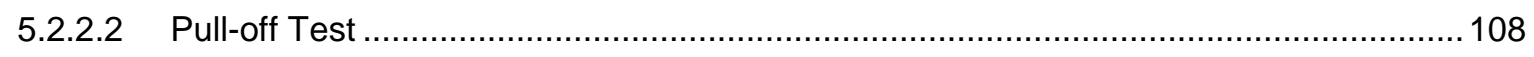

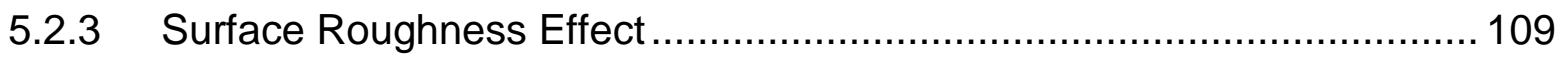

5.2.3.1 Surface Roughness Effect for Different Testing Methods..................................... 109

5.2.3.2 Surface Roughness Effect for Different Repair Materials ....................................... 109

5.3 Repairs Placed on Expanding Substrate - Suffering ACR (Phase-III) ........... 110

5.3.1 Bond Strength Testing Method ....................................................... 110

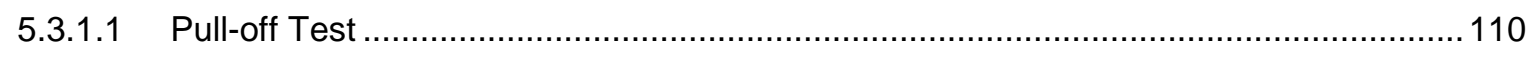

5.4 Validation of the Bond Strength Testing Results ..................................... 111

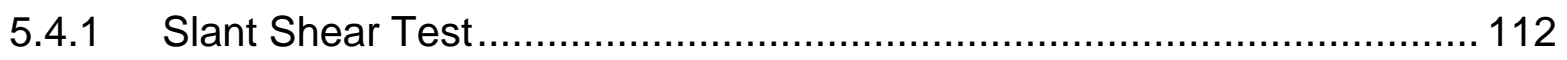

5.4.2 Splitting Tensile Test ................................................................... 113

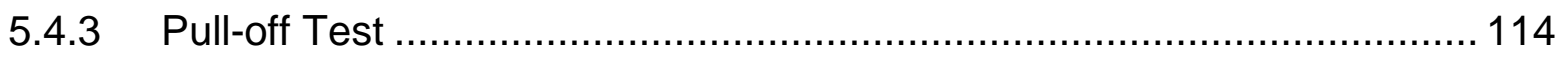

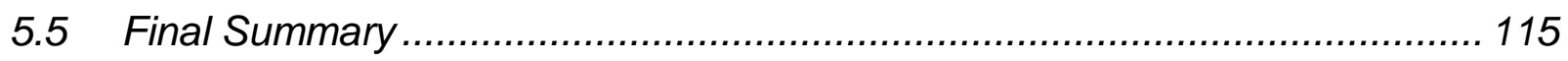

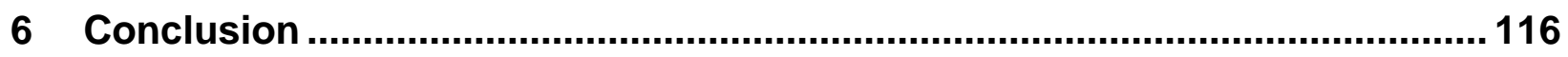

6.1 Materials Properties and Compatibility of Repairs with Substrate (Phase-I) .. 116

6.2 Repairs under Freeze-Thaw Cycles with De-icing Salt (Phase-II)................. 116

6.3 Repairs Placed on Expanding Substrate - Suffering ACR (Phase-III) ........... 117

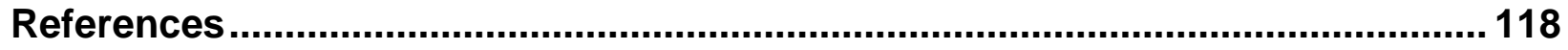




\section{List of Figures}

Figure 2-1: Wall Effect Illustration (Scrivener et al., 2004) ........................................ 5

Figure 2-2: Effect of Silica Fume on ITZ (Scrivener et al., 2004) ................................ 6

Figure 2-3: Grain Size Comparison of NC and UHPC (Zdeb, 2013) .......................... 9

Figure 2-4: High-pressure Mercury Porosimetry Test (Fehling et al., 2014) ................. 12

Figure 2-5: Multiple-micro Cracks under Bending of PVA-ECC (S. Wang \& Li, 2005) .. 16

Figure 2-6: Compressive Strength of PVA-ECC-FS (S. Wang \& Li, 2005) .................... 16

Figure 2-7: Crack width Development of PVA-ECC-FS (S. Wang \& Li, 2005) .............. 16

Figure 2-8: Tensile Strength-Strain of PVA-ECC-FS (S. Wang \& Li, 2005).................. 16

Figure 2-9: Bending Strength-Displacement of PVA-ECC-FS (S. Wang \& Li, 2005)..... 16

Figure 2-10: Drying Shrinkage Behaviour of PVA-ECC-FS (S. Wang \& Li, 2005)......... 16

Figure 2-11: Crack Width under Restrained Drying Shrinkage (S. Wang \& Li, 2005) ... 17

Figure 2-12: Autogenous Shrinkage of PVA-ECC-FS-M45 (S. Wang \& Li, 2005) ......... 17

Figure 2-13: Tensile Strength-Strain of PVA-ECC-SL (Zhou et al., 2010) .................... 18

Figure 2-14: Bending Strength-Displacement of PVA-ECC-SL (Zhou et al., 2010)....... 18

Figure 2-15: Particle Size of Slag, Limestone Powder \& Cement (Zhou et al., 2010) ... 19

Figure 2-16: Mix Design of SCC and NC (Kosmatka, Kerkhoff, \& Panarese, 2003) ..... 24

Figure 2-17: Volume Fraction Comparison of SCC \& NC (Bonen \& Shah, 2005) .......... 24

Figure 2-18: (a) Direct Tensile Test and (b) Pull-off Test (Espeche \& León, 2011)........ 34

Figure 2-19: Indirect Tensile Testing Methods - Bending (Saucier et al., 1991) ........... 34

Figure 2-20: Indirect Tensile Testing Method - Shear (Espeche \& León, 2011) ............ 35

Figure 2-21: Combined Shear \& Compression Tests (Saucier et al., 1991) .................. 35 
Figure 3-1: Compressive Strength Test before Crushing at 28 Days .......................... 43

Figure 3-2: Compressive Strength Test after Crushing at 28 Days ............................ 43

Figure 3-3: Static Modulus of Elasticity Measurements ........................................... 44

Figure 3-4: Standard Concrete Prisms Used for Drying Shrinkage ............................. 45

Figure 3-5: Exact Shrinkage Room Temp/RH by HOBO Sensor ................................ 46

Figure 3-6: Substrate Preparation for Slant Shear and Splitting Tensile Tests ............. 49

Figure 3-7: Typical Smooth Surface Texture ....................................................... 50

Figure 3-8: Typical Rough Surface Texture ......................................................... 50

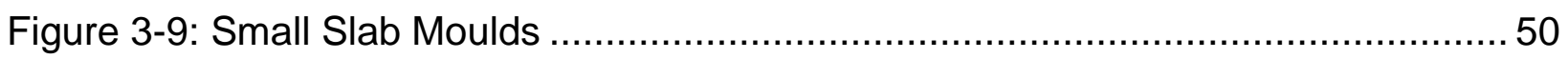

Figure 3-10: Sub-A Specimens in the Curing Room ................................................. 51

Figure 3-11: Typical Curing Room Temp/RH by HOBO Sensor ...................................51

Figure 3-12: Sub-A Specimens in Shrinkage Room ................................................. 52

Figure 3-13: Typical Shrinkage Room Temp/RH by HOBO Sensor ............................. 53

Figure 3-14: Preparation of Sub-A Samples Moisture Content ................................... 53

Figure 3-15: Typical Freezing and Thawing Cycles with De-icing Salt for Cylinders ..... 55

Figure 3-16: Typical Freezing and Thawing Cycles with De-icing Salt for Slabs ........... 55

Figure 3-17: Typical Temperature Profile of the Freezer by HOBO Sensor ................... 55

Figure 3-18: Freezing of the 5 Sets of Concrete Prisms with De-icing Salt ...................56

Figure 3-19: Thawing of the 5 Sets of Concrete Prisms with De-icing Salt .................. 56

Figure 3-20: Length Change Measurements of the Prisms ......................................5 57

Figure 3-21: Typical Condition of the Prisms after 50 Freeze-Thaw Cycles with Salt ... 57

Figure 3-22: Slant Shear Test - from Left to Right: UHPC, ECC, SCC, \& NC ...............59

Figure 3-23: Typical Slant Shear Failure-Smooth Surface (UHPC, ECC, SCC, \& NC) . 59

Figure 3-24: Typical Slant Shear Failure-Rough Surface (UHPC, ECC, SCC, \& NC) ... 59 
Figure 3-25: Splitting Tensile Test - from Left to Right: UHPC, ECC, SCC, \& NC........60 60 Figure 3-26: Typical Splitting Failure-Smooth Surface (UHPC, ECC, SCC, \& NC) ....... 60

Figure 3-27: Typical Splitting Failure-Rough Surface (UHPC, ECC, SCC, \& NC) ......... 60

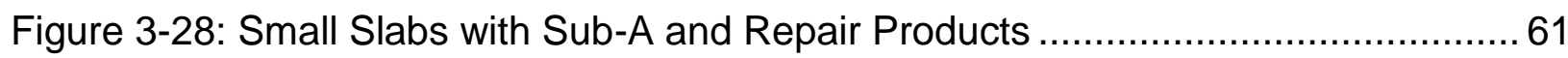

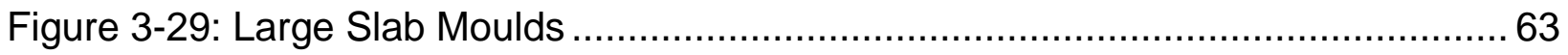

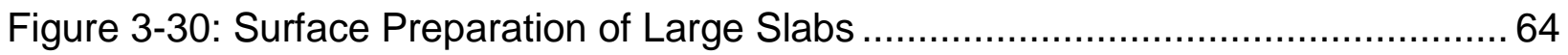

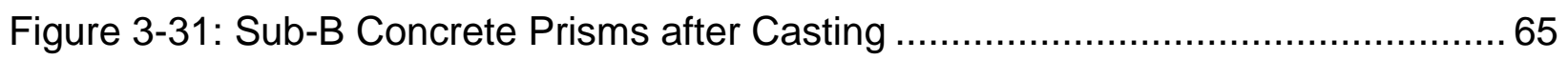

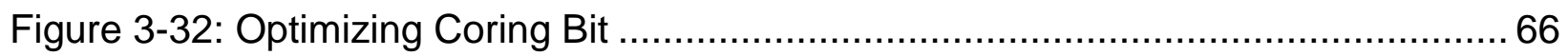

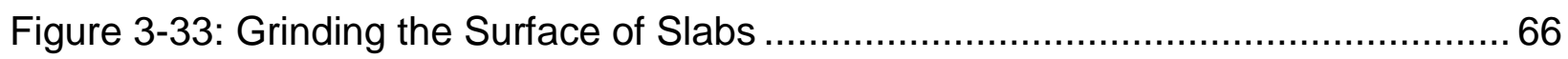

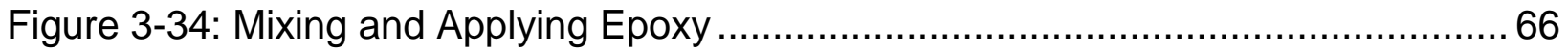

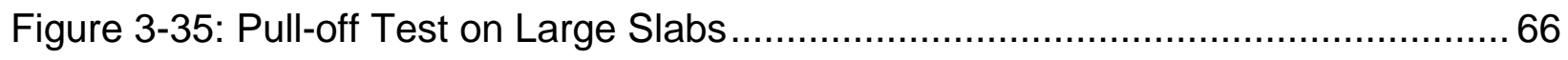

Figure 4-1: Compressive Strength Results........................................................ 70

Figure 4-2: Stress-Strain Curve for Substrates and Repair Products ........................... 72

Figure 4-3: Drying Shrinkage According to MTO LS-435-R28 ….............................. 73

Figure 4-4: Combined Autogenous and Drying Shrinkage …................................... 73

Figure 4-5: Repeatability of the Combined Autogenous and Drying Shrinkage e............. 75

Figure 4-6: Length Change of Concrete Prisms Following the Testing Conditions ....... 77

Figure 4-7: Bond Strength Results of Slant Shear Test - Rough Texture ................... 81

Figure 4-8: Slant Shear ECC-Slag Rough Samples at 15C-F\&T .............................. 83

Figure 4-9: Slant Shear ECC-Slag Rough Samples at 21C-F\&T (Debonded)............... 83

Figure 4-10: Bond Strength Results of Slant Shear Test - Smooth Texture ................. 84

Figure 4-11: Slant Shear ECC-Slag Smooth Samples at 2C-F\&T .............................. 85

Figure 4-12: Slant Shear ECC-Slag Smooth Samples at 5C-F\&T .............................. 85

Figure 4-13: Surface Roughness Effect for Slant Shear Test.................................... 86 
Figure 4-14: Bond Strength Results of Splitting Tensile Test - Rough Texture 88

Figure 4-15: Splitting Tensile SCC Rough Samples at 5C-F\&T .................................. 89

Figure 4-16: Splitting Tensile UHPC Rough Samples at 5C-F\&T.............................. 89

Figure 4-17: Bond Strength Results of Splitting Tensile Test - Smooth Texture............ 90

Figure 4-18: ECC-Slag Splitting Tensile Samples with Smooth Texture at 21C-F\&T.... 91

Figure 4-19: Surface Roughness Effect for Splitting Tensile Test .............................. 92

Figure 4-20: Bond Strength Results of Pull-off Test - Smooth Texture ........................94

Figure 4-21: ECC-Slag Pull-off Slab with 4 Specimens at 5C-F\&T (Debonded) ............96

Figure 4-22: SCC Pull-off Slab with 4 Specimens at 5C-F\&T.................................... 96

Figure 4-23: UHPC Pull-off Slab with 4 Specimens at 5C-F\&T .................................... 96

Figure 4-24: NC Pull-off Slab with 4 Specimens at 5C-F\&T ......................................96

Figure 4-25: Length Change of the Sub-B Following the Testing conditions.................97

Figure 4-26: Expansion Cracks on the Sub-B Prisms During 2M-Curing $+5 \mathrm{M} \ldots \ldots \ldots \ldots . . . .98$

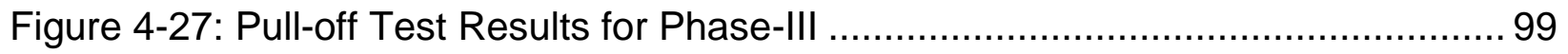

Figure 4-28: Start of Debonding Crack for the ECC-Slag at 1M-Curing ..................... 100

Figure 4-29: Debonding Crack for the ECC-Slag at 2M-Curing............................... 101

Figure 4-30: Start of Debonding Crack for the SCC at 2M-Curing + 3M ................... 102

Figure 4-31: Debonding Crack for the SCC at 2M-Curing + 5M ............................. 102 


\section{List of Tables}

Table 2-1: Typical UHPC Mix Compositions and Recommended .............................. 11

Table 2-2: Typical PVA-ECC Mix Proportion by Cement Weight ................................. 20

Table 2-3: Typical SCC Mix Design Proportions …................................................... 25

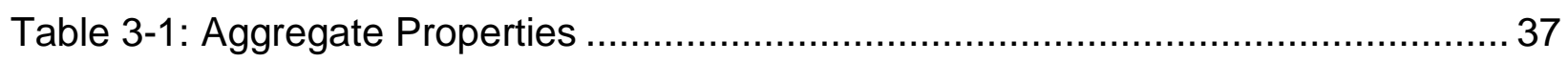

Table 3-2: Chemical Composition of General Use Portland cement (GU PC) ............... 38

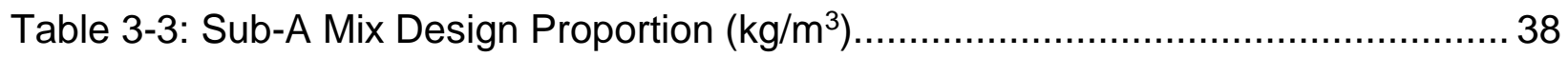

Table 3-4: Chemical Composition of the Pittsburg Aggregate (Shehata et al., 2017) ... 39

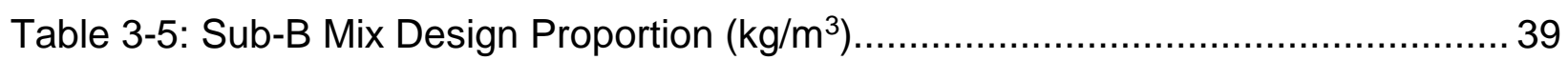

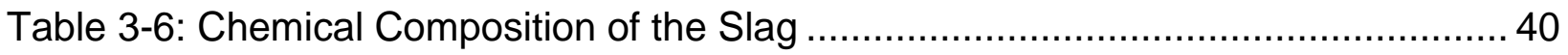

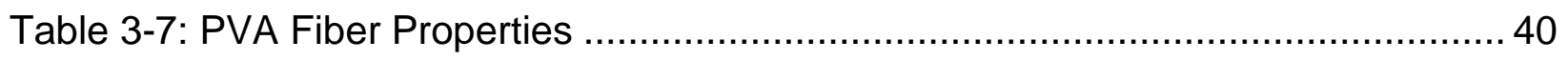

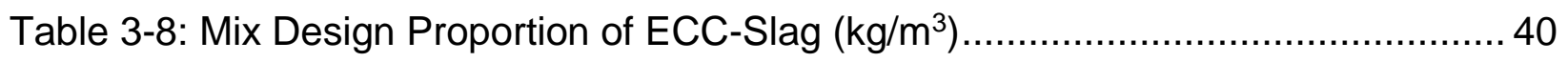

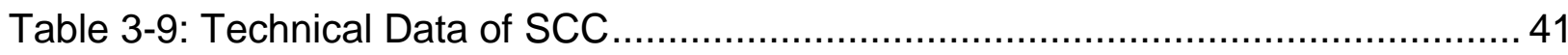

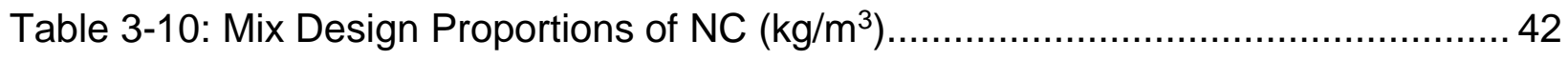

Table 3-11: Daily Mass Loss of Water Evaporation Measurements ............................. 47

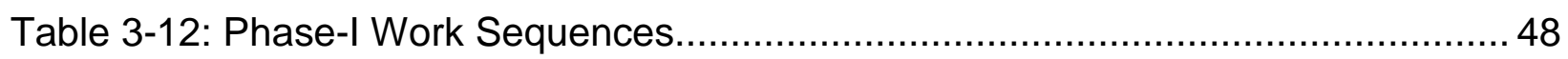

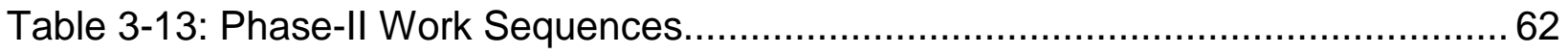

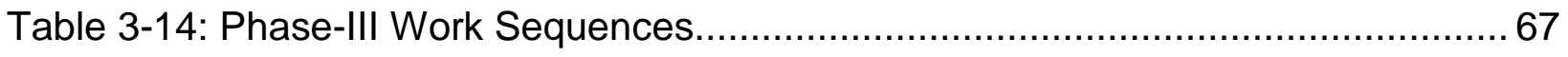

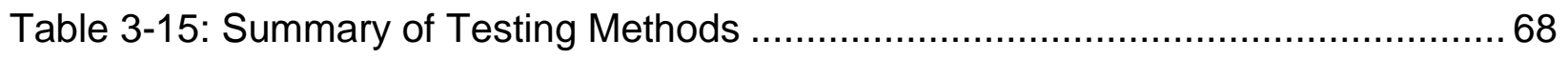

Table 4-1: Compressive Strength Results of SD (MPa) .......................................... 70

Table 4-2: Compressive Strength Results of CV (\%) ……....................................... 71

Table 4-3: Comparison of the Combined Autogenous and Drying Shrinkage (\%)......... 76

Table 4-4: Length Change Ranking Following the Testing Conditions (Phase-II) .......... 80 
Table 4-5: Stress Loss (\%) for Slant Shear Test - Rough Texture ............................. 82

Table 4-6: SD and CV Results for Slant Shear Test - Rough Texture ......................... 83

Table 4-7: Stress Loss (\%) for Slant Shear Test - Smooth Texture............................. 84

Table 4-8: SD and CV Results for Slant Shear Test - Smooth Texture ....................... 85

Table 4-9: Stress Improvement (\%) for Slant Shear Test.......................................... 87

Table 4-10: Stress Loss (\%) for Splitting Tensile Test - Rough Texture ....................... 89

Table 4-11: SD and CV Results for Splitting Tensile Test - Rough Texture ................. 89

Table 4-12: Stress Loss (\%) for Splitting Tensile Test - Smooth Texture .....................90

Table 4-13: SD and CV Results for Splitting Tensile Test - Smooth Texture................91

Table 4-14: Stress Improvement (\%) for Splitting Tensile Test ................................... 93

Table 4-15: Stress Loss (\%) for Pull-off Test (Phase-II) - Smooth Texture.................... 95

Table 4-16: SD and CV Results for Pull-off Test (Phase-II) - Smooth Texture .............. 96

Table 4-17: Stress Loss (\%) for Pull-off Test (Phase-III) .......................................... 102

Table 4-18: SD and CV Results for Pull-off Test (Phase-III) .................................... 102

Table 5-1: Compressive Strength to Substrate Ratio ….......................................... 105

Table 5-2: Static Modulus of Elasticity Ratio of Repairs to Substrates ....................... 105 


\section{List of Equations}

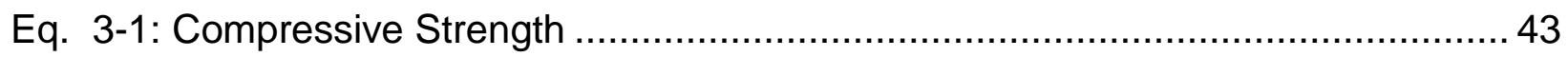

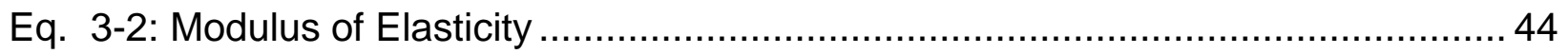

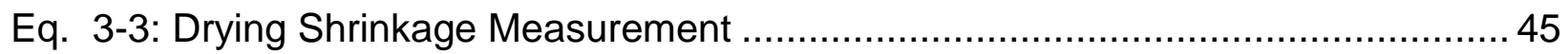

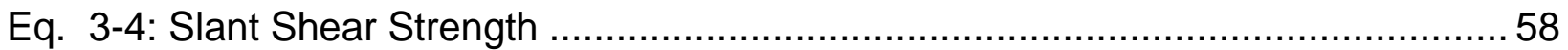

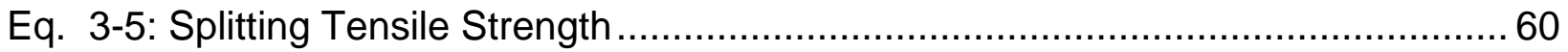

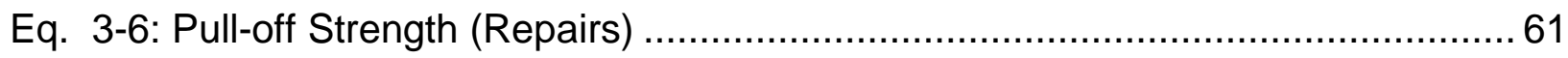

Eq. 3-7: Length Change Expansion Measurement...................................................... 65

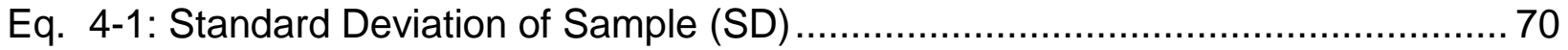

Eq. 4-2: Coefficient of Variation (CV) ………….............................................. 71

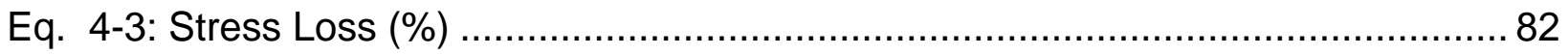

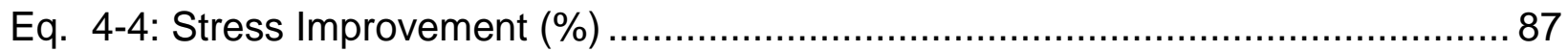




\section{Chapter 1}

\section{Introduction}

Many aged concrete buildings and infrastructures in North America are suffering severe deterioration due to external causes like aggressive environmental exposure or internal causes such as expansion due to alkali-aggregate reaction (AAR). These types of structures are in high demand for sustainable and long-lasting repair materials. Even though repairing deteriorated structures are being done for so many years, repair topic still requires a lot of investigations and studies because there are high amount unsuccessful concrete repairs (Tayeh, Bakar, Johari, \& Ratnam, 2013).

Nowadays, with advanced technology, the production of strong and durable construction materials becomes more feasible. Therefore, there is more motivation in the industry to replace the normal conventional concrete (NC) with new advanced cement-based materials although NC for several decades was the primary selection for restoration of deteriorated structures. The main reason behind this motivation is that NC failed to perform satisfactorily due to its porous structure in many conditions such as freezing and 
thawing with/without de-icing salt (Cai \& Liu, 1998; Hanjari, Utgenannt, \& Lundgren, 2011).

However, the use of advanced cement-based materials as a repair on top of existing deteriorated concrete (substrate) is challenging, since repairs rely not only on the quality and of the materials but also on the interaction and compatibility of such materials with the substrate. Usually, when repair products are failing, the bond interface between the substrate and repair material can be identified as the weakest point in the system. Consequently, this interface requires considerable attention.

Several factors directly influence the behaviour of bond interface strength such as:

1. Repair materials compatibility with the substrate,

2. Substrate preparation and surface texture,

3. The moisture content of the substrate at the time of applying repair,

4. Type of stress acting on the bond interface, and

5. The environmental exposure of the system (repair products and substrate).

Hence, it is recommended to further investigate the durability and sustainability of new advanced cement-based materials used as repairs, such as ultra-high performance concrete (UHPC), engineered cementitious composite (ECC), and specialized commercial repair material with self-consolidating properties (SCC) in comparison to the normal conventional concrete (NC).

\subsection{Research Objective and Scope}

The primary objective of this research aims to design an experimental program to evaluate the bond strength and durability performance of three different advanced cement-based materials used as repairs (UHPC, ECC, and SCC) in comparison to the $\mathrm{NC}$ under two most common deterioration modes in Canada. The deterioration modes implemented in this research include freezing and thawing cycles with de-icing salt and substrate suffering volumetric expansion - alkali-aggregate reactive (AAR). To achieve this purpose, three separate phases were defined: 
1. Materials properties and compatibility of repairs with substrate (Phase-I):

The mechanical properties and compatibility of repair products with a substrate such as compressive strength, modulus of elasticity, autogenous and drying shrinkage were evaluated in this phase.

2. Repairs under freeze-thaw cycles with de-icing salt (Phase-II):

The bond strength of four different repair products (UHPC, ECC-Slag, SCC, and $\mathrm{NC})$ under freeze-thaw cycles with de-icing salt which represents the severe weather conditions of Canada was investigated. To better evaluate the bond strength of the repair products, three diverse testing methods including slant shear, splitting tensile and pull-off test were performed on the specimens. Furthermore, the effect of two different surface textures on the bond strength and durability performance of the slant shear and splitting tensile tests were studied.

3. Repairs placed on expanding substrate - substrate suffering ACR (Phase-III):

The ability of the repair products to withstand the substrate expanding deterioration particularly in this research alkali-carbonate aggregate (ACR) was examined. Throughout this phase, only the pull of test was implemented to compare the durability performance and measure the bond strength of four different repair products.

\subsection{Research Significance}

Growing the number of deteriorated concrete infrastructures increases the needs for finding and recommending the best durable and economical repair products depending on the different deteriorated exposures. Thus, identifying long-lasting, inexpensive, and right repair materials which can perform better under different deteriorated exposures will be beneficial to the construction industry, infrastructures owners, and even the citizens. 


\section{Chapter 2}

\section{Literature Review on Bond Interface Properties for Repair Materials}

The performance of any structural restorations or repairs is significantly related to the quality of the bond between repair materials and old deteriorated concrete (substrate). This dependence is even more significant when the repair material is directly applied on top of the substrate without any bond interface increasing agent such as studs, reinforcement rebars, anchors, or epoxy. In this condition (which is the objective of this research), it is predicted that the failure occurs at the bond interface between repair and substrate which is classified as the weakest link in the system. Therefore, in order to select the most durable repair materials, understanding the mechanism, properties and behaviours of the bonding interface are very critical (Morgan, 1996). The following listed factors directly affect the bond interface strength (Austin, Robins, \& Pan, 1995; Emmons, Vaysburd, \& McDonald, 1993; Momayez, Ehsani, Ramezanianpour, \& Rajaie, 2005; Morgan, 1996; Saucier, Bastien, Pigeon, \& Fafard, 1991; Shin \& Wan, 2010):

1. Type of material used as a repair in terms of strength, permeability, durability, more specifically water to cement ratio $(W / C)$, aggregate to cement ratio $(A / C)$, amount of supplementary cementitious materials (SCMs) more importantly silica fume; 
2. Compatibility of repair materials with the substrate regarding physical, chemical, and electrochemical properties such as compressive strength, level of alkaline, and corrosion resistance, and so on;

3. Surface preparation of substrate including cleanliness, roughness (texture), and moisture condition at the time of applying repair products;

4. The environmental condition of the repair and substrate such as temperature, relative humidity $(\mathrm{RH})$, freezing and thawing, etc.;

5. Type of the testing methods or stress acting on the bond interface.

However, before getting to the above five factors in more details, it is better to understand the bond interface between repair and substrate and its properties.

\subsection{Bond Interfacial Layer}

The interfacial layer between the substrate and repair material is one of the most critical parameters to consider. This interfacial layer is very similar to the interfacial transition zone (ITZ) (Espeche \& León, 2011; Shin \& Wan, 2010). Thus, there is an essential need to entirely understand the ITZ characteristics. ITZ is known as the weakest connection of cement and aggregate in the NC which is mainly due to the wall effect. Wall effect defined as having a very large and flat surface of aggregate compared to the small size of cement or SCMs. Hence, the aggregate acts as a wall and do not allow other larger particles to get close to it (Scrivener, Crumbie, \& Laugesen, 2004).
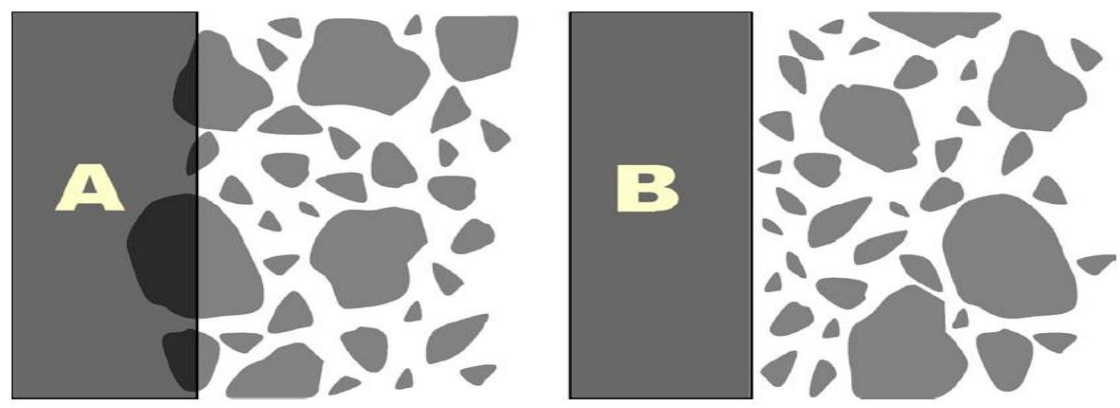

Figure 2-1: Wall Effect Illustration (Scrivener et al., 2004)

Figure 2-1 demonstrates the wall effect of coarse aggregates and consequently reducing the possibility of having larger particle size close to them. This phenomenon changes the normal distribution of cement particles around the coarse aggregates. As a result, the 
area close to aggregates has more porosity. So, it is more vulnerable to any sort of damage and deterioration in concrete (Scrivener et al., 2004; Zhou, et al., 2010). Since the ITZ is mainly dominated by the small grain size of aggregate and cement, it takes more water. As a result, the W/C ratio around the interface of aggregates is 20 to $30 \%$ higher than the bulk paste zone (Scrivener et al., 2004).

On the other hand, existence of high amount of small cement particles around the large aggregates, high porosity, and the tendency calcium hydroxide $(\mathrm{CH})$ particles to form far from cement particles make that ITZ zone susceptible to have more concentration of $\mathrm{CH}$ compare to calcium silicate hydrate $(\mathrm{CSH})$ which is the main component of cement hydration responsible for strength development. It was observed that ITZ also has a higher concentration of ettringite (Mindess, Young, \& Darwin, 2003; Scrivener et al., 2004). As a result, when it comes to the bond strength between substrate and repair, the same behaviour is expected.

To minimize the wall effect at the bond interface, it is recommended to implement repair products with (Espeche \& León, 2011; Scrivener et al., 2004; Shin \& Wan, 2010): (A) lower W/C ratio, (B) higher packing with a smaller gradation of aggregates, and (C) 5 to $10 \%$ replacement of cement with silica fume which has the particle size of roughly 0.1 $\mu \mathrm{m}$. Adding silica fume increases the packing and strength of the repair products at the bond interface (Figure 2-2).

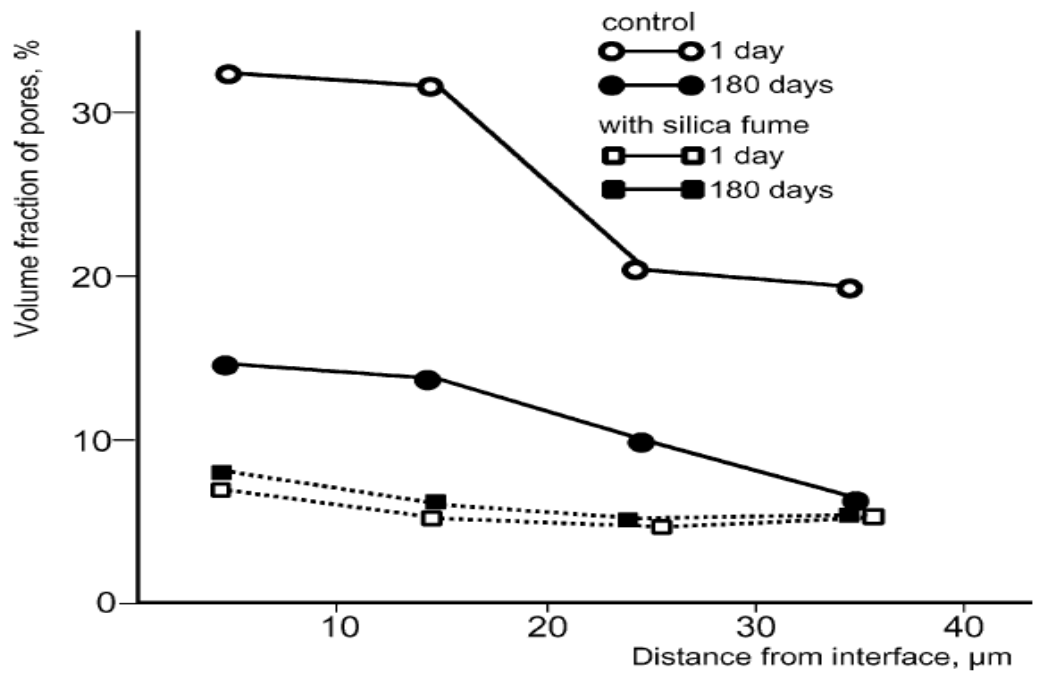

Figure 2-2: Effect of Silica Fume on ITZ (Scrivener et al., 2004) 


\subsection{Type of Material Used as Repairs and Their Requirements}

In this section of the research, three different type of advanced cement-based materials used as repairs including ultra-high performance concrete (UHPC), engineered cementitious composite (ECC), and specialized commercial repair material with selfconsolidating properties (SCC) in comparison to the normal conventional concrete (NC) was reviewed in terms of essential material characteristics and requirements such as strength, workability, permeability, and cost.

\subsubsection{Ultra-High Performance Concrete (UHPC)}

\subsubsection{Background and Fundamental Principles}

The first researcher that was able to identify and apply the basic vital rules to produce ultra-high strength concrete was Hans Hendrik Bache (1981). Richard and Cheyrezy (1995), improve the Bache's idea and introduce the "Reactive Powder Concrete (RPC)" by cooperating with Lafarge company. This was the first introduction of the very famous commercial UHPC product named Ducta ${ }^{\circledR}$ by the Lafarge. The basic principles of UHPC initially introduced by Bache and further developed by many researchers are listed as follow (Aitcin, 1998; Fehling, Schmidt, Walraven, Leutbecher, \& Fröhlich, 2014; Richard \& Cheyrezy, 1995):

(1) Having a maximum grain size of less than $600 \mu \mathrm{m}$. In other words, removing coarse aggregate from the mix design to reduce the stress concentration, eliminate the weak interfacial transition zone (ITZ) between coarse aggregate and binder, and improve the homogeneity of the mixture.

(2) Introducing reactive and non-reactive fillers to maximize the packing and density. Having very dense and impermeable microstructure enhance UHPC ability to withstand the higher amount of stress. Moreover, it produces exceptionally suitable product for any sort of deterioration including alkalis, carbonation, corrosion, and even salt scaling.

(3) Containing low water to binder (cement, supplementary cementitious materials particularly silica fume, any other reactive or non-reactive fillers) ratio (W/B) of 0.2 or 
less to ensure that the water in the mix is completely reacted. The extra amount of unhydrated binder in the blend is necessarily required to improve the packing because they work as fillers. In addition, it was observed by Aitcin (1998) that having very low W/B ratio produces smaller, more compacted matrix with lower porosity calcium silicate hydrate $(\mathrm{CSH})$ and less amount of sizeable hexagonal lime, $\mathrm{Ca}(\mathrm{OH})_{2}$.

(4) Enhancing the ductility by adding short steel fibers. The high fiber content (up to $2 \%$ by volume) of the UHPC is designed to assure that the tensile behaviour of structural elements is satisfied even without the reinforcement.

\subsubsection{Mix Proportion Characteristics}

\subsection{Cement and Superplasticizer}

Cement is the primary component of any concrete. About $30 \%$ by volume of the UHPC mixture is made of cement (Zdeb, 2013). CEM-I according to the ASTM or general use (GU) type A according to Canadian Standards Association (CSA) is the most suggested type of cement to be used in the UHPC mixture (Fehling et al., 2014). In terms of the grain size distribution, cement with larger particle size is suggested over the high Blaine fineness cement since fine-graded cement has a higher surface area and tendency to react with water. Therefore, the higher amount of water and superplasticizer are required to maintain the same workability (Fehling et al., 2014; Richard \& Cheyrezy, 1995). In terms of chemical composition, cement with the lower percentage of tri-calcium aluminate $\left(\mathrm{C}_{3} \mathrm{~A}\right)$, the higher percentage of di-calcium silicate $\left(\mathrm{C}_{2} \mathrm{~S}\right)$ and tri-calcium silicate $\left(\mathrm{C}_{3} \mathrm{~S}\right)$ was found to have better results. The higher amount of $\mathrm{C}_{2} \mathrm{~S}$ and $\mathrm{C}_{3} \mathrm{~S}$ contribute more into the strength development. However, $\mathrm{C}_{3} \mathrm{~A}$ with the high rate of hydration has a higher tendency to absorb water which makes the mix more viscous (Richard \& Cheyrezy, 1995; Wille, Naman, \& Parra-Montesinos, 2011). Generally, cement with less than $4 \% \mathrm{C}_{3} \mathrm{~A}$, less than $0.4 \%$ equivalent sodium content $\left(\mathrm{Na}_{2} \mathrm{O}_{e}\right)$, and Blaine fineness of approximately 340 $\mathrm{m}^{2} / \mathrm{kg}$ is recommended (Zdeb, 2013). It is highly endorsed to select the superplasticizer (Polycarboxylate ether based) which contains two different structured polymers to be more suitable for the UHPC mixture since UHPC mixture consist cement and high amount of silica fume (Fehling et al., 2014). 


\subsection{Sand and Powders}

The coarse aggregates were eliminated for the UHPC in order to make the mixture more homogeneous, eliminate the weak ITZ, and enhance the packing (Fehling et al., 2014; Zdeb, 2013). According to the Bailey Method (Vavrik, Huber, Pine, Carpenter, \& Bailey, 2002), after removing coarse aggregates, the fine aggregates are capable of creating voids (can be defined as new coarse aggregates) and powders - which are the small particles - are able to fill the voids (can be defined as new fine aggregates). Hence, the grain size distribution of fine aggregate and powders are very crucial. Figure 2-3 illustrates the comparison between NC and UHPC in terms of aggregate size.
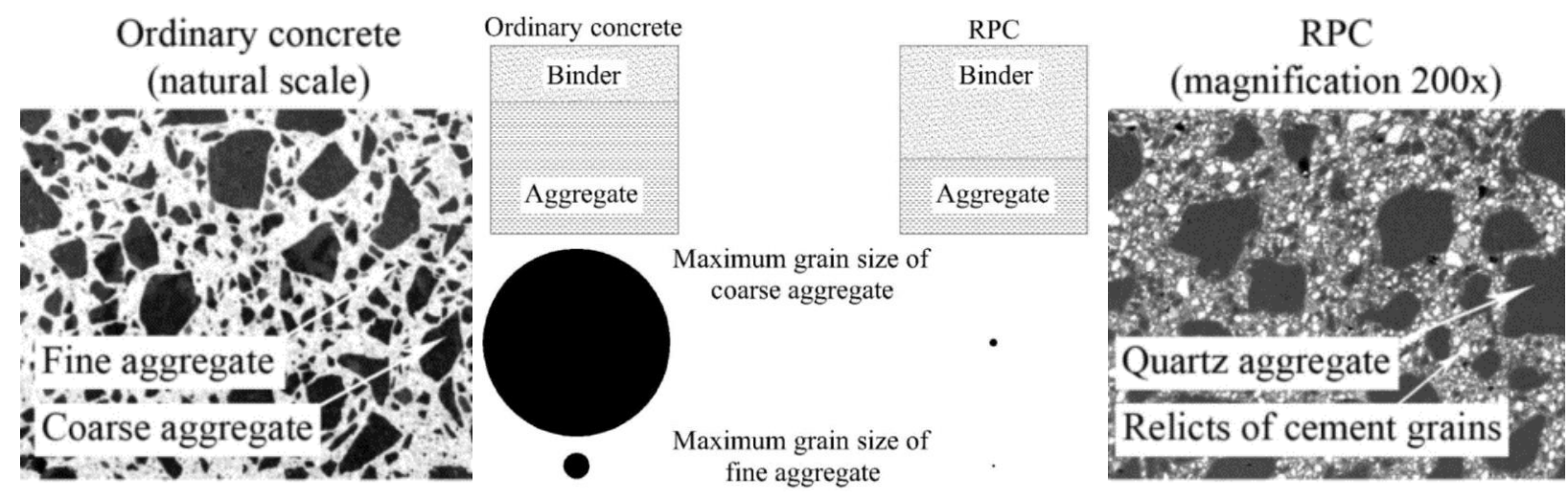

Figure 2-3: Grain Size Comparison of NC and UHPC (Zdeb, 2013)

The selection of the sand particle size, shape, strength and chemical composition are the most key factors. Well-graded fine sand - with roughly maximum, mean, and minimum particle size of 600,250 , and $150 \mu \mathrm{m}$, respectively - is suggested for UHPC. The minimum sand particle size of $150 \mu \mathrm{m}$ was recommended to minimize the interfering of the grain size distribution of sand and Portland cement. Crushed and natural sand both can be implemented in the UHPC mixture. However, natural sand is suggested over the crushed sand because crushed sand has more irregularity in the shape. Therefore, it has a higher surface area and slightly requires higher water. Moreover, the mineral composition of the sand also plays a significant role. In fact, the sand should be selected such a way to do not contain any reactive silica or carbonate. Thus, quartz sands are the most recommended type of sand for the UHPC mixtures (Fehling et al., 2014; Richard \& Cheyrezy, 1995; Zdeb, 2013). 
In terms of powder, crushed quartz powder which has high strength and availability is suggested with typically maximum, mean, and minimum particle size of $25 \mu \mathrm{m}, 10 \mu \mathrm{m}$, and $5 \mu \mathrm{m}$, respectively, almost same size as cement particles (Richard \& Cheyrezy, 1995).

It is important to note that limestone powder might be used in the UHPC mixture. However, experimental studies showed that it produces less strength and requires more water (Fehling et al., 2014). Practically, $38 \%$ to $45 \%$ by volume of the UHPC mixture consists of the sand (mostly quartz sand) and powder (mostly quartz powder) approximately 1000 to $1200 \mathrm{~kg} / \mathrm{m}^{3}$ (Zdeb, 2013).

\subsection{Supplementary Cementitious Materials (SCMs)}

The most common type of SCMs used in the UHPC mixture is silica fume at replacement level of approximately $20 \%$ to $25 \%$ of the cement weight due to its following characteristics (Richard \& Cheyrezy, 1995; Wille et al., 2011; Zdeb, 2013):

(a) Having approximately 20 times smaller particle size (mean particle size of about $0.5 \mu \mathrm{m})$ than the Portland cement and other powders in the mixture which can fill the smaller voids created by the Portland cement and other powders. Therefore, it highly improves the packing;

(b) Enhancing workability characteristics of the mix (explained in Section 2.2.1.6);

(c) Improving the strength due to producing the highest rate of pozzolanic reaction among all other SCMs. Hence, silica fume produces more $\mathrm{CSH}$ and reduces calcium hydroxide, $\mathrm{Ca}(\mathrm{OH})_{2}$. In fact, silica fume works as a nucleation site due to its minimal size and high surface area.

Richard and Cheyrezy (1995) found that the best results are from silica fume with Blaine fineness of 14000 to $18000 \mathrm{~m}^{2} / \mathrm{kg}$ produced from zirconium dioxide. Typical silica fumes with Blaine fineness of around $22000 \mathrm{~m}^{2} / \mathrm{kg}$ still provide decent results (Richard \& Cheyrezy, 1995). It is required to select the silica fume with fewer impurities, $96 \%$ or higher amount of amorphous silica $\left(\mathrm{SiO}_{2}\right)$. Besides, the silica fume with less amount of carbon $(C)$ is preferable due to the fact that carbon has a tendency to absorb water, consequently, reduce the workability (Fehling et al., 2014). 


\subsection{Steel Discontinuous Short Fibers}

In order to improve the ductility and reduce the crack spacing of the UHPC mixture, short steel fibers are added to the mix. The properties of steel fibers - such as fiber tensile strength, diameter, length, aspect ratio (length/diameter), and fiber surface texture significantly influence the UHPC material characteristics like strength and ductility. The recommended fiber properties are as follow: tensile strength of at least $2 \mathrm{GPa}$, maximum diameter of $0.20 \mathrm{~mm}$, length of approximately 9 to $17 \mathrm{~mm}$, and the fiber aspect ratio of at least 65 (Alkaysi \& El-Tawil, 2016; Fehling et al., 2014).

\subsubsection{Mix Design}

Up to date, many researchers tries to improve the UHPC mixture. Table 2-1 summarized the recommended weight percentage of each component of the UHPC mixture gathered by Ahlborn, Peuse, and Misson (2008) and three of the recognized researchers suggested UHPC mix designs.

Table 2-1: Typical UHPC Mix Compositions and Recommended

\begin{tabular}{|c|c|c|c|c|c|}
\hline \multirow{2}{*}{\multicolumn{2}{|c|}{ Components }} & \multirow{2}{*}{$\begin{array}{c}\text { Suggested } \\
(\%) \\
\text { by Weight }\end{array}$} & \multicolumn{3}{|c|}{ Cement Weight Proportion } \\
\hline & & & $\begin{array}{c}\text { (Richard \& } \\
\text { Cheyrezy, 1995) }\end{array}$ & $\begin{array}{l}\text { (Wille et al., } \\
\text { 2011) }\end{array}$ & $\begin{array}{c}\text { (Fehling et al., } \\
\text { 2014) }\end{array}$ \\
\hline \multirow{3}{*}{ 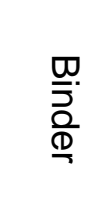 } & Portland Cement & $27-38$ & 1.00 & 1.00 & 1.00 \\
\hline & Silica Fume & $8-9$ & 0.23 & 0.25 & 0.16 \\
\hline & Quartz Powder & $0-8$ & 0.39 & 0.25 & 0.25 \\
\hline \multicolumn{2}{|c|}{ Quartz Sand } & $39-41$ & 1.10 & 1.29 & 1.17 \\
\hline \multicolumn{2}{|c|}{ Water } & $5-8$ & 0.19 & 0.22 & 0.20 \\
\hline \multicolumn{2}{|c|}{ Superplasticizer } & $0.5-1.0$ & - & - & - \\
\hline \multicolumn{2}{|c|}{ Short Steel Fiber } & $5-8$ & $2 \% *$ & $2.5 \%{ }^{*}$ & $2.5 \%{ }^{*}$ \\
\hline
\end{tabular}

* Percentage by Volume

\subsubsection{Strength}

As a matter of fact, all the first three fundamental principles of the UHPC introduced in Section 2.2.1.1 and furthered explained in Section 2.2.1.2 designed in such a way to enhance the packing and strength of the blend. The compressive strength of UHPC highly 
depends on the W/B ratio, amount and fineness of silica fume and quartz powder; however, typically the compressive strength and modulus of elasticity recorded to be between 150 to $300 \mathrm{MPa}$ (Zdeb, 2013) and 45 to $55 \mathrm{GPa}$ (Fehling et al., 2014).

\subsubsection{Permeability}

Again, having very high particle packing, dense microstructure, and very low W/B ratio $(<0.20)$ make UHPC mixture with almost zero capillaries (Fehling et al., 2014). The highpressure mercury porosimetry and carbonation test (Figure 2-4) with about $1 \mathrm{~mm}$ penetration also prove the very low permeability of UHPC (Fehling et al., 2014).

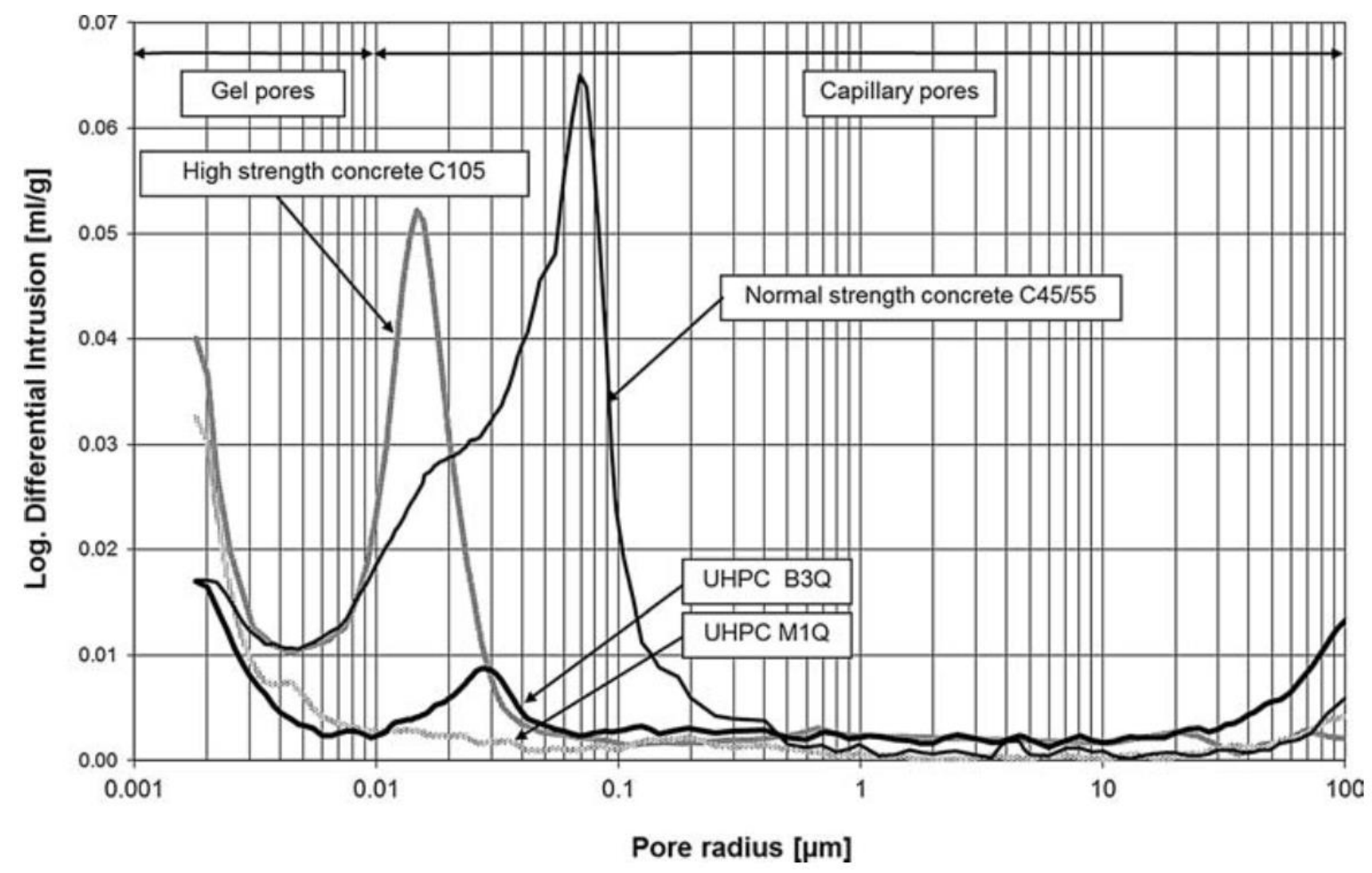

Figure 2-4: High-pressure Mercury Porosimetry Test (Fehling et al., 2014)

\subsubsection{Workability}

To enhance the strength of the UHPC mixture implementing the three main principles including eliminating coarse aggregate, optimizing the grain size distribution, and reducing the W/B ratio are mandatory. However, at the same time, adequate workability of the UHPC mixture for several construction stages such as transportation and placing is required (Aitcin, 1998). Since all the main principles of the UHPC mixture are designed 
to improve the strength and decrease the porosity, there is very little attention to the workability improvement. Generally, in the mixtures with very low W/B ratio, the workability of the mix is profoundly influenced by the shape, grain size distribution, and initial reactivity between water, cement and SCMs (Aitcin, 1998). Bache in 1981 for the first time introduced that the workability of mixtures with low W/B ratio such as UHPC can significantly improve by adding very fine spherical powder like silica fume. This idea later was proven by researchers that even the chemical properties of the powders (cement, quarts powder, and silica fume) do not play a key role (Aitcin, 1998; Fehling et al., 2014).

Therefore, to achieve adequate workability for UHPC, very close attention to the shape, and grain size distribution of cement particles, silica fume, and implementing efficient and right amount of superplasticizer besides general factors such as temperature, shear mixer efficiency and speed are recommended (Aitcin, 1998; Fehling et al., 2014). In fact, in UHPC about one-third (1/3) of the cement particles stay unhydrated due to very low W/B ratio which they can easily be replaced by any similar powder such as silica fume or quartz powder (silica sand) in order to make the mix more workable, economical, and even environmental friendly (Fehling et al., 2014).

\subsubsection{Cost}

UHPC generally defines as a very costly product. According to Ahlborn et al., (2008) the commercially available UHPC blend with $2 \%$ by volume short steel fibers costs $\$$ US 2615 per $\mathrm{m}^{3}$ which is 20 times higher than the NC. Another investigation recently done in 2016 showed that the price of UHPC product with $2 \%$ by volume steel fibers dropped to \$US1355 per $\mathrm{m}^{3}$ which is still 10 times higher than the NC (Alkaysi \& El-Tawil, 2016). The cost of NC was selected to be roughly $\$ U S 130$ per $\mathrm{m}^{3}$ (Wille \& Boisvert-Cotulio, 2015). Although the initial cost of the UHPC mixture is much higher than the NC, the entire project and design service life of the structure should be considered while making the judgment. For instance, the footbridge project was constructed in Japan by implementing UHPC instead of NC which leads to a reduction of $80 \%$ of the self-weight. This considerable reduction saves a lot on the cost of foundation and overall add $10 \%$ saving to the final project cost (Fehling et al., 2014). 


\subsubsection{Engineered Cementitious Composites (ECC)}

\subsubsection{Background and Fundamental Principles}

Engineered cementitious composite (ECC) - known as bendable concrete - was advanced in the early 1990 s by professor Victor C. Li at the University of Michigan. ECC has a tensile strength of approximately 4 to $6 \mathrm{MPa}$ and high ductility in the range of 3 to $5 \%$ (V. C. Li, 2007). In order to achieve high ductility with multiple micro-cracks and very small crack width opening (less than $100 \mu \mathrm{m}$ ), the essential mix design principles of ECC are defined as follow (V. C. Li, 1993, 2007; V. C. Li et al., 2003; S. Wang \& Li, 2008):

1. Excluding coarse aggregates to enhance the homogeneity of the mixture,

2. Implementing low $W / C M$ ratio $(<0.25)$ with high amount of low calcium fly ash (Type F) typically in the range of 0.8 to 1.5 by cement proportion to improve the strength properties, decrease the porosities, improve workability, and control the matrix toughness of the blend (will be discussed in more details),

3. Using silica sand with a maximum grain size of $250 \mu \mathrm{m}$ to increase the packing of the mixture and decrease the porosities, and

4. Including discontinuous short polymer fibers such as polyvinyl alcohol (PVA), high modulus polyethylene (PE) and polypropylene (PP) by the volume fraction of $2 \%$ or less to improve the ductility and shrinkage cracking.

\subsubsection{Mix Proportion Characteristics}

\subsection{Discontinuous Short Polymer Fibers}

Polyvinyl Alcohol (PVA), high modulus Polyethylene (PE) and Polypropylene (PP) are the most common type of polymer fibers used in ECC. Among these three, PVA is the most popular one due to having higher durability and mechanical characteristics. Besides, PVA-ECC has lower producing cost and faster processing time (Yang, Wang, Yang, \& Li, 2008). Moreover, short and randomly distributed PVA fibers with a small amount of volume fraction ( $2 \%$ or less) can provide a self-consolidation behaviour which makes this kind of fiber even more desirable for various type of constructions (Kong, Bike, \& Li, 2003). 
Thus, PVA fibers are the most practical type of fibers typically used for the field construction (Kong et al., 2003; Yang et al., 2008).

When it comes to strain-hardening, and multiple-micro cracking behaviour of ECC, two main properties of PVA-ECC blend which work simultaneously should be considered (Yang et al., 2008):

(1) Fiber-matrix interface toughness, and (2) Fiber bridging strength.

Fiber-matrix interface toughness should be designed in such a way to allow fibers to slip and release energy. If the matrix was very strong and dense, it causes the fibers breakage. On the other hand, in a very loose matrix, the fibers get easily pull out. Consequently, the matrix and fiber interface toughness should be engineered to allow the fibers to slip and release energy without breakage or pull out. The optimum slippage of the PVA fibers without any pull out or breakage was found to be when the PVA fibers are more hydrophobic instead of hydrophilic which gain by oil coating fibers, roughly $1.2 \%$ by weight. After slippage, the fiber acts as a bridge between two cracked faced of the matrix. This behaviour called fiber bridging. Fiber bridging tensile strength must be higher than the matrix strength in order to keep the cracks tight and transfer the force to the adjacent element (Redon et al., 2001; Yang et al., 2008; Zhou et al., 2010). PVA fibers should have a small length and diameter usually between 6 to $12 \mathrm{~mm}$ and 10 to $100 \mu \mathrm{m}$ (12 mm length and $39 \mu \mathrm{m}$ diameter is recommended), respectively, with maximum tensile strength of $1600 \mathrm{MPa}$, and density of approximately $1300 \mathrm{~kg} / \mathrm{m}^{3}$ (Yang et al., 2008; Zhou et al., 2010).

\subsection{PVA-ECC Mix Design with Fly Ash (Type F) and Silica Sand (PVA-ECC-FS)}

This is the original mixture that was introduced by professor Victor C. Li. The mixture contains cement (type I or GU), low calcium fly ash (Type F), silica sand with maximum grain size of $250 \mu \mathrm{m}$ an average size of $110 \mu \mathrm{m}$, PVA fiber with $39 \mu \mathrm{m}$ diameter, $12 \mathrm{~mm}$ length, overall Young's modulus of $25.8 \mathrm{MPa}$, apparent fiber strength of $900 \mathrm{MPa}$, fiber surface oil coating content of $1.2 \%$, and polycarboxylate ether base superplasticizer (V. C. Li, 2007; S. Wang \& Li, 2005). One of the PVA-ECC mix design which was optimized and advanced by professor Victor $\mathrm{C}$. Li and his colleagues was M45 (Table 2-2). Figure 2-5 to Figure 2-10 illustrate some of the PVA-ECC-FS-M45 mechanical properties. 


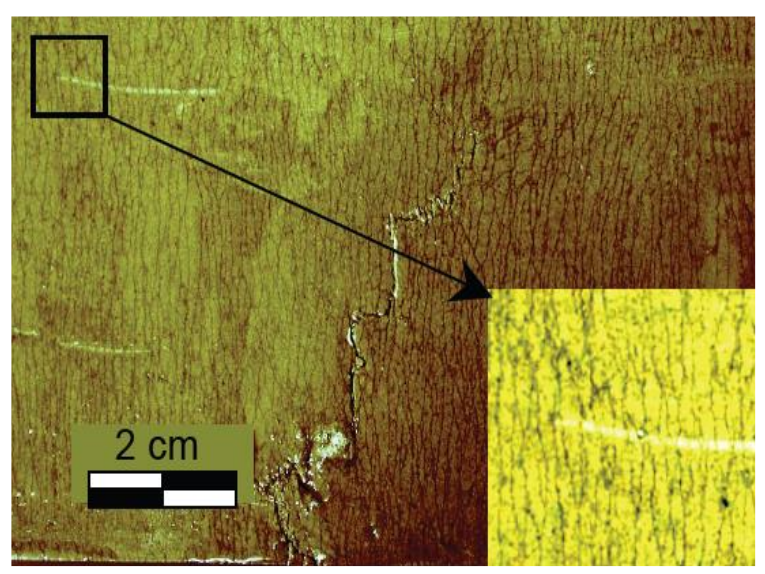

Figure 2-5: Multiple-micro Cracks under Bending of PVA-ECC (S. Wang \& Li, 2005)

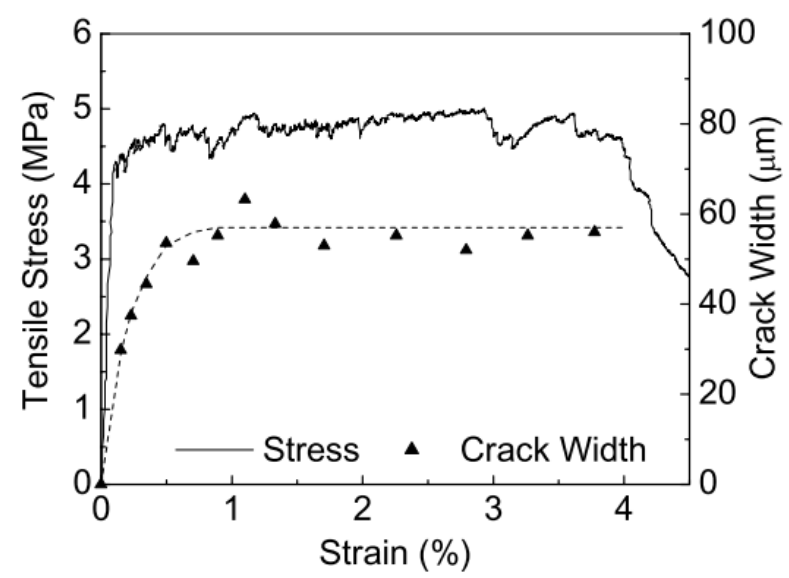

Figure 2-7: Crack width Development of PVA-ECCFS (S. Wang \& Li, 2005)

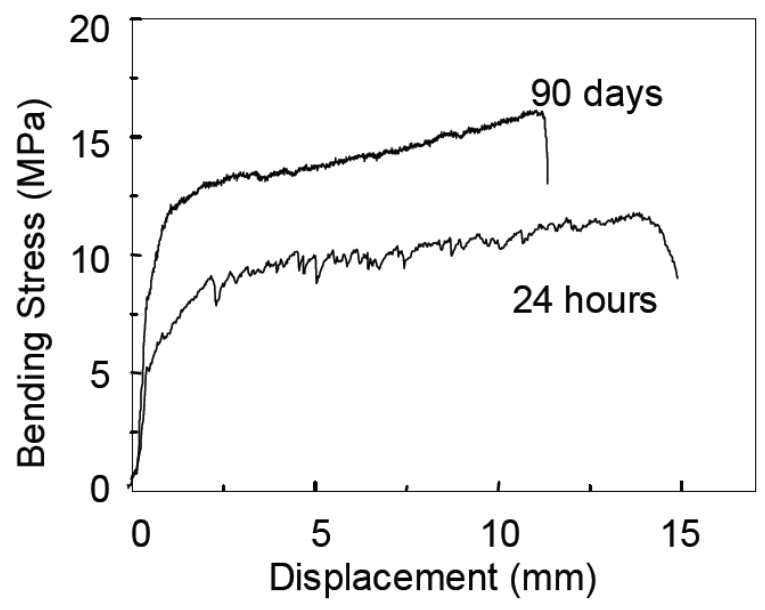

Figure 2-9: Bending Strength-Displacement of PVA-ECC-FS (S. Wang \& Li, 2005)

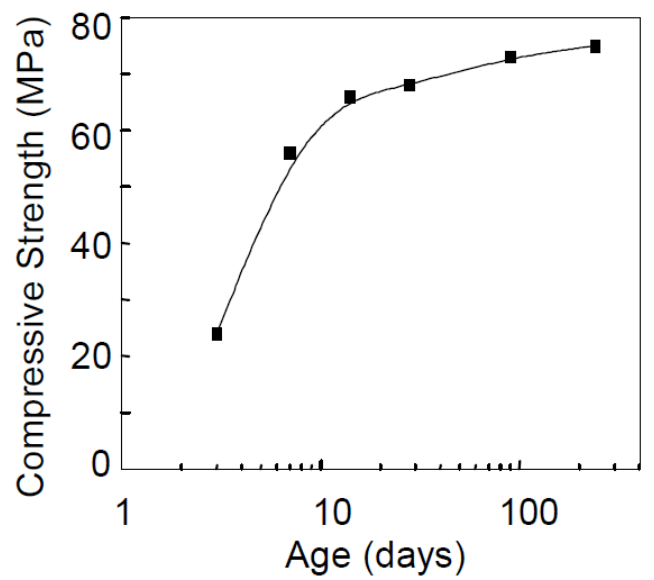

Figure 2-6: Compressive Strength of PVA-ECCFS (S. Wang \& Li, 2005)

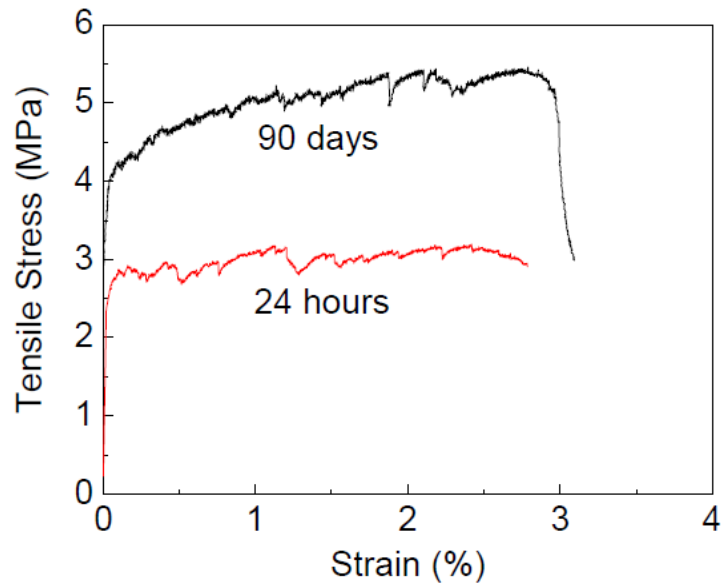

Figure 2-8: Tensile Strength-Strain of PVA-ECCFS (S. Wang \& Li, 2005)

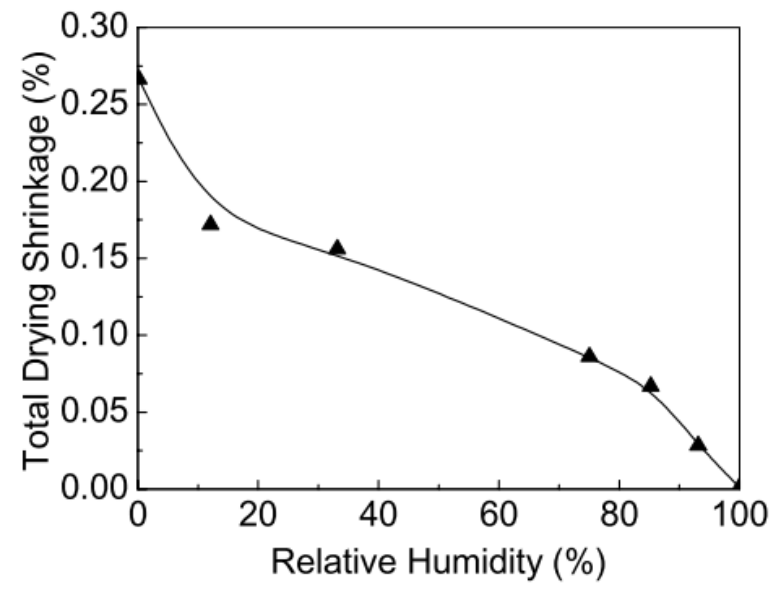

Figure 2-10: Drying Shrinkage Behaviour of PVAECC-FS (S. Wang \& Li, 2005) 
As it is illustrated in Figure 2-10, the drying shrinkage of the ECC is approximately $80 \%$ higher than NC due to having higher cementitious materials content and eliminating coarse aggregate. However, the presence of short fibers in the blend and its multiplemicro cracking behaviour distribute the drying shrinkage effect through more number of cracks and reduce the damage compare to one large crack width in NC which leads to a high reduction of the strength capacity (Figure 2-11).

In terms of autogenous shrinkage (Figure 2-12), PVA-ECC showed the unusually high amount of shrinkage in 2 days while the zero reading was taken immediately after setting. This high amount of autogenous shrinkage is again due to the high amount of cementitious materials which leads to the high amount of hydraulic and pozzolanic reactions (S. Wang \& $\mathrm{Li}, 2005$ ). It should be noted that the positive deformation is defined as shrinkage by Wang and $\mathrm{Li}(2005)$.

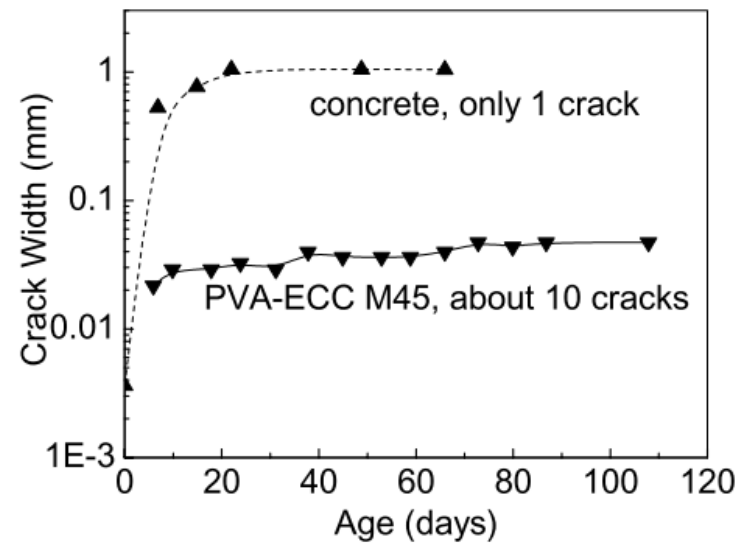

Figure 2-11: Crack Width under Restrained Drying Shrinkage (S. Wang \& Li, 2005)

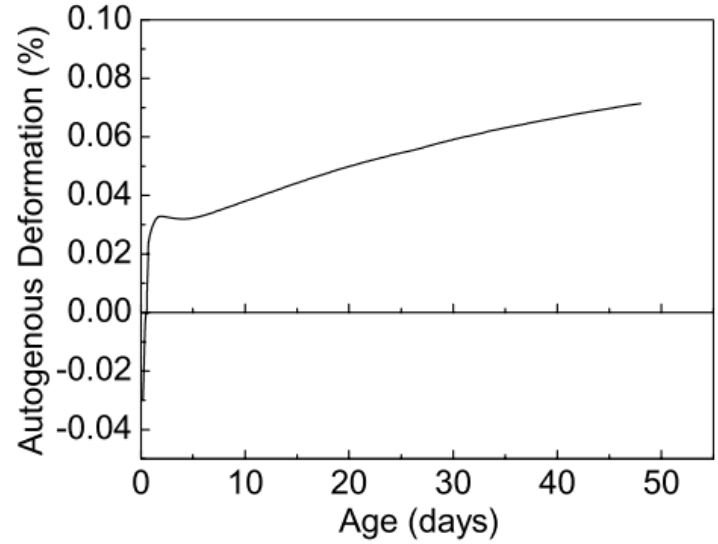

Figure 2-12: Autogenous Shrinkage of PVA-ECCFS-M45 (S. Wang \& Li, 2005)

\subsection{PVA-ECC Mix Design with Slag and Limestone Powder (PVA-ECC-SL)}

In order to make the original PVA-ECC-FS mix design more economical, locally available, and decrease the environmental effect of using high content of cement, fly ash, and silica sand, a PVA-ECC-SL blend with slag and limestone powder was introduced by many researchers (Kim, Kim, Ha, \& Kim, 2007; Zhou et al., 2010).

Replacing fly ash with slag up to $70 \%$ decreases the early compressive strength. However, compressive strength is not profoundly affected after 28 days (Tsivilis, Batis, 
Chaniotakis, Grigoriadis, \& Theodossis, 2000). On the other hand, PVA-ECC-SL mixture improves sulfate attack resistance, prevents chloride ion penetration even more than fly ash mix design (PVA-ECC-FS), and finally enhances the homogeneity of PVA fiber distribution due to slag surface oxidation ( $\mathrm{Si}-\mathrm{O}$ ) ability which has electrical double layer characteristic and causes better distribution of PVA fibers (Kim et al., 2007).

It is highly relevant to consider that slag produces higher matrix-fiber bond interface toughness compare to fly ash due to its nature and shape which is less around (spherical) and much textured. This characteristic of slag reduces the bridging ability of PVA fibers and increase the probability of fiber rupture. Hence, the number of multiple-micro crack decreases and consequently the ductility (Kim et al., 2007; Zhou et al., 2010).

Figure 2-13 and Figure 2-14 demonstrate the loss in the tensile strength and deflection when compared with Figure 2-8 and Figure 2-9 (comparison between PVA-ECC-FL and PVA-ECC-Slag).

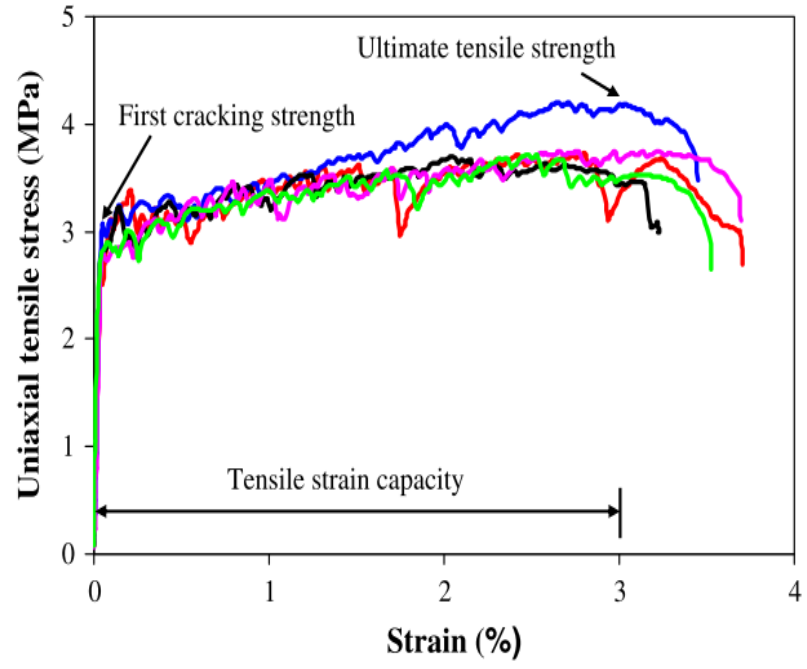

Figure 2-13: Tensile Strength-Strain of PVA-ECCSL (Zhou et al., 2010)

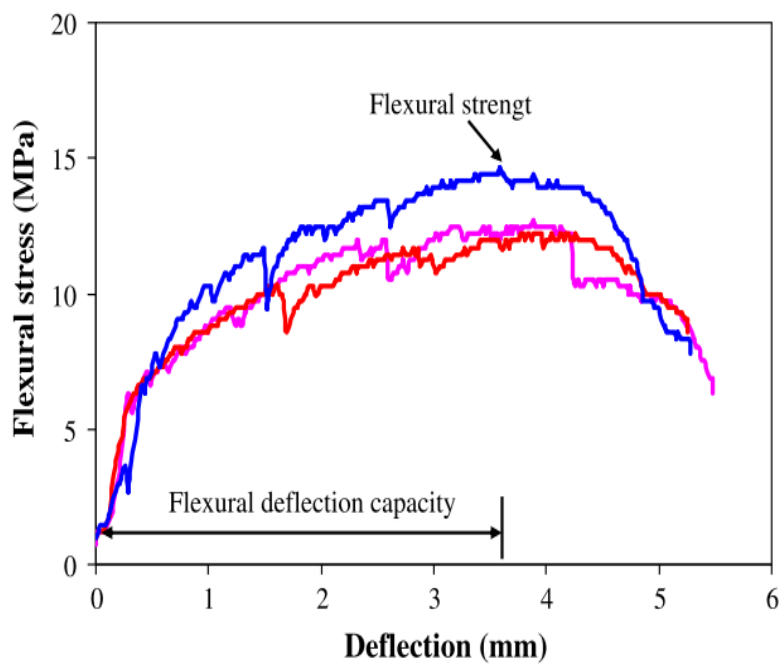

Figure 2-14: Bending Strength-Displacement of PVA-ECC-SL (Zhou et al., 2010)

Limestone powder is the production of grinding the limestone $(\mathrm{CaCo3})$ to very fine particles, can be used as an inert filler material in PVA-ECC mix design. Since it does not react with cement particles, and hydration products $(\mathrm{CSH}$, and $\mathrm{CH})$ or the reaction is very negligible, it can neutralize the adverse effect of extra matrix-fiber toughness created by the slag (Zhou et al., 2010). 
In fact, adding limestone powder with an average particle size of approximately $13 \mu \mathrm{m}$ is beneficial to the PVA-ECC blend in terms of improving durability, causing early compressive strength, increasing workability, and finally enhancing tensile strength capacity by decreasing the extra fiber-matrix toughness created by slag (Tsivilis et al., 2000; Zhou et al., 2010). However, use of a large amount of limestone powder is not recommended because it reduces the possibility of getting multiple-micro cracking with very small crack width. In fact, limestone powder decreases the tensile strength and toughness of the matrix due to being work as an inert filler and breaks easily under load since it has a very low hardness (Zhou et al., 2010).

The particle size distribution of limestone powder and slag suggested by Zhou et al. (2010) is illustrated and compared with Portland cement type I and III in Figure 2-15.

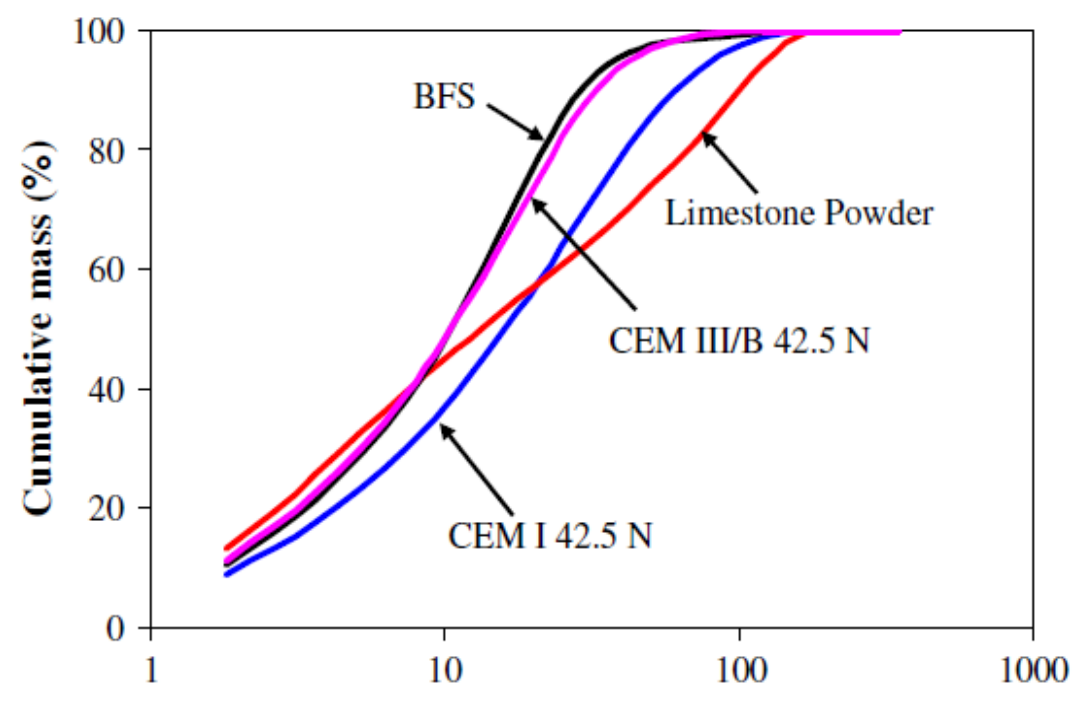

Particle size $(\mu \mathrm{m})$

Figure 2-15: Particle Size of Slag, Limestone Powder \& Cement (Zhou et al., 2010)

Another critical consideration for PVA-ECC-SL blend is the water adjustment. In fact, slag has higher water absorption compare to fly ash due to its irregular and textured shape although they both have almost the same particle size. In addition, limestone powder (average particle size of $13.4 \mu \mathrm{m}$ ) has also smaller particle size compared to silica sand (average particle size of $110 \mu \mathrm{m}$ ) which increases the water demand due to having higher surface area. Therefore, the PVA-ECC-SL mixture typically should have the higher amount of water in comparison to the PVA-ECC-FS (Zhou et al., 2010). 


\subsubsection{Mix Design}

As it was discussed above, there are two main categories for PVA-ECC mixtures. The original blend which contains low calcium fly ash and silica sand (PVA-ECC-FS) and the second group with slag and limestone powder (PVA-ECC-SL). Table 2-2 summarized some of the well-known and popular mix design in each category.

Table 2-2: Typical PVA-ECC Mix Proportion by Cement Weight

\begin{tabular}{llcccc}
\hline & \multicolumn{2}{c}{ Components } & \multicolumn{2}{c}{ PVA-ECC-FS $^{1}$} & \multicolumn{2}{c}{ PVA-ECC-SL $^{2}$} \\
& M45 $^{\mathbf{a}}$ & M48 $^{\mathbf{b}}$ & M3 $^{\mathbf{c}}$ & M6 $^{\mathbf{d}}$ \\
\hline \hline \multirow{2}{*}{ Portland Cement } & 1.00 & 1.00 & 1.00 & 0.60 \\
$\stackrel{0}{\mathbf{D}}$ Fly ash (Type F) or Slag & 1.20 & 1.20 & 1.20 & 1.40 \\
Water to Powder Ratio (W/P) & 0.80 & 1.60 & 2.00 & 2.00 \\
Superplasticizer & 0.26 & 0.26 & 0.26 & 0.26 \\
PVA Fiber (by Volume Fraction) & 0.012 & 0.012 & 0.018 & 0.020 \\
\hline
\end{tabular}

${ }^{1}$ PVA-ECC-FS contains low calcium fly ash and silica sand. ${ }^{2}$ PVA-ECC-SL contains slag and limestone powder. aM45 (V. C. Li, 2007), bM48 (Lepech \& Li, 2008), c,dM3 and M6 (Zhou et al., 2010).

\subsubsection{Strength}

PVA-ECC can achieve a high range of compressive strength and modulus of elasticity between 20 to $95 \mathrm{MPa}$, and 18 to $34 \mathrm{GPa}$, respectively, (depending on the mix design) which is almost same as NC to high strength concrete. It has a compressive strain capacity of $0.45 \%$ to $0.65 \%$ which is a bit higher than NC. The flexural strength of the PVA-ECC is mainly between 10 to $30 \mathrm{MPa}$, and its tensile strength capacity is approximately between 4 to 12 MPa depend on the mix design (V. C. Li, 2007).

This particular type of cementitious material is highly beneficial in fatigue loading over another kind of advanced cement-based materials and particularly NC because of having large deformability (ductility). Having very tight crack width and dense matrix increase resistance of PVA-ECC to freezing and thawing cycles with or without de-icing salt, alkalis, and chemical attacks. As a result, the durability and sustainability of PVA-ECC structures are reported to be much higher than NC (V. C. Li, 2007). 


\subsubsection{Permeability}

Uncrack PVA-ECC is impermeable or have a very low permeability since it does not have coarse aggregates, contains a large amount of Portland cement and cementitious materials including fly ash or slag, and have a very low W/CM ratio. However, the permeability of the cracked PVA-ECC should be the primary concern. According to the numerous studies, it was proven that the permeability coefficient does not change significantly when the crack widths remain under $100 \mu \mathrm{m}$ (Lepech \& Li, 2009; K. Wang, Jansen, Shah, \& Karr, 1997).

Since PVA-ECC is engineered to have saturated multiple-micro cracks with the very tight crack width generally smaller than $100 \mu \mathrm{m}$, it is predicted that PVA-ECC can perform almost same as sound concrete even after cracking. In order to prove that the above statement, cracked (preloaded) PVA-ECC was investigated with reinforced mortar by Lepech and $\mathrm{Li}$ (2009). PVA-ECC and reinforced mortar were cracked by pre-tensioning up to $1.5 \%$ deformation. Results demonstrated that PVA-ECC (permeability coefficient $\approx$ $5 \times 10^{-11} \mathrm{~m} / \mathrm{s}$ ) acts almost exactly same as a sound concrete (permeability coefficient $\approx$ $1.0 \times 10^{-11} \mathrm{~m} / \mathrm{s}$ ) by showing very low permeability (Lepech \& Li, 2009).

\subsubsection{Cost}

Generally, one cubic meter of PVA-ECC mixture is three times more expensive than NC (V. C. Li, 2006). This higher cost of PVA-ECC is mainly due to having polymer fibers (PVA), high cement and SCMs content (V. C. Li, 2003). However, PVA-ECC is cheaper than UHPC due to following reasons:

(1) PVA-ECC does not require a high amount of grinding, and fine powders such as silica fume and quartz powder;

(2) The price of polymer fibers used in the PVA-ECC mixture is less than the steel fibers although steel fibers are cheaper based on the unit weight. However, it should be considered that the steel fibers weight 6 to 7 times more than the polymer (PVA) fibers which makes the steel fibers overall more expensive;

(3) Replacing high cement content with fly ash or slag helps in reducing the price of ECC blend (V. C. Li, 2003). 


\subsubsection{Self-Compacting Concrete (SCC)}

\subsubsection{Background and Fundamental Principles}

Self-compacting concrete or self-consolidating concrete (SCC) is a unique type of concrete that has the ability to retain its stable condition during transportation and placing, consolidate under its own weigh, discharge entrapped air, move around obstacles, fills formworks with high amount of reinforcement without any vibrations, compactions, signs of segregation, or separation of materials. Hence, SCC decreases the construction time, cost, and noise (Khayat, Ghezal, \& Hadriche, 2000; Z. Li, 2011; Okamura \& Ouchi, 2003). Requiring horizontal surface is the major disadvantage of the SCC (Neville \& Brooks, 2010). SCC is very beneficial in pre-cast, pre-stressed, and cast in place construction (Hwang \& Khayat, 2008). Okamura in 1986 for the first time stated the need of having this unique type of concrete since skilled construction workers responsible for vibrating the concrete structures were gradually decreasing at the time in Japan. The initial development of durable concrete structures without any needs for compaction or vibration was investigated in the University of Tokyo by Okumura, Ozawa and Maekawa between 1986 to 1999 (Okamura \& Ouchi, 2003). The first SCC mixture was developed in 1988 by paying close attention to three different ages of concrete and improving each age properties: (Stage-I) while the concrete is fresh, self-consolidating behaviour is required; (Stage-II) producing concrete without any initial defects and cracks at early age; and (Stage-III) constructing durable concrete and protecting it from external deterioration after hardening (Okamura \& Ouchi, 2003). To achieve SCC with these properties, the three fundamental principles were defined by Okamura and Ozawa in 1995 as follow (Bonen \& Shah, 2005; Khayat, Ghezal, \& Hadriche, 1999; Okamura \& Ouchi, 2003):

1. Reducing the aggregate content by increasing the amount of fine aggregate or powders in the mixture which prevents interlocking and accumulation of coarse aggregate, and provides adequate particle distance.

2. Decreasing the W/B which enhances the strength properties, reduces the ITZ and porosity of the final product.

3. Implementing superplasticizer and/or viscosity modifying agent (VMA) 
Implementing these three principles help to achieve concrete about 10 times smaller yielding stress than NC with a proper plastic viscosity (Bonen \& Shah, 2005).

\subsubsection{Mix Proportion Characteristics}

SCC mix design requires many trials since high flow-ability, deformability, and cohesiveness with a minimum amount of bleeding and segregation of the blend is required (Khayat et al., 1999). As discussed above (Section 2.2.3.1), several factors including W/B, the type and amount of SCMs, volume and size of coarse aggregate, amount of superplasticizer, and VMA directly influence the blend properties. For example, increasing the W/B provides the blend with good deformability. However, it increases the bleeding and segregation at the same time (Khayat et al., 1999). It is essential to optimize the W/B ratio in such a way to have both cohesiveness (resistance to segregation) and deformability in the desirable limit. The W/B ratio between 0.30 to 0.45 was proven to provide the best results and recommended (Z. Li, 2011). Moreover, increasing fine aggregate to the total aggregate ratio $(F / T)$ by more than $25 \%$ in comparison to $N C$ provides lower shear stress, adequate viscosity, and better deformability (Z. Li, 2011). In addition to W/CM and F/T, SCC blend has the much higher volume of the paste (water and powders) in comparison to NC. The excess amount of paste is designed to minimize the interlocking of large particles and to increase the self-consolidation properties of the mixture. It also enhances the workability and deformability of the blend (Z. Li, 2011). The SCC mix proportion is classified into two primary categories including powder-type SCC and VMA-type SCC (Bonen \& Shah, 2005).

\subsection{Powder-type}

The powder-type SCC is the original type that was first introduced by Okamura in 1988. Figure 2-16 illustrates the mix design proportion of the powder-type SCC in comparison to the NC. As it can be seen, the amount of air, water, and fine aggregate were kept the same. To accomplish the SCC major properties (explained in Section 2.2.3.1), the amount of powder (cement, SCMs, and fillers) was increased, and simultaneously the coarse aggregate content was decreased. Therefore, the powder-type SCC contains a lower amount of aggregate to binder ratio $(\mathrm{AGG} / \mathrm{B})$ and water to powder ratio $(\mathrm{W} / \mathrm{P})$. This type 
of SCC also includes superplasticizer to ensure of having low yield strength and good deformability of the mixture (Bonen \& Shah, 2005; Okamura \& Ouchi, 2003).

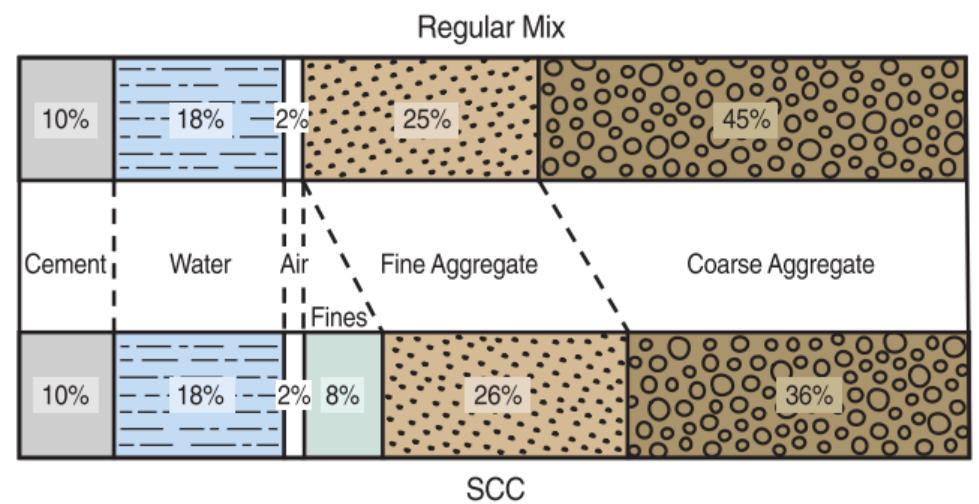

Figure 2-16: Mix Design of SCC and NC (Kosmatka, Kerkhoff, \& Panarese, 2003)

\subsection{VMA-type}

In the VMA-type SCC superplasticizer and viscosity modifying agent (VMA) are both implemented in the SCC blend. Superplasticizer decreases the yielding strength and bleeding of SCC mixture while VMA enhances the plastic viscosity and decreases the segregation. In other words, the benefit of incorporating VMA in the system is to achieve a desirable plastic viscosity by implementing less powder and not changing the amount of water (Bonen \& Shah, 2005). Figure 2-17 compares the volume fraction of NC, VMAtype, and powder-type SCC with the same compressive strength. Also, it can be interpolated from the Figure 2-17 that the fine to the coarse aggregate ratio (FA/CA) increases from NC to powder-type SCC (Bonen \& Shah, 2005).

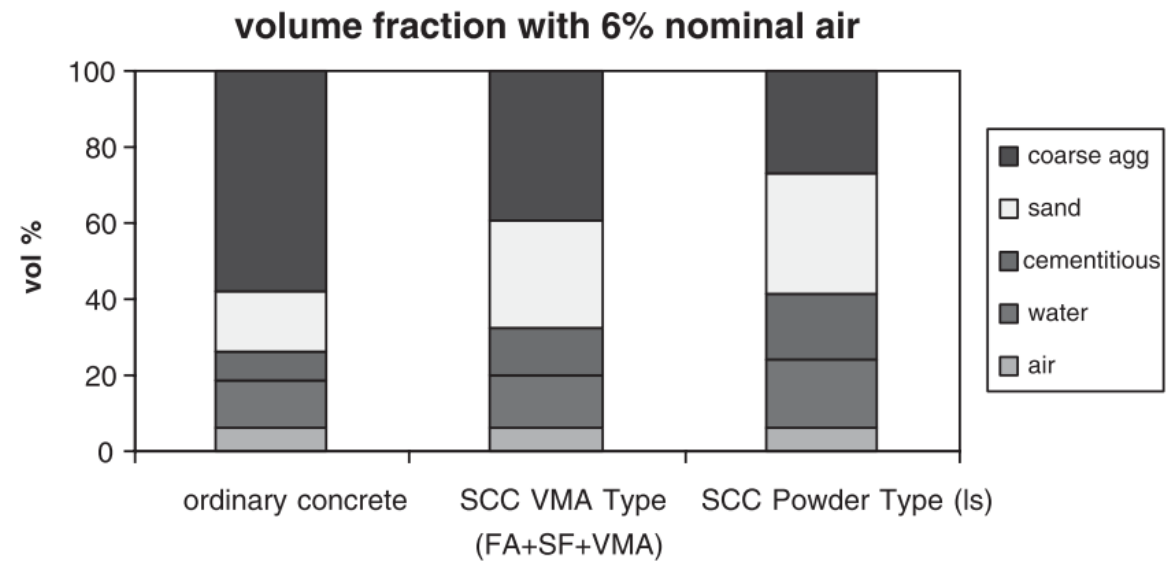

Figure 2-17: Volume Fraction Comparison of SCC \& NC (Bonen \& Shah, 2005) 


\subsection{Powder Content}

Powder in the SCC blend includes cement, SCMs mostly silica fume and fly ash, and/or fillers such as limestone powder. Among the SCMs, fly ash is preferable over others due to its complete spherical shape and less tendency to absorb water compare to silica fume and Slag (Z. Li, 2011).

\subsubsection{Mix Design}

In this section four typical mix design of SCC, two of them recommended by researchers and two of them used in the previous projects is summarized to provide the better understanding of the blend composition and its major properties.

Table 2-3: Typical SCC Mix Design Proportions

\begin{tabular}{|c|c|c|c|c|c|c|}
\hline \multicolumn{2}{|c|}{ Components $\left(\mathrm{kg} / \mathrm{m}^{3}\right)$} & SCC1 & SCC2 & $\begin{array}{c}\text { Chinese } \\
\text { Center } \\
\text { TV }\end{array}$ & $\begin{array}{l}\text { Trade } \\
\text { Center } \\
\text { Tower }\end{array}$ & $\begin{array}{l}\text { Tunnel } \\
\text { lining } \\
\text { Japan }\end{array}$ \\
\hline \multirow{4}{*}{$\begin{array}{l}D \\
\sum_{0}^{0} \\
\frac{D}{D} \\
\infty\end{array}$} & Portland Cement (GU) & 360 & 350 & 380 & 360 & 320 \\
\hline & Fly Ash & - & - & 150 & 240 & 80 \\
\hline & Silica Fume & 22.5 & 40 & - & - & - \\
\hline & Limestone Powder & $67.5^{1}$ & - & - & - & - \\
\hline \multicolumn{2}{|c|}{ Sand } & 842 & 825 & 840 & 800 & 859 \\
\hline \multicolumn{2}{|c|}{ Coarse Aggregate } & 950 & 825 & 850 & $840^{a}$ & 878 \\
\hline \multicolumn{2}{|c|}{ Water } & 123 & 183 & 170 & 175 & 154 \\
\hline \multicolumn{2}{|c|}{ Superplasticizer } & $8280^{2}$ & 14.4 & 7.4 & 7.1 & 7.2 \\
\hline \multicolumn{2}{|c|}{ W/C (Water to Cement Ratio) } & 0.34 & 0.52 & 0.45 & 0.49 & 0.48 \\
\hline \multicolumn{2}{|c|}{ W/P (Water to Powders Ratio) } & 0.27 & 0.47 & 0.32 & 0.29 & 0.38 \\
\hline \multicolumn{2}{|c|}{ F/T (Fine to Total aggregate Ratio) } & 0.470 & 0.500 & 0.497 & 0.488 & 0.495 \\
\hline \multicolumn{2}{|c|}{ Slump Flow (mm) } & 680 & 640 & 720 & 665 & 570 \\
\hline \multicolumn{2}{|c|}{ Compressive Strength at $28 \mathrm{~d}$. (MPa) } & - & 36.5 & 72.3 & 83.6 & $>24$ \\
\hline
\end{tabular}

SCC1: (Panesar, Aqel, Rhead, \& Schell, 2017) - SCC2: (Diab, Abd Elmoaty, \& Tag Eldin, 2017)- Chinese Center Television and International Trade Center: (Yan \& Yu, 2009) - Tunnel Lining Japan: (Zhang, Hughes, Jeknavorian, Nishimura, \& Yang, 2009) - ${ }^{1}$ Limestone powder with nominal particle size of $17 \mu \mathrm{m}$ was used -2 The reported superplasticizer amount is $\mathrm{ml}$. 


\subsubsection{Strength}

Depending on the mix design, the SCC can have a high range of the compressive strength. For example, implementing SCMs specifically silica fume increases the strength. Well design SCC can have high compressive strength range from NC to HPC, 30 to 80 MPa (Kosmatka et al., 2003; Paultre, Khayat, Cusson, \& Tremblay, 2005). The high range of compressive strength can be observed in Table 2-3. The compressive strength of SCC is equal or higher than NC for the same W/C (Kapoor, 2012).

\subsubsection{Permeability}

According to the study was done by Tragardh (1999) on the microstructural features, the ITZ and bulk paste of SCC were found to be smaller than NC while for both mixtures the $\mathrm{W} / \mathrm{C}$ ratio, type of cement and aggregate were kept same. This behaviour of SCC mix is mainly due to reducing the amount of coarse aggregate and implementing the higher amount of powder like SCMs which both increase packing. Moreover, there is less amount of water for micro-bleeding in the SCC mixture since the vibration is eliminated. Hence, increasing packing (having denser microstructure), improving ITZ, and reducing the internal bleeding lead to having less permeability, and lower sorptivity for SCC in comparison to NC (Hwang \& Khayat, 2008; Tragardh, 1999; Zhu \& Bartos, 2005).

\subsubsection{Cost}

Since SCC mix design generally contains the higher amount of fine particles including cement, SCMs, or fillers and implements the different type of admixtures such as superplasticizer and/or VMA, the initial material cost of SCC mixture is estimated to be higher than NC. Pai (2004) reported that the SCC initial material cost could be 10 to $15 \%$ higher than NC. Recently, Another investigation showed approximately 5 to $10 \%$ difference in cost (Murthy, Rao, \& Reddy, 2014). The recent reduction in the price of SCC is due to the improvement of the admixture industry and replacing the more cement content with SCMs. However, the total SCC cost is even less than NC due to decreasing the placing time, eliminating vibration, reducing maintenance cost, and enhancing the labour safety (Murthy et al., 2014). 


\subsection{Materials Properties and Compatibility of Repairs with Substrate}

Compatibility - which is a very well-known word in the restoration and repair industry was first introduced by Emmons et al. (1993) as follow:

"Compatibility can be defined as a balance of physical, chemical and electrochemical properties and dimensions between a repair material and existing substrate that will ensure that the repair can withstand all the stress induced by volume changes and chemical and electrochemical effects without distress and deterioration over a designated period of time."

Some of the most important compatibility factors which are also considered in this research are the compressive strength, modulus of elasticity, and autogenous and drying shrinkage (Emmons et al., 1993).

\subsubsection{Compressive Strength}

The maximum resistance of concrete specimen - while it is subjected to axial compressive load - defines as compressive strength. Compressive strength is mainly related to the W/C ratio, cement and cementitious material content, the degree of compaction, curing, temperature and age of concrete sample although other factors such as porosity, aggregate to cement ratio, properties of aggregate, and the transition zone between aggregate and past have influence as well (Kosmatka et al., 2003; Neville \& Brooks, 2010).

Compressive strength is one of the most important physical characteristics of the material and used in almost all design applications such as bridges and buildings (Kosmatka et al., 2003; Neville \& Brooks, 2010). Since the compressive strength of any concrete or cementitious composites change over the sample age, the compressive strength development was defined which evaluates the compressive strength of materials at different age with the same method of curing. 


\subsubsection{Modulus of Elasticity}

Concrete is categorized as non-linear and non-elastic materials in both compression and tension. Therefore, it is not possible to define a linear modulus of elasticity for concrete with a single value. Different modulus of elasticities was defined for concrete including the initial tangent modulus, dynamic modulus, secant modulus, and static (chord) modulus (Mindess et al., 2003).

Each of these moduli has their definitions, advantages and disadvantages. Initial tangent modulus defines as the slope of the tangent line at the starting point of the stress-strain curve. This modulus is not a good indication of the structural behaviour because it just represents a limited portion of the stress-strain curve. Dynamic modulus of elasticity also is very similar to the initial tangent modulus because it determines by low-frequency vibration of specimens (Mindess et al., 2003).

Secant modulus is the slope of the line drawn between origin and any specific point on the stress-strain curve. This modulus is more practical because it clearly illustrates that the concrete is non-linear and non-elastic. The value of the secant modulus directly depends on the selected point on the stress-strain curve. Hence, the results may be varied. Finally, the chord or static modulus is kind of secant modulus with the fixed value ( $40 \%$ of maximum stress) for selecting points on the stress-strain curve (Mindess et al., 2003).

In this research, the static modulus of elasticity was selected and measured. Modulus of elasticity influences by the strength of the paste (factors such as W/C, type of Portland cement, amount of SCMs, etc.), characteristics of aggregate, the density of the mixture, moisture condition of and age of samples at the time of performing the test. For instance, implementing a low $\mathrm{W} / \mathrm{C}$ ratio enhances the strength of the paste and reduces the porosity. Thus, it increases the modulus of elasticity (Mindess et al., 2003; Neville \& Brooks, 2010). 


\subsubsection{Shrinkage}

In selecting or optimizing the mix design to be used as a repair, shrinkage considers as one of the most essential mechanical compatibility aspects. Shrinkage is one of the characteristics of the paste. However, coarse aggregates in particular have a restraining impact on the mixture (Mindess et al., 2003). In the following sections, three main types of shrinkage were explained.

\subsubsection{Plastic Shrinkage}

Plastic shrinkage defines as the loss of moisture while concrete is in the plastic (fresh) condition. This type of shrinkage happens in the form of surface cracking due to water evaporation from the surface of the concrete. Plastic shrinkage can also extract some water from the inside of the concrete and leave cracks or cavities behind; however, it is not that common (Emmons et al., 1993; Mindess et al., 2003). Since plastic shrinkage mostly occurs on the surface of the concrete with minimal crack depth, it reduces the surface strength and durability of the concrete. Hence, the substrate in the repair system (because the surface of the substrate is in contact with repair products) requires more attention in this regard. The mixing temperature and environmental conditions such as high wind, low humidity, and high temperature directly affect the plastic shrinkage. All these factors should be controlled throughout the casting (Mindess et al., 2003). In this research, the best standard practice was done to eliminate or minimize the plastic shrinkage for substrates and repair products.

\subsubsection{Autogenous Shrinkage}

Autogenous shrinkage, self-desiccation, or chemical shrinkage is the type of microscopic volumetric change while concrete particularly binder hydrate and lose moisture. The loss of moisture should be only due to the chemical reactions (Emmons et al., 1993). In fact, this type of shrinkage is primarily due to the reaction of excess water inside capillaries and unhydrated cement after hardening. Hence, autogenous shrinkage does not occur due to loss of water to the environment. Autogenous shrinkage is more common and severe on the mixtures with low W/C ratio (less than 0.3 ), high amount of SCMs 
specifically silica fume, and more critically concrete with very low permeability since the excess amount of water provided by curing cannot penetrate inside the sample. Hence, the $\mathrm{RH}$ inside the sample decreases by the process of hydration and causes shrinkage (Mindess et al., 2003). Among the repair materials studied in this research, an extensive amount of attention to UHPC and ECC is required due to implementing very high cement content, SCMs, eliminating coarse aggregate, and being almost impermeable. SCC should also be considered because of having a high amount of powder such as silica fume and using smaller coarse aggregate sizes.

\subsubsection{Drying Shrinkage}

Drying shrinkage is due to loss of capillary water inside the paste or more specifically calcium silicate hydrate gel (CSH) while concrete is in the hardened situation (Emmons et al., 1993). Losing water from the capillaries put concrete under capillary tensile stress and causes cracks. Drying shrinkage is the most crucial and important type of shrinkage in concrete. Several factors directly influence the drying shrinkage including W/C ratio, degree of hydration, paste properties (like cement composition, SCMs, admixture, etc.) aggregate properties and sizes, and environmental parameters (such as relative humidity, temperature, time of drying, etc.) (Mindess et al., 2003). Measuring autogenous and drying shrinkage for each repair products is very important due to the fact that these types of shrinkage can reduce the bond strength by adding undesirable stress to the bond.

\subsection{Substrate Surface Preparation}

To have a successful repair products, substrate surface preparation is one of the most influential factors to consider. Substrate surface preparation defines as all the factors or process on the contact area of the substrate that affect the bond strength of a repair system (Bissonnette et al., 2013). If the substrate surface preparation was not done correctly, the repair products fail no matter what type of repair material is selected, how the bond interface is developed, and how compatibility of repair product is optimized (Austin et al., 1995; Morgan, 1996). 


\subsubsection{Roughness}

For a long time, substrate surface roughness was determined to have the maximum influence on the bond strength of repair products due to enlarging the contact area and providing more mechanical interlocks between repair and substrate. However, this point of view nowadays is changing (Lukovic, Schlangen, Ye, \& Savija, 2013).

There are different methods recommended to create the surface roughness. The surface texture can be prepared by casting, saw cutting, sandblasting, hydro jetting, wire brushing, hammering (pneumatic and chisel), needle gunning, and using chemical agents. Some of these methods especially the mechanical or impacting ones like hammering create a very rough surface in comparison to saw cutting and sandblasting. However, they produce high number of microcracks on the substrate which act as a plan of weakness due to stress concentration, consequently, reduces the bond strength (Austin et al., 1995; Cleland, Naderi, \& Long, 1986; Hindo, 1990; Morgan, 1996).

Cleland et al. (1986) investigated two different level of roughness created by the chisel hammer (very rough) and saw cut (very smooth). The results demonstrated remarkably higher bond tensile strength for the saw cut (very smooth surface roughness). In addition, Hindo (1990) compared the bond interface strength of two different surface roughness preparations, one by pneumatic hammer and the other one by hydro jetting; the results indicated higher bond strength for samples prepared by hydro jetting.

Therefore, just increasing the substrate surface roughness does not lead to having higher bond strength. The method of surface roughness preparation, level of microcracks, and also the bond testing method play significant roles (Austin et al., 1995). Moreover, Lukovic et al. (2013) reported that increasing the roughness higher than certain value does not enhance the bond strength anymore. Another research was recently conducted on the UHPC demonstrated the same behaviour and proved that increasing the roughness more than 4 to $5 \mathrm{~mm}$ does not enhance the bond strength (B. Wang, Xu, \& Liu, 2016). 


\subsubsection{Cleanliness}

Another critical factor in the substrate preparation is to have the bond interface area entirely clean in such a way that there is zero or minimum amount of dust, oil, or any other contaminants on the substrate surface before applying repair material (Bissonnette et al., 2013). Typically, hydro jetting and sandblasting roughness preparation produce very clean substrate. However, surface roughness created by chemical agent requires considerable attention (Austin et al., 1995).

\subsubsection{Moisture Condition}

There are numerous studies and researches about the substrate moisture level at the time of applying repair. Erhard and Chorinsky (1986) showed that the dry condition of the substrate might cause the substrate to absorb water from the repair material. As a result, it reduces the $\mathrm{W} / \mathrm{C}$ ratio and the amount of hydration at the bond interface. Therefore, less amount of hydration product (CSH) is available to penetrate through the porosities and bond with the substrate. On the other hand, when the substrate is entirely wet, the extra amount of water increases the W/C ratio of repair product at the interface which reduces the bond strength. Furthermore, the excess amount of water prevents the penetration of repair material into the substrate porosities by filling them. Thus, the bond interface strength decreases significantly.

Cleland and Long (1997) conducted four different laboratory moisture levels for a substrate including air dry, saturated surface dry (SSD), oven dry, and wet condition. The results indicated that the air dry and SSD conditions did not affect the bond strength profoundly and indicated almost equivalent results. However, for oven dry and wet conditions, the bond strength decreased significantly.

Shin and Wan (2010) investigated the bond performance of new and old concretes under two different substrate conditions: (i) dry and (ii) SSD. They concluded that the substrate with the SSD condition produces almost twice bond strength compared to the dry condition. According to the above discussion, all the researchers confirm that the SSD moisture level of the substrate is the optimum condition at the time of applying repair. 


\subsection{Type of Testing Methods}

There are different types of testing methohs available to measure the bond strength between repair and substrate. The testing methods are divided into three main categories by Saucier et al. (1991), based on the type of stress acting on the specimen: (1) direct tensile stress (e.g., pull-off test), (2) indirect tensile stress such as splitting tensile method, and (3) combined shear and compression stress like slant shear method. Despite the fact that several testing methods and procedures to evaluate the bond strength were developed, few numbers of studies compared the testing methods and their results.

It is important to mention that the results measured by each of these testing methods might be completely different from each other due to the nature of acting force and geometry (size) of samples (Lukovic et al., 2013; Momayez et al., 2005). However, According to Lukovic et al. (2013), the bond strength of cement-based repair product evaluated by direct shear was at least twice the tensile strength. In addition, it was reported by Momayez et al. (2005) that the slant shear and pull-off test provide the highest and lowest bond interface strength, respectively.

\subsubsection{Direct Tensile Stress}

The pull-off and direct tension tests as illustrated in Figure 2-18 are the two testing methods in the direct tensile stress classification. Specimens in this category consider to be under pure direct tensile stress. As a result, any misalignment in the direction of the load axis can cause high bending moment and false bond strength measurement. Therefore, operating this category of testing methods remains very difficult.

Besides, to transfer the direct tensile stress to the specimens, metal disks with epoxy are implemented in most of the cases. The process of selecting, mixing, applying, curing, and finally cleaning epoxy (to be able to reuse the disks) is very time-consuming and costly. Despite all the disadvantage, this category precisely represents the bond strength under direct tension.

Among the two direct tensile testing methods represented in Figure 2-18, pull-off test is the most popular one in the field and laboratory due to its practicality (Saucier et al., 1991) 
although several parameters including repair material thickness, coring depth into the substrate, and coring bit diameter should be considered (Bonaldo, Barros, \& Lourenço, 2005). For the purpose of this research, pull-off test was selected due to the availability of the testing apparatus and simplicity.

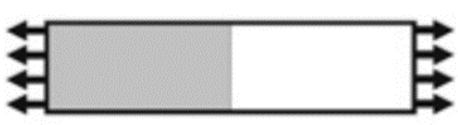

(a)

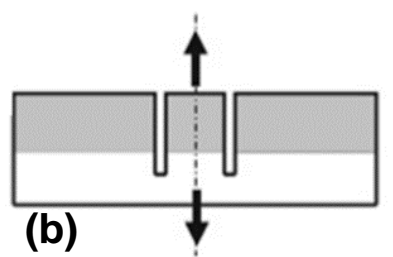

(b)

Figure 2-18: (a) Direct Tensile Test and (b) Pull-off Test (Espeche \& León, 2011)

\subsubsection{Indirect Tensile Stress}

In this category of testing methods, direct shear stress or combined shear and bending stresses apply to the specimens. Splitting tensile with cylinder or prism, L-shaped, monosurface shear, bi-surface shear or any test that involve any combination of bending (Figure 2-19) and shear stresses (Figure 2-20) fall in this group.

Experiments in this category are much easier to perform. However, most of the specimens are long in comparison to their cross-sections. So, they are not efficient in terms of space and materials. Among all the testing methods, splitting tensile test with cylinder (Figure 2-20-e) and bi-surface direct shear test (Figure 2-20-j and k) are the most popular ones due to being easy to construct, consuming less materials and space (Momayez et al., 2005; Saucier et al., 1991). The result of splitting tensile test is approximately 8 to $15 \%$ higher than direct tensile test (Z. Li, 2011; Mindess et al., 2003). The standard concrete cylinders $(100 \times 200 \mathrm{~mm})$ were selected here for this research.
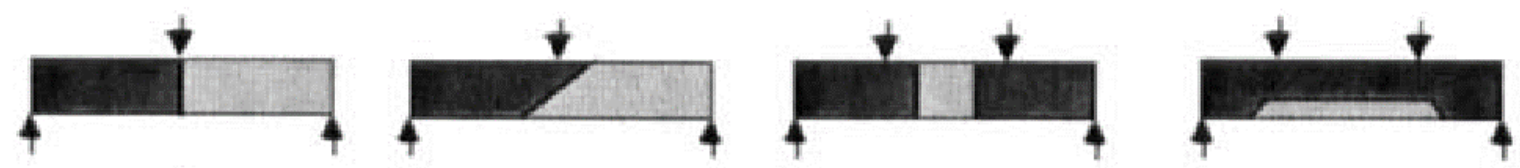

Figure 2-19: Indirect Tensile Testing Methods - Bending (Saucier et al., 1991) 

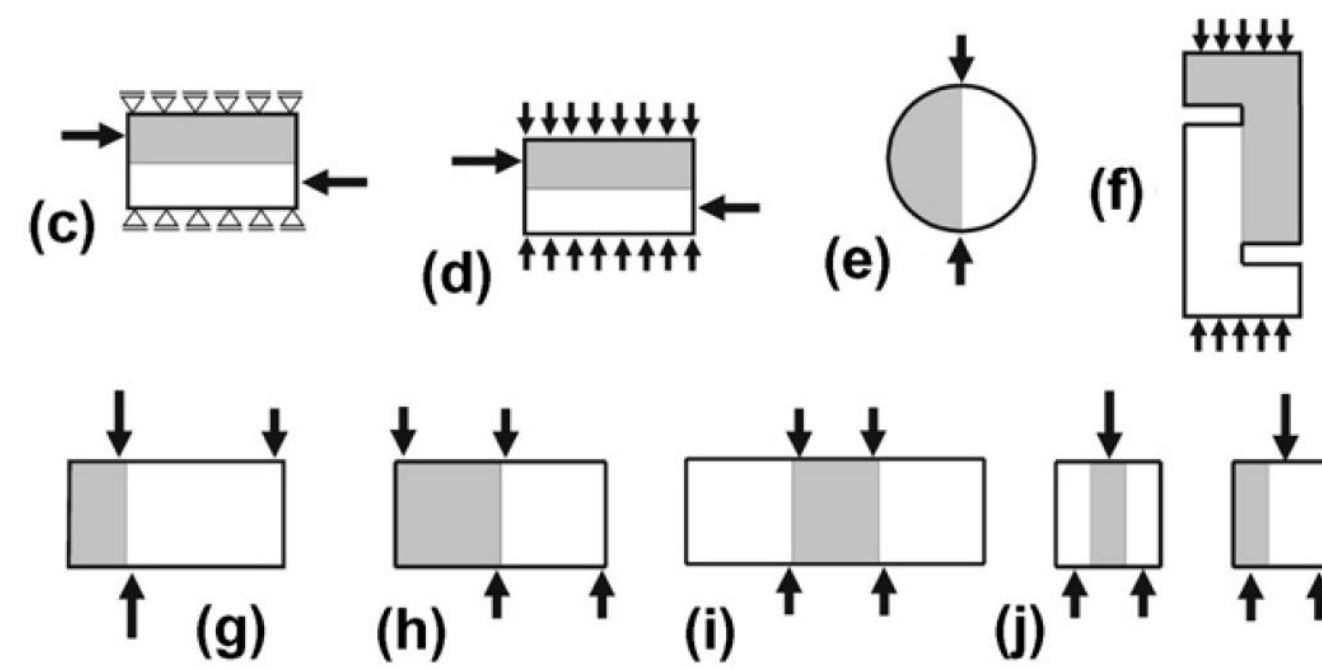

(h)

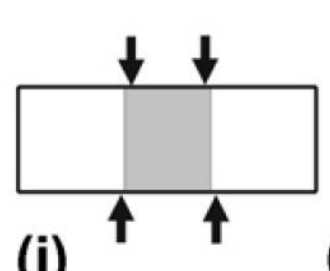

(i)
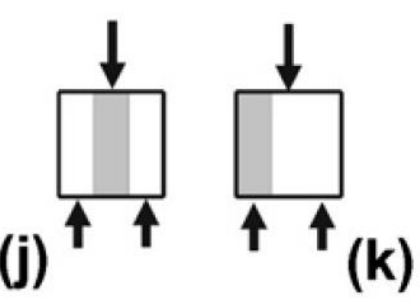

Figure 2-20: Indirect Tensile Testing Method-Shear (Espeche \& León, 2011)

\subsubsection{Combined Shear and Compression Stress}

In this category of evaluating bond strength testing methods, the bond interface is under a combination of the compression and shear stress. The slant shear test - also known as the Arizona test, which is the most popular test among researchers - can perform on cylinders or square cross-section prisms (Figure 2-21).

The inclined plane angle directly influences the bond strength results and type of failure. Therefore, the inclined plane of 60-degree angle with a horizontal line (30-degree vertical) between substrate and repair material is fixed by standard tests such as ASTM C882 (Austin, Robins, \& Pan, 1999).
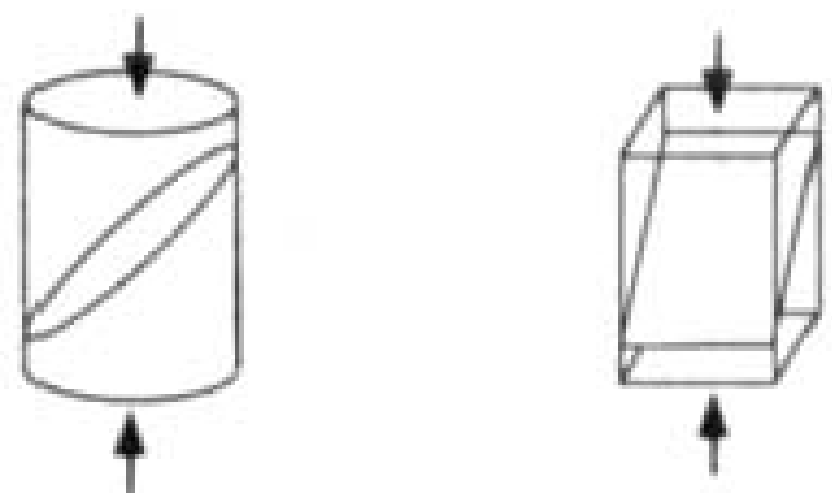

Figure 2-21: Combined Shear \& Compression Tests (Saucier et al., 1991) 


\section{Chapter 3}

\section{Materials and Experimental Program}

In this research, the experimental program was divided into three major phases as it was explained in Section 1.1 (Research Objective and Scope). Phase-I examines and compares the mechanical compatibility of four type of repair products used in this research including UHPC, ECC-Slag, SCC, and NC with two different substrates. The characteristics such as compressive strength, modulus of elasticity, and shrinkage investigated to better understand the repair products compatibility with its substrate. The second primary phase (Phase-II) was designed to study the bond strength behaviour of repair materials with the substrate (Sub-A) under freezing and thawing cycles in the present of de-icing salt. Phase-II represents one of the main sources of deterioration in Canada which includes severe weather exposure in the winter season. Phase-III was intended to evaluate the bond strength of the different repair products under the substrate (Sub-B) with expanding deterioration condition. This phase demonstrates any type of deterioration due to expansion such as alkali-silicate reaction (ASR), alkali-carbonate reaction $(A C R)$, and even sulphide attacks. In this section, the mix designs implemented for each substrate and repair products were discussed. Afterward, in the experimental program, the steps and procedure used to achieve each of the objectives of this research will be explained in more details. 


\subsection{Materials}

Materials used in this research divided into two main subsections of concrete substrates and repair materials.

\subsubsection{Concrete Substrates}

\subsubsection{Substrate A (Sub-A) - Normal Conventional Concrete (NC)}

This substrate was designed for the second objective (Phase-II) of this research which is evaluating the bond performance of the repair materials under freezing and thawing in the presence of de-icing salt (explained in Section 1.1). Since most of the aged and deteriorated concrete structures were built with normal conventional concrete (NC), this type of concrete was selected for substrate A (Sub-A). The Sub-A mix design has the following properties: class exposure of $\mathrm{C} 2$ (non-structurally reinforced concrete exposed to chloride and freeze-thaw cycles), W/C of 0.42 , design slum of $75 \mathrm{~mm}$, air category 1 (5 to $8 \%$ air entrainment), and minimum specified compressive strength of $32 \mathrm{MPa}$. The Sub-A mixture contained crushed limestone with nominal maximum size (NMSA) of 20 $\mathrm{mm}$ and concrete sand with NMSA of 5 . The entire coarse and fine aggregate properties is listed in Table 3-1. In addition, general use (GU) Portland cement from Holcim Canada Inc., Mississauga Plant, with chemical composition provided in Table 3-2, density of 3150 $\mathrm{kg} / \mathrm{m}^{3}$, Blaine fineness of $410 \mathrm{~m}^{2} / \mathrm{kg}$, and MasterAir® AE 200 supplied by BASF corporation as an air entraining admixture without any SCMs and superplasticizer were implemented in the mix design of Sub-A. The mix design proportion of the Sub-A is also provided in Table 3-3 (CSA A23.1/CSA A23.2, 2014).

Table 3-1: Aggregate Properties

\begin{tabular}{lcccccc}
\hline Aggregate Type & $\begin{array}{c}\mathbf{N M S A}^{1} \\
(\mathbf{m m})\end{array}$ & $\begin{array}{c}\mathbf{A b s}^{2} \\
(\%)\end{array}$ & $\mathbf{M C}^{3}(\%)$ & $\mathbf{S G}^{4}$ Dry & $\begin{array}{c}\mathbf{D R D}^{5} \\
\left(\mathbf{k g} / \mathbf{m}^{3}\right)\end{array}$ & FM $^{6}$ \\
\hline Coarse Aggregate & 20 & 0.81 & 0.07 & 2.73 & 1623.54 & - \\
Fine Aggregate & 5 & 1.30 & 0.25 & 2.54 & - & 2.8 \\
\hline
\end{tabular}

${ }^{1}$ Nominal Maximum Size of Aggregate, ${ }^{2}$ Absorption, ${ }^{3}$ Moisture Content, ${ }^{4}$ Specific Gravity, ${ }^{5}$ Dry Rodded Density, ${ }^{6}$ Finesse Modulus 
Table 3-2: Chemical Composition of General Use Portland cement (GU PC)

\begin{tabular}{lclc}
\hline Chemical Composition & $(\%)$ & Chemical Composition & (\%) \\
\hline Calcium Oxide $(\mathrm{CaO})$ & 62.39 & Sulfur Trioxide $\left(\mathrm{SO}_{3}\right)$ & 4.03 \\
Silicon Dioxide $\left(\mathrm{SiO}_{2}\right)$ & 19.54 & Free Lime & 1.33 \\
Aluminium Oxide $\left(\mathrm{Al}_{2} \mathrm{O}_{3}\right)$ & 5.21 & Total Alkali $\left(\mathrm{Na}_{2} \mathrm{O}\right.$ eq. $)$ & 0.95 \\
Ferric Oxide $\left(\mathrm{Fe}_{2} \mathrm{O}_{3}\right)$ & 2.16 & Loss on Ignition (LOI) & 2.36 \\
Magnesium Oxide $(\mathrm{MgO})$ & 2.39 & & \\
\hline
\end{tabular}

Table 3-3: Sub-A Mix Design Proportion $\left(\mathrm{kg} / \mathrm{m}^{3}\right)$

\begin{tabular}{ccccccc}
\hline Mixture ID & W/C & Cement & Water & $\begin{array}{c}\text { Coarse } \\
\text { Aggregate }\end{array}$ & $\begin{array}{c}\text { Fine } \\
\text { Aggregate }\end{array}$ & Air $^{1}(\%)$ \\
\hline \hline Sub-A & 0.42 & 440 & 184 & 1023 & 584 & $5-8 \%$ \\
\hline
\end{tabular}

${ }^{1}$ Air content was designed for $7 \%$; however, the range of 5 to $8 \%$ was accepted.

\subsubsection{Substrate B (Sub-B) - Alkali-Carbonate Reaction Concrete (ACR)}

Substrate B (Sub-B) was designed to simulate the deterioration due to expansion such as alkali-silicate reaction (ASR), alkali-carbonate reaction (ACR), and sulphide attacks as it was explained in Section 1.1. Hence, to simulate the expansion over a shorter period of time substrate with highly reactive carbonate aggregate (ACR) was chosen.

The carbonate aggregate implemented in the mix design was from Pittsburg quarry in Kingston, ON, Canada. The Pittsburg aggregate contains 5 to $15 \%$ clay silica, 35 to $40 \%$ dolomite, and 45 to $60 \%$ calcite. Table 3-4 lists the chemical composition of this highly reactive carbonate aggregate which was found by X-ray fluorescence (Shehata, Jagdat, Rogers, \& Lachemi, 2017).

The mix design of the Sub-B was adopted according to alkali-silica reactive aggregate (ASR) mix design as specified by CSA A23.2-14A (2014) since there is no specific standard available for ACR mix design. However, instead of silicate aggregate, the Pittsburg aggregate was used. Furthermore, to increase the rate of expansion even 
faster, the alkalinity of the mixture raised from $0.95 \%$ to $1.25 \%$. The air content of the mix design was assumed to be $2 \%$; therefore, no air entrainment admixture was added. The mix design proportion of the Sub-B is listed in Table 3-5.

Table 3-4: Chemical Composition of the Pittsburg Aggregate (Shehata et al., 2017)

\begin{tabular}{llll}
\hline Chemical Composition & (\%) & Chemical Composition & (\%) \\
\hline \hline Calcium Oxide $(\mathrm{CaO})$ & 43.2 & Titanium Dioxide $\left(\mathrm{TiO}_{2}\right)$ & 0.06 \\
Silicon Dioxide $\left(\mathrm{SiO}_{2}\right)$ & 4.67 & Phosphorus Pentoxide $\left(\mathrm{P}_{2} \mathrm{O}_{5}\right)$ & 0.02 \\
Aluminium Oxide $\left(\mathrm{Al}_{2} \mathrm{O}_{3}\right)$ & 1.81 & Manganese Monoxide $(\mathrm{MnO})$ & 0.03 \\
Ferric Oxide $\left(\mathrm{Fe}_{2} \mathrm{O}_{3}\right)$ & 0.65 & Total Alkali $\left(\mathrm{Na}_{2} \mathrm{O}\right.$ eq. & $<0.05$ \\
Magnesium Oxide $(\mathrm{MgO})$ & 8.31 & Loss on Ignition (LOI) & 42.1 \\
\hline
\end{tabular}

Table 3-5: Sub-B Mix Design Proportion $\left(\mathrm{kg} / \mathrm{m}^{3}\right)$

\begin{tabular}{lcccccc}
\hline Mixture ID & W/C & Cement & Water & $\begin{array}{c}\text { Coarse } \\
\text { Aggregate }\end{array}$ & $\begin{array}{c}\text { Fine } \\
\text { Aggregate }\end{array}$ & Air $^{1}(\%)$ \\
\hline \hline Sub-B & 0.45 & 420 & 190 & 1046 & 697 & $0-2$ \\
\hline
\end{tabular}

${ }^{1}$ Air content was designed for $2 \%$; therefore, no air entrainment was used.

\subsubsection{Repair Materials}

Four different repair materials (UHPC, ECC-Slag, SCC, and NC) were implemented in this research to compare and investigate the bond strength behaviour of each repair products under two different deterioration conditions.

\subsubsection{Ultra-High Performance Concrete (UHPC)}

This research project was the engage industrial project between Ryerson University and an industrial partner (CRH Canada Group Inc.). As a result, the mix design for the UHPC was provided by the $\mathrm{CRH}$ company, and it was asked to remain confidential. However, the complete literature review on the UHPC and its properties were done in Section 2.2.1. 


\subsubsection{Engineered Cementitious Composite (ECC-Slag)}

The ECC mix design was adopted based on the previous development at Ryerson University (Sherir, Hossain, \& Lachemi, 2015). This Specific mixture of ECC contains slag and concrete sand instead of low calcium fly ash and silica sand. This mixture of ECC which throughout this research was named ECC-Slag - showed an adequate amount of bendability and performance while it was able to reduce the cost significantly (Sherir et al., 2015). Therefore, future investigation in terms of the bond strength was required.

The ECC mixture includes the general use Portland cement (Table 3-2), slag from Holcim Canada Inc., Mississauga Plant, with a density of $2940 \mathrm{~kg} / \mathrm{m}^{3}$, Blaine fineness of 430 $\mathrm{m}^{2} / \mathrm{kg}$ and chemical composition listed in Table 3-6, concrete sand passing sieve \#16 (Sieve opening of $1.18 \mathrm{~mm}$ ), water, ADVA ${ }^{\odot}$ CAST 575 provided by Grace Concrete Products as a superplasticizer, and polyvinyl alcohol (PVA) fibers supplied by NYCON Corporation with the properties listed in Table 3-7. The mix design proportion of this specific type of ECC-Slag is provided in Table 3-8. The W/B ratio was chosen to be 0.30 .

Table 3-6: Chemical Composition of the Slag

\begin{tabular}{lcll}
\hline Chemical Composition & (\%) & Chemical Composition & (\%) \\
\hline \hline Calcium Oxide $(\mathrm{CaO})$ & 40.80 & Magnesium Oxide $(\mathrm{MgO})$ & 8.00 \\
Silicon Dioxide $\left(\mathrm{SiO}_{2}\right)$ & 35.40 & Sulfur Trioxide $\left(\mathrm{SO}_{3}\right)$ & 0.10 \\
Aluminium Oxide $\left(\mathrm{Al}_{2} \mathrm{O}_{3}\right)$ & 13.00 & Total Alkali $\left(\mathrm{Na}_{2} \mathrm{O}\right.$ eq.) & 0.20 \\
Ferric Oxide $\left(\mathrm{Fe}_{2} \mathrm{O}_{3}\right)$ & 0.50 & Loss on Ignition (LOI) & 1.00 \\
\hline
\end{tabular}

Table 3-7: PVA Fiber Properties

\begin{tabular}{ccccccccc}
\hline $\begin{array}{c}\text { Diameter } \\
(\boldsymbol{\mu m})\end{array}$ & $\begin{array}{c}\text { Length } \\
(\mathbf{m m})\end{array}$ & $\begin{array}{c}\text { Specific } \\
\text { Gravity }\end{array}$ & $\begin{array}{c}\text { Tensile } \\
\text { Strength } \\
(\mathrm{MPa})\end{array}$ & $\begin{array}{c}\text { Flexural } \\
\text { Strength } \\
(\mathrm{GPa})\end{array}$ & $\begin{array}{c}\text { Melting } \\
\text { Point } \\
\left({ }^{\circ} \mathrm{C}\right)\end{array}$ & $\begin{array}{c}\text { Water } \\
\text { Abs. }^{1}\end{array}$ & $\begin{array}{c}\text { Alkali }_{\text {Res. }^{2}} \\
\text { Cor. }^{3} \\
\text { Res. }\end{array}$ \\
\hline 100 & 13 & 1.3 & 1200 & 25 & 225 & $<1 \%$ & Exc. $^{4}$ & Exc. \\
\hline
\end{tabular}

${ }^{1}$ Absorption, ${ }^{2}$ Resistance, ${ }^{3}$ Corrosion, ${ }^{4}$ Excellent

Table 3-8: Mix Design Proportion of ECC-Slag $\left(\mathrm{kg} / \mathrm{m}^{3}\right)$

\begin{tabular}{cccccccc}
\hline $\begin{array}{c}\text { Mixture } \\
\text { ID }\end{array}$ & W/C & Cement & Slag & Water & $\begin{array}{c}\text { Fine } \\
\text { Aggregate }^{1}\end{array}$ & $\begin{array}{c}\text { PVA } \\
\text { Fibers }^{2}\end{array}$ & SP $^{3}$ \\
\hline ECC-Slag & 0.65 & 575 & 690 & 374 & 456 & 26 & 4.45 \\
\hline
\end{tabular}

${ }^{1}$ Fine aggregates are passed through sieve \#16, ${ }^{2} \mathrm{PVA}$ fibers ( $2 \%$ by volume), ${ }^{3}$ Superplasticizer 


\subsubsection{Self-Consolidating Concrete (SCC)}

One of the top and most respected commercial specialized repair material with selfconsolidating properties (SCC) available in the market was selected to have a comparison between other repair materials under research. According to the provider, this repair product has a density of $2300 \mathrm{~kg} / \mathrm{m}^{3}$ and NMSA of $10 \mathrm{~mm}$. Other important properties of SCC are provided in Table 3-9.

Table 3-9: Technical Data of SCC

\begin{tabular}{lr}
\hline Slump Flow - ASTM C1611 & $650 \pm 50 \mathrm{~mm}$ \\
J-Ring Passing Ability - ASTM C1621 & $0-25 \mathrm{~mm}$ \\
Compressive Strength at 28 Days - ASTM C39 & $40 \mathrm{MPa}$ \\
Flexural Strength at 28 Days - ASTM C78 & $10.5 \mathrm{MPa}$ \\
Modulus of Elasticity at 28 Days - ASTM C469 & $26.4 \mathrm{GPa}$ \\
Bond Strength by Slant Shear - ASTM C882 & $20 \mathrm{MPa}$ \\
Uniaxial Drying Shrinkage at 30 Days - ASTM C157 & $400 \mu \mathrm{m} / \mathrm{m}$ \\
Air Content - ASTM C457 & $4.0-9.0 \%$ \\
Freeze-Thaw Resistance - ASTM C666 & $99 \%$ \\
Salt Scaling Resistance after 50 Cycles - ASTM C672 & $<0.03 \mathrm{~kg} / \mathrm{m}^{2}$ \\
Rapid Chloride Permeability - ASTM C1202 & 750 Coulombs \\
\hline
\end{tabular}




\subsubsection{Normal Conventional Concrete (NC)}

The similar mix design used for Sub-A (Section 3.1.1.1) was implemented for this repair. The only change was through the NMSA which was reduced from $20 \mathrm{~mm}$ to $16 \mathrm{~mm}$. CSA 23.1 (2014) defines the acceptable NMSA with certain limitations. As it was stated by the CSA 23.1, the NMSA should be less than one-third of a repair thickness. The thickness of repair was selected to be $50 \mathrm{~mm}$. Therefore, $20 \mathrm{~mm}$ was higher than the limitation (onethird of 50 equals to 16.67). To avoid this problem, the aggregates passing sieve opening of $16 \mathrm{~mm}$ were selected.

Some of coarse aggregate properties including absorption and specific gravity did not change and they can be found in Table 3-1. However, the dry rodded density (DRD) was changed as it was expected since coarse aggregate nominal maximum size and gradation were altered. Therefore, the new DRD test was performed, and it was calculated to be $1581.82 \mathrm{~kg} / \mathrm{m}^{3}$.

Moreover, the moisture content was recorded to be $0.08 \%$ due to the fact that the NC repair was casted approximately 2 months after Sub-A which the environmental condition of the storage room was entirely different. The fine aggregate and cement properties stayed the same as reported in Table 3-1 and Table 3-2. Due to the change in the DRD, the mix design proportion of coarse and fine aggregate was modified. The new mix design proportion for NC as a repair product is reported in Table 3-10.

Table 3-10: Mix Design Proportions of $\mathrm{NC}\left(\mathrm{kg} / \mathrm{m}^{3}\right)$

\begin{tabular}{lcccccc}
\hline Mixture ID & W/C & Cement & Water & $\begin{array}{c}\text { Coarse } \\
\text { Aggregate }\end{array}$ & $\begin{array}{c}\text { Fine } \\
\text { Aggregate }\end{array}$ & Air $^{1}(\%)$ \\
\hline \hline NC & 0.42 & 440 & 184 & 949 & 652 & $5-8$ \\
\hline
\end{tabular}

${ }^{1}$ Air content was designed for $7 \%$; however, the range of 5 to $8 \%$ was accepted. 


\subsection{Materials Properties and Compatibility of Repairs with Substrate (Phase-I)}

\subsubsection{Compressive Strength}

In this research, three standard concrete cylinders $(100 \times 200 \mathrm{~mm})$ for 5 materials under moist curing $(\mathrm{RH}>98 \%)$ and temperature of $23 \pm 2{ }^{\circ} \mathrm{C}$ were tested by hydraulic compressive machine with the stress rate of $0.25 \pm 0.05 \mathrm{MPa} / \mathrm{s}$ at different age $(1,7,14$, 28,56 , and 90 days) as specified by ASTM C39 (2017). It is important to note that smaller cylinders $(75 \times 150 \mathrm{~mm})$ were implemented for the UHPC specimens to protect the compressive machine. Thus, the total number of tested samples is equal to 108 . The compressive strength can be calculated by Eq. 3-1, where $\sigma$ is the compressive strength in $\mathrm{MPa}, \mathrm{F}$ is the maximum force at failure in $\mathrm{N}$, and $\mathrm{A}$ is the contact surface area in $\mathrm{mm}$.

$$
\sigma_{\text {Compressive Strength }}=\frac{F}{A}
$$

Eq. 3-1: Compressive Strength
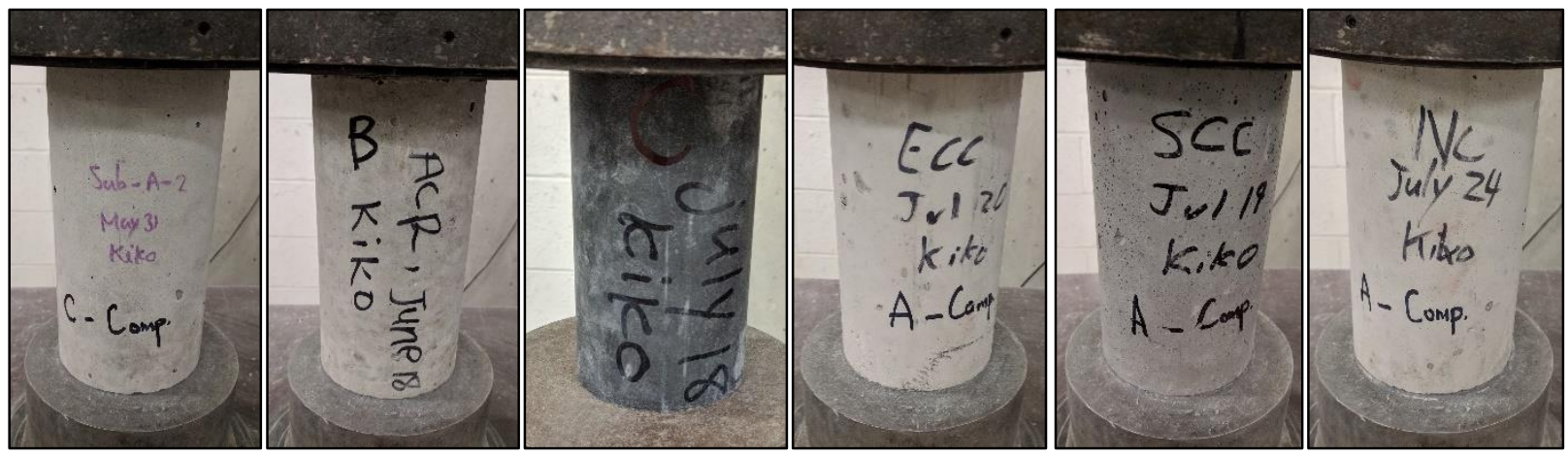

Figure 3-1: Compressive Strength Test before Crushing at 28 Days
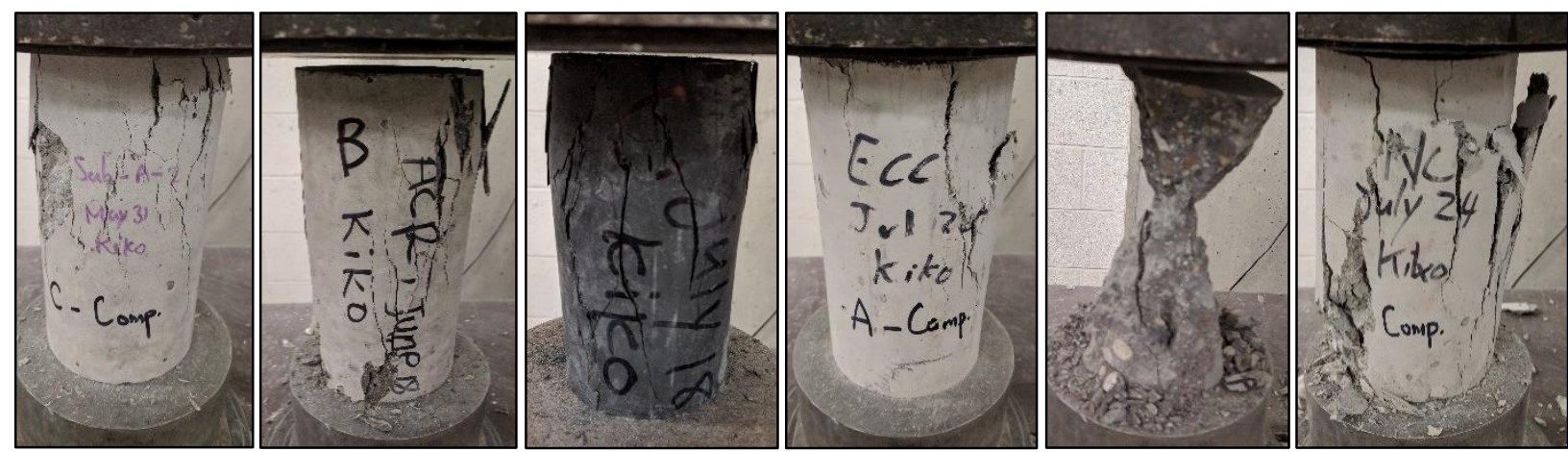

Figure 3-2: Compressive Strength Test after Crushing at 28 Days 


\subsubsection{Static Modulus of Elasticity}

As it was discussed in Section 2.3.2, to standardize the modulus of elasticity's calculation, the static modules were selected according to ASTM C469 (2014). As specified by the standard, the static modulus of elasticity in MPa was calculated by Eq. 3-2, where $S_{2}$ and $S_{1}$ are the stress at $40 \%$ of maximum load, and stress equivalent to longitudinal strain of 50 millionths $(0.000050)$ in $\mathrm{MPa}$, respectively. Also, $\varepsilon_{2}$ is the longitudinal strain produced by $40 \%$ of ultimate load.

$$
E=\frac{S_{2}-S_{1}}{\varepsilon_{2}-0.000050}
$$

Eq. 3-2: Modulus of Elasticity

To calculate the static modulus of elasticity, two longitudinal strain gauges were placed at sides of the specimen $\left(180^{\circ}\right.$ angle cross-section view), and one transverse strain gauge was glued at the center of the concrete cylinder in between two other longitudinal strain gauges (Figure 3-3). The Stress rate was kept same as the compressive strength test $(0.25 \pm 0.05 \mathrm{MPa} / \mathrm{s})$ and per ASTM C469 (2014). Three samples for each repair materials and substrates at 28 days of moist curing $(\mathrm{RH}>98 \%)$ were tested which equals to 18 ( $3 \mathrm{x}$ 6) samples in total.
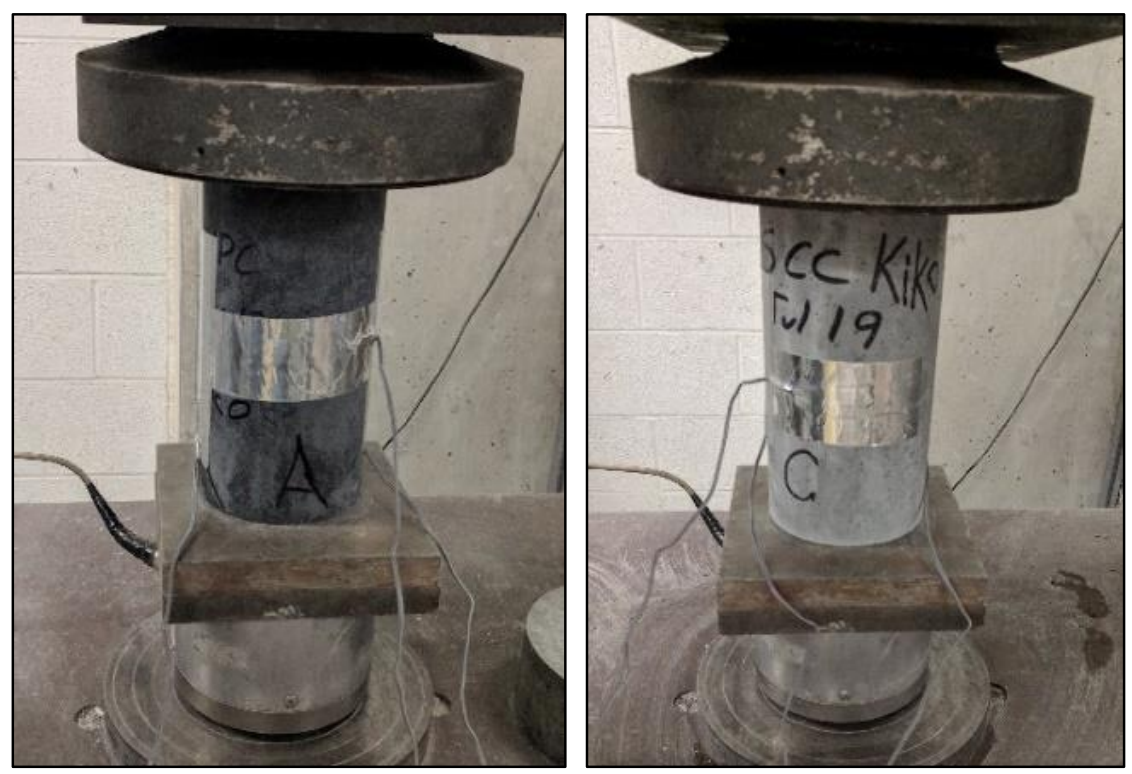

Figure 3-3: Static Modulus of Elasticity Measurements 


\subsubsection{Shrinkage}

\subsubsection{Drying Shrinkage}

In this research, the drying shrinkage of repairs was calculated based on the MTO LS435-R28 (2013). As it was specified by LS-435, three standard concrete prisms (75 x 75 x $285 \mathrm{~mm}$ ) were casted for each repair materials (Figure 3-4). The inner length of studs inside the prisms was fixed at $250 \mathrm{~mm}$. This length was used as a gauge length for shrinkage calculation according to Eq. 3-3.

$$
\Delta L_{x}=\frac{R_{x}-R_{0}}{G} \times 100
$$

Eq. 3-3: Drying Shrinkage Measurement

Where $\Delta L_{x}$ is the length change movement of the sample in $\%$ at the age of $x, R_{x}$ is the difference between the specimen reading and zeroing (reference) bar at the age of $x, R_{0}$ is the difference between the specimen reading and zeroing bar for an initial reading.

The concrete prisms demoulded after $24 \pm 2$ hours, completely submerged in the saturated lime-water at the environmental temperature of $23 \pm 2{ }^{\circ} \mathrm{C}$ for 7 days, and then moved into the shrinkage room with $\mathrm{RH}$ of $50 \% \pm 4 \%$ for 35 days (according to standard) and longer. Length measurements of specimens were monitored based on initial reading right after finishing saturation period (zero reading) and continued weekly for 5 weeks (35 days).
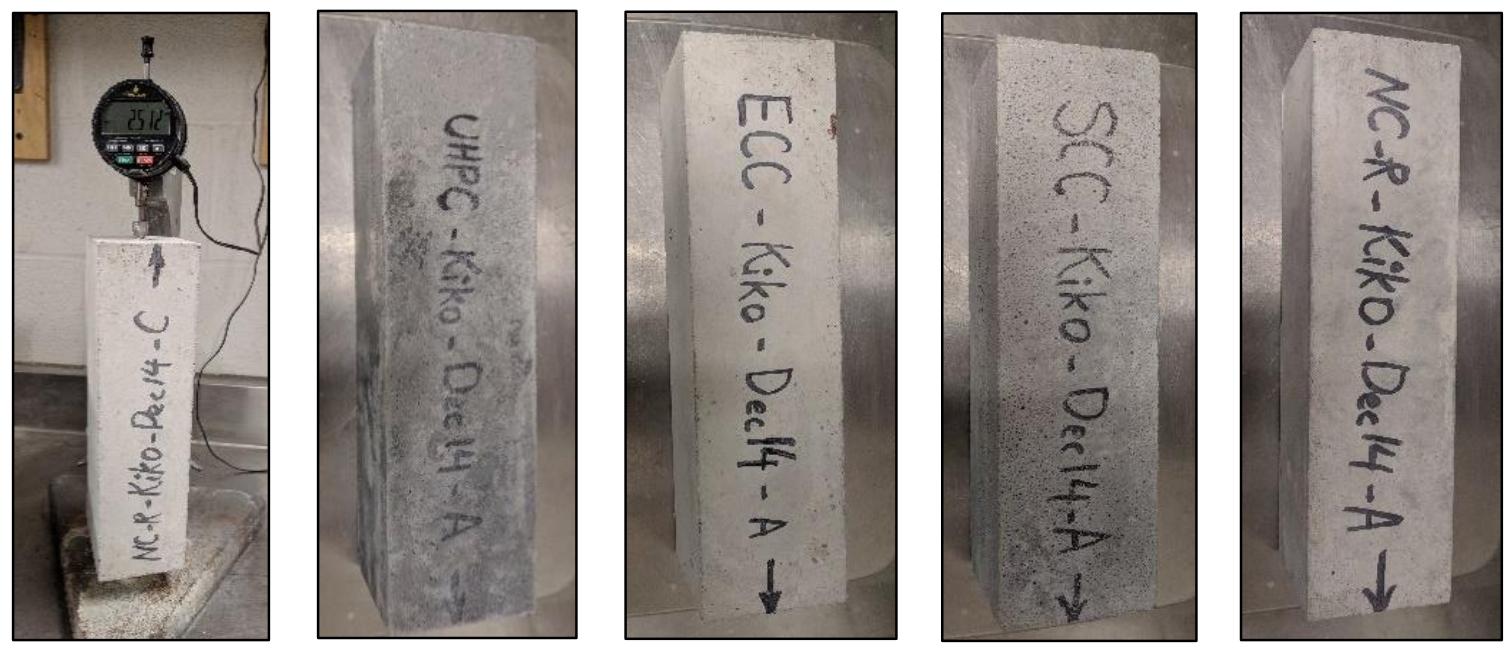

Figure 3-4: Standard Concrete Prisms Used for Drying Shrinkage 
The $\mathrm{RH}$ and temperature of the shrinkage room were controlled throughout the research by the HOBO-U23-Temp/RH sensors (Figure 3-5) and the daily water evaporation mass loss from $400 \mathrm{ml}$ Griffin low-form beaker (Table 3-11). The acceptable range of mass loss is $13 \pm 5 \mathrm{ml}$ per 24 hours according to ASTM C157 (2016).

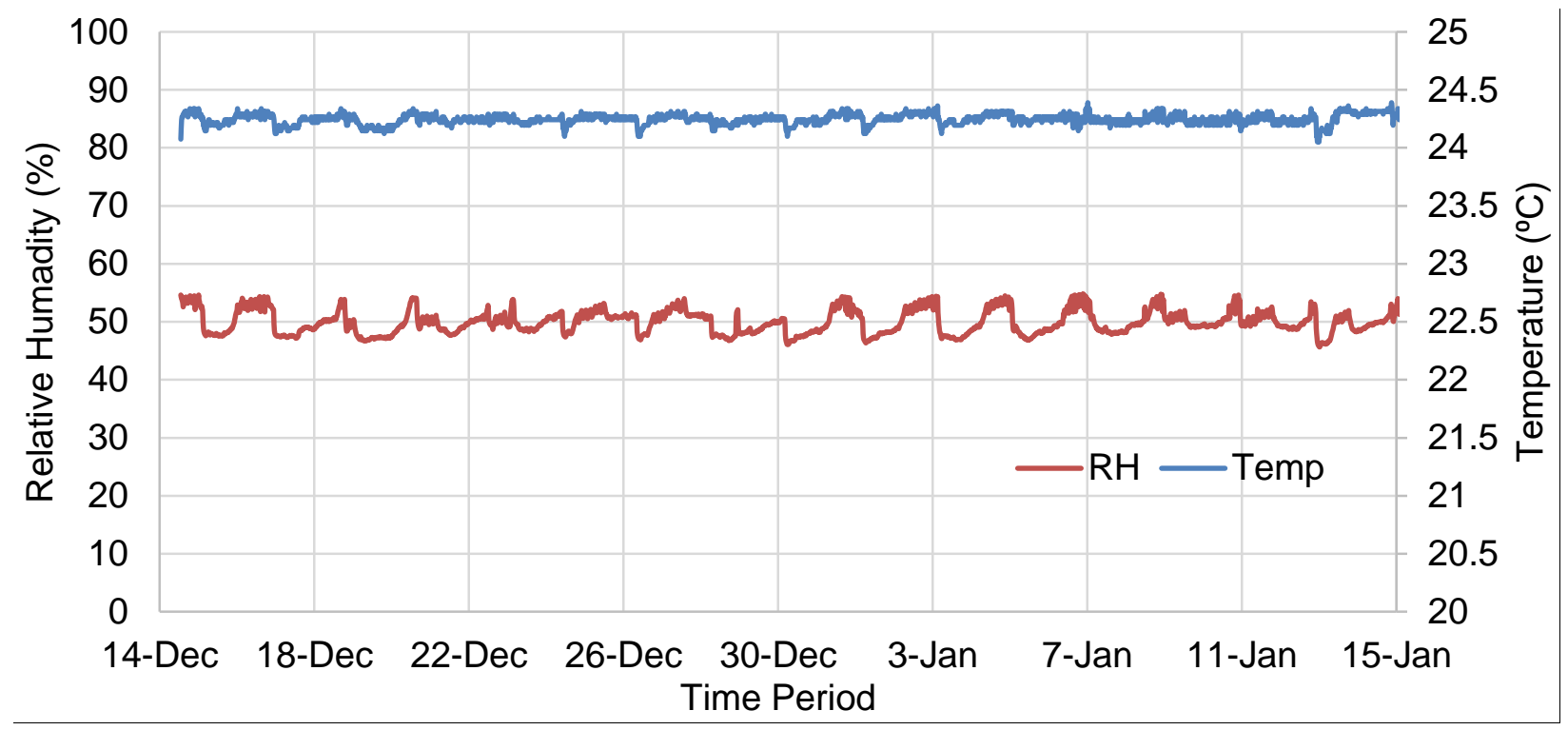

Figure 3-5: Exact Shrinkage Room Temp/RH by HOBO Sensor

\subsubsection{Autogenous Shrinkage}

As it was discussed in Section 2.3.3.2, measuring the autogenous shrinkage is very crucial especially for UHPC, ECC-Slag, and SCC. However, the ASTM C1698 (2014) which measures the autogenous shrinkage is quite challenging to perform and requires a unique instrument. In addition, it only considers the cement paste, and it is not very reliable for the entire material. Therefore, to have a better understanding of the combined autogenous and drying shrinkage, the MTO LS-435-R28 (2013) was revised, and zero reading was taken immediately after demoulding of samples, other procedures were followed as it was specified in the standard and explained in the previous section.

Some can argue that this is not a valid indication of the autogenous shrinkage because the samples are submerged in lime-saturated water. However, the results demonstrate that for UHPC and ECC could be a reliable indicator because these materials are almost impermeable. On the other hand, it was not an excellent suggestion for SCC and NC. 
Table 3-11: Daily Mass Loss of Water Evaporation Measurements

\begin{tabular}{|c|c|c|c|c|c|c|c|}
\hline \multirow{2}{*}{ \# } & \multirow{2}{*}{ Date $^{1}$} & \multicolumn{4}{|c|}{ Griffin low-form beaker } & \multirow{2}{*}{$\begin{array}{l}R^{2}{ }^{2} \\
(\%)\end{array}$} & \multirow{2}{*}{$\begin{array}{c}\text { Temp. }{ }^{3} \\
\left({ }^{\circ} \mathrm{C}\right)\end{array}$} \\
\hline & & 1 & 2 & 3 & 4 & & \\
\hline 1 & Thursday, December 14, 2017 & 16.5 & 14.6 & 14.6 & 10.8 & 50 & 23.8 \\
\hline 2 & Friday, December 15, 2017 & $18.2^{*}$ & 15.7 & $18.8^{*}$ & 10.6 & 48 & 24.1 \\
\hline 3 & Saturday, December 16, 2017 & 14.9 & 13.3 & 15.7 & 9.5 & 50 & 24.2 \\
\hline 4 & Sunday, December 17, 2017 & $18.1^{*}$ & 14.8 & 17.9 & 9.9 & 49 & 24.2 \\
\hline 5 & Monday, December 18, 2017 & 16.1 & 13.0 & 15.7 & 9.3 & 50 & 24.2 \\
\hline 6 & Tuesday, December 19, 2017 & 14.2 & 11.9 & 14.6 & 8.6 & 52 & 24.3 \\
\hline 7 & Wednesday, December 20, 2017 & 15.8 & 12.8 & 15.0 & 9.3 & 51 & 24.4 \\
\hline 8 & Thursday, December 21, 2017 & 16.2 & 12.9 & 15.4 & 9.8 & 50 & 24.1 \\
\hline 9 & Friday, December 22, 2017 & 14.4 & 11.5 & 13.4 & 8.8 & 51 & 24.2 \\
\hline 10 & Saturday, December 23, 2017 & 14.7 & 11.6 & 14.3 & 9.1 & 50 & 23.8 \\
\hline 11 & Sunday, December 24, 2017 & 15.3 & 12.0 & 15.0 & 8.9 & 51 & 24.0 \\
\hline 12 & Monday, December 25, 2017 & 12.9 & 10.6 & 12.7 & 8.0 & 50 & 24.1 \\
\hline 13 & Tuesday, December 26, 2017 & 14.2 & 11.4 & 13.7 & 8.8 & 51 & 24.2 \\
\hline 14 & Wednesday, December 27, 2017 & 12.0 & 10.4 & 12.0 & $7.6^{*}$ & 51 & 23.9 \\
\hline 15 & Thursday, December 28, 2017 & 16.7 & 13.7 & 16.3 & 10.0 & 51 & 24.1 \\
\hline 16 & Friday, December 29, 2017 & 15.4 & 12.3 & 14.7 & 8.9 & 51 & 24.1 \\
\hline 17 & Saturday, December 30, 2017 & 15.6 & 13.2 & 16.6 & 10.5 & 51 & 24.1 \\
\hline 18 & Sunday, December 31, 2017 & 16.0 & 13.3 & 15.0 & 10.8 & 51 & 24.1 \\
\hline 19 & Monday, January 1, 2018 & 15.6 & 12.7 & 14.4 & 9.6 & 51 & 24.1 \\
\hline 20 & Tuesday, January 2, 2018 & 13.9 & 10.6 & 13.8 & 8.6 & 51 & 24.1 \\
\hline 21 & Wednesday, January 3, 2018 & 12.5 & 9.7 & 11.2 & 8.0 & 50 & 23.2 \\
\hline 22 & Thursday, January 4, 2018 & 12.4 & 10.8 & 12.0 & 9.0 & 51 & 23.9 \\
\hline 23 & Friday, January 5, 2018 & 14.1 & 11.2 & 13.4 & 8.5 & 50 & 24.0 \\
\hline 24 & Saturday, January 6, 2018 & 13.5 & 10.4 & 12.5 & 8.7 & 51 & 24.1 \\
\hline 25 & Sunday, January 7, 2018 & 11.7 & 8.5 & 9.1 & 8.2 & 50 & 24.0 \\
\hline 26 & Monday, January 8, 2018 & 9.5 & 8.2 & 8.6 & $6.8^{*}$ & 49 & 23.2 \\
\hline 27 & Tuesday, January 9, 2018 & 10.7 & 8.5 & 9.1 & 8.0 & 50 & 23.2 \\
\hline 28 & Wednesday, January 10, 2018 & 14.0 & 12.1 & 14.3 & 9.3 & 50 & 23.2 \\
\hline 29 & Thursday, January 11, 2018 & 13.0 & 11.1 & 13.3 & 8.7 & 50 & 24.2 \\
\hline 30 & Friday, January 12, 2018 & 13.7 & 11.3 & 13.6 & 8.9 & 50 & 24.9 \\
\hline 31 & Saturday January 13, 2018 & 13.2 & 11.2 & 13.1 & 9.1 & 50 & 25.0 \\
\hline 32 & Sunday, January 14, 2018 & 13.4 & 11.4 & 13.6 & 9.8 & 50 & 24.4 \\
\hline 33 & Monday, January 15, 2018 & 12.8 & 10.8 & 13.0 & 12.0 & 50 & 23.8 \\
\hline 34 & Tuesday, January 16, 2018 & 12.6 & 10.7 & 12.7 & 12.6 & 50 & 23.5 \\
\hline 35 & Wednesday, January 17, 2018 & 12.6 & 10.5 & 12.2 & 11.8 & 50 & 23.4 \\
\hline
\end{tabular}

${ }^{1}$ All the measurements were done between 2:30 to 4:00 pm and beakers filled according to standard on Dec 27, 2017 and Jan 9, 2018 (Blue highlighted rows). ${ }^{2} \mathrm{RH}$ was read from the humidifier. ${ }^{3}$ Temp was read from the air conditioning system in the shrinkage room. ${ }^{*}$ Red highlighted cells indicate that the evaporation was out of the standard range. 


\subsubsection{Summary of Phase-I}

The entire procedure that was taken for Phase-I is summarized in Table 3-12. All of the testing implemented in Phase-I are not in sequence and can be performed at the same time. Thus, the total duration of Phase-I was selected as the longer task in Table 3-12.

Table 3-12: Phase-I Work Sequences

\begin{tabular}{|c|c|c|}
\hline Steps & Descriptions Summary of Phase-I & Period \\
\hline \multirow{4}{*}{$\begin{array}{l}1 . \\
1 . \\
1 .\end{array}$} & Compressive Strength Test & 97 days \\
\hline & Casting Materials (Two Substrates and Four Repairs) ${ }^{1}$ & 6 days $^{1}$ \\
\hline & Curing Materials up to 90 days & 90 days \\
\hline & Testing Materials at $1,7,28,56$, and 90 days & 1 day \\
\hline 2. & Modulus of Elasticity & 43 days \\
\hline 2.1. & Ordering Strain Gauges & 7 days \\
\hline 2.2. & Casting Materials (Two Substrates and Four Repairs) ${ }^{1}$ & 6 days $^{1}$ \\
\hline 2.3. & Curing Materials & 28 days \\
\hline 2.4. & Preparing the Testing Samples & 1 day \\
\hline 2.5. & Testing Materials at 28 days & 1 day \\
\hline 3. & Shrinkage (Trial-1) & 103 days \\
\hline 3.1. & Preparing Studs & 7 days \\
\hline 3.2. & Casting Materials (Four Repairs) ${ }^{1}$ & 4 days $^{1}$ \\
\hline 3.3. & Curing Materials in Saturated Lime-water & 7 days \\
\hline 3.4. & Shrinking Materials up to 84 days & 84 days \\
\hline 3.5. & Measuring Shrinkage Weekly & $n / a^{2}$ \\
\hline 4. & Shrinkage (Trial-2) & 110 days \\
\hline 4.1. & Preparing Studs & 7 days \\
\hline 4.2. & Casting Materials (Sub-A and Four Repairs) ${ }^{1}$ & 5 days $^{1}$ \\
\hline 4.3. & Curing Materials in Moist Curing Room & 14 days \\
\hline 4.4. & Shrinking Materials up to 84 days & 84 days \\
\hline 4.5 . & Measuring Shrinkage Weekly & $n / a^{2}$ \\
\hline 5. & Sub-B (ACR) Expansion Measurements & 241 days \\
\hline 5.1. & Casting Sub-B Concrete Prisms ${ }^{1}$ & 1 day $^{1}$ \\
\hline 5.2. & Curing for $1+2$ Months & 90 days \\
\hline 5.3. & Storing in Typical Room Condition for 5 months & 150 days \\
\hline \multirow[t]{2}{*}{5.4.} & Measuring Sub-B Prisms periodically & $n / a^{2}$ \\
\hline & Total Duration of the Phase-I & 241 days \\
\hline
\end{tabular}

${ }^{1}$ The time allocation for casting is one day for each material, ${ }^{2}$ Measuring length change is not that long. 


\subsection{Repairs under Freeze-Thaw Cycles with De-icing Salt (Phase-II)}

To assess the bond strength under freezing and thawing with de-icing salt, three bond strength evaluating methods was investigated including slant shear, splitting tensile and pull-off test. As it was explained in Section 3.1.1.1, for this phase Sub-A with NC mix design was selected. In this section, first the substrate preparation, second the experimental program and finally the test will be discussed in detail.

\subsubsection{Sub-A Preparation}

\subsubsection{Casting, Surface Roughness, and Curing}

To evaluate the effect of surface roughness on the bond strength for slant shear and splitting tensile tests, two different surface textures - rough and smooth - were tested. To minimize the damage may cause by surface texture preparation such as grinding, hammering, milling, sand-water blasting, wire-brushing, etc., specimens were textured while they were fresh. In order to achieve this goal, special cylindrical moulds were prepared as illustrated in Figure 3-6 for both slant shear and splitting tensile tests. Two different technics of surface preparation for fresh cylindrical specimens were implemented: (1) the surface of specimens were trowelled by a wooden float and broomed to slightly texture the substrate according to MTO LS-412-R17 (1997). Figure 3-7 shows the smooth surface texture of the substrate. (2) For the rough texture, the specimens were not trowelled; So, some portion of cement coated coarse aggregates were left on the surface to provide extra roughness (Figure 3-8).
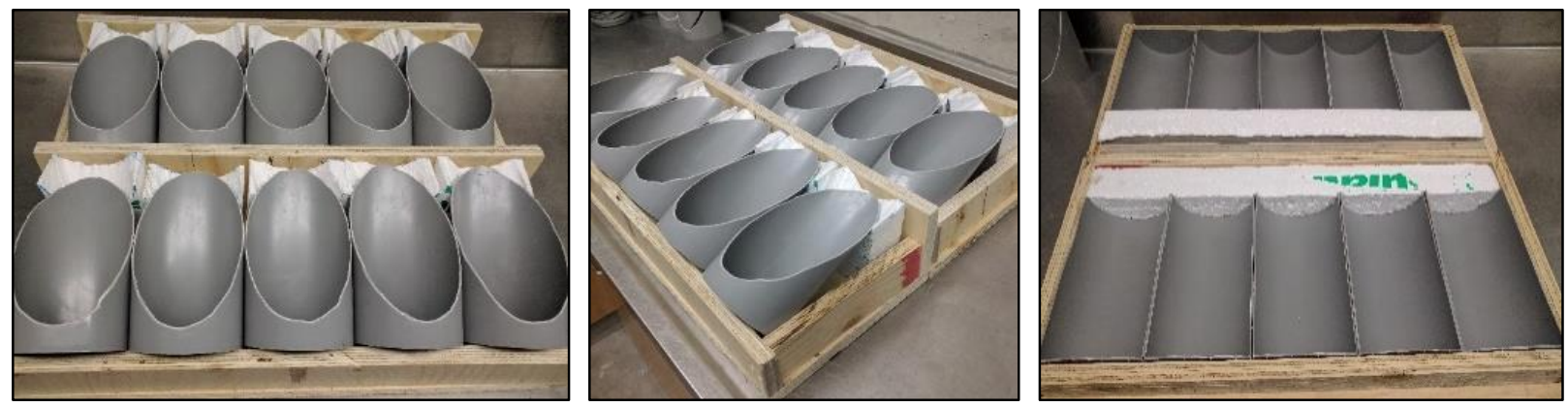

Figure 3-6: Substrate Preparation for Slant Shear and Splitting Tensile Tests 

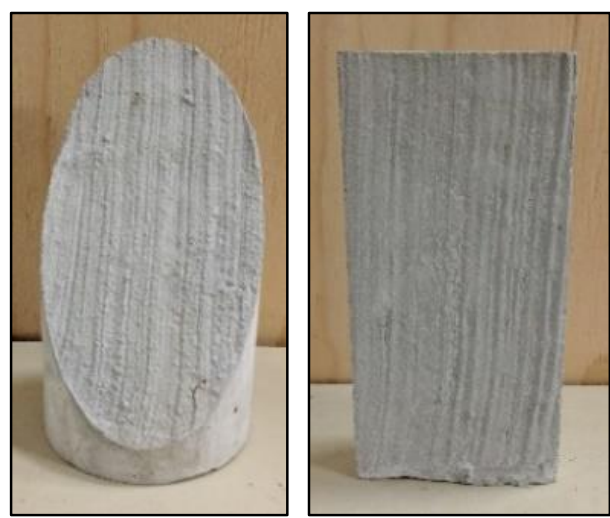

Figure 3-7: Typical Smooth Surface Texture
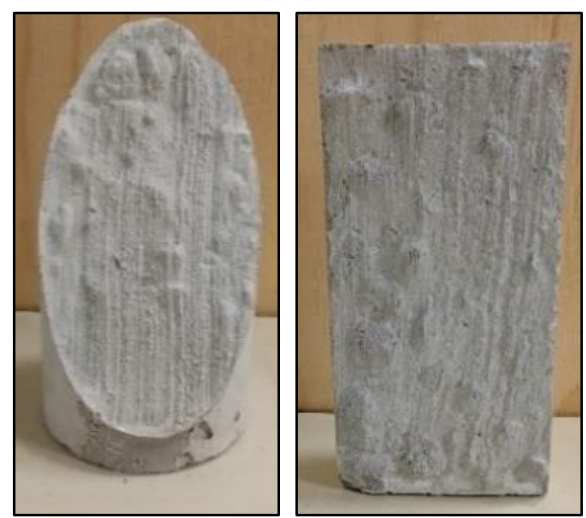

Figure 3-8: Typical Rough Surface Texture

The moulds for slant shear and splitting tensile test were fabricated such a way to be in accordance of the ASTM C882 (2013) and ASTM C496 (2011), respectively.

For the direct pull-off test, small slab specimens with length, width, and height of 300 , 300 , and $75 \mathrm{~mm}$, respectively, as it is specified by MTO LS-412-R17 (1997). The exact same procedure as it was explained through the MTO LS-412-R17 (1997) was implemented while casting the Sub-A. The slab specimens with these specific dimensions were selected to be able to comfortably carry the samples through the freezing and thawing cycles. For the small slab substrate specimens, the only smooth surface texture was used considering the insignificant impact of roughness under direct tensile force. Figure 3-9 demonstrates the mould used to cast the small slab specimens with Sub-A.
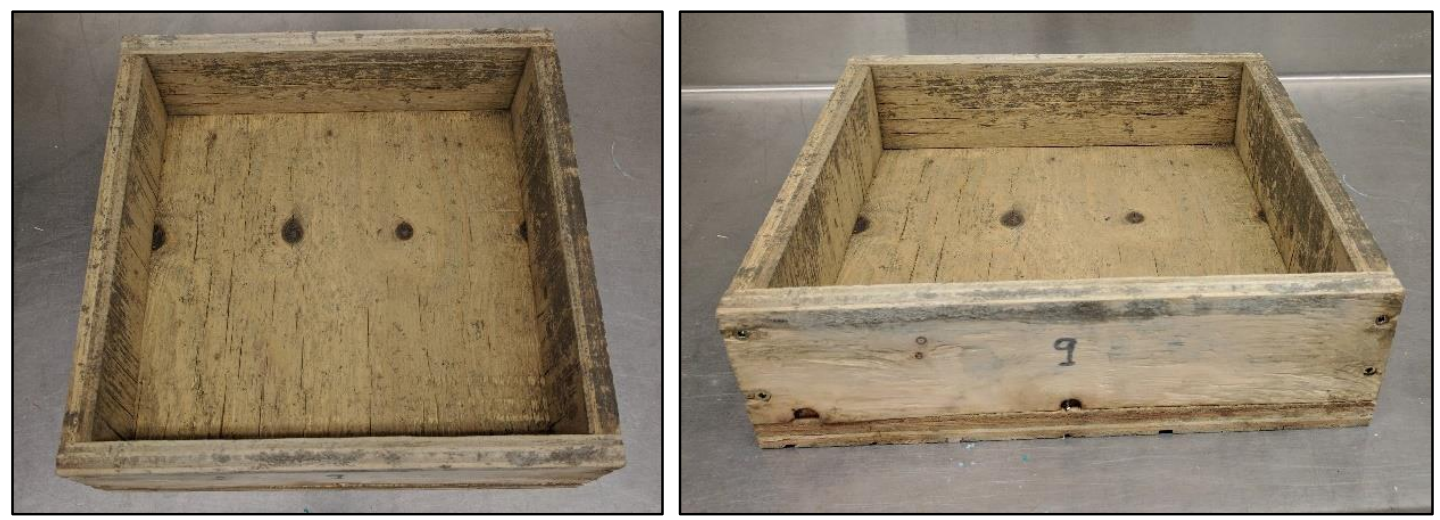

Figure 3-9: Small Slab Moulds

It is important to note that all the Sub-A samples (Figure 3-10) were kept in moist curing room with $\mathrm{RH}>98 \%$ for 14 days to gain their specified strength. The $\mathrm{RH}$ and temperature 
of the curing room were controlled throughout the research by the HOBO-U23-Temp/RH sensors and the typical $\mathrm{RH}$ and temperature graph is provided by Figure 3-11.

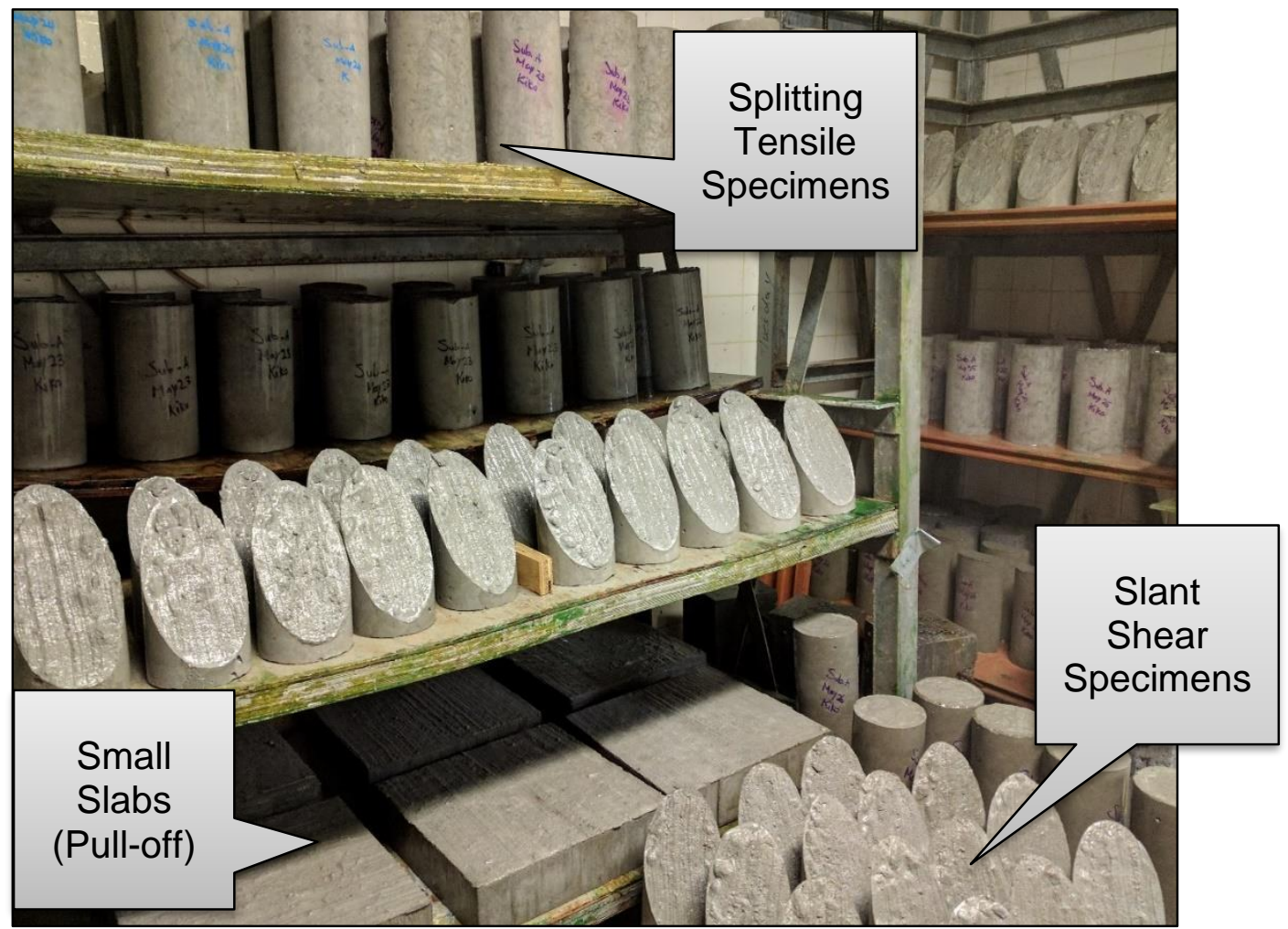

Figure 3-10: Sub-A Specimens in the Curing Room

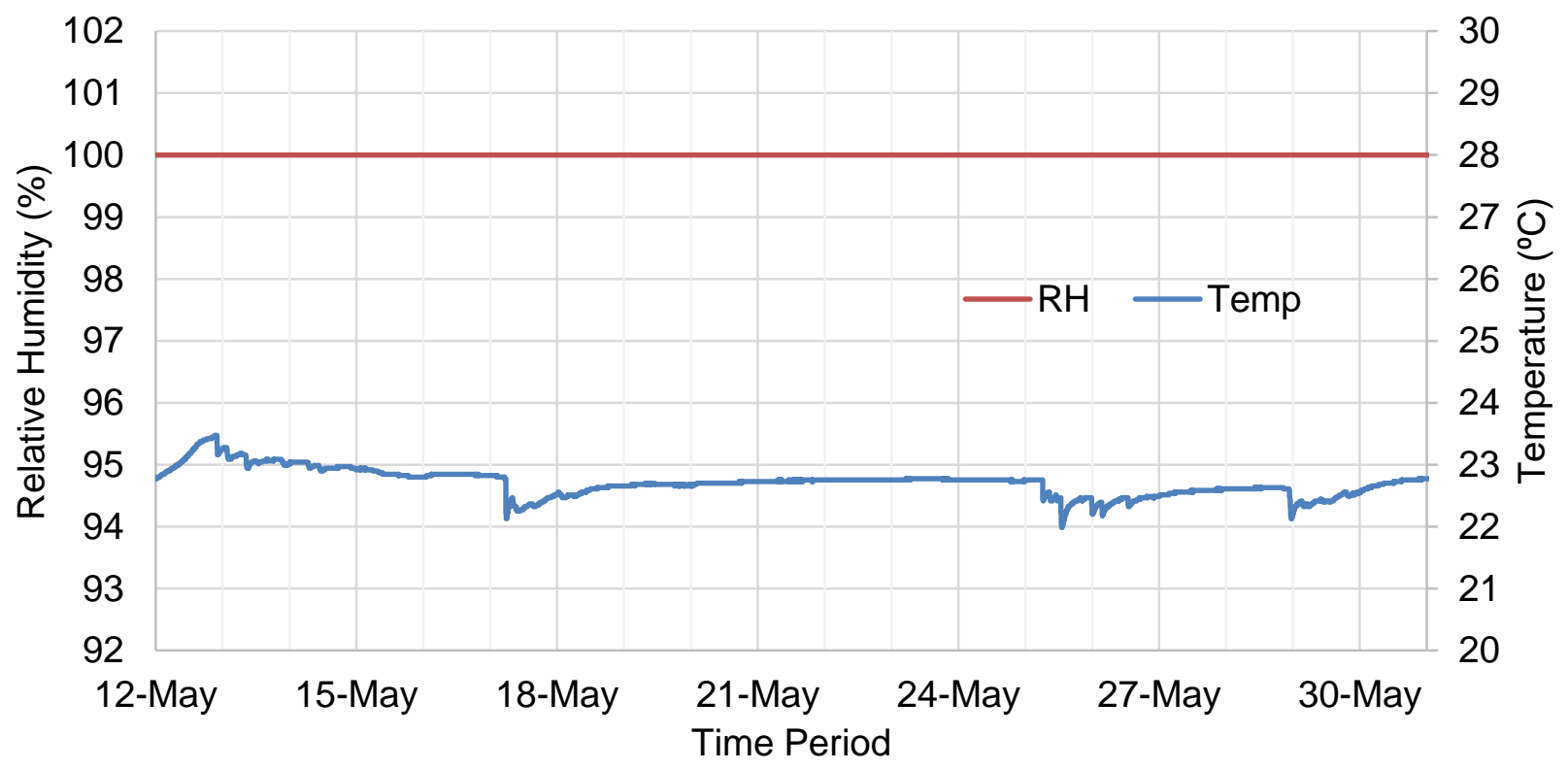

Figure 3-11: Typical Curing Room Temp/RH by HOBO Sensor 


\subsubsection{Stabilizing the Substrate (Sub-A) Shrinkage}

Allowing the Sub-A to shrink in a laboratory is essential since deteriorated concrete (substrate) under service condition is usually experienced most of its shrinkage while it is exposed to the freezing and thawing cycles with or without de-icing salt. Therefore, to stabilize and better simulate the life condition, the Sub-A was casted with NC (Section 3.1.1.1), stored in the moist curing room $(\mathrm{RH}>98 \%)$ for 14 days to gain its specified strength (Figure 3-10). After that, it was relocated to the shrinkage room with $\mathrm{RH}$ of $50 \pm 4 \%$ and temperature of $23 \pm 2^{\circ} \mathrm{C}$ for 70 days prior to applying repair materials (Figure 3-12). The condition of shrinkage room and rate of evaporation was checked through the standard beaker measurement as specified by CSA A23.2-21C (2014), In addition, HOBO U23 Temp/RH data logger was used and the typical measurements of $\mathrm{RH}$ and temperature in the month of July is demonstrated by Figure 3-13.
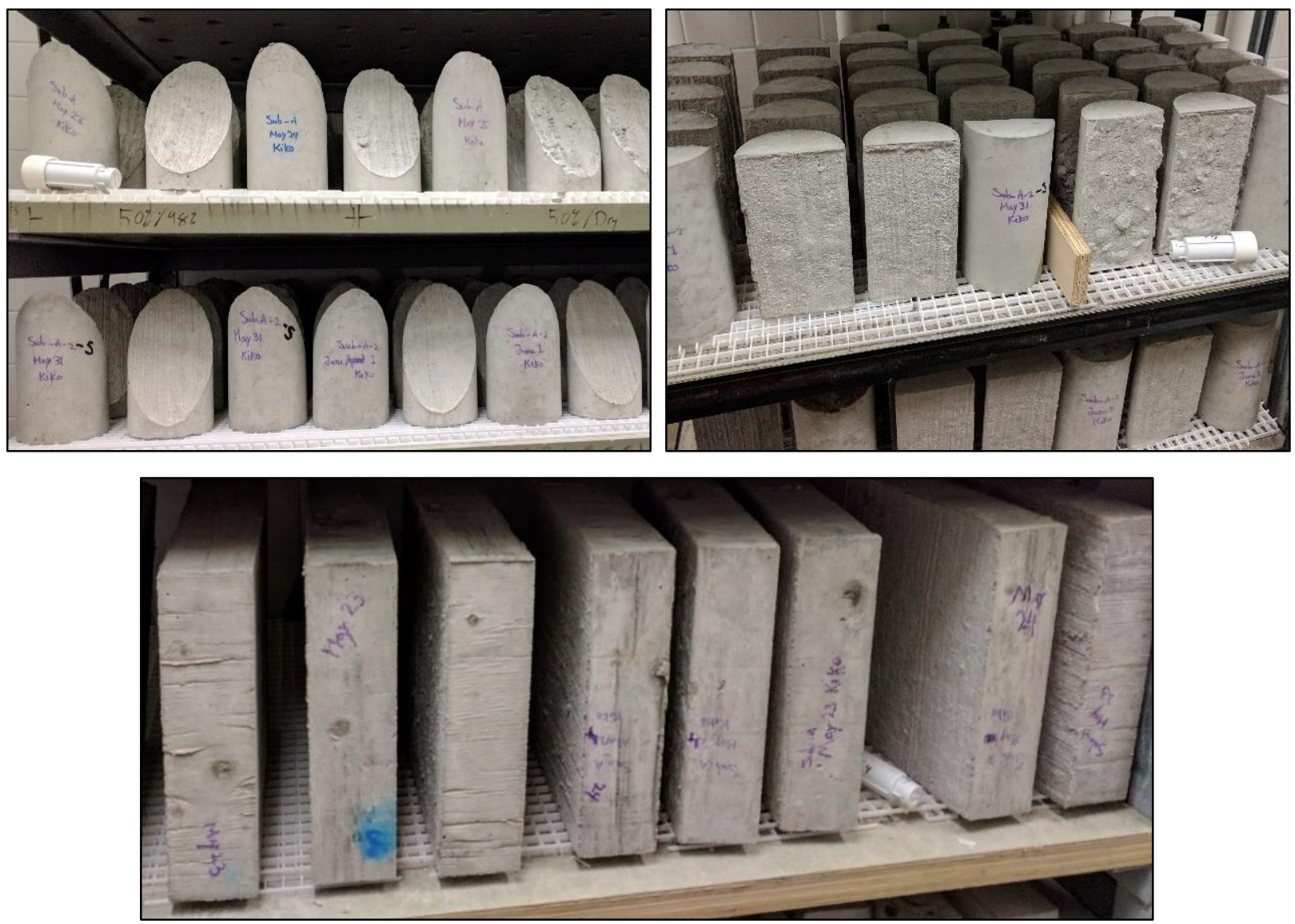

Figure 3-12: Sub-A Specimens in Shrinkage Room 


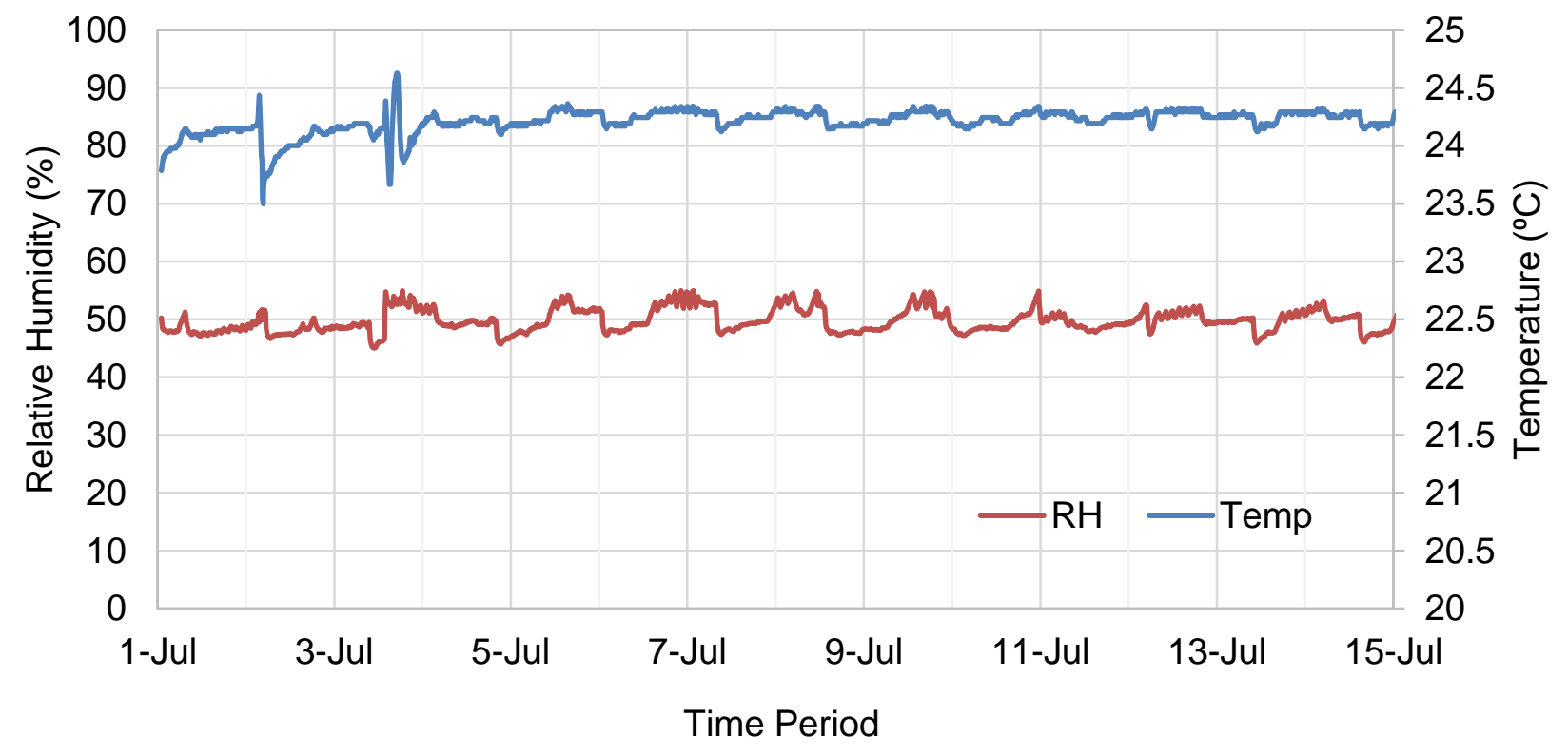

Figure 3-13: Typical Shrinkage Room Temp/RH by HOBO Sensor

\subsubsection{Moisture Condition at the Time of Applying Repairs}

During the casting of repair products, it was decided to keep the Sub-A in SSD condition according to the literature review. To achieve this condition, one day prior to casting of the repair products, the substrate was moved out of shrinkage room, sprayed with water and transferred to the curing room (Figure 3-14). Finally, one hour before casting to make sure the Sub-A surface is in a dry condition, it was moved outside of curing room.
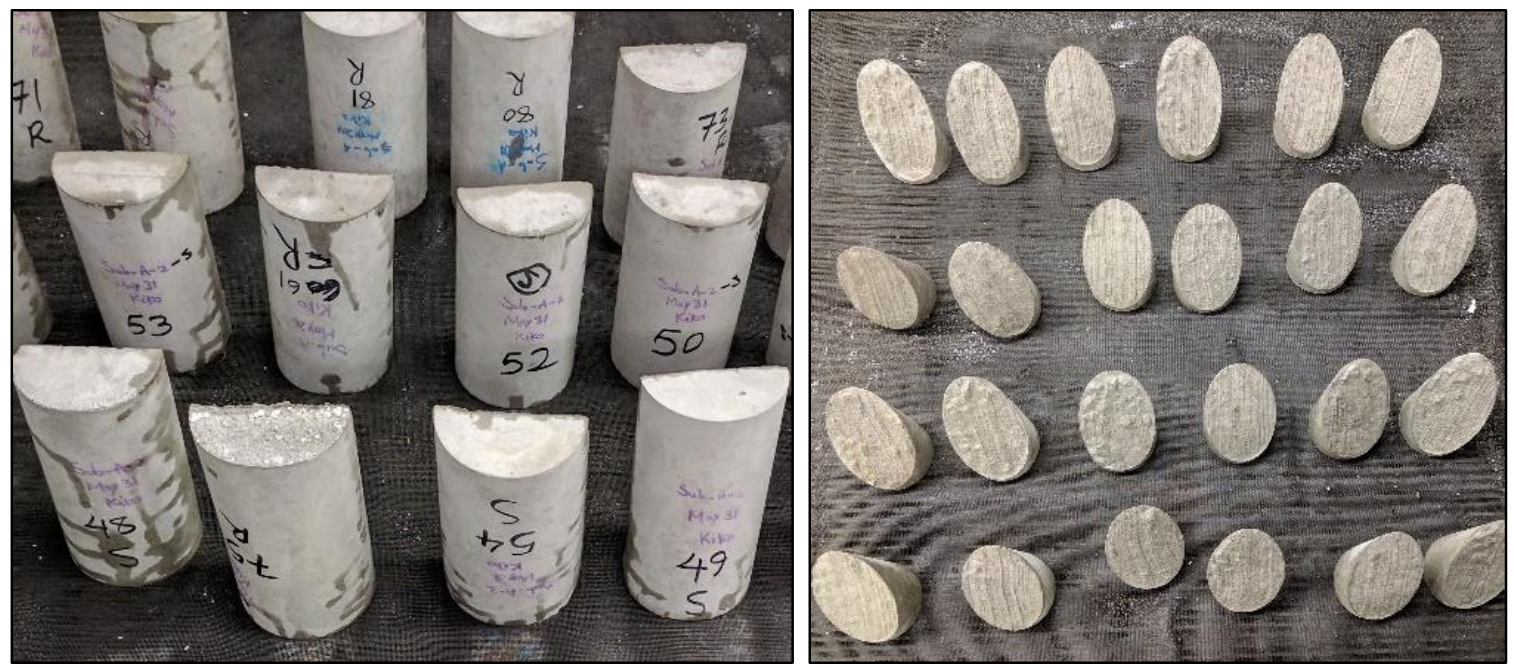

Figure 3-14: Preparation of Sub-A Samples Moisture Content 


\subsubsection{Applying Repairs and Conditioning (Sub-A and Repair Products)}

After finishing the Sub-A preparation, repair products were casted on top of the Sub-A. Afterward, samples (including Sub-A and repair products) were kept in the moist curing room $(\mathrm{RH}>98 \%)$ for 14 days to make sure that the repair products have enough time to gain their minimum required strength. Furthermore, the specimens (repairs and substrates) were cured for 14 days to be consistent with Sub-A curing (Section 3.3.1.1). Immediately following, specimens stored in the shrinkage room for two months (60 days) allowing the repair materials to shrink and stabilize. All the testing samples brought outside of the shrinkage room and kept in the normal temperature room $\left(23 \pm 2{ }^{\circ} \mathrm{C}\right)$ for four days. Meanwhile, the initial bond strength was evaluated on the specimens and named as a zero cycle of freezing and thawing. Then, samples submerged in $3 \%$ sodium chloride $(\mathrm{NaCl})$ solution water for another 3 days (total of one week) to provide the specimens with real exposure of the field before starting the freezing and thawing cycles.

Next, it was followed by freezing and thawing cycles in the presence of $3 \%$ sodium chloride $(\mathrm{NaCl})$ solution. The cylindrical samples were completely submerged in the salt solution (Figure 3-15) while slab specimens were covered by $6 \mathrm{~mm}$ salt solution (Figure 3-16) according to MTO LS-412-R17 (1997). In order to ensure that the specimens experience complete cycles of freezing and thawing, the samples were stored in a freezer at $-18 \pm 2^{\circ} \mathrm{C}$ for $24 \pm 2$ hours and thawed at room temperature $\left(23 \pm 2^{\circ} \mathrm{C}\right)$ for another $24 \pm 2$ hours. At the end of thawing cycles, if any loss due to evaporation, leakage, or splash of the solution was observed, the de-icing salt solution was added to ensure that samples are completely submerged.

For freezing, the industrial True Freezer, model T-49F-HC, was used. Figure 3-17 demonstrates the typical temperature profile of the freezer in 24 hours. The two peaks in the temperature profile are due to the automatic deforesting of the freezer. It was tried at best to match the time of the replacement of the samples between freeze-thaw cycles with the second defrosting period. Finally, to evaluate the durability of repair products, the bond strength testing methods were performed on the samples after 5,15 , and 25 cycles of freezing and thawing in the presence of de-icing salt. 

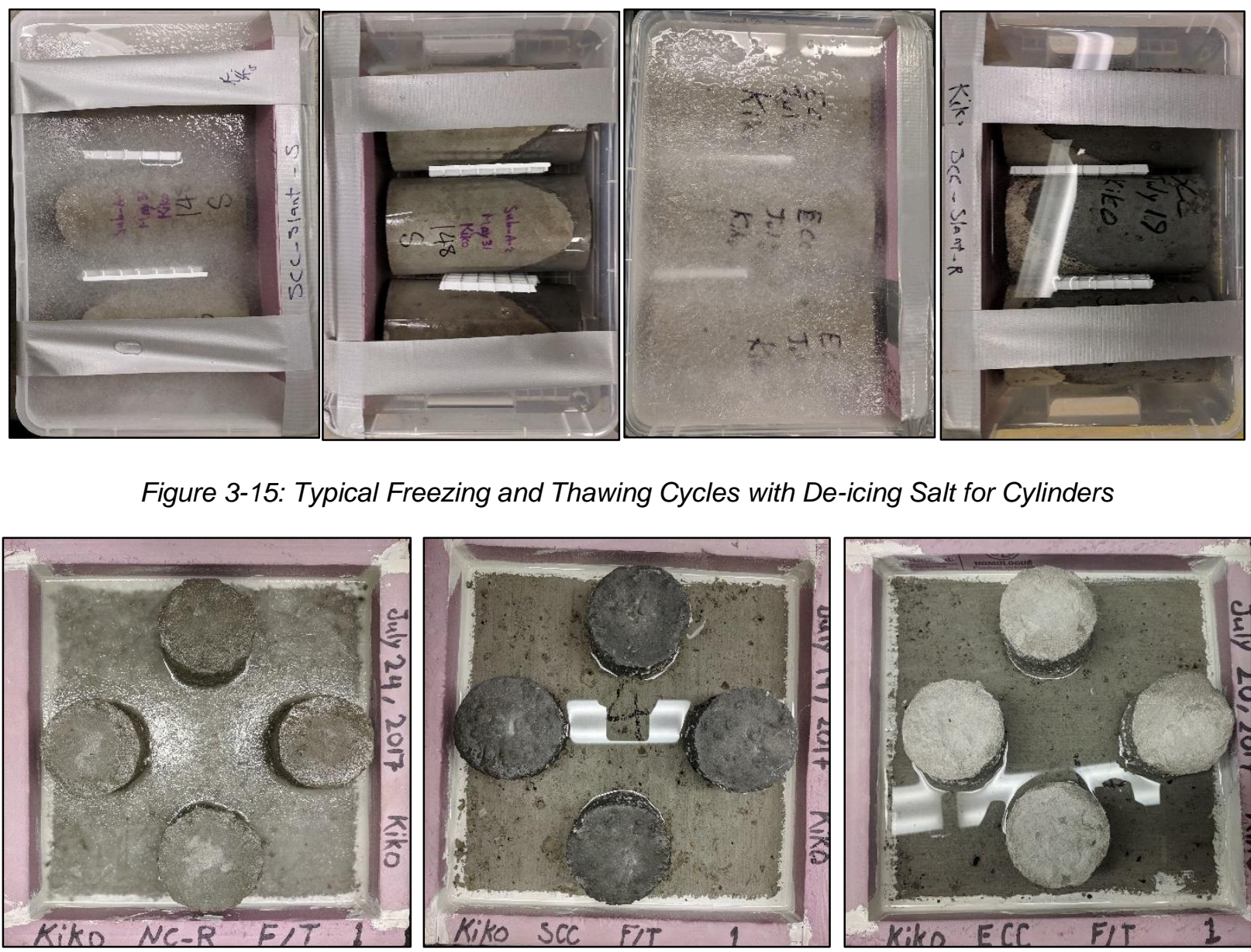

Figure 3-15: Typical Freezing and Thawing Cycles with De-icing Salt for Cylinders

Figure 3-16: Typical Freezing and Thawing Cycles with De-icing Salt for Slabs

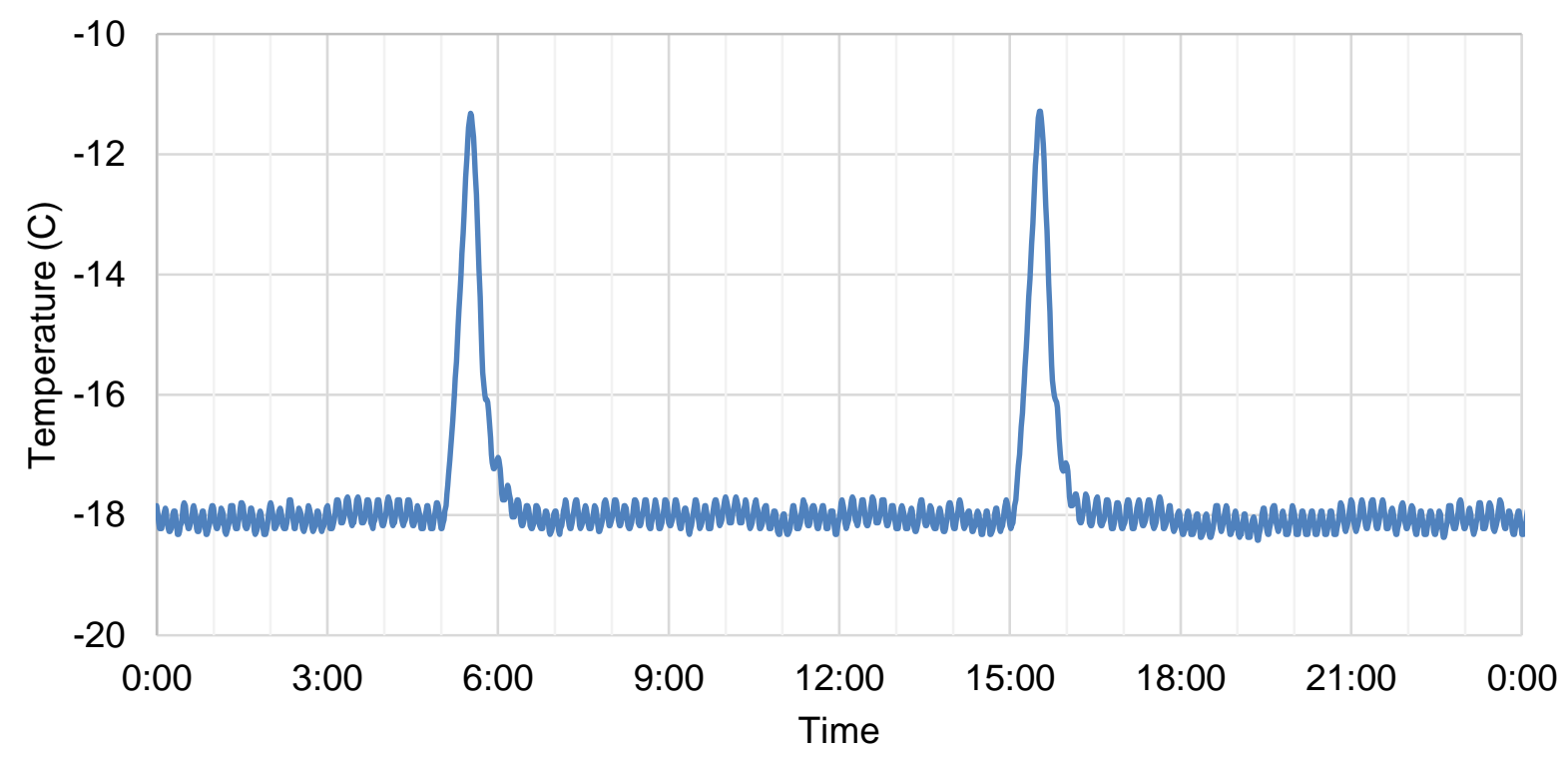

Figure 3-17: Typical Temperature Profile of the Freezer by HOBO Sensor 


\subsubsection{Length Change of Concrete Prisms Following the Testing Conditions}

To perform the conditioning length change measurement which is the idea of the author, three standard concrete prisms with Sub-A were casted and conditioned similar to the Sub-A cylindrical and slab specimens (curing and shrinking). After that, three concrete prisms for each repair materials (four sets) were casted and conditioned exact same as testing specimens (curing, shrinking, and freeze-thaw cycles in the presence of de-icing salt) while at the same time, the Sub-A prisms undergone the same conditions as the repair prisms. Therefore, the Sub-A concrete prisms experienced curing and shrinkage before applying the repair products, and curing, shrinkage, and freeze-thaw cycles with de-icing salt after applying the repair materials. The repair prisms encountered with curing, shrinkage, and freeze-thaw cycles in the presence of de-icing salt (Figure 3-18 and Figure 3-19). The length change of concrete prisms was done weekly (Figure 3-20) until the start of the freezing and thawing cycles. After that, the measurements were performed at the end of $5,10,15,25$, and 50 cycles.
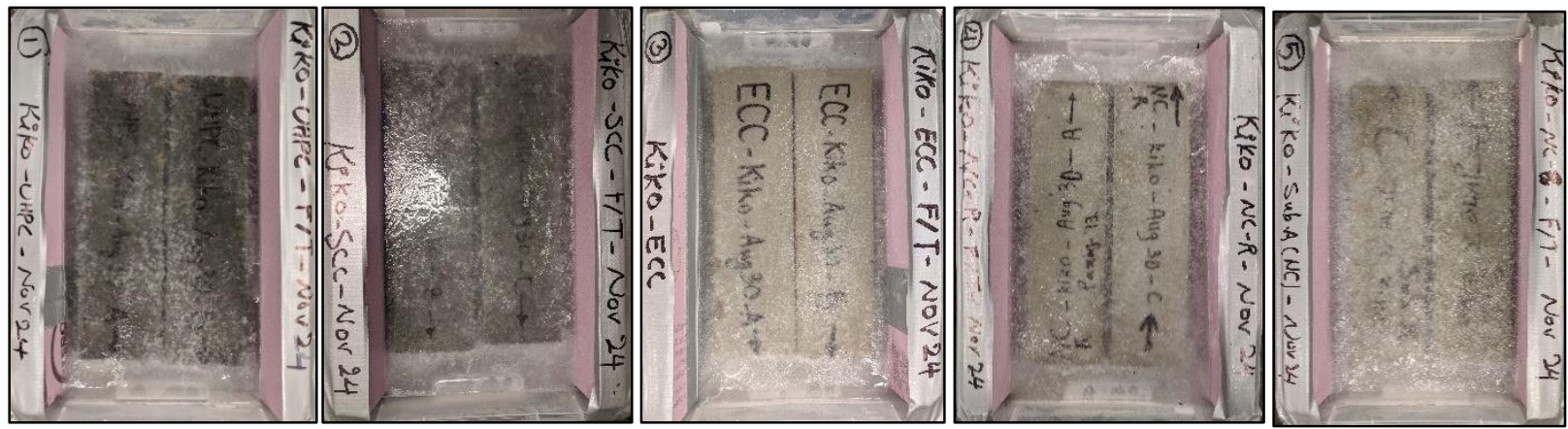

Figure 3-18: Freezing of the 5 Sets of Concrete Prisms with De-icing Salt
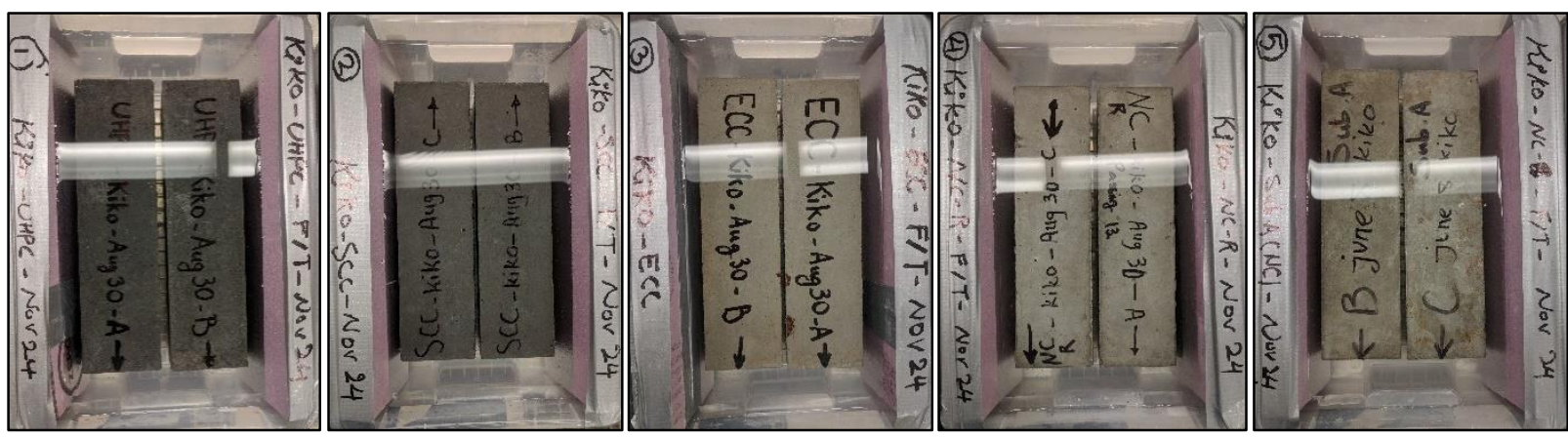

Figure 3-19: Thawing of the 5 Sets of Concrete Prisms with De-icing Salt 
To be consistent with all the length change measurements for the freezing and thawing cycles, the measurements were performed at the end of each specific thawing cycles. Before any measurements, prisms took outside of there saturated de-icing salt condition, rinsed with water, dried by the towel, and left in the normal room temperature $\left(23 \pm 2{ }^{\circ} \mathrm{C}\right)$ for approximately an hour (Figure 3-20).
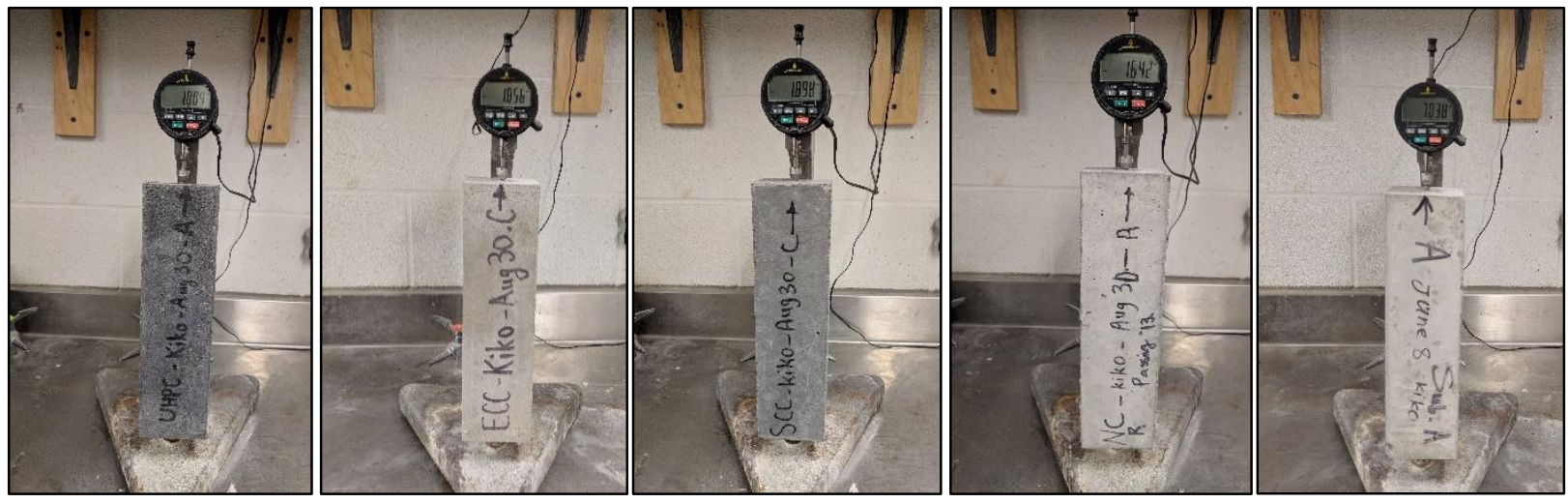

Figure 3-20: Length Change Measurements of the Prisms

It is important to mention that the five sets of concrete prisms (one set of Sub-A and four sets of repairs) also were experienced same one-week conditions ( 3 days in normal room temperature and 4 days in de-icing salt water) before freezing and thawing cycles.
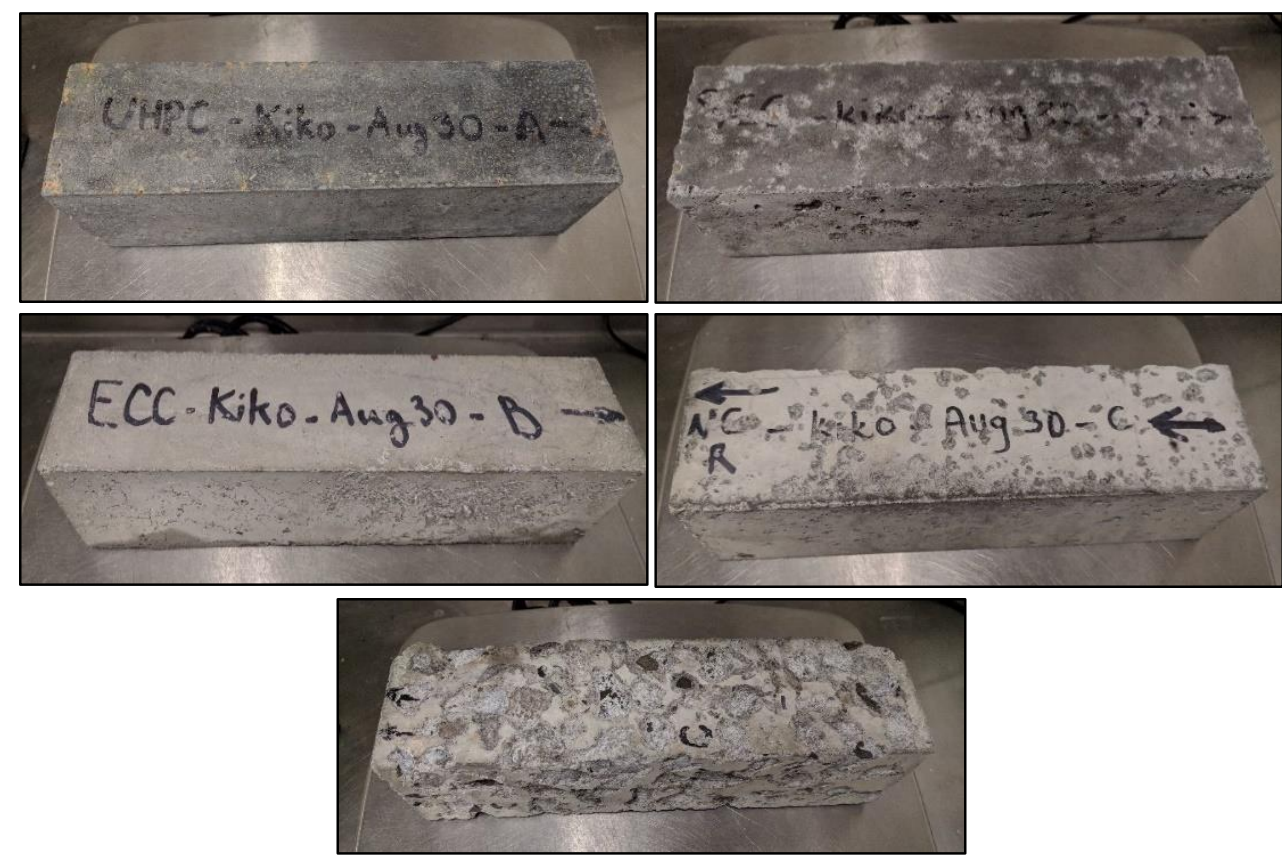

Figure 3-21: Typical Condition of the Prisms after 50 Freeze-Thaw Cycles with Salt 


\subsubsection{Bond Strength Testing Methods}

In this research, three different testing methods were implemented for Phase-II (freezing and thawing cycles in the presence of de-icing salt) including slant shear, splitting tensile and direct pull-off tests. For the first two methods of testing (slant shear and splitting tensile), the tests measurements were performed on the samples at four different cycles. the first measurement was done after finishing the shrinkage period of the specimens (0cycle). The second measurement was implemented after finishing 5-cycles. Third measurement was performed after finishing 15-cycles; and last one was evaluated after 25-cycles of freezing and thawing with de-icing salt.

three standard cylinders for each repair products were tested during each of the four cycles. Therefore, 192 - two testing methods, four repair products, two surface textures, four cycles, and three samples for each - cylindrical samples were tested in this part of the research. The third testing method (pull-off) was planned to execute at the same four cycles of freezing and thawing. However, the bond strength of samples did not reach the 25 -cycles, and complete deboning happened at between 15 to 25 -cycles.

\subsubsection{Slant Shear Test}

One of the popular test methods to evaluate bond strength of the repair product with the substrate is the slant shear test. As recommended by ASTM C882 (2013), the standard cylinder specimens $(100 \times 200 \mathrm{~mm})$ at a loading rate of $0.25 \pm 0.05 \mathrm{MPa} / \mathrm{s}$ were tested (Figure 3-22). The substrate bond interface in the slant shear test is prepared with a 60degree angle from the horizontal line. According to the ASTM C882, slant shear strength is equal to the maximum load applied to the specimen at failure divided by the bonded interface area. The actual elliptical bonded area is equivalent to 0.7854 multiply by two diameters of the elliptical shape.

$$
T_{\text {Slant Shear Strength }}=\frac{F}{A_{\text {Bonded Area }}}=\frac{F}{0.7854 a b} \quad \text { Eq. 3-4: Slant Shear Strength }
$$



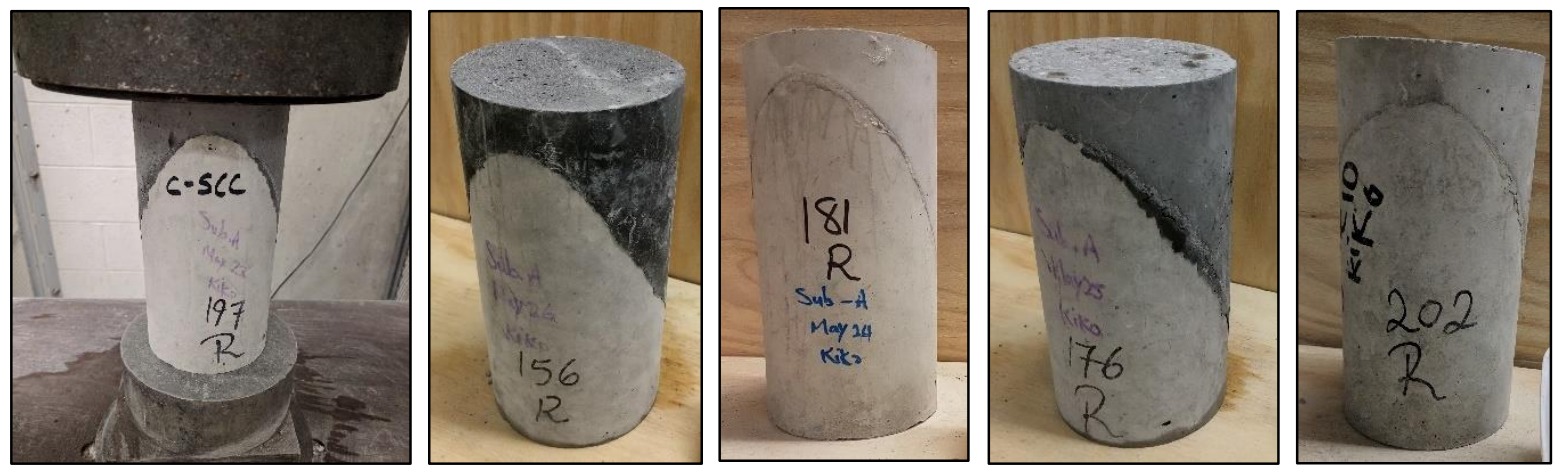

Figure 3-22: Slant Shear Test - from Left to Right: UHPC, ECC, SCC, \& NC
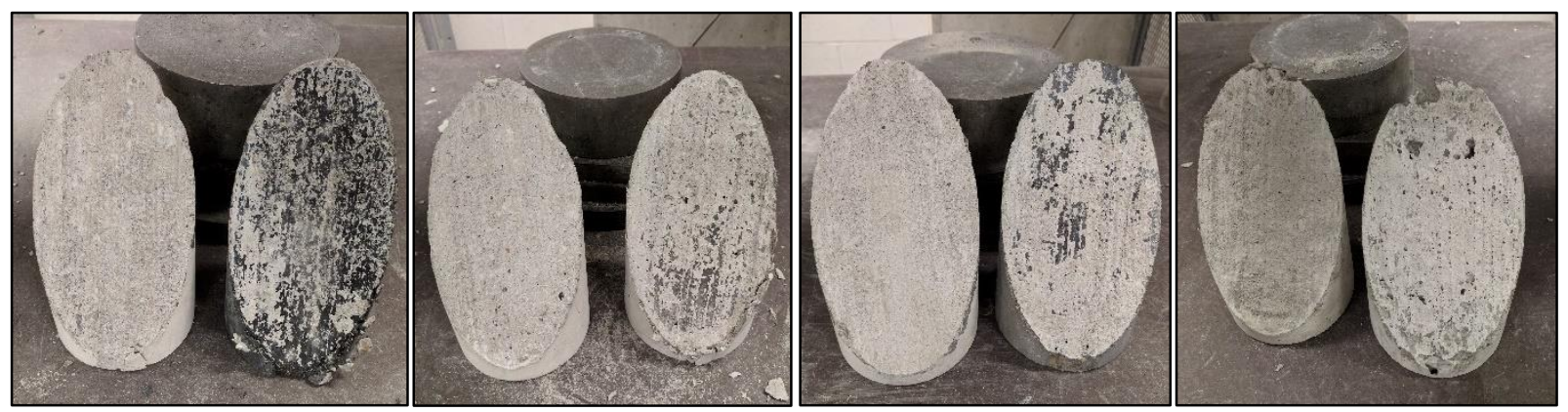

Figure 3-23: Typical Slant Shear Failure-Smooth Surface (UHPC, ECC, SCC, \& NC)
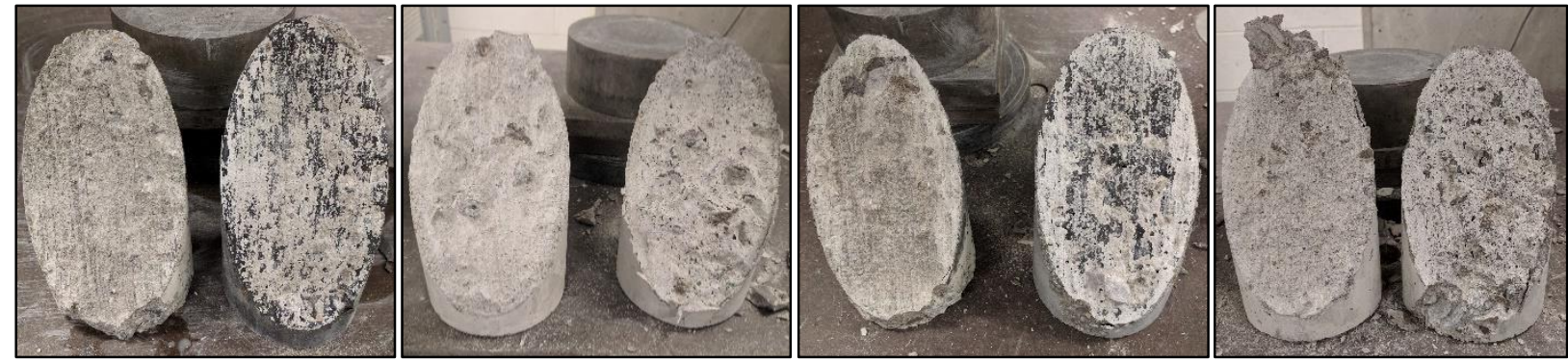

Figure 3-24: Typical Slant Shear Failure-Rough Surface (UHPC, ECC, SCC, \& NC)

\subsubsection{Splitting Tensile Test}

Splitting tensile test is another popular test method to evaluate the bond strength of the repair system. Splitting tensile method is the indirect test for measuring the tensile strength of concrete. The splitting tensile strength is lower than slant shear and flexural strength. However, it is approximately 10 to $15 \%$ higher than the direct tensile strength (Mehta \& Monteiro, 2006). 
This test was implemented according to ASTM C496 (2011) with standard cylindrical specimens $(100 \times 200 \mathrm{~mm})$ at the constant loading rate of 0.7 to $1.4 \mathrm{MPa} / \mathrm{min}$. The splitting tensile strength in MPa can be calculated by according to the following equation:

$T_{\text {Splitting Tensile Strength }}=\frac{2 P}{\pi l d}$

Eq. 3-5: Splitting Tensile Strength

Where $\mathrm{P}$ is the maximum applied load at failure in $\mathrm{N}, \mathrm{I}$ and $\mathrm{d}$ are the length and diameter of the specimen in $\mathrm{mm}$, respectively.
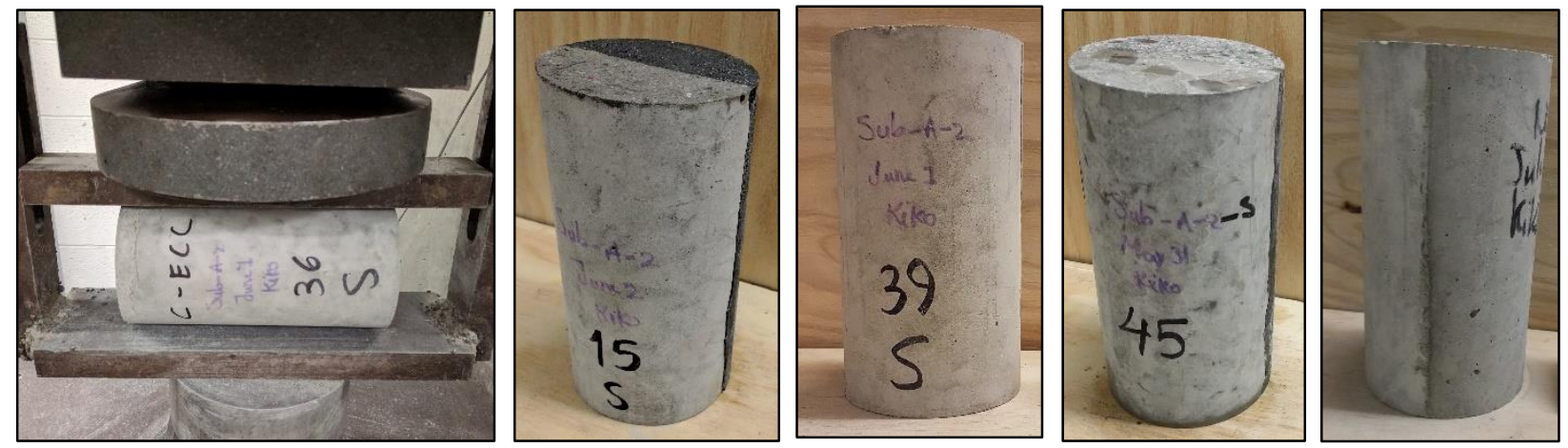

Figure 3-25: Splitting Tensile Test - from Left to Right: UHPC, ECC, SCC, \& NC

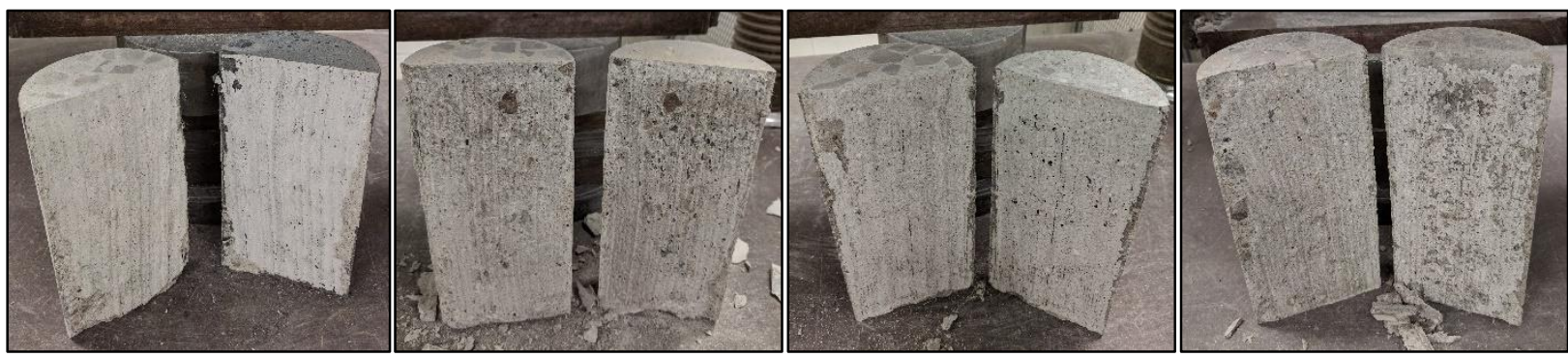

Figure 3-26: Typical Splitting Failure-Smooth Surface (UHPC, ECC, SCC, \& NC)

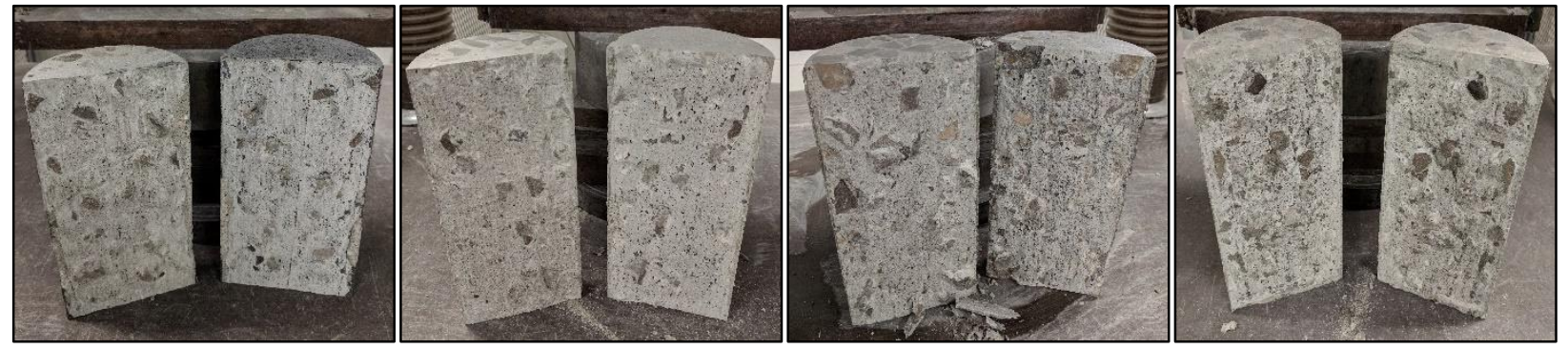

Figure 3-27: Typical Splitting Failure-Rough Surface (UHPC, ECC, SCC, \& NC) 


\subsubsection{Pull-off Test}

Pull-off test is a more practical test particularly in site for quality control. This test is more appropriate for field than laboratory to measure the direct tensile strength of thin overlay repair materials. Pull-off test can measure the bond direct tensile strength if the failure happens exactly at bond (Bonaldo et al., 2005). Coring of repair material and part of the substrate prior to testing is one of the major disadvantages of this test. Excessive vibration of the coring machine, not placing it perpendicular to the sample, size, and depth of coring can significantly affect the results. To eliminate the coring disadvantages and investigate the impact of the freezing and thawing cycles with de-icing salt at the bond interface, four small cylindrical repair specimens with a diameter of $75 \mathrm{~mm}$ and height of $50 \mathrm{~mm}$ were casted on top of small slabs with Sub-A (Figure 3-28a).

Small slabs with repair samples were sealed with dense Styrofoam on each side (Figure $3-28 b)$ to be able to condition them through the cycles of freezing and thawing with deicing salt (Figure 3-28c \& d). At the end of each cycle $(0,5,15$, and 25$)$, the pull-off test (Figure 3-28d) was performed as specified by ASTM C1583 (2013). The direct tensile strength was calculated by Eq. 3-6. Four small slabs were casted for each cycles with four small cylindrical specimens on top. Therefore, total of 64 samples (16 slabs with 4 cylinders) were evaluated for this method. It should be mentioned that none of the repair products reached the 25 -cycle of freezing and thawing with de-icing salt.

$$
T_{\text {Pull-off }}=\frac{F}{A_{\text {Bonded Area }}}=\frac{F}{\pi r^{2}}
$$
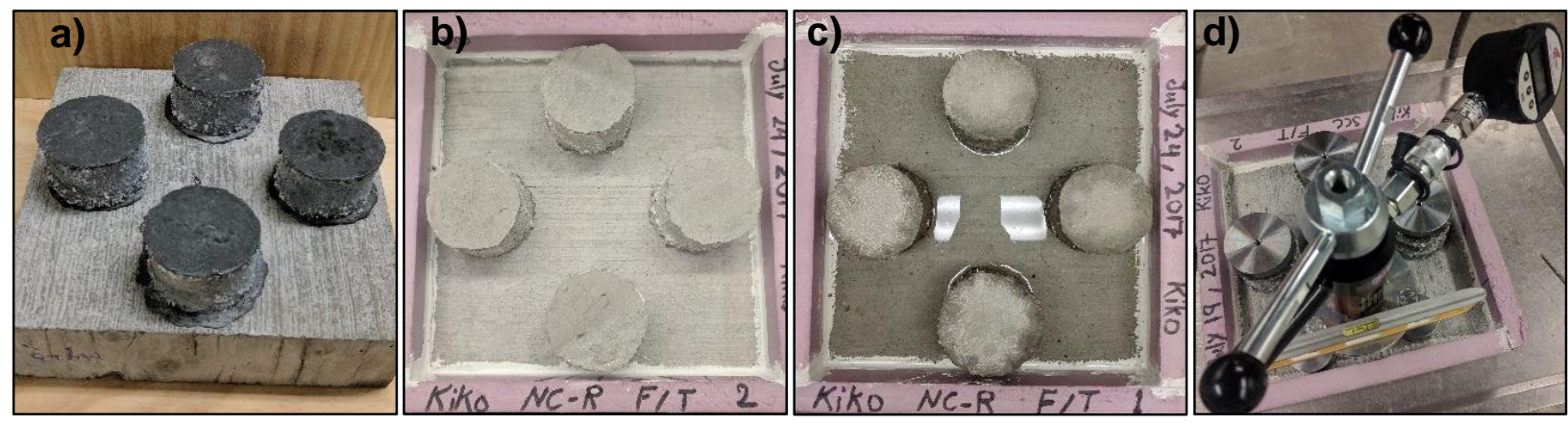

Figure 3-28: Small Slabs with Sub-A and Repair Products 


\subsubsection{Summary of Phase-II}

The complete steps followed through Phase-II are summarized in Table 3-13. The summary illustrates the work sequences and their allocated time period. Sub-A in the table represents substrate with NC mix design (Section 3.1.1.1). Sub-A specimens refer to the 16 small slabs, 192 slant shear and splitting tensile cylindrical samples with the rough and smooth surface texture. Finally, the repair system indicates the Sub-A specimens with their added repair products. The different bond strength testing methods including slant shear, splitting tensile, and pull-off tests were performed in this phase.

Table 3-13: Phase-II Work Sequences

\begin{tabular}{lll}
\hline Steps & Descriptions Summary of Phase-II & Period \\
\hline \hline 1. & Preparing and Fabricating the Moulds & 16 days \\
2. & Casting Sub-A Specimens & 1 day \\
3. & Curing Sub-A Specimens & 14 days \\
4. & Shrinking the Sub-A Specimens & 70 days \\
5. & Preparing SSD Moisture Condition of Sub-A Specimens & 1 day \\
6. & Applying Repair Materials on Top of Sub-A Specimens & 4 days \\
6.1. & Applying UHPC & 1 day \\
6.2. & Applying ECC-Slag & 1 day \\
6.3. & Applying SCC & 1 day \\
6.4. & Applying NC & 1 day \\
7. & Curing Repair System (Including Sub-A and Repairs) & 14 days \\
8. & Shrinking Repair System & 60 days \\
9. & Adopting Repair System & 7 days \\
9.1. & Performing the Initial Bond Strength Test (0-cycle) & 4 days ${ }^{1}$ \\
10. & Freezing and Thawing Cycles with De-icing Salt & 65 days \\
10.1. & Performing Bond Strength Test after 5-cycles & 4 days ${ }^{1}$ \\
10.2. & Performing Bond Strength Test after 15-cycles & 4 days ${ }^{1}$ \\
10.3. & Performing Bond Strength Test after 25-cycles & 4 days ${ }^{1}$ \\
\hline \hline
\end{tabular}

${ }^{1}$ The 4-days testing period includes 2-days crushing 96 slant shear and 96 splitting tensile cylindrical specimens, 1-day grinding and gluing pull-off disks, and 1-day performing the pull-off test on small slabs. 


\subsection{Repairs Placed on Expanding Substrate - Suffering ACR (Phase-III)}

Since Phase-III was designed to evaluate the bond strength of deteriorated concrete due to volumetric expansion, the substrate (Sub-B) mix design with alkali-carbonate reactive aggregate (ACR) was selected (Section 3.1.1.2). To evaluate the bond strength in this phase of the research, the pull-off test was performed.

\subsubsection{Sub-B Preparation}

\subsubsection{Casting, Surface Roughness, and Curing}

To increase the probability of expansion cracks (higher exposed area over volume) the lager slab in length $(1000 \mathrm{~mm}$ ) with same width and height (300 and $75 \mathrm{~mm}$, respectively) as Phase-II was designed and fabricated (Figure 3-29). For the surface preparation, the smooth surface roughness (Section 3.3.1.1) was implemented. The surface of large slabs was trowelled by a wooden float and broomed to slightly texture the substrate according to MTO LS-412-R17 (1997). Figure 3-30 demonstrates the final surface texture of the large stabs. Due to the insignificant influence of roughness under direct tensile force, only smooth roughness was selected for Phase-III.

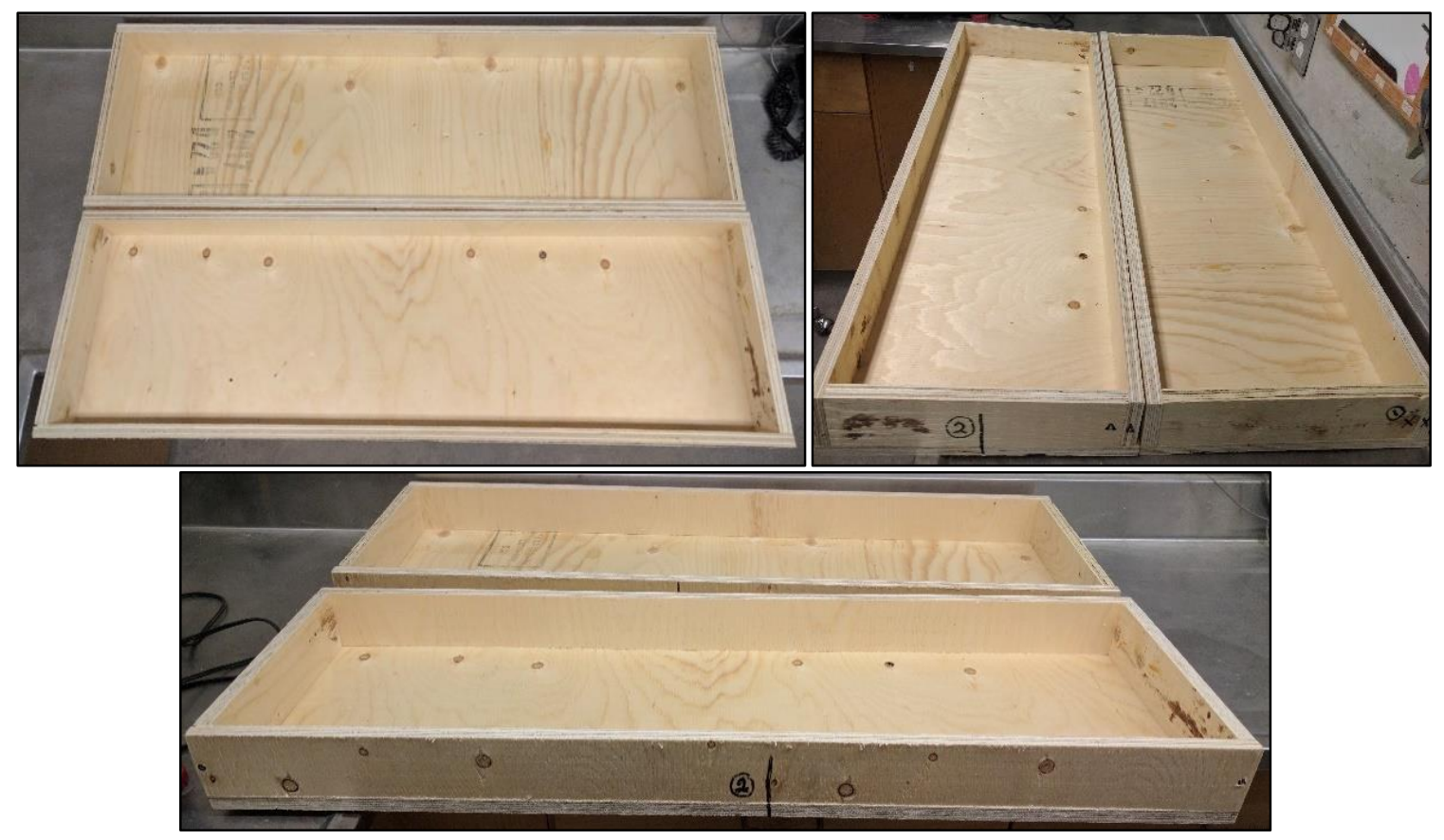

Figure 3-29: Large Slab Moulds 

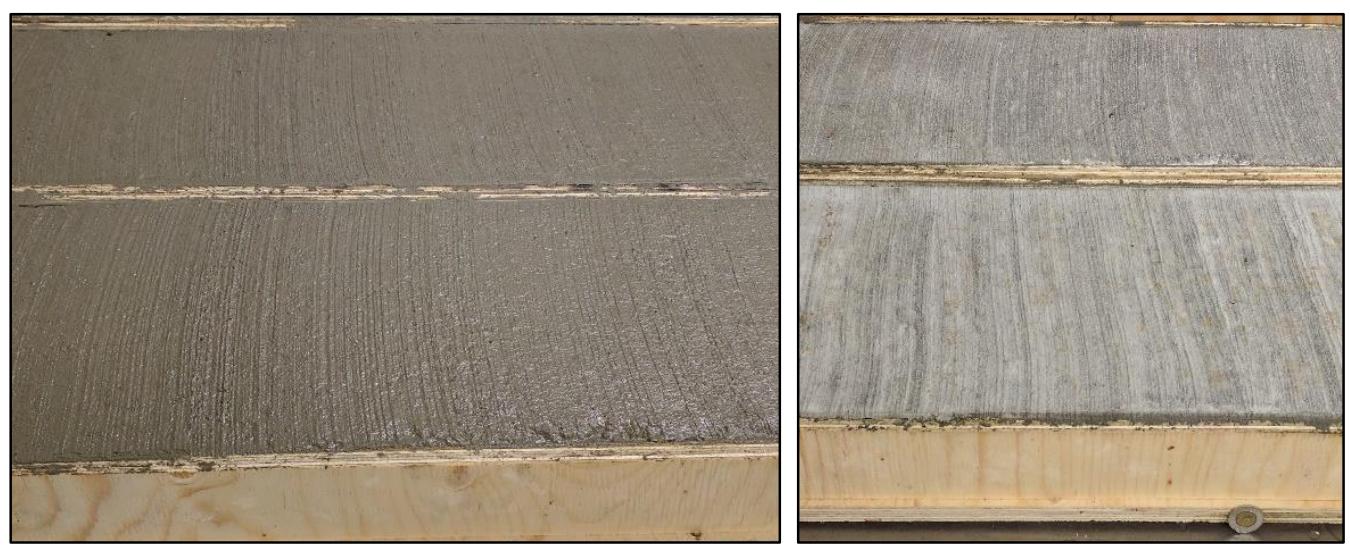

Figure 3-30: Surface Preparation of Large Slabs

The Sub-B was stored in the moist curing room for 1 month (28 days) to promote the ACR expansion. Three standard concrete prisms were also casted at the same time to evaluate the level of expansion in the Sub-B.

\subsubsection{Moisture Condition at the Time of Applying Repairs}

According to the literature review (Section 2.4.3), substrate SSD condition was selected to be implemented at the time of applying repair products. To achieve this condition, an hour prior to applying repairs, samples just moved outside of the moist curing room $(\mathrm{RH}>98 \%)$ allowing the extra water on the surface of the Sub-B to evaporate.

\subsubsection{Applying Repairs and Conditioning (Sub-B and Repair Products)}

After finishing the curing period and preparing SSD condition for Sub-B, the repair materials were casted on top of Sub-B. Repair products were casted as one uniform and continuous layer to bridge the expansion cracks, consequently, slow down the expansion. The repair thickness was decided to be $50 \mathrm{~mm}$. After casting the repair products, the specimens were kept in the moist curing room for 2 months to cure the repair products and more importantly provide Sub-B with moisture for further ACR expansion. After 2 months of curing, the samples moved outside the curing room and stored in the normal room temperature $\left(23 \pm 2{ }^{\circ} \mathrm{C}\right)$ for another 5 months. 


\subsubsection{Length Change of Concrete Prisms Following the Testing Conditions}

The length change expansion movement of the Sub-B with ACR mix design was measured according to the ASTM C157 (2016). Base on the standard, the average length change movement of the three concrete prisms $(75 \times 75 \times 285 \mathrm{~mm})$ was calculated. Again, the gauge length for the expansion calculation according to Eq. 3-7 was considered to be $250 \mathrm{~mm}$. In the following equation, $\Delta \mathrm{L}_{x}$ is the length change movement (expansion) of the sample in $\%$ at any age, $R_{x}$ is the difference between the specimen reading and reference bar at the age of $x, R_{0}$ is the difference between the specimen reading and reference bar for an initial reading.

$$
\Delta L_{x}=\frac{R_{x}-R_{0}}{G} \times 100
$$

Eq. 3-7: Length Change Expansion Measurement

The conditioning of the concrete prisms was selected to be similar to the Phase-III. Therefore, the prisms were stored in the curing room $(\mathrm{RH}>98 \%)$ for 3 months (1 month for Sub-B only and 2 months for repair system). Immediately after that, they were moved outside of the curing room into a normal room temperature for 5 months. During this total 8 months ( 3 months curing and 5 months outside the curing room), the length change measurements were done periodically. In fact, the measurements through the first three months were performed weekly and continued after over a more extended period of time.

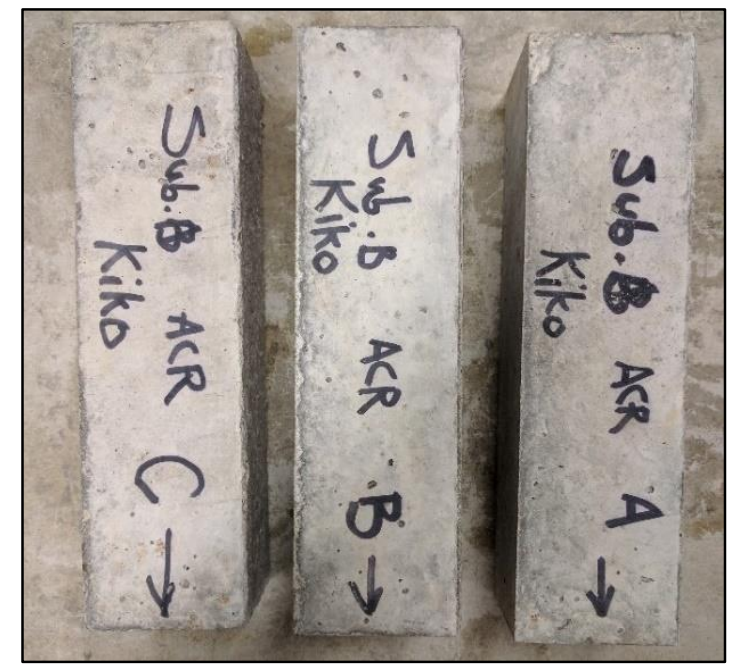

Figure 3-31: Sub-B Concrete Prisms after Casting 


\subsubsection{Bond Strength Testing Method}

\subsubsection{Pull-off Test}

The first pull-off test was performed after 2 months curing of the repair system and was continued at 1,2, and 5 months outside the curing room based on the ASTM C1583 (2013). Prior to the pull-off test, the specimens were cored. After that, some coring trials with different diamond bits of 25, 75, and $100 \mathrm{~mm}$ (Figure 3-32) were performed. The bit of $75 \mathrm{~mm}$ was chosen since it produced the minimum vibration and required less amount of epoxy for testing. After coring, the top surface of the repair products was ground (Figure 3-33) to increase the uniformity of the load over area and adhesion of steel disk, epoxy, and concrete (Figure 3-34). Finally, the pull-off test was performed (Figure 3-35).

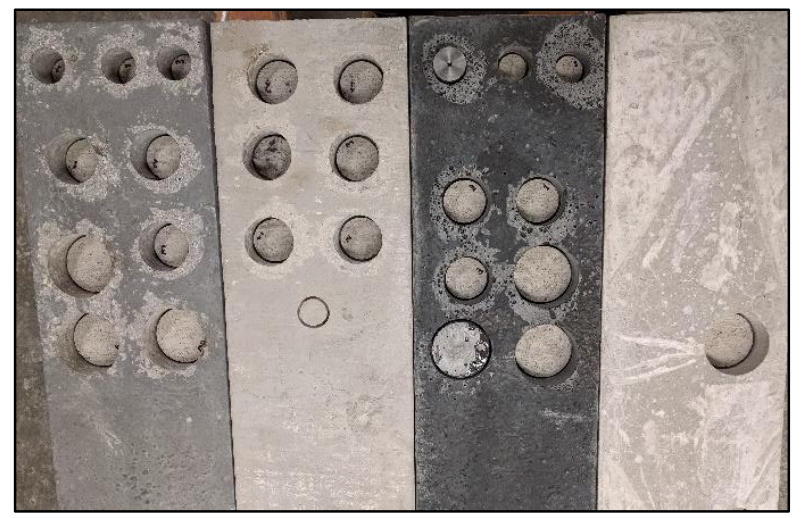

Figure 3-32: Optimizing Coring Bit

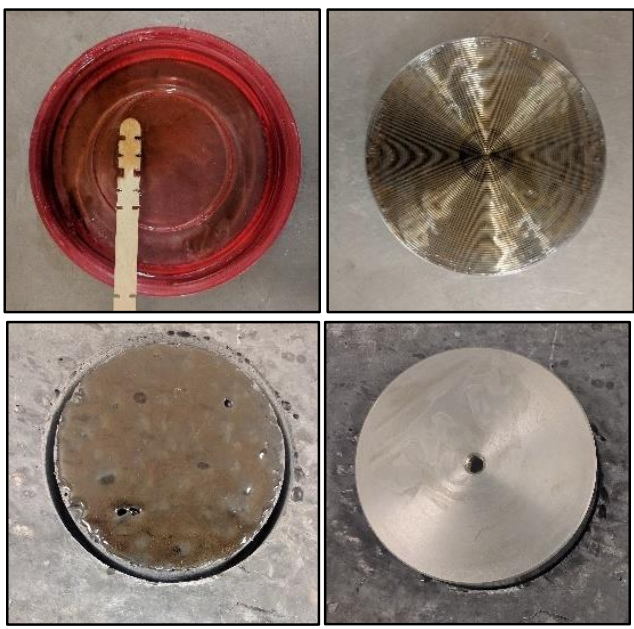

Figure 3-34: Mixing and Applying Epoxy

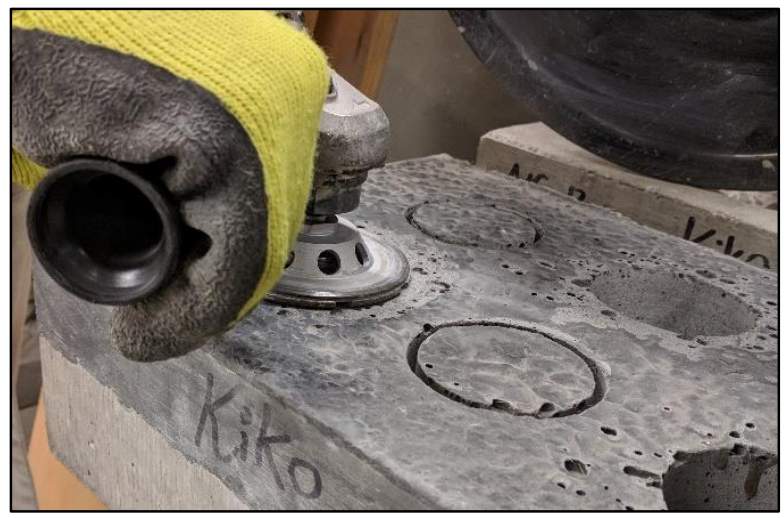

Figure 3-33: Grinding the Surface of Slabs
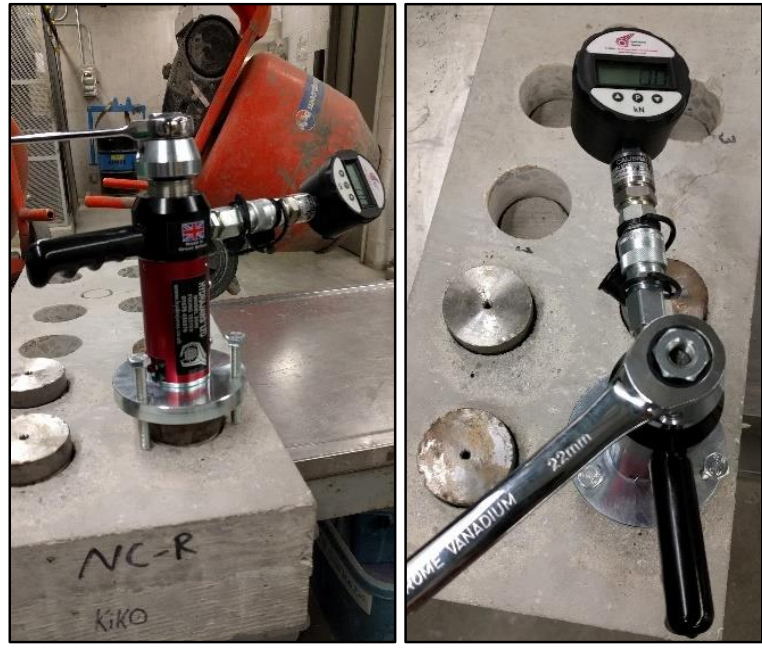

Figure 3-35: Pull-off Test on Large Slabs 


\subsubsection{Summary of Phase-III}

The complete work sequences followed through the bond strength evaluation under expanding deterioration (Phase-III) is summarized in Table 3-14. The summary shows the work done step by step and their time period. Sub-B in the table refers to a substrate with ACR mix design (Section 3.1.1.2). Sub-B specimens represent 4 large slabs with smooth surface texture. Finally, repair system means the Sub-B samples with $50 \mathrm{~mm}$ repair products added on top. The pull-off test was implemented to evaluate the bond strength.

Table 3-14: Phase-III Work Sequences

\begin{tabular}{|c|c|c|}
\hline Steps & Description Summary of Phase-III & Period \\
\hline 1. & Preparing and Fabricating the Moulds & 4 days \\
\hline 2. & Casting the Sub-B Specimens & 1 day \\
\hline 3. & Curing the Sub-B Specimens & 28 days \\
\hline 4. & Preparing SSD Moisture Condition of the Sub-B Specimens & 1 day \\
\hline 5. & Applying the Repair Materials on Top of the Sub-B Specimens & 4 days \\
\hline 5.1. & Applying the UHPC & 1 day \\
\hline 5.2. & Applying the ECC-Slag & 1 day \\
\hline 5.3. & Applying the SCC & 1 day \\
\hline 5.4. & Applying the NC & 1 day \\
\hline 6. & Curing the Repair System (Including Sub-B and Repairs) & 62 days \\
\hline 6.1. & Performing the Initial Bond Strength Test after 2M-Curing ${ }^{1}$ & 4 days $^{3}$ \\
\hline 7. & Storing the Repair System into the Typical Room Condition & 165 days \\
\hline 7.1. & Performing Bond Strength Test after $2 M-$ Curing $+1 M^{2}$ & 4 days $^{3}$ \\
\hline 7.2. & Performing Bond Strength Test after $2 M$-Curing $+2 M$ & 4 days $^{3}$ \\
\hline 7.3. & Performing Bond Strength Test after $2 M$-Curing $+5 M$ & 4 days $^{3}$ \\
\hline & Total Duration of the Phase-II & 265 days \\
\hline
\end{tabular}

${ }^{1}$ The $2 \mathrm{M}$-Curing represents 2 months curing of the repair system. ${ }^{2}$ The $2 \mathrm{M}$-Curing $+1 \mathrm{M}$ denoted 2 months curing plus 1 months outside the curing room for the repair system. ${ }^{3}$ The 4 -days testing period includes 1 day coring and drying the samples, 1-day grinding and applying epoxy for pull-off disks, 1-day curing of the epoxy, and finally, 1-day performing the pull-off test on large slabs. 


\subsection{Summary of the Experimental Program}

The testing methods to evaluate the repair materials compatibility with substrate were defined as Phase-I. In addition, Phase-II and Phase-III was designed to measure the bond strength of repair products (UHPC, ECC-Slag, SCC, NC) under freeze-thaw cycles in the presence of de-icing salt and volumetric expansion, respectively.

Different substrates were introduced for Phase-II and Phase-III; substrate used for PhaseII named Sub-A and substrate implemented for Phase-III termed Sub-B. Besides, two different surface roughness were employed; smooth and rough surface texture. Finally, three type of bond strength testing methods were studied; slant shear, splitting tensile, and pull-off tests. Table 3-15 summarizes type of sample, number of specimens for each related testing method and the total number of samples in each phase.

Table 3-15: Summary of Testing Methods

\begin{tabular}{|c|c|c|c|c|c|}
\hline Phases & Testing methods & $\begin{array}{l}\text { Surface } \\
\text { Texture }\end{array}$ & $\begin{array}{l}\text { Type of } \\
\text { Sample } \\
\end{array}$ & $\begin{array}{l}\text { Sample } \\
\text { (Detail) }\end{array}$ & $\begin{array}{c}\text { Sample } \\
\text { (Total) }\end{array}$ \\
\hline \multirow{4}{*}{ Phase-I } & Comp. Strength Development & \multirow{3}{*}{ n/a } & Cylinder $^{1}$ & $3^{\mathrm{a}} \times 6^{\mathrm{b}} \times 6^{\mathrm{c}}$ & 108 \\
\hline & Static Modulus of Elasticity & & Cylinder ${ }^{1}$ & $3^{\mathrm{a}} \times 6^{\mathrm{c}}$ & 18 \\
\hline & Shrinkage (Autogenous \& Drying) & & Prism² $^{2}$ & $3^{a} \times 2^{d} \times 4^{c}$ & 24 \\
\hline & \multicolumn{5}{|c|}{ Total Samples: 126 Cylinders \& 24 Prisms } \\
\hline \multirow{7}{*}{$\begin{array}{l}\text { Phase-II } \\
\text { (Sub-A) }\end{array}$} & Length Change of Concrete Prisms & $\mathrm{n} / \mathrm{a}$ & Prism $^{2}$ & $3^{\mathrm{a}} \times 5^{\mathrm{c}}$ & 15 \\
\hline & Slant Shear Test & Smooth & Cylinder ${ }^{1}$ & $3^{a} \times 4^{b} \times 4^{c}$ & 48 \\
\hline & Slant Shear Test & Rough & Cylinder ${ }^{1}$ & $3^{a} \times 4^{b} \times 4^{c}$ & 48 \\
\hline & Splitting Tensile Test & Smooth & Cylinder ${ }^{1}$ & $3^{a} \times 4^{b} \times 4^{c}$ & 48 \\
\hline & Splitting Tensile Test & Rough & Cylinder ${ }^{1}$ & $3^{a} \times 4^{b} \times 4^{c}$ & 48 \\
\hline & Pull-off Test & Smooth & Small Slab ${ }^{3}$ & $4^{a} \times 4^{b} \times 4^{c}$ & 64 \\
\hline & \multicolumn{5}{|c|}{ Total Samples: 192 Cylinders, 64 Samples from 16 Small Slabs, \& 15 Prisms } \\
\hline \multirow{3}{*}{$\begin{array}{l}\text { Phase-III } \\
\text { (Sub-B) }\end{array}$} & Length Change of Concrete Prisms & $\mathrm{n} / \mathrm{a}$ & Prism $^{2}$ & $3^{\mathrm{a}} \times 1^{\mathrm{c}}$ & 3 \\
\hline & Pull-off Test & Smooth & Large Slab ${ }^{4}$ & $3^{a} \times 4^{b} \times 4^{c}$ & 48 \\
\hline & \multicolumn{5}{|c|}{ Total Samples: 48 Cored Samples from 4 Large Slabs \& 3 Prisms } \\
\hline
\end{tabular}

${ }^{1}$ Cylinder:100x200mm, ${ }^{2}$ Prism:75x75x285mm, ${ }^{3}$ Small Slab:300x300x75mm, ${ }^{4}$ Large Slab:1000x300x75mm

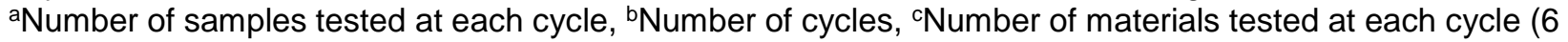
represents repairs and substrates, 5 is repairs and Sub-A, 4 represents repairs only, and 1 is Sub-B), dNumber if times that test was repeated. 


\section{Chapter 4}

\section{Results and Analysis}

\subsection{Materials Properties and Compatibility of Repairs with Substrates (Phase-I)}

Throughout this section, the material characteristics of the two different substrates including Sub-A (NC) and Sub-B (ACR), and four repairs products (UHPC, ECC-Slag, SCC, and NC) were presented.

\subsubsection{Compressive Strength}

The results of the compressive strength test (according to ASTM C39) were shown in Figure 4-1. To distinguish the substrates from repair products, substrates were illustrated by dotted lines. Sub-A represents the NC which was selected as a substrate for the Phase-II (freeze-thaw cycles in the presence of de-icing salt), and Sub-B expresses the Phase-III substrate (expanding deterioration). The four repair materials are demonstrated in the figure by solid lines. As expected, the UHPC had the highest compressive strength through all different periods of curing among other materials. ECC-Slag and SCC performed almost identical throughout the first 28 days of curing with a slight improvement of compressive strength for SCC after 28 days of curing. The other three materials including NC, Sub-A, and Sub-B showed very similar behaviour. 


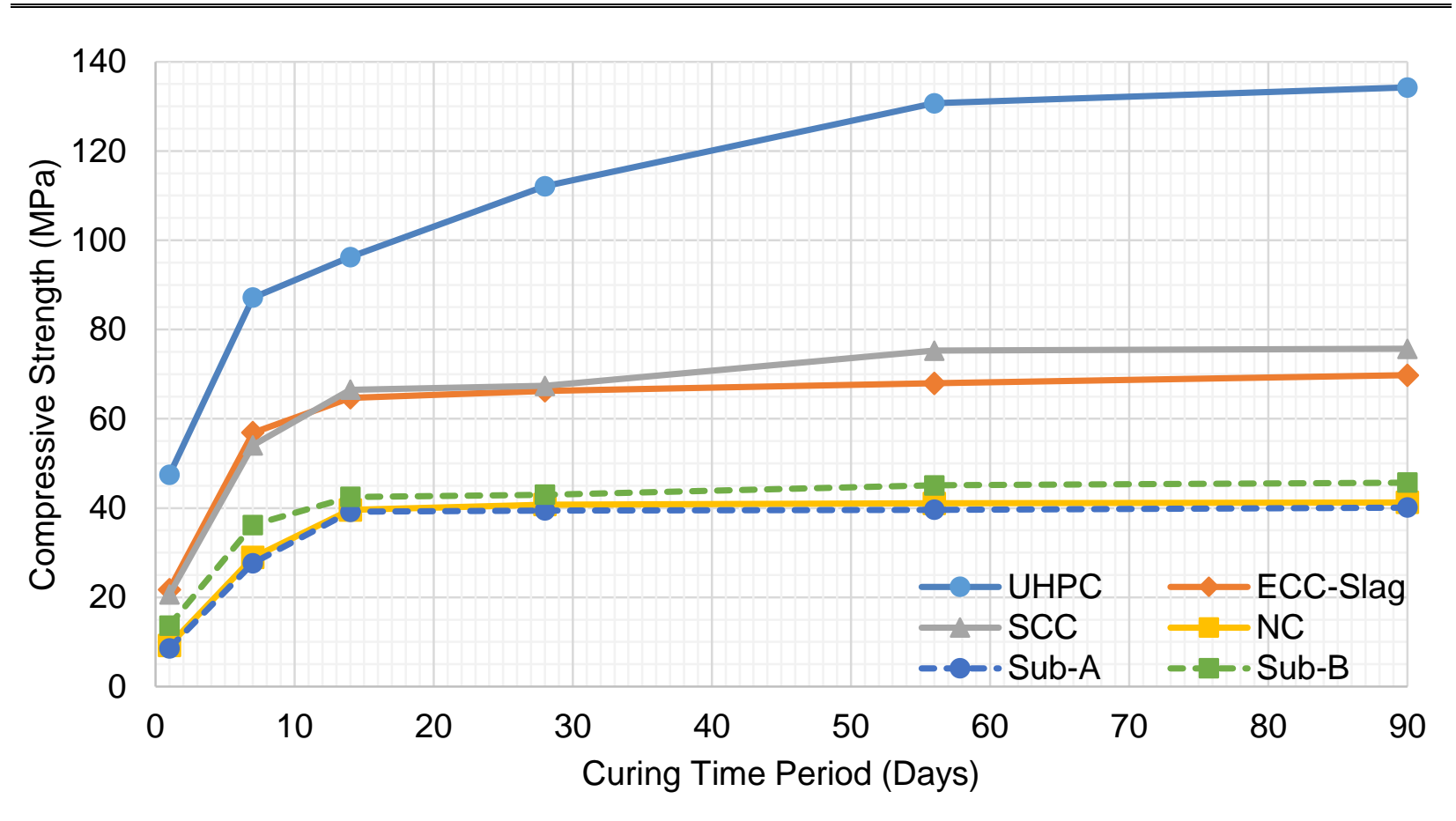

Figure 4-1: Compressive Strength Results

For the results presented in this research, the standard deviation of the sample (SD) was calculated according to Eq. 4-1, where $\mathrm{N}$ is the number of samples, $x_{i}$ is the result of each sample, and $\bar{x}$ represents the average of the results. The SD values of compressive strength for each material within different curing period were reported in Table 4-1. Based on the reported values, UHPC is the only material with the SD of higher than $2.85 \mathrm{MPa}$.

$$
S D=\sqrt{\frac{\sum_{i=1}^{N}\left(x_{i}-\bar{x}\right)^{2}}{N-1}}
$$

Eq. 4-1: Standard Deviation of Sample (SD)

Table 4-1: Compressive Strength Results of SD (MPa)

\begin{tabular}{ccccccc}
\hline $\begin{array}{c}\text { Curing } \\
\text { Period }\end{array}$ & UHPC & ECC-Slag & SCC & NC & Sub-A & Sub-B \\
\hline \hline 1 day & 2.73 & 0.89 & 0.42 & 0.04 & 0.19 & 0.04 \\
7 days & 6.42 & 2.83 & 1.90 & 0.49 & 0.39 & 0.21 \\
14 days & 10.20 & 2.64 & 0.54 & 0.18 & 0.48 & 0.19 \\
28 days & 19.33 & 2.37 & 2.75 & 0.22 & 0.36 & 2.65 \\
56 days & 4.28 & 1.60 & 2.20 & 1.36 & 0.40 & 2.74 \\
90 days & 2.16 & 0.63 & 2.04 & 0.52 & 0.12 & 2.00 \\
\hline Average & $\mathbf{7 . 5 2}$ & $\mathbf{1 . 8 2}$ & $\mathbf{1 . 6 4}$ & $\mathbf{0 . 4 7}$ & $\mathbf{0 . 3 2}$ & $\mathbf{1 . 3 1}$ \\
\hline
\end{tabular}


However, it is known that the coefficient of variation (CV) - which was calculated by Eq. 4-2 - is the better way to evaluate the variability since it is dimensionless value. Table 4-2 demonstrates the $\mathrm{CV}$ values for compressive strength.

$$
C V(\%)=\frac{S D}{\text { Average }} \times 100
$$

Eq. 4-2: Coefficient of Variation (CV)

Table 4-2: Compressive Strength Results of CV (\%)

\begin{tabular}{ccccccc}
\hline $\begin{array}{c}\text { Curing } \\
\text { Period }\end{array}$ & UHPC & ECC-Slag & SCC & NC & Sub-A & Sub-B \\
\hline \hline day & 5.76 & 4.07 & 2.03 & 0.43 & 2.22 & 0.29 \\
7 days & 7.36 & 4.97 & 3.52 & 1.71 & 1.40 & 0.59 \\
14 days & 10.60 & 4.07 & 0.81 & 0.45 & 1.21 & 0.45 \\
28 days & 17.25 & 3.58 & 4.08 & 0.54 & 0.93 & 6.17 \\
56 days & 3.28 & 2.35 & 2.93 & 3.31 & 1.01 & 6.08 \\
90 days & 1.61 & 0.90 & 2.69 & 1.25 & 0.29 & 4.37 \\
\hline Average & $\mathbf{7 . 6 4}$ & $\mathbf{3 . 3 2}$ & $\mathbf{2 . 6 8}$ & $\mathbf{1 . 2 8}$ & $\mathbf{1 . 1 8}$ & $\mathbf{2 . 9 9}$ \\
\hline
\end{tabular}

According to Table 4-2, All the CV values for single-operator precision (3 cylinders) were in the acceptable range ( $\leq 10.6 \%)$ according to ASTM C39 (2017) with only one exception which was the highest CV (17.25\%) recorded for UHPC at the 28 days curing. For all products excluding UHPC, the CV were recorded to be less than $5.00 \%$ within all the curing periods. By analyzing the CV values for substrates, the Sub-B started to show more dispersion of the results in comparison to the Sub-A after 14 days of curing. This behaviour of Sub-B could be due to ACR reaction and creation of none homogeneous expanding cracks inside the specimens.

To even more simplify the comparison of the different materials tested in this section and eliminate the curing period factor, the average $\mathrm{CV}$ for different materials were calculated. The results showed that UHPC has the highest CV $(7.64 \%)$ among other repair products followed by ECC-Slag (3.32\%), Sub-b (2.99\%), SCC (2.68\%), and NC (1.28\%), with SubA having the lowest $(1.18 \%)$. Generally, the results of the all materials (repairs and substrates) tested here were in the acceptable range by considering the mixture nature and procedure even for UHPC. 


\subsubsection{Static Modulus of Elasticity}

The compressive stress-strain curve of the substrate and repair products were demonstrated by Figure 4-2. In addition, the value of static modulus of elasticity was calculated according to ASTM C469 and reported in the right-hand side of Figure 4-2.

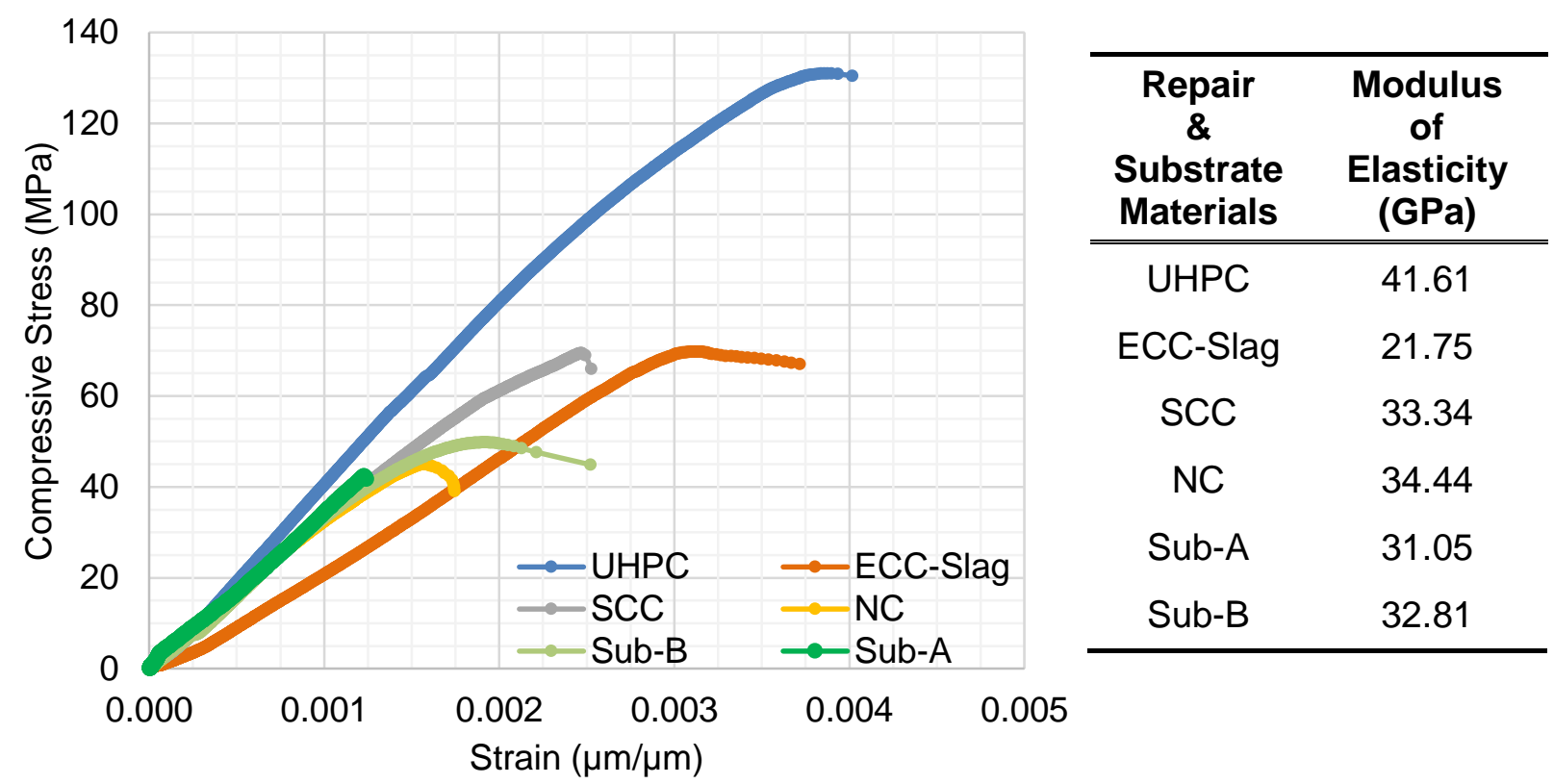

Figure 4-2: Stress-Strain Curve for Substrates and Repair Products

According to Figure 4-2, the UHPC and ECC-Slag showed the highest and lowest modulus of elasticity (41.61 and $21.75 \mathrm{GPa}$, respectively) with considerably large variance with other products (substrates and repairs). They also indicated the first and second largest amount of strain (deformation) among other materials, 0.00402 and $0.00372 \mu \mathrm{m} / \mu \mathrm{m}$, respectively. The moduli of elasticity of Sub-A (31.05 GPa), Sub-B (32.81 GPa), SCC (33.34 GPa), and NC (34.44 GPa) were calculated to be very close to each other since all these four materials implement the high amount of coarse aggregate in their mix design. In fact, the presence of coarse aggregate and its properties significantly influences the modulus of elasticity (Section 2.3.2).

All the moduli of elasticity reported in Figure 4-2 were in the acceptable range based on the characteristics of materials. For instance, the moduli of elasticity of untreated UHPC and ECC-Slag were reported to be $42.7 \mathrm{GPa}$ (Graybeal, 2006) and between 18 to 34 GPa (V. C. Li, 2007), respectively. 


\subsubsection{Shrinkage (Trial-1)}

The length change measurement (\%) of 12 concrete prisms (3 prisms for each of 4 repair materials) according to the MTO LS-435-R28 (2013) for drying shrinkage and with small adjustment as it was explained in Section 3.2.3.2 for combined autogenous and drying shrinkage were presented by Figure 4-3 and Figure 4-4, respectively.

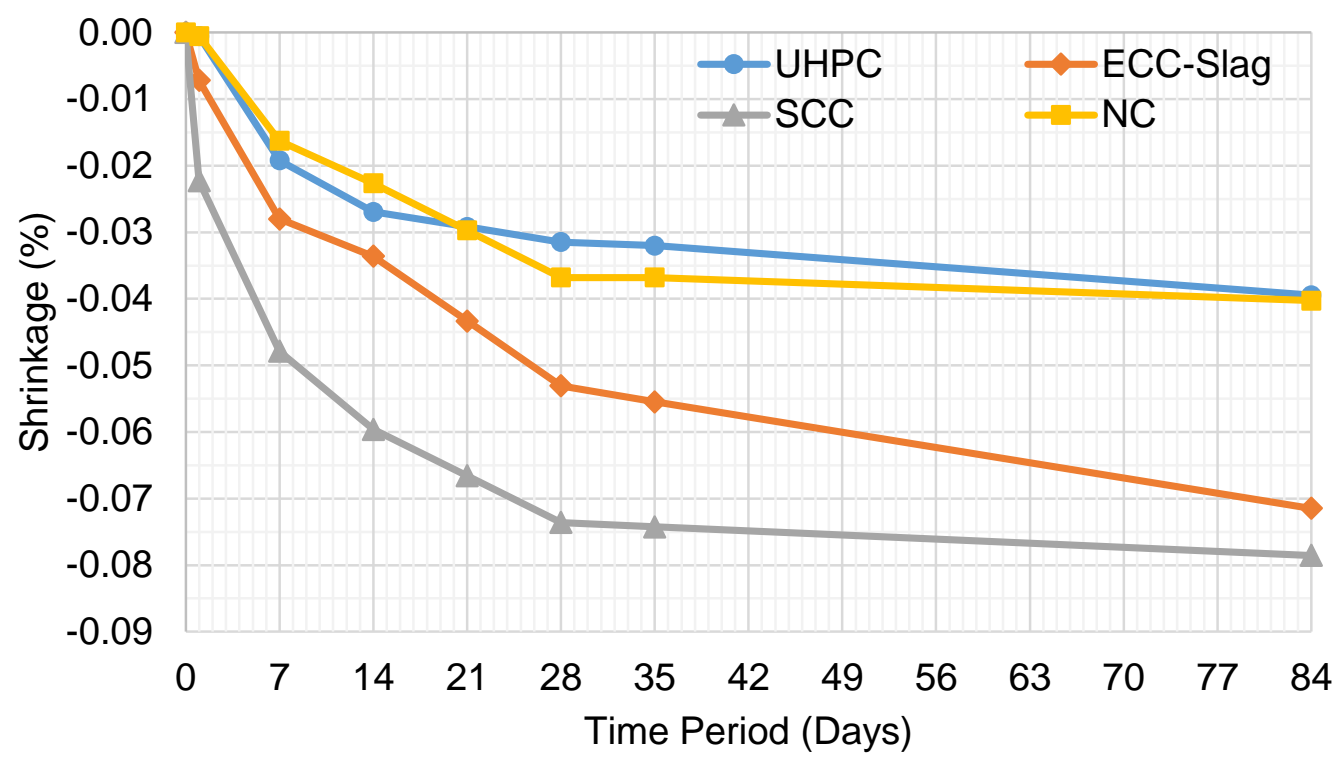

Figure 4-3: Drying Shrinkage According to MTO LS-435-R28

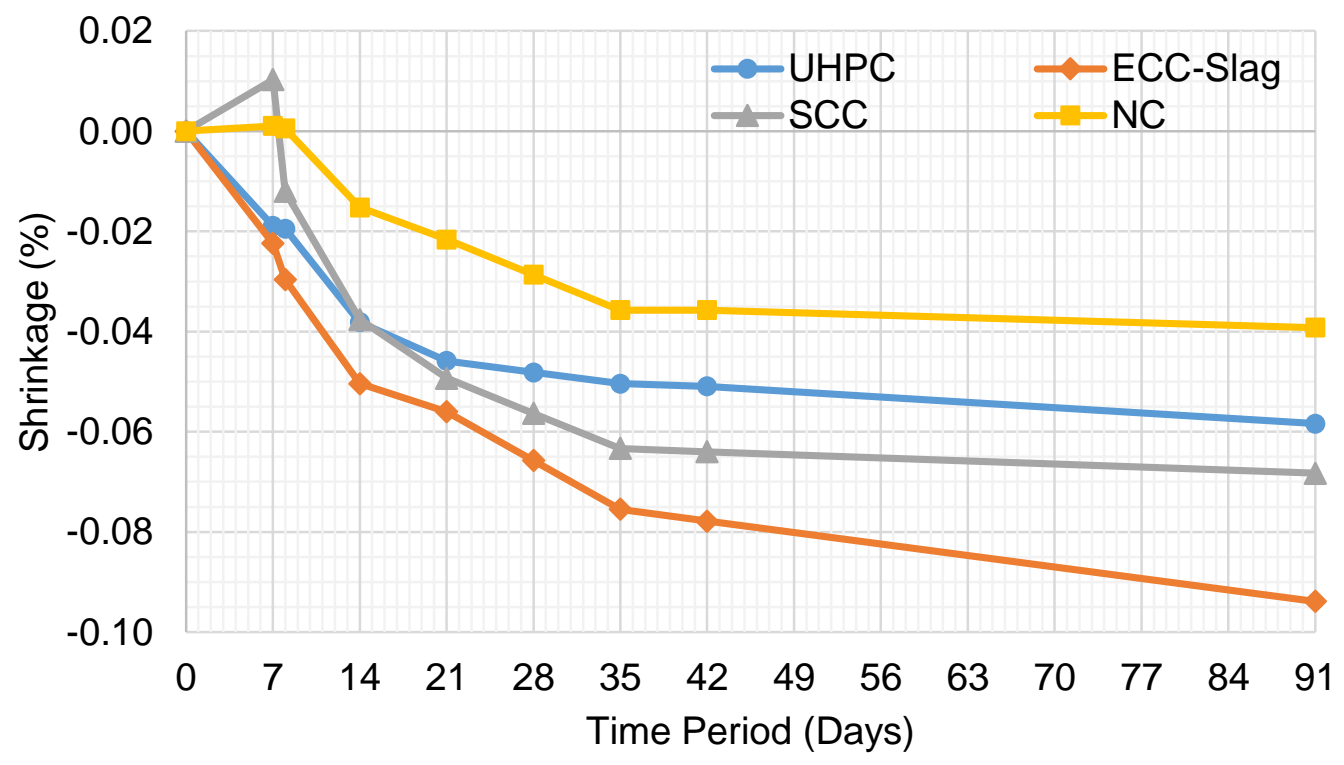

Figure 4-4: Combined Autogenous and Drying Shrinkage 
The drying shrinkage measurements (Figure 4-3) as it was specified by MTO LS-435R28 (2013) was started after 1-week submerging of samples in saturated lime-water. Therefore, the first week of the samples movement has not been considered although it may have a crucial impact on the bond strength particularly for materials with high amount of Portland cement and SCMs. Combined autogenous and drying shrinkage (Figure 4-4) was adjusted such a way to consider the first-week length change movement as well.

The author firmly believes that when it comes to the compatibility of repair materials to substrate the combined autogenous and drying shrinkage (Figure 4-4) is the better representative of the specimen movements. By comparing Figure 4-3 to Figure 4-4, UHPC and ECC-Slag produced a significant amount of autogenous shrinkage in the first week while they are even submerged in the saturated lime-water. This behaviour which is mainly due to their mix nature - not containing coarse aggregate and implementing the high amount of cement and SCMs - proves that the combined autogenous and drying shrinkage (Figure 4-4) is the better representative of the repair materials movements.

Hence, the NC demonstrated the minimum combined autogenous and drying shrinkage of $0.039 \%$ among other repair products after 91 days. UHPC - which showed very high autogenous shrinkage $(0.019 \%)$ in the first seven days while it was submerged in the lime-water - was ended up having the second minimum combined autogenous and drying shrinkage after 91 days (0.058\%). SCC which showed the highest amount of drying shrinkage $(0.079 \%)$ - Figure $4-3$ - had the second highest amount of combined autogenous and drying shrinkage with $0.068 \%$ after 91 days (Figure $4-4$ ). It is important to note that the drying shrinkage of SCC was measured to be higher than the combined autogenous and drying shrinkage since SCC was experienced $0.011 \%$ swelling while it was submerged in the saturated lime-water for the first week. ECC-Slag showed the maximum combined autogenous and drying shrinkage $(0.094 \%)$ after 91 days and the second maximum amount of drying shrinkage $(0.071 \%)$ after 84 days.

Based on the above analysis, NC and UHPC demonstrated the minimum length change movement. Thus, they can produce better bond strength with the substrate. In this regard, ECC-Slag performed the worst among other repair products. 


\subsubsection{Repeatability of the Shrinkage (Trial-2)}

Another 12 concrete prisms were tested to find out if the length change measurements were done in the previous section are reliable and repeatable. This time to be consistent with our preparation procedure specimens were moist cured $(\mathrm{RH}>98 \%)$ for 14 days instead of submerging in the saturated lime-water for 7 days. The average results of measuring 3 prisms for each of the repair product regarding the combined autogenous and drying shrinkage were presented in Figure 4-5.

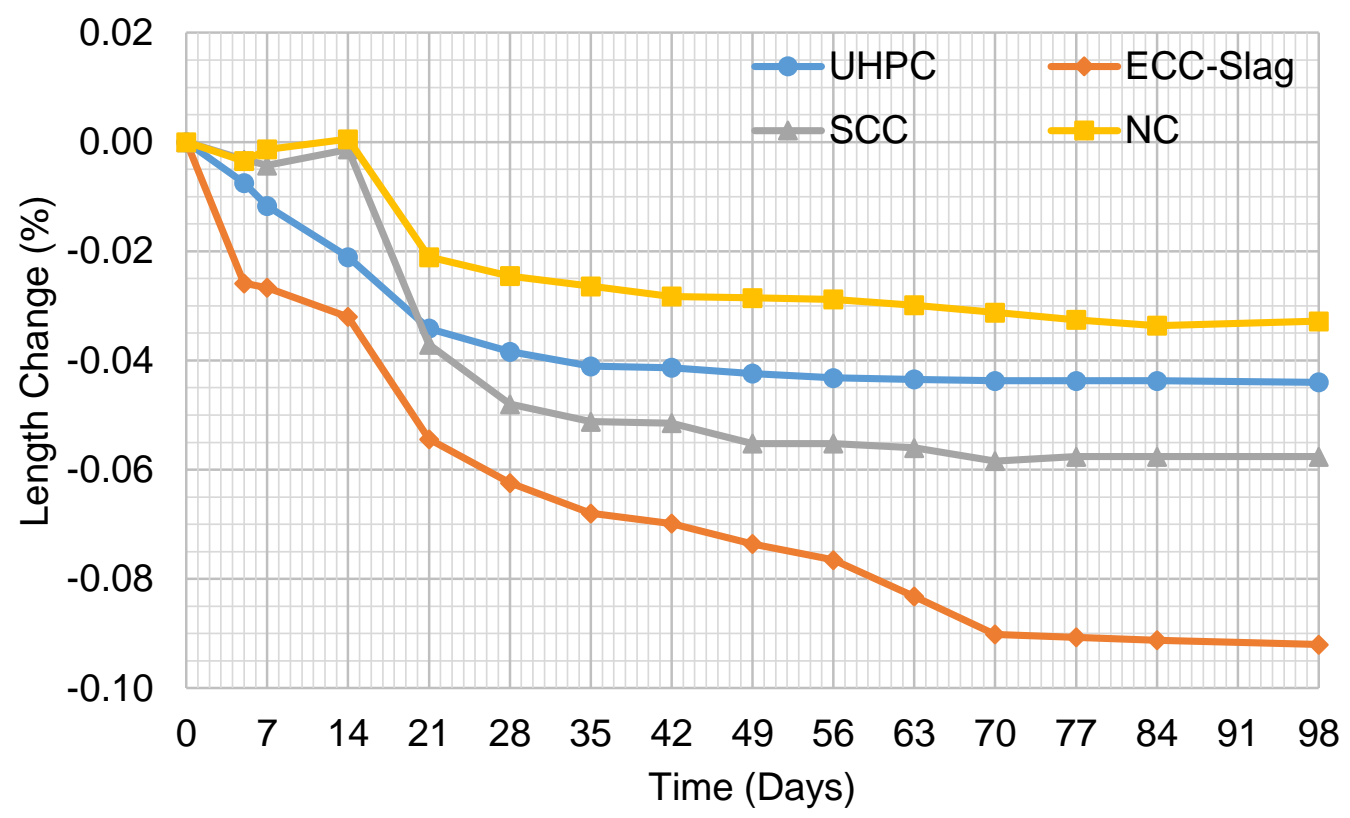

Figure 4-5: Repeatability of the Combined Autogenous and Drying Shrinkage

While comparing the shrinkage results of Figure 4-4 and Figure 4-5, it should be mentioned that since the specimens in the Trial-2 were moist cured for 14 days instead of 7 days submerging in the saturated lime-water (Trial-1 - according to standard), the comparison cannot be implemented at the same day.

In fact, the comparison should be made at the same duration which the samples were maintained in the shrinkage room. Therefore, the 35 days in the Trial-1 approximately represents to the $42(35+7)$ days in the Trial-2. This way at least both trials experienced the same period of shrinkage which is 28 days. 
Furthermore, Table 4-3 compares the results of these two trials for two specific shrinkage duration of 28 and 84 days. For Trial- 1 ( 7 days curing in lime-water), 35 and 91 days were selected, and for Trial-2 (14 days most curing), 42 and 98 days were picked.

Table 4-3: Comparison of the Combined Autogenous and Drying Shrinkage (\%)

\begin{tabular}{|c|c|c|c|c|c|c|c|c|}
\hline \multirow{2}{*}{$\begin{array}{l}\text { Time }^{1} \\
\text { (Days) }\end{array}$} & \multicolumn{4}{|c|}{7 days Submerged in Lime-water ${ }^{2}$} & \multicolumn{4}{|c|}{14 days Moist Curing ${ }^{3}$} \\
\hline & UHPC & ECC-Slag & Scc & NC & UHPC & ECC-Slag & SCC & NC \\
\hline 28 & 0.050 & 0.075 & 0.063 & 0.036 & 0.041 & 0.070 & 0.051 & 0.028 \\
\hline 84 & 0.058 & 0.094 & 0.068 & 0.039 & 0.044 & 0.092 & 0.058 & 0.033 \\
\hline
\end{tabular}

${ }^{1}$ Duration of keeping concrete prisms in the shrinkage room, ${ }^{2}$ Trial-1, ${ }^{3}$ Trial-2

By comparing the combined autogenous and drying shrinkage results in Figure 4-4 and Figure 4-5, it can be safely concluded that the length change behaviour of the repair materials regarding their order is unchanged. In another words, repair products revealed similar behaviour under two different trials with two different methods of curing. However, slightly decrease in the measured values between Trial-1 and Trial-2 (Table 4-3) were observed. The smaller shrinkage value of Trial-2 can be due to the more extended period of curing implemented for this trial (more probable reason), a different condition of the shrinkage room such as temperature and $\mathrm{RH}$ although it was monitored entirely, and even small uncertainties in the new repair product mixtures casted for the second time.

The principal conclusion from these two combined autogenous and drying shrinkage trials is that the type of curing does not affect the UHPC and ECC-Slag length change movement (shrinkage). As a matter of fact, these two types of repair products are very dense and impermeable in such a way that they do not take any access water from the environment for their hydration. Therefore, these two materials demonstrate high amount of autogenous shrinkage due to having very low W/B ratio, no coarse aggregate, and high amount of Portland cement and SCMs. Moreover, the relatively high drying shrinkage of the SCC can be explained due to its high W/B ratio and small coarse aggregate gradation implemented in its mixture. 


\subsection{Repairs under Freeze-Thaw Cycles with De-icing Salt (Phase-II)}

\subsubsection{Length Change of Concrete Prisms Following the Testing Conditions}

Fifteen concrete prisms ( 1 set for the Sub-A and 4 sets for the repair materials - each set consists of three prisms) were casted and conditioned as it was discussed in Section 3.3.3. The length change measurements were performed based on different conditions including shrinkage, curing, and freeze-thaw cycles with de-icing salt (Figure 4-6).

In Figure 4-6, the Sub-A prisms were casted and cured for 14 days. Immediately after, the reference length of specimens was measured, and samples were transferred to the shrinkage room for 70 days (first vertical black line). Then repair materials were applied on top, and the samples cured for 14 days (second vertical black line at 84 days). After that, all the concrete prisms were relocated to shrinkage room for approximately two months (third vertical black line at 147 days). The length change measurements were performed weekly. Ultimately, the 50 cycles of freezing and thawing with de-icing salt were completed on the specimens. The dotted vertical black lines represent the 5, 15, 25, and 50-cycles of freezing and thawing at 166, 188, 214, and 267 days, respectively.

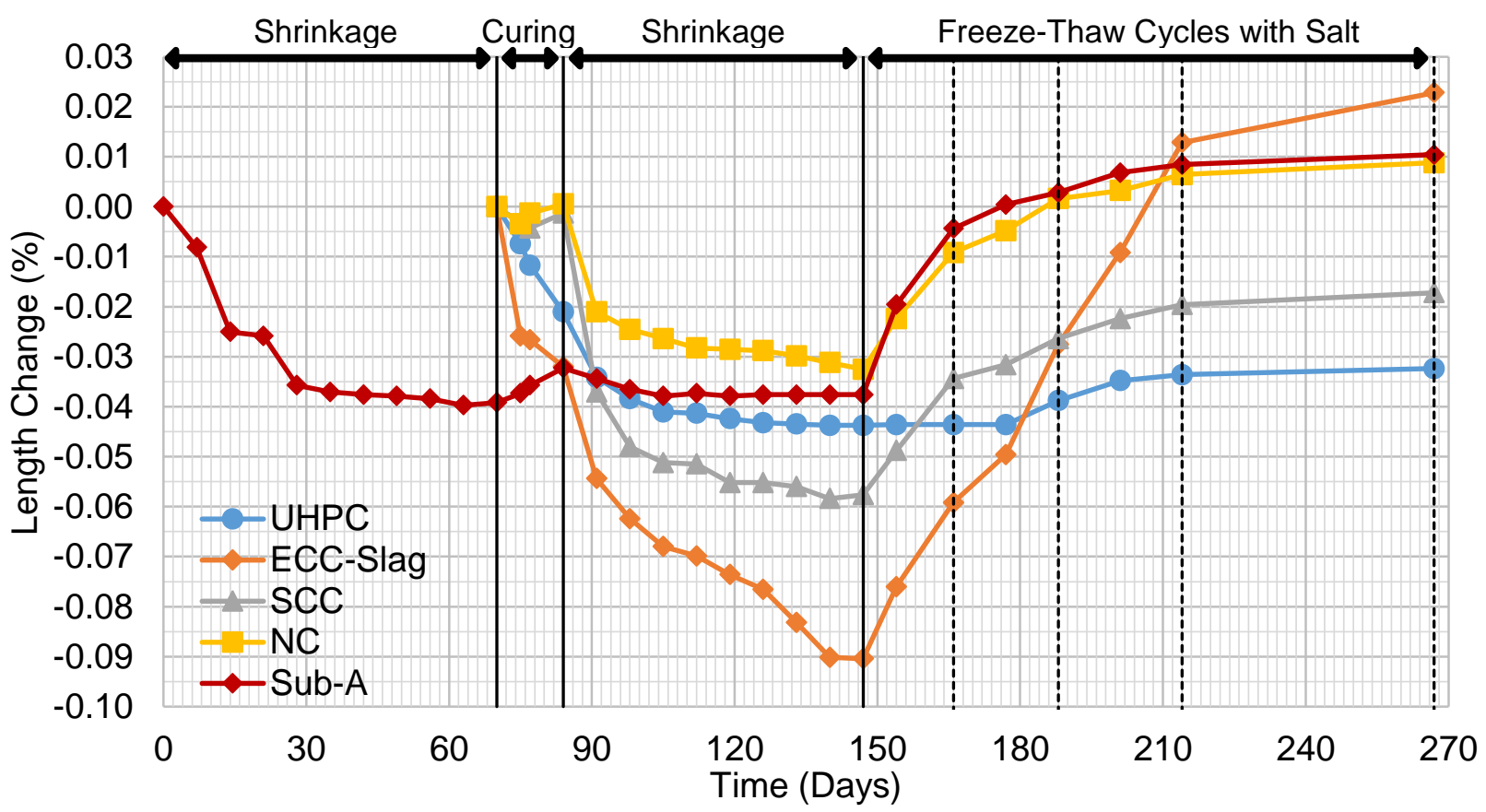

Figure 4-6: Length Change of Concrete Prisms Following the Testing Conditions 
By precisely studing Figure 4-6, the length change movement of the repairs in comparison to the Sub-A can be determined. Three important periods demand more attention while studying Figure 4-6 which they were explained as follow:

1. Period-1 (Curing)

Throughout the 14 days curing of the repair products from day 70 to 84 (between first and second vertical black line), it was recognized that UHPC and ECC-Slag were rapidly shrinking $(0.021 \%$ and $0.032 \%$, respectively) although the Sub-A was swelling $(0.007 \%)$. This complete difference in the direction of movement between Sub-A and these two repair products (UHPC and ECC-Slag) cause substantial bond stress loss. The NC and SCC length change movements were negligible. Consequently, NC and SCC were more dimensionally compatible with Sub-A in comparison to UHPC and ECC-Slag during the curing period.

2. Period-2 (Shrinkage)

2.1. During the first week of the shrinkage from day 84 to 91 (after the second vertical black line), it was detected that SCC among all the repair materials was experienced the highest amount of shrinkage $(0.036 \%)$. After SCC, ECC-Slag and NC had the second $(0.022 \%)$ and third $(0.021 \%)$ highest measured shrinkage, respectively. Interestingly, UHPC showed the minimum amount of shrinkage compared to the other repair products $(0.013 \%)$. Thus, it is expected to have higher bond stress loss for SCC and ECC-Slag during this period. The minimum bond stress loss is predicted to be for UHPC.

2.2. Within the second portion of the shrinkage period from day 91 to 147 (between second to the third vertical black line), ECC-Slag and SCC were undergone the first $(0.036 \%)$ and second $(0.021 \%)$ maximum shrinkage, while the Sub-A length change movement was almost zero $(0.003 \%)$. Again, UHPC and NC had the first $(0.010 \%)$ and second $(0.011 \%)$ the minimum amount of shrinkage, respectively. Hence, the same conclusion as the second period can be drawn.

3. Period-3 (F\&T)

During the cycles of freezing and thawing from day 147 to 267 (50-cycles) was realized that ECC-Slag swelling was unexpectedly high $(0.113 \%)$. This large 
swelling may result in some bond stress loss for ECC-Slag. Moreover, the NC length change swelling $(0.041 \%)$ was very close to Sub-A $(0.048 \%)$ which causes minimum bond stress loss for NC.

The first two periods (Curing and Shrinkage) affect the bond strength evaluation at 0 cycle of freezing and thawing with de-icing salt. However, the Period-3 (F\&T) directly impacts the bond strength measurements through the 5, 15, and 25-cycles. Therefore, it is necessary to analyze Period-3 (F\&T) more comprehensive for each cycle duration:

3.1. Throughout the first five cycles from day 147 to 166 (between the last vertical black line and the first dotted one) was noticed that the Sub-A, ECC-Slag, SCC, and NC started to swell but the UHPC experienced zero-length change movement. This behaviour of UHPC may cause some bond stress loss. Also, the length change expansion (swelling) of the ECC-Slag was considered to be high which is estimated to lead to some extra bond stress loss for this particular repair. The closest compatibility to Sub-A was found for NC and SCC.

3.2. Between 5 to 15 -cycles from day 166 to 188 (between first and second dotted lines) was noted that ECC-Slag has a very high length change swelling $(0.032 \%)$ compare to the Sub-A $(0.007 \%)$ and other repair products. Hence, some additional bond stress loss for ECC-Slag is predicted. Expect ECC-Slag, all other repair products' movements remained very close to the Sub-A. The closest compatibility to Sub-A with $0.007 \%$ swelling was found for SCC and UHPC with the expansion of $0.008 \%$ and $0.005 \%$, respectively. The length change enlargement of NC during this period was measured to be $0.011 \%$.

3.3. Repeatedly, exact same behaviour from ECC-Slag was seen between 15 to 25-cycles from day 188 to 214 (between second and third dotted lines). This time, the Sub-A length change expansion was even smaller than the previous 15 -cycles $(0.006 \%)$ but the ECC-Slag swelling measured to be higher $(0.040 \%)$. This may cause even more bond stress loss for ECC-Slag in comparison to the first 15-cycles. The length change expansion of UHPC $(0.005 \%)$, SCC $(0.007 \%)$, and NC $(0.005 \%)$ was found to be very close to SubA with $0.006 \%$ swelling during this period. 
Table 4-4 ranks the length change (dimensional compatibility) of repair products with respect to Sub-A through different periods based on the above discussion and analysis. Repair material with rank 1 has the worst dimensional compatibility with Sub-A and rank 4 represents the best compatibility. If two repair materials performance was the same or very close, the same ranking was assigned.

Table 4-4: Length Change Ranking Following the Testing Conditions (Phase-II)

\begin{tabular}{|c|c|c|c|c|c|}
\hline Period & Duration & UHPC & ECC-Slag & scc & NC \\
\hline Period-1 (Curing) & 14 days & 2 & 1 & 3 & 4 \\
\hline Period-2 (Shrinkage) & 63 days & & & & \\
\hline Period-2.1 (1W'-Shrinkage) & 7 days & 4 & 3 & 1 & 3 \\
\hline Period-2.2 (8W²-Shrinkage) & 56 days & 4 & 1 & 2 & 4 \\
\hline Period-3 $\left(50 \mathrm{C}^{3}-\mathrm{F} \& \mathrm{~T}^{4}\right)$ & 120 days & & & & \\
\hline Period-3.1 (5C-F\&T) & 19 days & 1 & 2 & 3 & 3 \\
\hline Period-3.2 (15C-F\&T) & 22 days & 4 & 1 & 4 & 3 \\
\hline Period-3.3 (25C-F\&T) & 26 days & 4 & 1 & 4 & 4 \\
\hline Period-3.4 (50C-F\&T) & 53 days & 4 & 2 & 4 & 4 \\
\hline Total & 197 days & 23 & 10 & 21 & 25 \\
\hline
\end{tabular}

${ }^{1}$ First week of the shrinkage, ${ }^{2}$ Another 8 weeks of the shrinkage period, ${ }^{3}$ Cycles, ${ }^{4}$ Freezing and thawing with de-icing salt

As it can be observed in Table 4-4, NC with the total ranking of 25 and UHPC with the overall ranking of 23 showed the best and second-best dimensional compatibility with respect to Sub-A. ECC-Slag with a complete ranking of 10 by far was the worst in this regard. Based on the mixture characteristics of the repair products and before this analysis, the assumption was that the UHPC has the strongest bond, followed by ECCSlag, SCC, and NC. However, the above analysis reveals that the majority of the ECCSlag and SCC bond strength will be lost due to length change movement adopting the testing conditions. By studying the Table 4-4 in more depth particularly for the freezing and thawing cycles with de-icing salt, the following behaviour of repair products is predicted: (1) the first and second maximum stress loss for UHPC and ECC-Slag during first 5-cycles, and (2) the first and second minimum stress loss (best dimensional compatibility or durability performance) for NC and UHPC between 5 to 25-cycles. 


\subsubsection{Bond Strength Testing Methods}

\subsubsection{Slant Shear Test}

\subsection{Rough Surface Texture}

The average slant shear testing results of 3 standard concrete cylinders for 4 repair products through 4 different cycles of freezing and thawing $(0,5,15$, and 25$)$ with rough surface texture (48 specimens in total) were summarized in Figure 4-7. In addition, Table 4-6 provides the SD and CV of the results for the rough surface texture.

As it can be observed in Figure 4-7, at 0-cycle, UHPC demonstrated the highest bond strength followed by other repair materials which they almost illustrated the same bond strength. At 5, 15, and 25-cycles, UHPC continued to have higher bond strength followed by SCC and NC. During the 15-cycles, the bond strength of SCC was measured to be marginally higher than NC. However, at 25-cycles, NC showed slightly better bond strength over SCC. In fact, NC demonstrated the second-best durability performance after UHPC under cycles of freezing and thawing with de-icing salt. The minimum durability performance was found for the ECC-Slag which completely lost its bond strength even before reaching 25-cycles (Figure 4-8 and Figure 4-9)

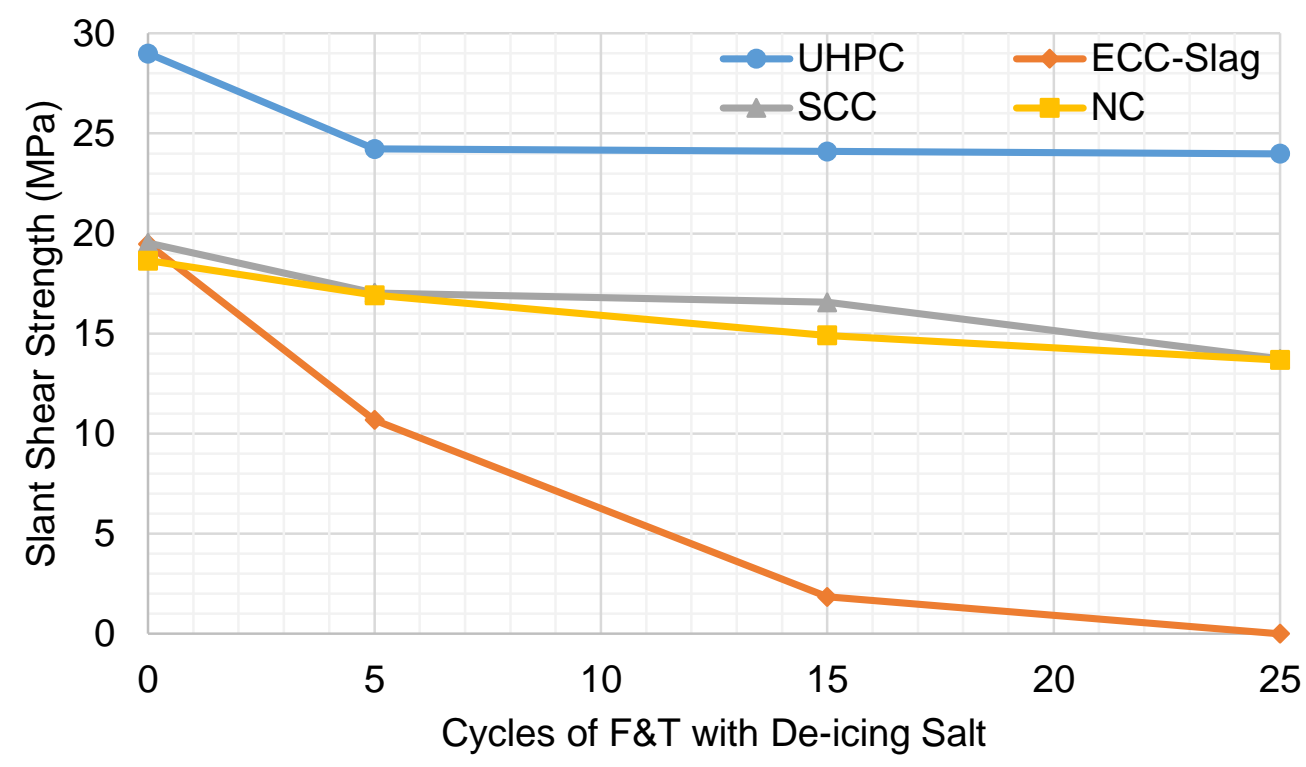

Figure 4-7: Bond Strength Results of Slant Shear Test-Rough Texture 
The term stress loss (\%) adopted in this chapter demonstrates the amount of stress which is lost through the cycles of freezing and thawing with respect to the first measurement (0-cycle) for each repair products (Table 4-5). In other words, this term determines the durability of the repair materials under freezing and thawing with de-icing salt. The stress loss with smaller percentage describes the better durability. The stress loss (\%) was calculated based on Eq. 4-3, where $\sigma_{i}$ is the stress at the initial cycles or period, and $\sigma_{x}$ represents the stress at any cycles or period.

$$
\text { Stress loss }(\%)=\left(\frac{\sigma_{i}-\sigma_{x}}{\sigma_{i}}\right) \times 100
$$

Eq. 4-3: Stress Loss (\%)

During the cycles, ECC-slag revealed the worst durability by having $100.00 \%$ stress loss which is an indication of having zero bond strength at 25-cycles. UHPC and NC exposed the best durability by possessing first and second minimum stress loss of $20.03 \%$ and $26.62 \%$ within 25 -cycles, respectively. The outcomes of stress loss (Table $4-5$ ) also confirms the prediction that was presented in Section 4.2.1 (Table 4-4) regarding UHPC and ECC-Slag to have the maximum stress loss in their first 5-cycles.

Table 4-5: Stress Loss (\%) for Slant Shear Test-Rough Texture

\begin{tabular}{ccccc}
\hline Cycles & UHPC & ECC-Slag & SCC & NC \\
\hline \hline 5C-F\&T & 18.82 & 45.09 & 12.79 & 9.26 \\
15C-F\&T & 19.67 & 90.51 & 15.20 & 20.02 \\
25C-F\&T & 20.03 & 100.00 & 29.71 & 26.62 \\
\hline
\end{tabular}

The results of SD and CV for rough surface texture were presented in Table 4-6. Generally, the NC demonstrated the best consistency and minimum result dispersion (SD) among other repairs followed by SCC, UHPC, and ECC-Slag. The results of the ECC-Slag were not calculated for 15 and 25-cycles due to the fact that at 15-cycles (Figure 4-8), two-third of the specimens completely lost their bond and none of the samples reached 25-cycles (Figure 4-9).

The CV is the more accurate parameter to compare repair products regarding the consistency of the results because its value is dimensionless. Therefore, concerning of 
having the minimum variation of results, NC showed the best performance with an average CV of $6.00 \%$ followed by SCC (6.83\%), UHPC (7.55\%), and ECC-Slag (8.99\%).

Table 4-6: SD and CV Results for Slant Shear Test-Rough Texture

\begin{tabular}{|c|c|c|c|c|c|c|c|c|}
\hline \multirow[b]{2}{*}{ Cycles } & \multicolumn{2}{|c|}{ UHPC } & \multicolumn{2}{|c|}{ ECC-Slag } & \multicolumn{2}{|c|}{ SCC } & \multicolumn{2}{|c|}{ NC } \\
\hline & $\begin{array}{c}\text { SD } \\
(\mathrm{MPa})\end{array}$ & $\begin{array}{l}\text { CV } \\
\text { (\%) }\end{array}$ & $\begin{array}{l}\text { SD } \\
(\mathrm{MPa})\end{array}$ & $\begin{array}{l}\text { CV } \\
\text { (\%) }\end{array}$ & $\begin{array}{c}\text { SD } \\
(\mathrm{MPa})\end{array}$ & $\begin{array}{l}\text { CV } \\
\text { (\%) }\end{array}$ & $\begin{array}{c}\text { SD } \\
(\mathrm{MPa})\end{array}$ & $\begin{array}{l}\text { CV } \\
\text { (\%) }\end{array}$ \\
\hline OC-F\&T & 3.21 & 10.69 & 1.24 & 6.39 & 1.30 & 6.64 & 0.27 & 1.47 \\
\hline 5C-F\&T & 0.42 & 1.74 & 1.24 & 11.59 & 0.87 & 5.13 & 1.49 & 8.81 \\
\hline $15 C-F \& T$ & 1.36 & 5.65 & $\mathrm{n} / \mathrm{a}$ & $\mathrm{n} / \mathrm{a}$ & 1.10 & 6.63 & 0.80 & 5.34 \\
\hline $25 C-F \& T$ & 2.91 & 12.13 & $\mathrm{n} / \mathrm{a}$ & $\mathrm{n} / \mathrm{a}$ & 1.23 & 8.93 & 1.15 & 8.38 \\
\hline Average & 1.98 & 7.55 & 1.24 & 8.99 & 1.13 & 6.83 & 0.93 & 6.00 \\
\hline
\end{tabular}
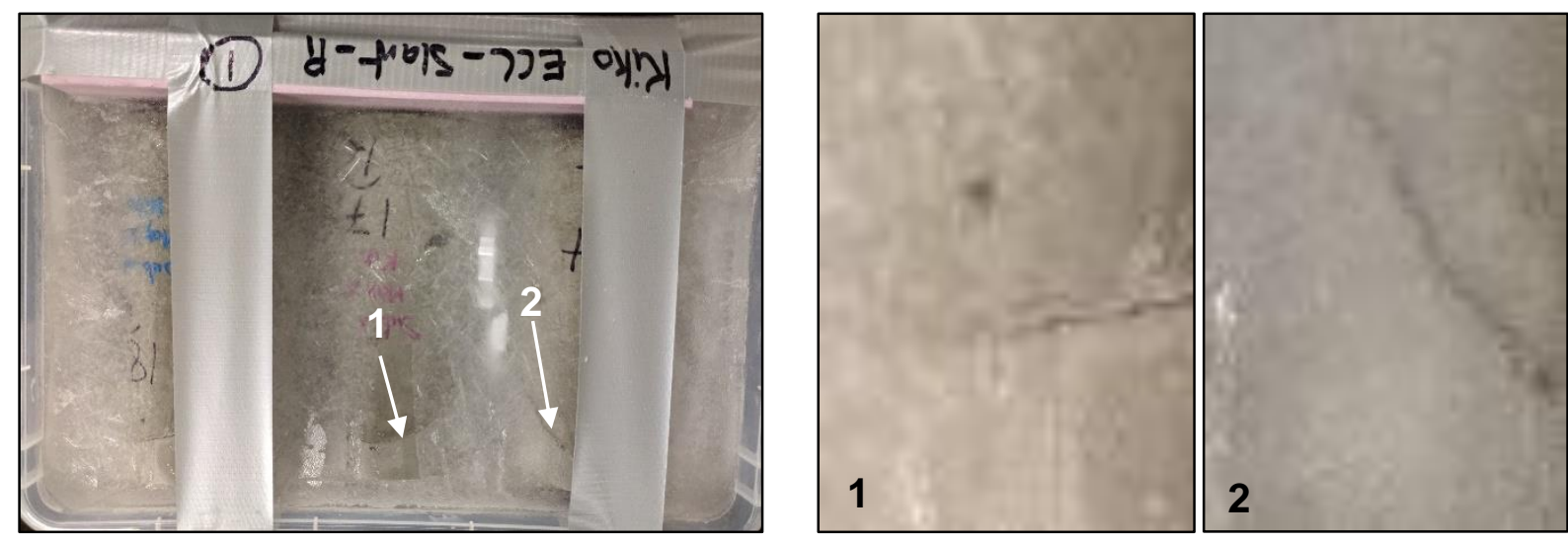

Figure 4-8: Slant Shear ECC-Slag Rough Samples at 15C-F\&T
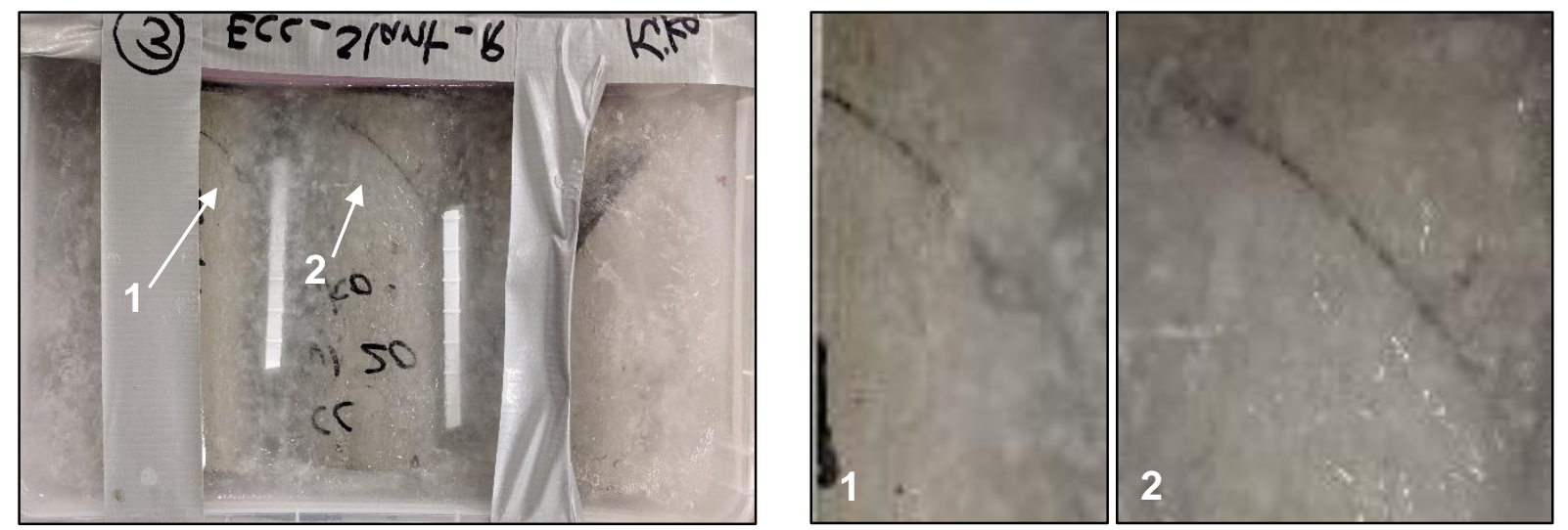

Figure 4-9: Slant Shear ECC-Slag Rough Samples at 21C-F\&T (Debonded) 


\subsection{Smooth Surface Texture}

Figure 4-10 illustrates results of the slant shear test for smooth surface texture. Again, UHPC started with the highest bond strength, followed by SCC and NC. According to Figure 4-10 and Table 4-7, Although NC began with lower bond strength compared to SCC, the bond strength loss of NC (45.88\%) through the 25-cycles was lower than SCC (76.35\%). Consequently, NC showed better durability and higher bond strength at 25cycles which is the exact similar conclusion as it was made for the rough surface texture.

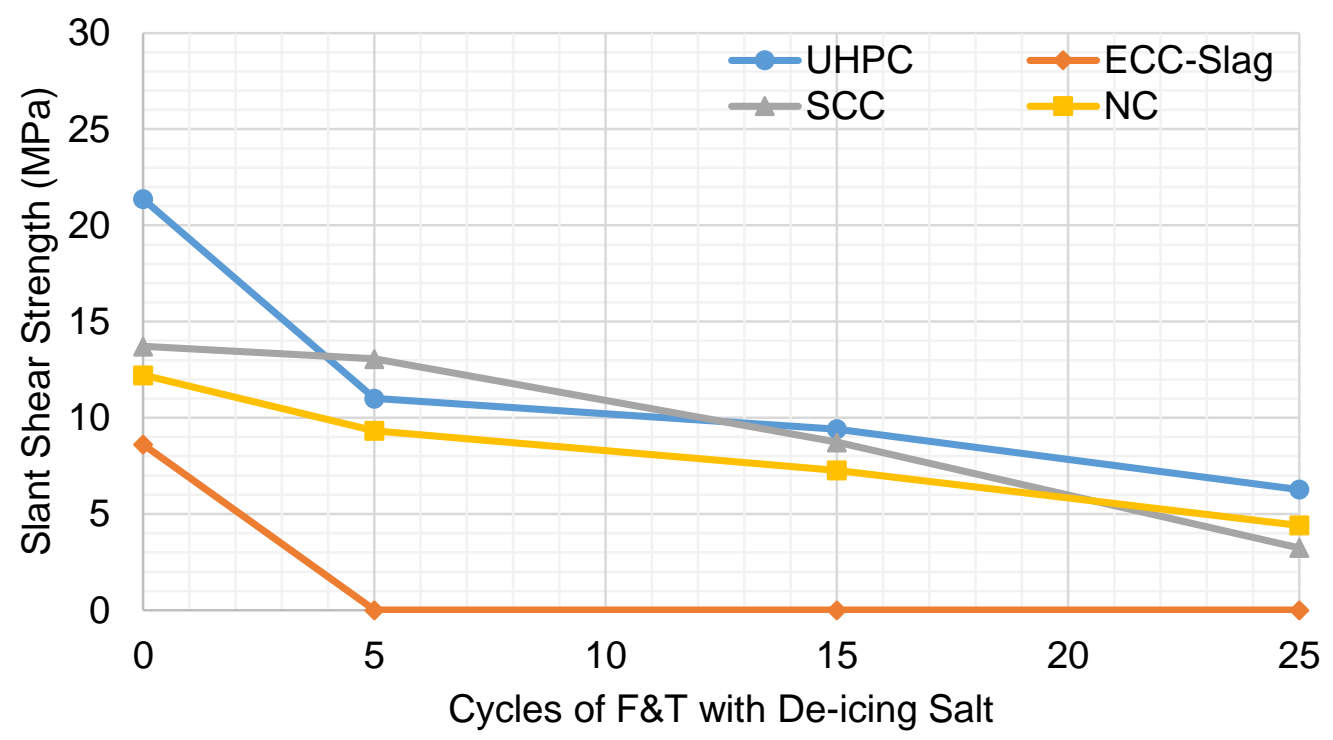

Figure 4-10: Bond Strength Results of Slant Shear Test - Smooth Texture

It is also important to note that first and second maximum stress loss was found to be for ECC-Slag $(100.00 \%)$ and UHPC $(52.11 \%)$ at first 5-cycles which again satisfy the prediction was made based on the length change of prisms (Section 4.2.1). During the first 5-cycles, the minimum stress loss was calculated for SCC (4.68\%). Between 5 to 25cycles, UHPC had the minimum stress loss of $20.56 \%$ followed by NC $(22.20 \%)$.

Table 4-7: Stress Loss (\%) for Slant Shear Test-Smooth Texture

\begin{tabular}{ccccc}
\hline Cycles & UHPC & ECC-Slag & SCC & NC \\
\hline 5C-F\&T & 52.11 & 100.00 & 4.68 & 23.68 \\
15C-F\&T & 58.99 & 100.00 & 36.29 & 40.51 \\
25C-F\&T & 72.67 & 100.00 & 76.35 & 45.88 \\
\hline
\end{tabular}


Table 4-8: SD and CV Results for Slant Shear Test-Smooth Texture

\begin{tabular}{|c|c|c|c|c|c|c|c|c|}
\hline \multirow[b]{2}{*}{ Cycles } & \multicolumn{2}{|c|}{ UHPC } & \multicolumn{2}{|c|}{ ECC-Slag } & \multicolumn{2}{|c|}{ SCC } & \multicolumn{2}{|c|}{ NC } \\
\hline & $\begin{array}{c}\text { SD } \\
(\mathrm{MPa})\end{array}$ & $\begin{array}{l}\text { CV } \\
\text { (\%) }\end{array}$ & $\begin{array}{c}\text { SD } \\
(\mathrm{MPa})\end{array}$ & $\begin{array}{l}\text { CV } \\
\text { (\%) }\end{array}$ & $\begin{array}{c}\text { SD } \\
(\mathrm{MPa})\end{array}$ & $\begin{array}{l}\text { CV } \\
\text { (\%) }\end{array}$ & $\begin{array}{c}\text { SD } \\
(\mathrm{MPa})\end{array}$ & $\begin{array}{l}\text { CV } \\
(\%)\end{array}$ \\
\hline OC-F\&T & 2.83 & 12.51 & 1.84 & 21.36 & 0.71 & 5.20 & 0.27 & 11.29 \\
\hline 5C-F\&T & 0.64 & 5.91 & $\mathrm{n} / \mathrm{a}$ & $\mathrm{n} / \mathrm{a}$ & 1.09 & 8.35 & 1.49 & 9.96 \\
\hline 15C-F\&T & 1.69 & 18.20 & $\mathrm{n} / \mathrm{a}$ & $\mathrm{n} / \mathrm{a}$ & 0.86 & 9.86 & 0.80 & 4.07 \\
\hline 25C-F\&T & 0.06 & 1.01 & $\mathrm{n} / \mathrm{a}$ & $\mathrm{n} / \mathrm{a}$ & 0.24 & 7.28 & 1.15 & 13.65 \\
\hline Average & 1.31 & 9.41 & n/a & $n / a$ & 0.73 & 7.67 & 0.93 & 9.74 \\
\hline
\end{tabular}

The CV results for smooth surface texture (Table 4-8) demonstrated that SCC with an average $\mathrm{CV}$ of $7.67 \%$ had the minimum standard error between repairs accompanied by UHPC $(9.41 \%)$ and NC (9.74\%). The results of the ECC-Slag were not calculated since all the samples completely lost their bond at 5-cycles (Figure 4-11and Figure 4-12).
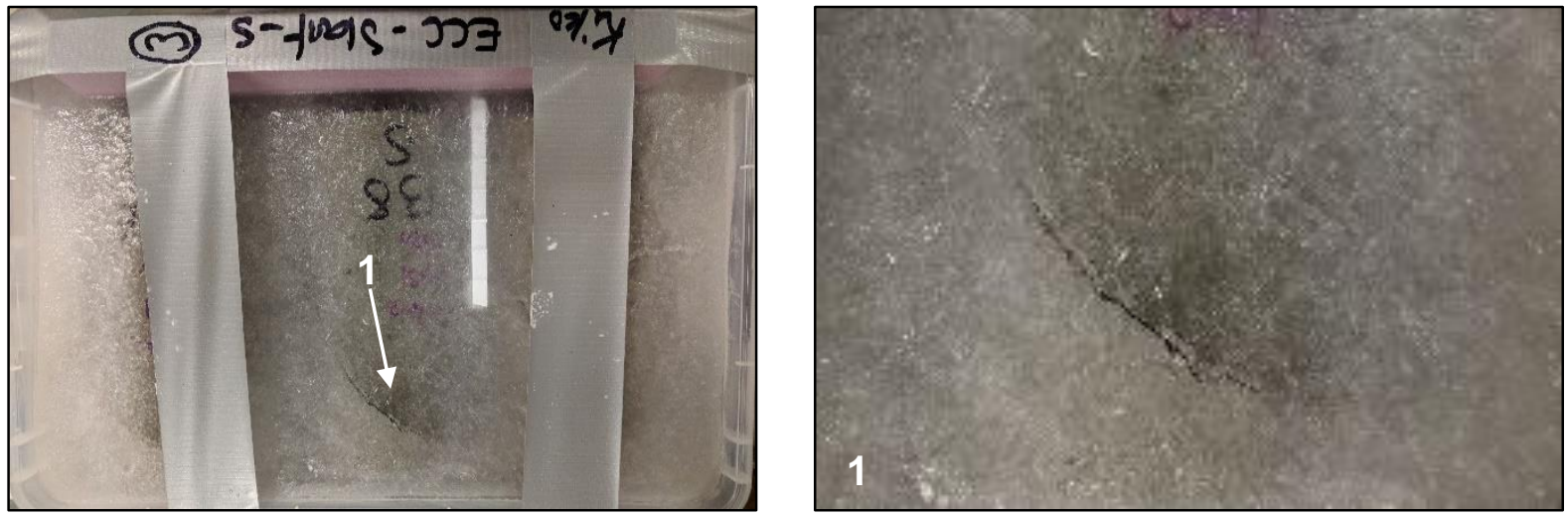

Figure 4-11: Slant Shear ECC-Slag Smooth Samples at 2C-F\&T
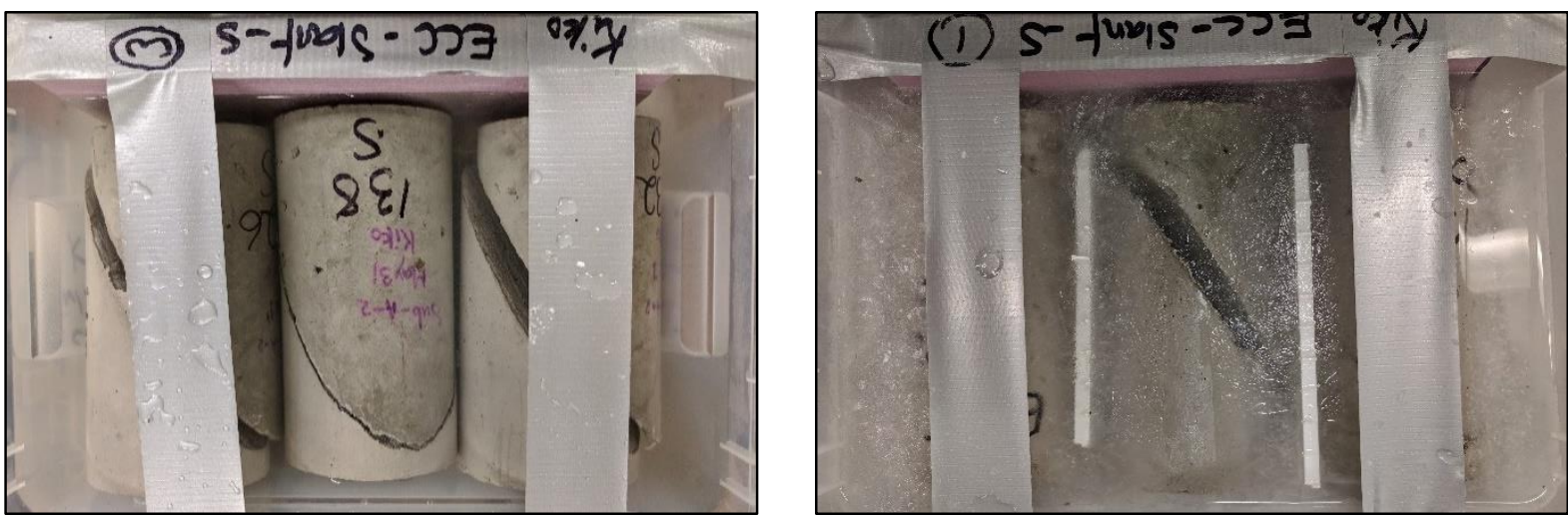

Figure 4-12: Slant Shear ECC-Slag Smooth Samples at 5C-F\&T 


\subsection{Surface Roughness Effect}

In order to examine the surface roughness effect under slant shear test, four different graphs describing the average bond strength of each repair materials for rough and smooth surface texture through cycles of freezing and thawing with de-icing salt were represented (Figure 4-13). Furthermore, to have a better idea of the dispersion of the results from average, the error bars demonstrating SD were implemented. If the error bars could not be identified in Figure 4-13, it means the standard deviation (SD) is minimal.
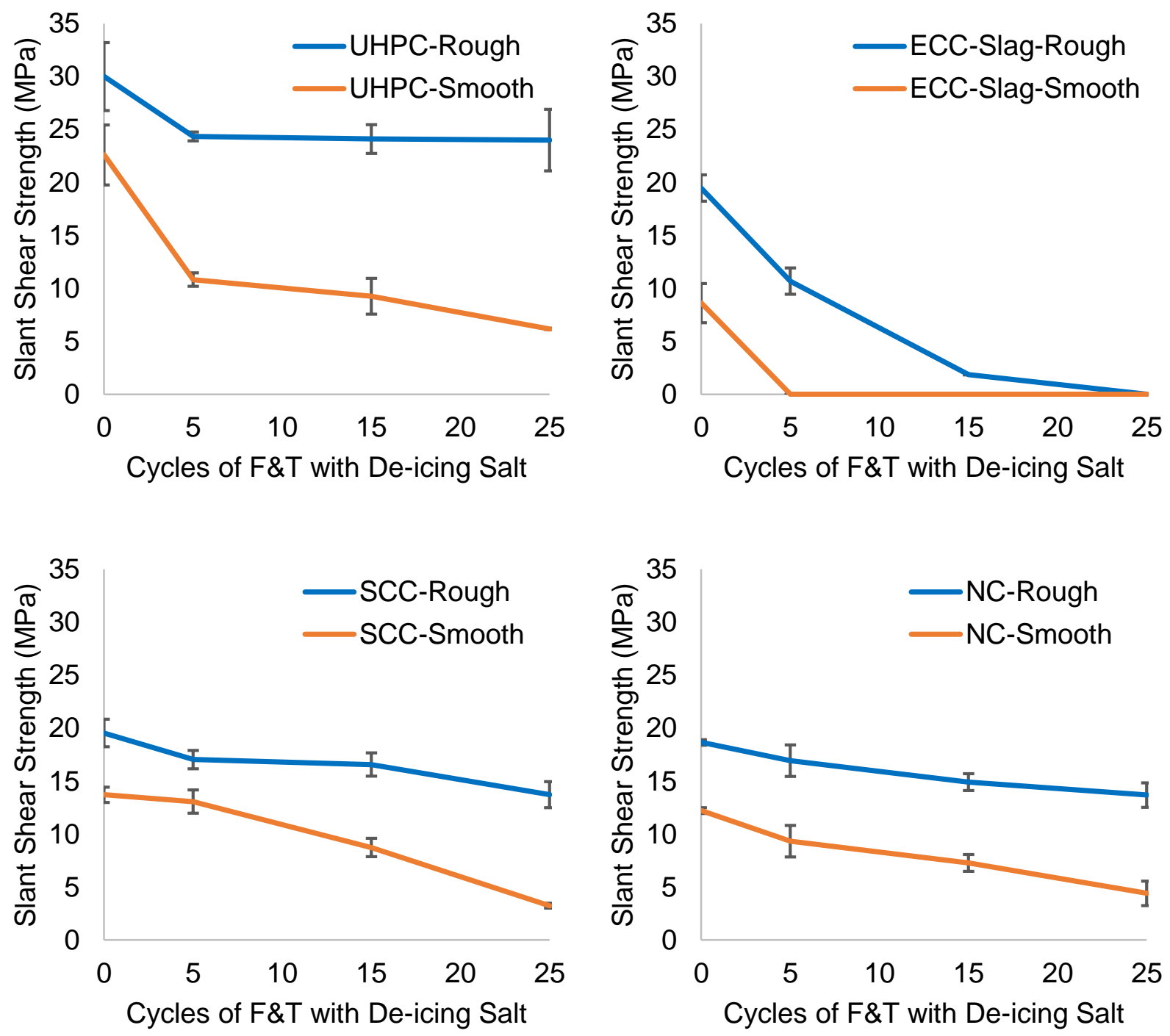

Figure 4-13: Surface Roughness Effect for Slant Shear Test 
Besides, to adequately evaluate the surface roughness effect, the term stress improvement (\%) between two different surface textures within the same cycle was defined. The stress improvement was calculated According to Eq. 4-4, where $\sigma_{r}$ represents the stress for rough surface texture, $\sigma_{s}$ is the stress for the smooth surface texture during the same period or cycles.

$$
\text { Stress Imp. }(\%)=\left(\frac{\sigma_{r}-\sigma_{s}}{\sigma_{r}}\right) \times 100
$$

Eq. 4-4: Stress Improvement (\%)

Hence, the positive stress improvement indicates the higher bond strength for rough over smooth surface texture. Results of the stress improvement calculation were provided in Table 4-9.

Table 4-9: Stress Improvement (\%) for Slant Shear Test

\begin{tabular}{ccccc}
\hline Cycles & UHPC & ECC-Slag & SCC & NC \\
\hline 0C-F\&T & 32.73 & 126.04 & 42.48 & 52.60 \\
5C-F\&T & 124.99 & + & 30.36 & 81.43 \\
15C-F\&T & 159.96 & + & 89.65 & 105.16 \\
25C-F\&T & 288.36 & $\mathrm{n} / \mathrm{a}$ & 323.48 & 106.88 \\
\hline Average & $\mathbf{1 5 1 . 5 1}$ & $\mathbf{1 2 6 . 0 4}$ & $\mathbf{1 2 1 . 4 9}$ & $\mathbf{8 6 . 5 2}$ \\
\hline
\end{tabular}

According to the above table and figures, increasing surface roughness enhances the bond strength of slant shear test no matter the type of materials and cycles of freezing and thawing with de-icing salt. The UHPC with an average of $151.51 \%$ had the highest bond strength improvement followed by SCC (121.49\%) and NC (86.52\%). For ECCSlag, the stress improvements were not reported at 5, 15, and 25-cycles since the bond strength measurements for smooth surface texture were recorded to be zero throughout 5,15 , and 25 -cycles of freezing and thawing. 


\subsubsection{Splitting Tensile Test}

\subsection{Rough Surface Texture}

Figure 4-14 illustrates the average splitting tensile strength results of crushing 48 standard concrete cylinders ( 4 materials, 4 different freeze-thaw cycles, and 3 specimens tested for each) for rough surface texture. At 0-cycle, UHPC revealed the highest bond strength followed by SCC, NC, and ECC-Slag. After 25-cycles, UHPC continued to show the highest bond strength followed by SCC, NC, and ECC-Slag.

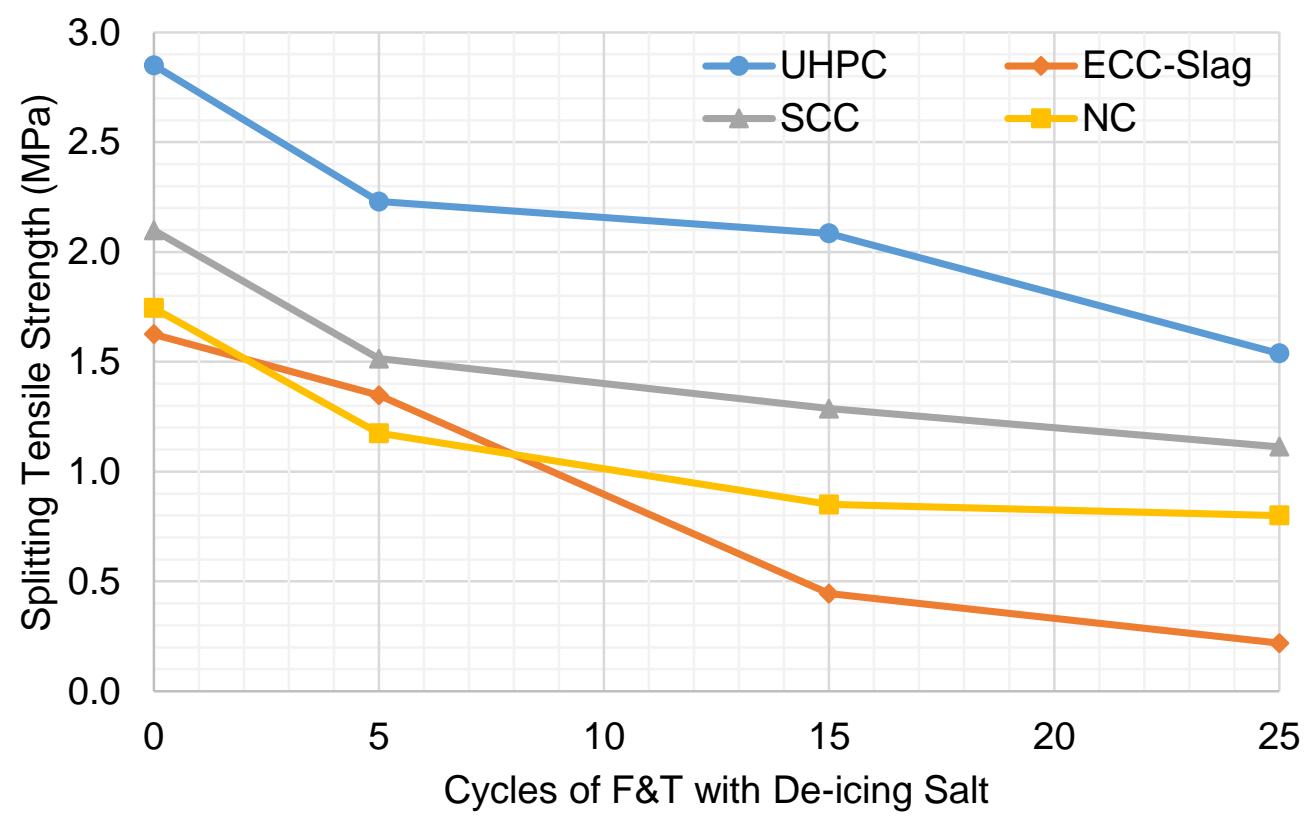

Figure 4-14: Bond Strength Results of Splitting Tensile Test - Rough Texture

The stress loss results (Table 4-10) within 25-cycles demonstrated the first and second maximum stress loss for ECC-Slag (86.55\%) and NC (54.16\%), respectively. The stress loss performance of UHPC and SCC was very similar by having $46.05 \%$ and $46.95 \%$, respectively. Between the 5 to 25-cycles, ECC-Slag represented the highest stress loss (69.45\%), followed by UHPC (24.28\%), NC (21.51\%), and SCC (19.13\%). Therefore, ECC-Slag showed the minimum durability performance throughout the 25-cycles. Since the results of the stress loss for UHPC, SCC, and NC were reported to be very close to each other, it is reasonable to conclude that the predicted behaviour in Section 4.2.1 was agreed. Figure 4-15 and Figure 4-16 demonstrate the representative samples at 5-cycles. 
Table 4-10: Stress Loss (\%) for Splitting Tensile Test-Rough Texture

\begin{tabular}{ccccc}
\hline Cycles & UHPC & ECC-Slag & SCC & NC \\
\hline \hline 5C-F\&T & 21.77 & 17.11 & 27.82 & 32.66 \\
15C-F\&T & 26.88 & 72.69 & 38.69 & 51.27 \\
25C-F\&T & 46.05 & 86.55 & 46.95 & 54.16 \\
\hline
\end{tabular}

The results of SD and CV were presented in Table 4-11. The UHPC and SCC showed first and second best consistency or minimum dispersion of the results (CV) among other repair products. The results of CV for the ECC-Slag were incomparably the worst. The very high CV value for ECC-Slag particularly at 25 -cycles ( $87.12 \%)$ is due to having zero bond strength measurement for one of the specimens.

Table 4-11: SD and CV Results for Splitting Tensile Test-Rough Texture

\begin{tabular}{|c|c|c|c|c|c|c|c|c|}
\hline \multirow[b]{2}{*}{ Cycles } & \multicolumn{2}{|c|}{ UHPC } & \multicolumn{2}{|c|}{ ECC-Slag } & \multicolumn{2}{|c|}{ SCC } & \multicolumn{2}{|c|}{ NC } \\
\hline & $\begin{array}{c}\text { SD } \\
\text { (MPa) }\end{array}$ & $\begin{array}{l}\text { CV } \\
(\%)\end{array}$ & $\begin{array}{c}\text { SD } \\
\text { (MPa) }\end{array}$ & $\begin{array}{l}\text { CV } \\
\text { (\%) }\end{array}$ & $\begin{array}{c}\text { SD } \\
\text { (MPa) }\end{array}$ & $\begin{array}{l}\text { CV } \\
(\%)\end{array}$ & $\begin{array}{c}\text { SD } \\
\text { (MPa) }\end{array}$ & $\begin{array}{l}\text { CV } \\
(\%)\end{array}$ \\
\hline OC-F\&T & 0.17 & 5.99 & 0.31 & 18.90 & 0.05 & 2.44 & 0.19 & 10.61 \\
\hline 5C-F\&T & 0.08 & 3.64 & 0.21 & 15.92 & 0.11 & 7.24 & 0.06 & 4.99 \\
\hline $15 C-F \& T$ & 0.13 & 6.12 & 0.04 & 9.10 & 0.10 & 8.05 & 0.08 & 9.97 \\
\hline 25C-F\&T & 0.06 & 4.04 & 0.19 & 87.12 & 0.04 & 3.91 & 0.06 & 8.07 \\
\hline Average & 0.11 & 4.95 & 0.19 & 32.76 & 0.08 & 5.41 & 0.10 & 8.41 \\
\hline
\end{tabular}

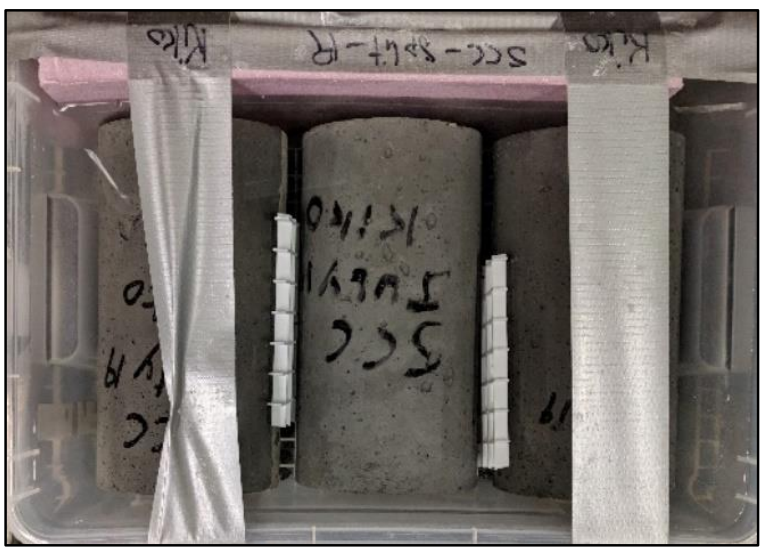

Figure 4-15: Splitting Tensile SCC Rough Samples at 5C-F\&T

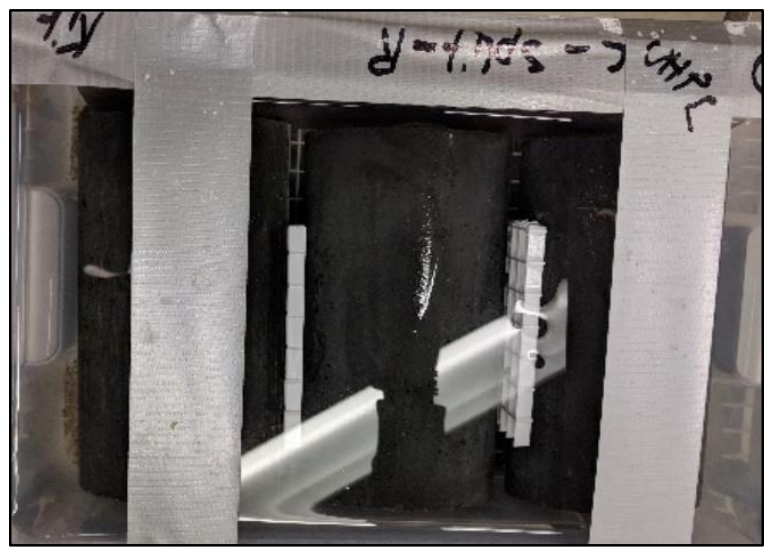

Figure 4-16: Splitting Tensile UHPC Rough Samples at 5C-F\&T 


\subsection{Smooth Surface Texture}

Figure 4-17 represents the results of the splitting tensile for smooth surface texture (48 specimens). The behaviour of repair products at 0 -cycle was recognized to be similar to rough texture with only one exemption that ECC-Slag performed slightly better than NC.

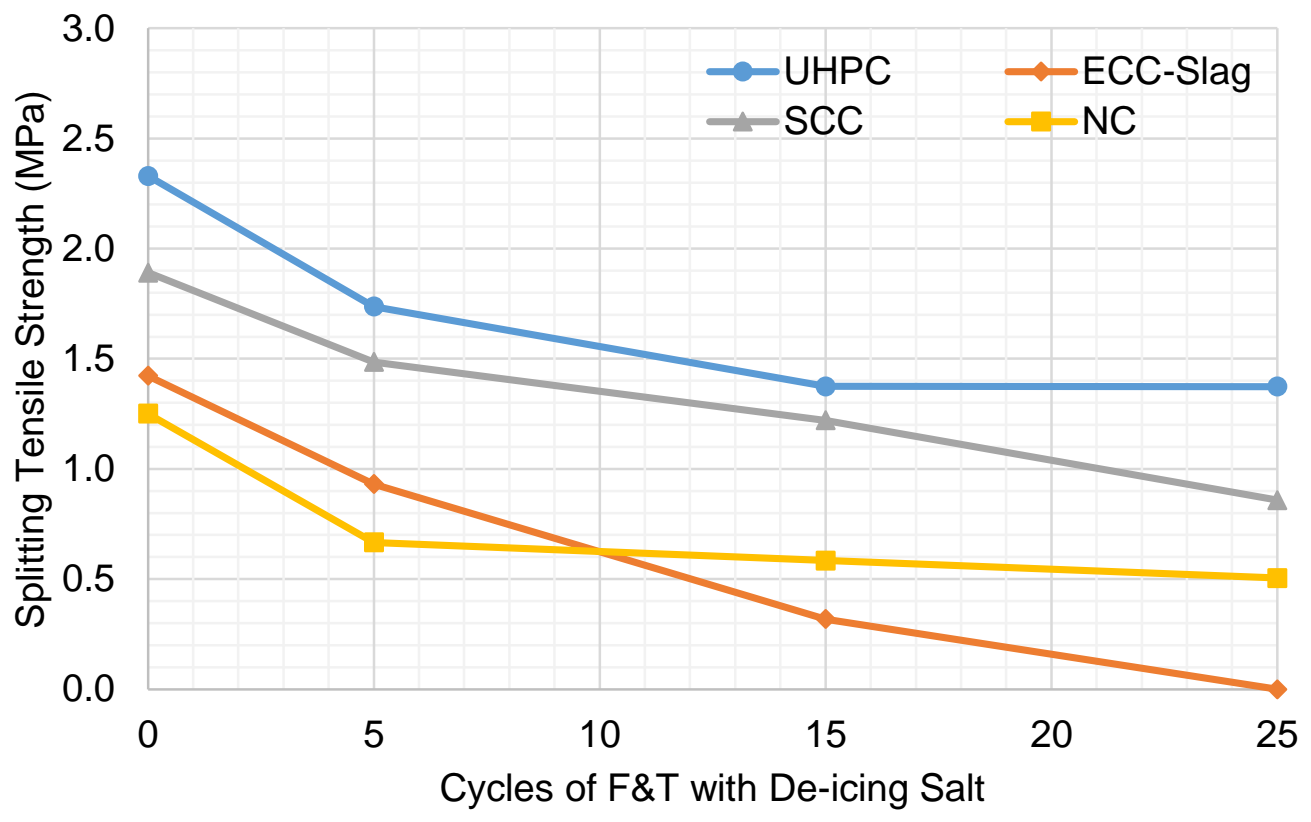

Figure 4-17: Bond Strength Results of Splitting Tensile Test - Smooth Texture

The maximum stress loss of $100.00 \%$ (complete debonding) was detected to be for ECCSlag at 25-cycles (Figure 4-18) which proves the prediction was stated on the conditioning length change (Section 4.2.1). During the first 5-cycles, the maximum stress loss was calculated for NC (46.74\%) followed by ECC-Slag (34.57\%), UHPC (25.48\%), and SCC (21.54\%). Among 5 to 25 -cycles, NC and UHPC had the first and second minimum stress loss of $12.96 \%$ and $15.65 \%$, respectively, followed by SCC (33.16\%) and ECC-Slag $(65.43 \%)$. This results also validate the estimation was made on Section 4.2.1.

Table 4-12: Stress Loss (\%) for Splitting Tensile Test - Smooth Texture

\begin{tabular}{ccccc}
\hline Cycles & UHPC & ECC-Slag & SCC & NC \\
\hline 5C-F\&T & 25.48 & 34.57 & 21.45 & 46.74 \\
15C-F\&T & 40.98 & 77.67 & 35.44 & 53.33 \\
25C-F\&T & 41.04 & 100.00 & 54.61 & 59.69 \\
\hline
\end{tabular}


As stated in Table 4-13, the highest average CV reported for ECC-Slag (12.48\%) followed by UHPC $(9.77 \%)$, SCC $(7.41 \%)$, and NC $(7.16 \%)$. For all the repair products the average CV values were in the acceptable range $(<15 \%)$. The results of the ECC-Slag were not calculated at 25-cycles because all the samples completely lost their bond before even reaching 25 cycles of freezing and thawing with de-icing salt (Figure 4-18).

Table 4-13: SD and CV Results for Splitting Tensile Test - Smooth Texture

\begin{tabular}{|c|c|c|c|c|c|c|c|c|}
\hline \multirow[b]{2}{*}{ Cycles } & \multicolumn{2}{|c|}{ UHPC } & \multicolumn{2}{|c|}{ ECC-Slag } & \multicolumn{2}{|c|}{ SCC } & \multicolumn{2}{|c|}{ NC } \\
\hline & $\begin{array}{c}\text { SD } \\
\text { (MPa) }\end{array}$ & $\begin{array}{l}\text { CV } \\
(\%)\end{array}$ & $\begin{array}{c}\text { SD } \\
\text { (MPa) }\end{array}$ & $\begin{array}{l}\text { CV } \\
(\%)\end{array}$ & $\begin{array}{c}\text { SD } \\
\text { (MPa) }\end{array}$ & $\begin{array}{l}\text { CV } \\
(\%)\end{array}$ & $\begin{array}{l}\text { SD } \\
\text { (MPa) }\end{array}$ & $\begin{array}{l}\text { CV } \\
(\%)\end{array}$ \\
\hline OC-F\&T & 0.05 & 2.20 & 0.11 & 7.68 & 0.14 & 7.26 & 0.13 & 10.34 \\
\hline 5C-F\&T & 0.32 & 18.27 & 0.09 & 10.13 & 0.09 & 5.95 & 0.06 & 8.69 \\
\hline 15C-F\&T & 0.15 & 10.60 & 0.06 & 19.62 & 0.04 & 3.09 & 0.04 & 6.65 \\
\hline 25C-F\&T & 0.11 & 7.99 & $n / a$ & $\mathrm{n} / \mathrm{a}$ & 0.11 & 13.36 & 0.01 & 2.96 \\
\hline Average & 0.16 & 9.77 & 0.09 & 12.48 & 0.09 & 7.41 & 0.06 & 7.16 \\
\hline
\end{tabular}
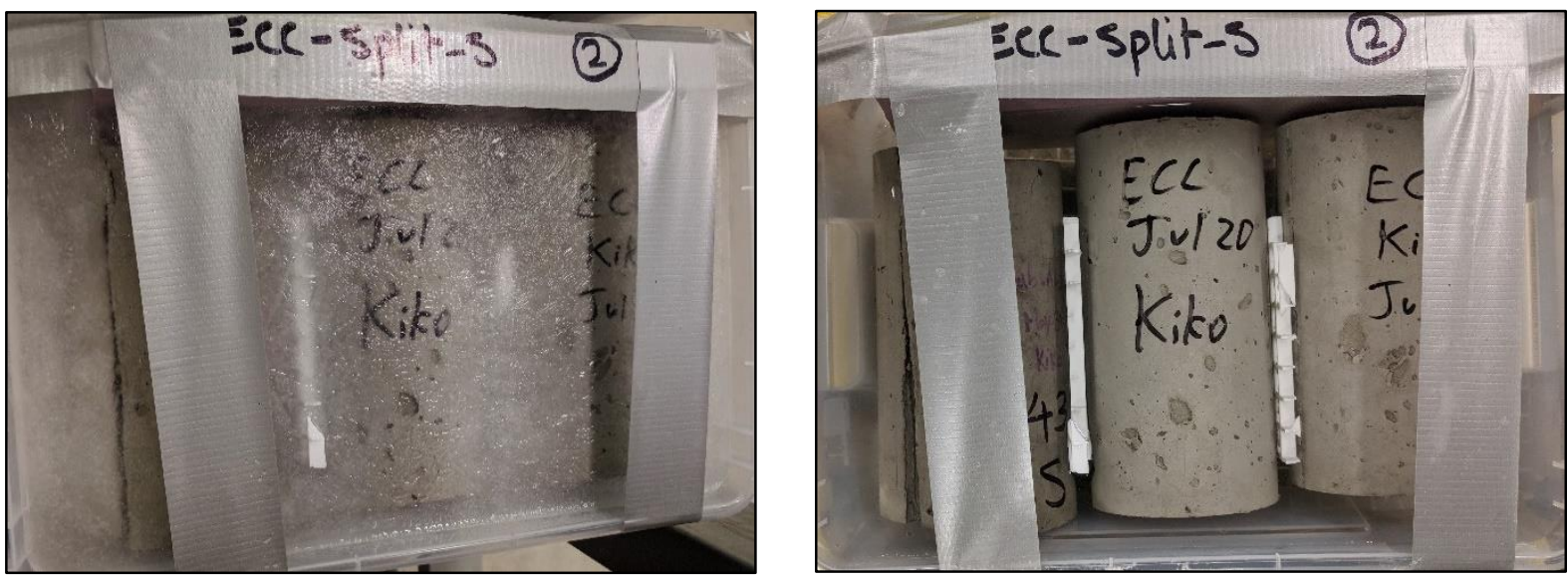

Figure 4-18: ECC-Slag Splitting Tensile Samples with Smooth Texture at 21C-F\&T 


\subsection{Surface Roughness Effect}

To entirely evaluate the surface roughness effect under splitting tensile test, the rough and smooth surface texture results within the freeze-thaw cycles for each of the four repair products were shown in four separate graphs (Figure 4-19). Besides, to accurately interpret the dispersion of the results from average, the error bars demonstrating SD were implemented. If the error bars could not be noticed in Figure 4-19, it is an evidence of having very small dispersion of the results from the average (SD).
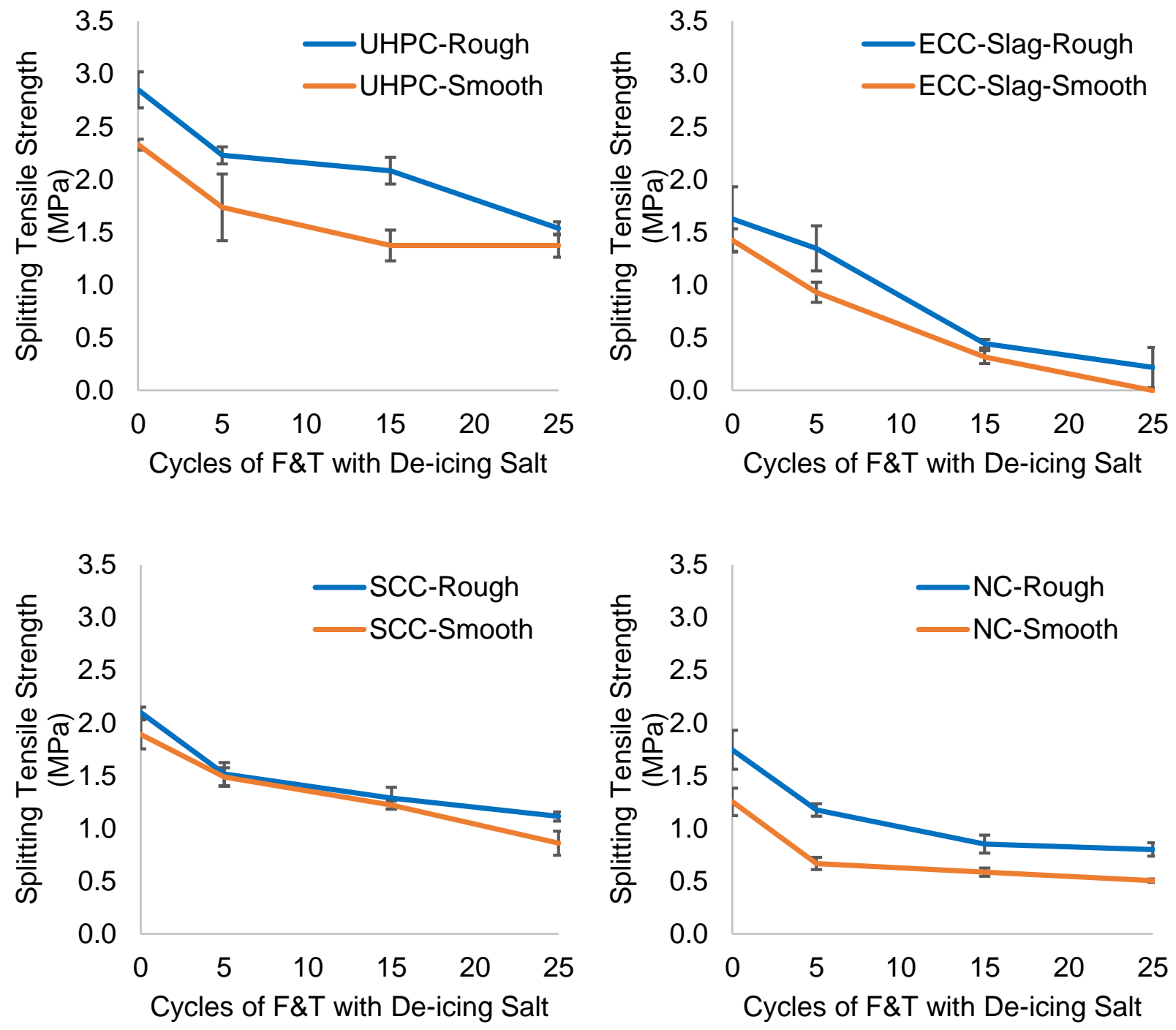

Figure 4-19: Surface Roughness Effect for Splitting Tensile Test 
The stress improvement (\%) results for splitting tensile test are also listed in Table 4-14. As it can be observed in Table 4-14, the stress improvement results are all positive which confirm the enhancement of the increasing surface roughness for splitting tensile test. Among the repair materials, NC showed the maximum average stress improvement of $55.00 \%$ followed by ECC-Slag (32.84\%) and UHPC (28.56\%). The minimum average stress improvement (surface roughness effect) was rated for SCC with $11.98 \%$.

Table 4-14: Stress Improvement (\%) for Splitting Tensile Test

\begin{tabular}{ccccc}
\hline Cycles & UHPC & ECC-Slag & SCC & NC \\
\hline \hline OC-F\&T & 22.33 & 14.20 & 10.95 & 39.47 \\
5C-F\&T & 28.42 & 44.67 & 1.95 & 76.33 \\
15C-F\&T & 51.57 & 39.65 & 5.36 & 45.60 \\
25C-F\&T & 11.93 & $\mathrm{n} / \mathrm{a}$ & 29.66 & 58.60 \\
\hline Average & $\mathbf{2 8 . 5 6}$ & $\mathbf{3 2 . 8 4}$ & $\mathbf{1 1 . 9 8}$ & $\mathbf{5 5 . 0 0}$ \\
\hline
\end{tabular}

Therefore, increasing the surface roughness enhance the bond strength no matter what type of repair products are implemented, and even the cycles of freezing and thawing with de-icing salt since positive stress improvement results were seen for splitting tensile test (Figure 4-19 and Table 4-14). 


\subsubsection{Pull-off Test}

The results of testing 64 specimens (16 slab substrates with 4 cylindrical repair samples on top of each slab) under pull-off force were provided in Figure 4-20. Two important considerations should be discussed before analyzing the results. The first one is that the pull-off test was just completed on the smooth surface texture. In fact, the surface roughness effect under the pull-off test is minimal or can be neglected since the samples are under direct tensile force. Second, all cylindrical repair products on top of slab substrates (Sub-A) lost their bond even before reaching 25 cycles. Thus, it was decided to not include the 25-cycles in the results (Figure 4-20) since the specific debonding time of the repair samples were unknown.

Not having the bond strength for any of the repair products at 25-cycles might be due to the harshness of the experimental setup. Indeed, the repair materials were not casted as one connected or a continuous piece on top of Sub-A which may increase the possibility of any source of imperfections at the bond interface. Moreover, freeze-thaw cycles with de-icing salt directly affect the bond interface which is very severe exposure and could cause high bond damage. Finally, the bond interface perimeter to area ratio was very high which could result in even more bond stress loss.

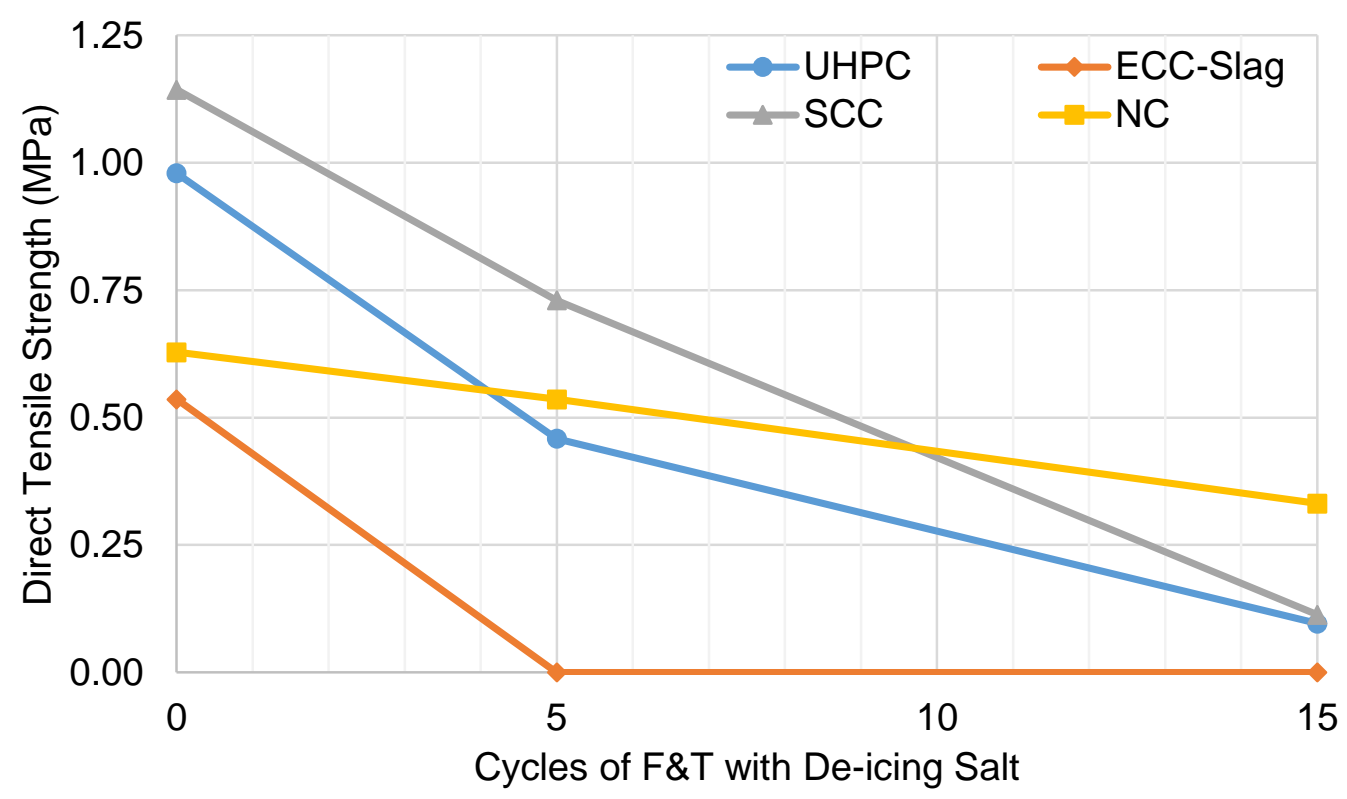

Figure 4-20: Bond Strength Results of Pull-off Test-Smooth Texture 
Since the specimens for the pull-off test are under direct tensile load, the bond strength was expected to be at its minimum compared to the slant shear and splitting tensile tests. Therefore, any prediction that was made in Section 4.2.1 is expected to have more severe damage under the pull-off test.

By studying Figure 4-20, it can be observed that for the first time at 0-cycle, SCC showed the highest bond strength followed by UHPC, NC, and ECC-Slag. Having higher bond strength for SCC might be due to the following reasons: (1) significant amount of shrinkage of UHPC and ECC-Slag during curing period, (2) Impermeability of the UHPC and ECC-Slag could result of having a higher salt concentration at the perimeter of the bond interface, consequently, producing higher damage to the bond and substrate surface. However, further investigation in this regard is highly recommended.

During 5-cycles (Table 4-15), the ECC-Slag (100.00\%) and UHPC (53.18\%) had the first and second highest stress loss followed by SCC (36.14\%) and NC (14.71\%) which exactly match the prediction that was stated in Section 4.2.1 based on the shrinkage data. Throughout 15-cycles, UHPC and SCC reached about the same bond strength. NC was showed the best and ECC-Slag worst durability performance under 15-cycles. By 25cycles, all the materials completely lost their bond. Figure 4-21 through Figure 4-24 illustrate the small slabs with repairs after performing the pull-off test at 5-cycles of freezing and thawing with salt.

Table 4-15: Stress Loss (\%) for Pull-off Test (Phase-II) - Smooth Texture

\begin{tabular}{ccccc}
\hline Cycles & UHPC & ECC-Slag & SCC & NC \\
\hline \hline 5C-F\&T & 53.18 & 100.00 & 36.14 & 14.71 \\
15C-F\&T & 90.17 & 100.00 & 90.10 & 47.23 \\
25C-F\&T & 100.00 & 100.00 & 100.00 & 100.00 \\
\hline
\end{tabular}

The CV results for the pull-off test (Table 4-16) demonstrate that NC with an average CV of $8.02 \%$ had the minimum standard error between other repairs accompanied by SCC $(11.62 \%)$ and UHPC (18.26\%). The results of all the repair materials excluding ECC-Slag was in the acceptable range $(<15 \%)$ during the 5 -cycles. At 15 -cycles, the CV increased significantly since the bond strengths were very low specifically for UHPC and SCC. 
CHAPTER 4. RESULTS AND ANALYSIS

Table 4-16: SD and CV Results for Pull-off Test (Phase-II) - Smooth Texture

\begin{tabular}{|c|c|c|c|c|c|c|c|c|}
\hline \multirow[b]{2}{*}{ Cycles } & \multicolumn{2}{|c|}{ UHPC } & \multicolumn{2}{|c|}{ ECC-Slag } & \multicolumn{2}{|c|}{ SCC } & \multicolumn{2}{|c|}{ NC } \\
\hline & $\begin{array}{c}\text { SD } \\
(\mathrm{MPa})\end{array}$ & $\begin{array}{l}\text { CV } \\
(\%) \\
\end{array}$ & $\begin{array}{c}\text { SD } \\
\text { (MPa) }\end{array}$ & $\begin{array}{l}\text { CV } \\
(\%) \\
\end{array}$ & $\begin{array}{c}\text { SD } \\
(\mathrm{MPa})\end{array}$ & $\begin{array}{l}\text { CV } \\
(\%) \\
\end{array}$ & $\begin{array}{c}\text { SD } \\
(\mathrm{MPa})\end{array}$ & $\begin{array}{l}\text { CV } \\
\text { (\%) }\end{array}$ \\
\hline OC-F\&T & 0.09 & 9.32 & 0.17 & 30.95 & 0.15 & 12.99 & 0.07 & 11.91 \\
\hline 5C-F\&T & 0.07 & 14.75 & 0.00 & 0.00 & 0.10 & 13.49 & 0.06 & 11.64 \\
\hline 15C-F\&T & 0.05 & 48.98 & 0.00 & 0.00 & 0.02 & 20.00 & 0.03 & 8.52 \\
\hline Average & 0.05 & 18.26 & 0.04 & 30.95 & 0.07 & 11.62 & 0.04 & 8.02 \\
\hline
\end{tabular}

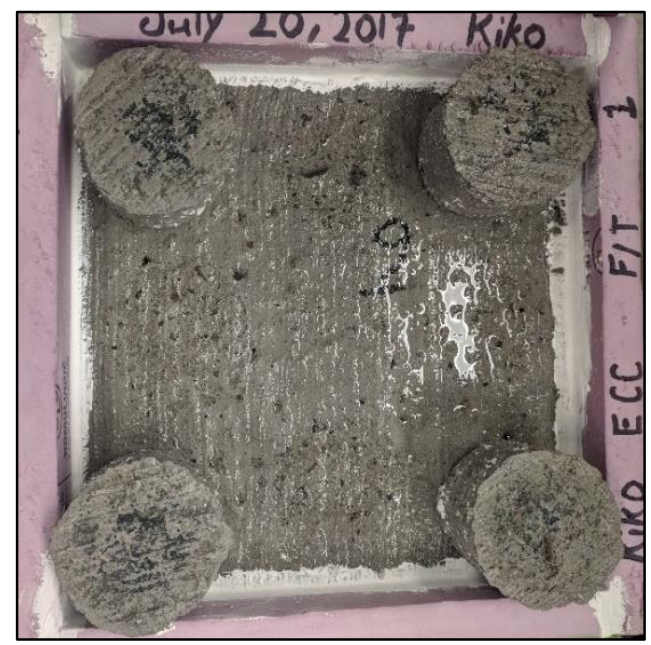

Figure 4-21: ECC-Slag Pull-off Slab with 4 Specimens at 5C-F\&T (Debonded)

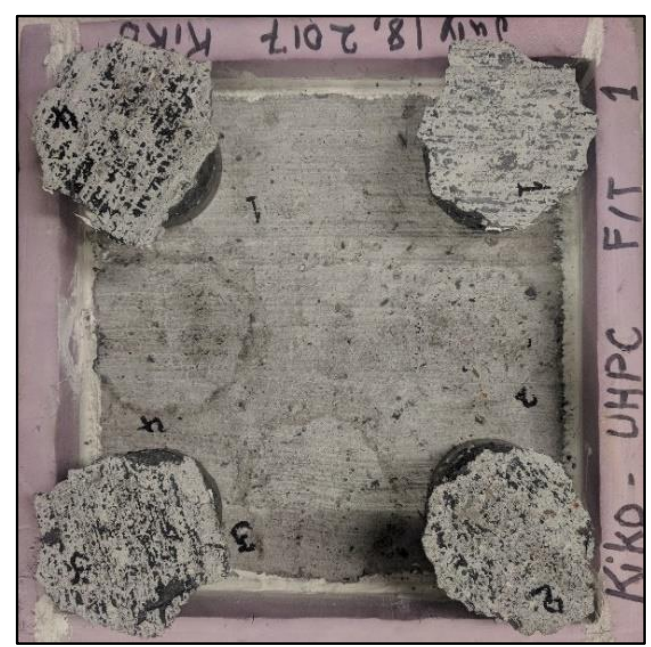

Figure 4-23: UHPC Pull-off Slab with 4 Specimens at $5 C-F \& T$

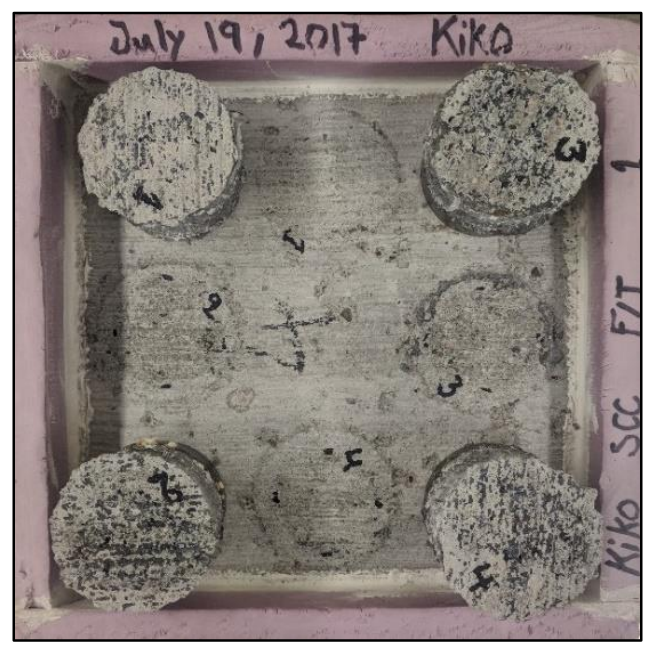

Figure 4-22: SCC Pull-off Slab with 4 Specimens at $5 C-F \& T$

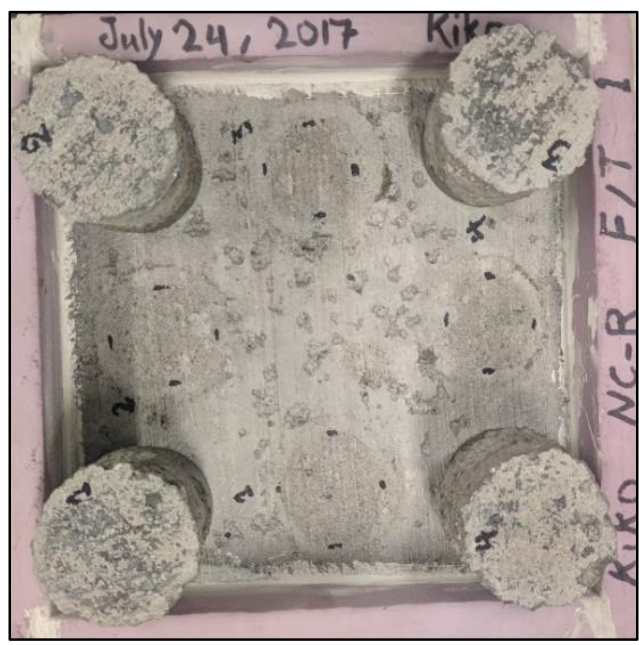

Figure 4-24: NC Pull-off Slab with 4 Specimens at $5 C-F \& T$ 


\subsection{Repairs Placed on Expanding Substrate - Suffering ACR (Phase-III)}

\subsubsection{Length Change of Concrete Prisms Following the Testing Conditions}

The average results of the three concrete prisms - casted with Sub-B (ACR), cured for 3 months in the moist curing room $(\mathrm{RH}>98 \%)$, and stored for 5 months in the typical condition room - were provided in Figure 4-25. It is important to mention that out of the 3 months curing, 1 month was just for Sub-B and another 2 months were for the repair system (which implies after applying the repair products).

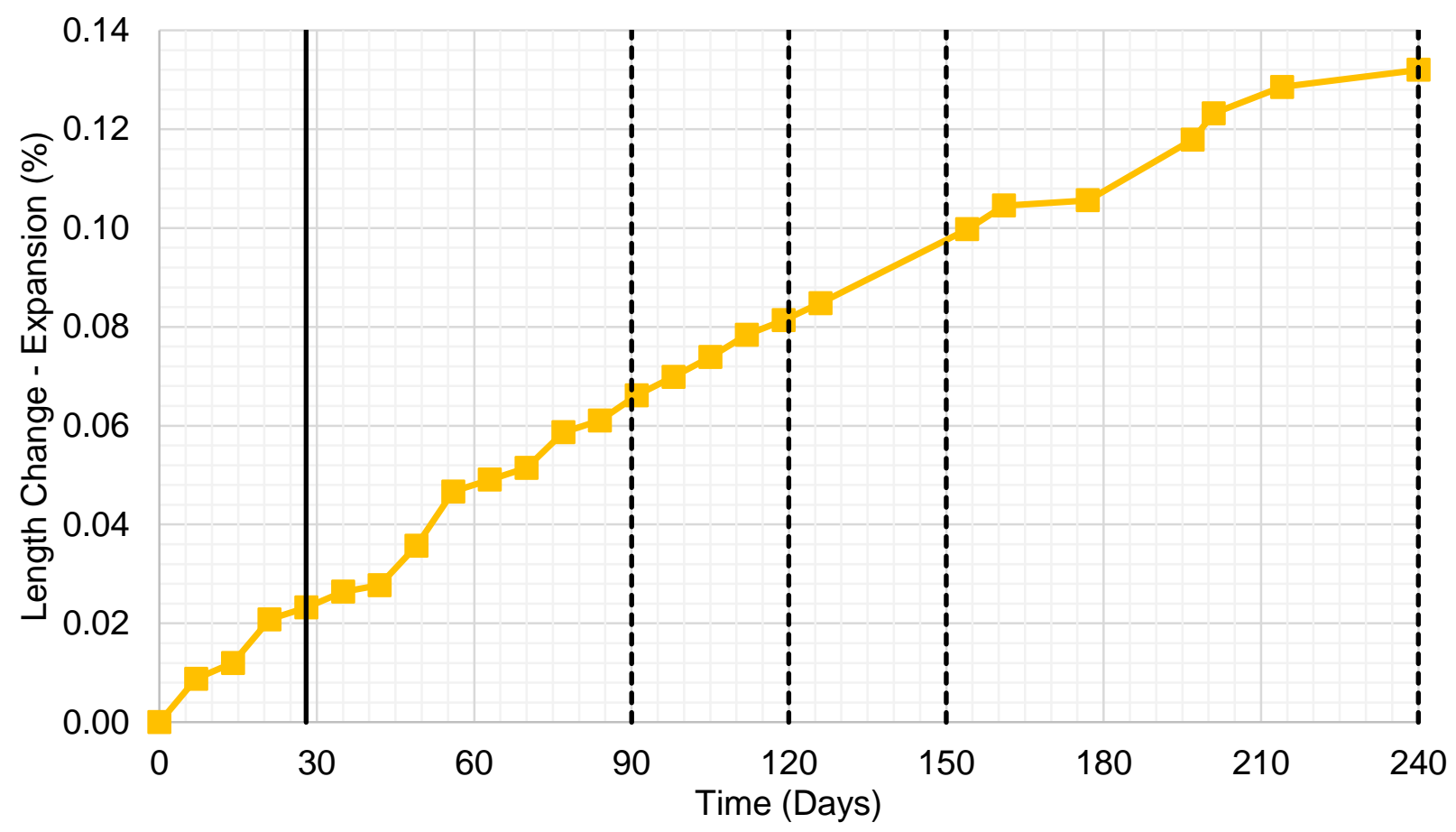

Figure 4-25: Length Change of the Sub-B Following the Testing conditions

The solid black line in Figure 4-25 represents the 1 month curing (28 days) of the Sub-B and the time that repair materials were applied on top of the Sub-B (large slabs). The 4 dotted black lines in Figure 4-25 show the 4 periods that the pull-off tests were performed on the large slabs. These periods are as follow:

i. 2M-Curing: 2 months curing immediately after applying repair materials between the solid black line (at 28 days) and first dotted black line (at 90 days). 
ii. $2 \mathrm{M}$-Curing $+1 \mathrm{M}: 2$ months curing plus 1 month outside the curing room between the first and second dotted black line (90 to 120 days).

iii. $2 \mathrm{M}$-Curing $+2 \mathrm{M}: 2$ months curing plus 2 months outside curing room between second and third dotted black line (120 to 150 days).

iv. $2 \mathrm{M}$-Curing $+5 \mathrm{M}: 2$ months curing plus 5 months in the typical condition room between third and last dotted black line (150 to 240 days).

The bond strength evaluation testing method (pull-off test) was performed at the end all the above periods or in other words, right at the dotted black lines. As it can be observed in Figure 4-25, the highest amount of expansion for Sub-B was seen during the 2M-Curing period with $0.043 \%$ (expansion at 90 days minus expansion at 28 days) followed by $2 \mathrm{M}$ Curing $+5 \mathrm{M}(0.032 \%), 2 \mathrm{M}$-Curing $+2 \mathrm{M}(0.018 \%)$, and $2 \mathrm{M}$-Curing $+1 \mathrm{M}(0.015 \%)$. Therefore, the first and second maximum bond stress loss is estimated to happen within the first period (2M-Curing) and the last period $(2 \mathrm{M}$-Curing $+5 \mathrm{M})$. Besides, the minimum bond stress loss is predicted to be experienced for the second period ( $2 \mathrm{M}-\mathrm{Curing}+1 \mathrm{M})$. During the last period from 150 to 240 days (2M-Curing $+5 \mathrm{M})$, the expansion cracks on the concrete prisms were wide and extended enough which they could be even observed by naked eyes. Figure 4-26 demonstrates two of these expansion cracks on two different concrete prisms.
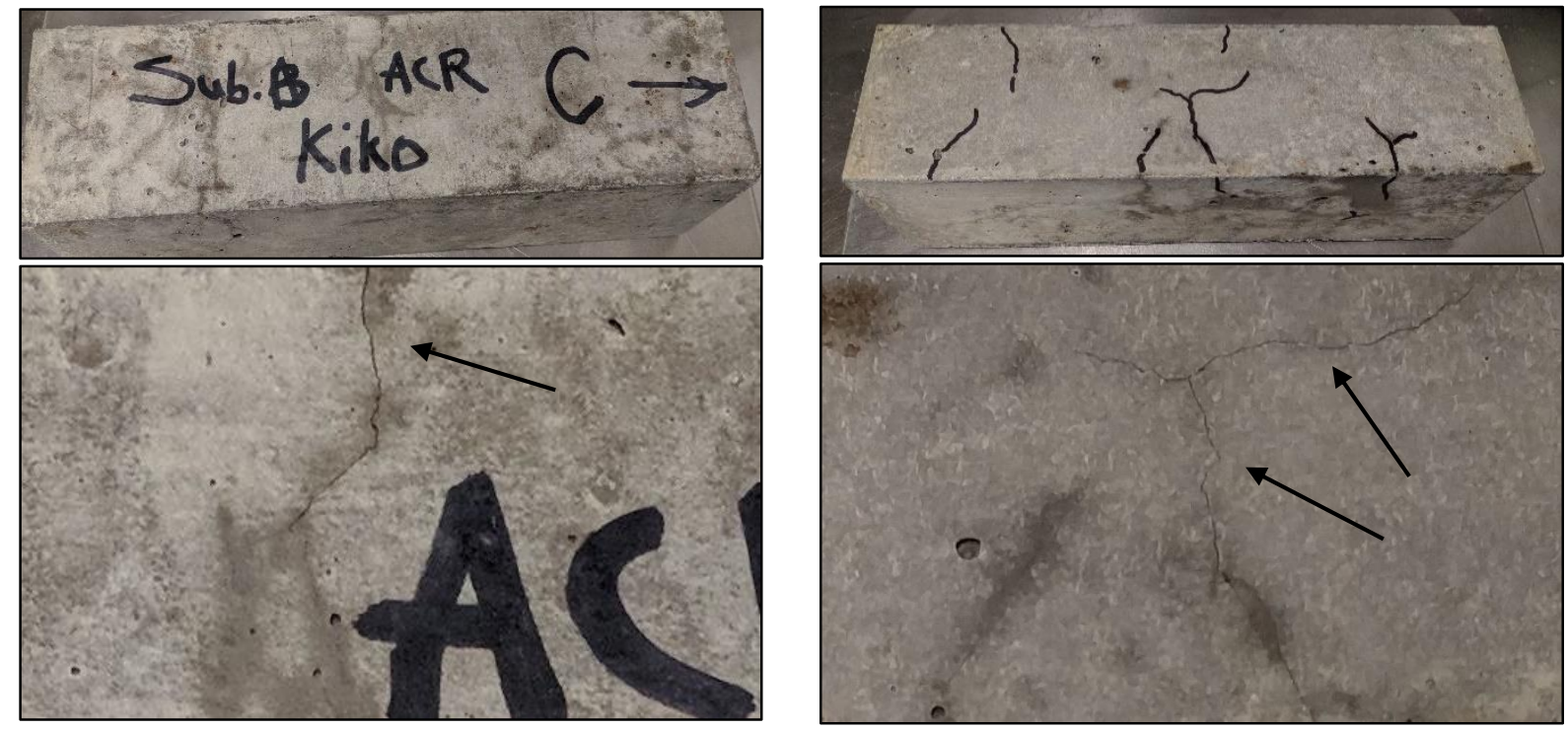

Figure 4-26: Expansion Cracks on the Sub-B Prisms During 2M-Curing $+5 M$ 


\subsubsection{Bond Strength Testing Method}

\subsubsection{Pull-off Test}

In this section, the results of the pull-off test on the 4 large slabs with Sub-B which represents expanding deterioration substrate (ACR) were summarized in Figure 4-27. The pull-off test was performed at 4 different time durations after applying repairs, $2 \mathrm{M}$ Curing, $2 \mathrm{M}$-Curing $+1 \mathrm{M}, 2 \mathrm{M}$-Curing $+2 \mathrm{M}, 2 \mathrm{M}$-Curing $+5 \mathrm{M}$ as explained above. For the first three periods, 3 samples were cored through the large slabs for each repairs and for the final period ( $2 M-C u r i n g+5 M) 4$ samples were tested. Since the samples were cored, some bond strength loss due to the vibration and coring effect was expected. The range of bond strength was also illustrated in Figure 4-27 by the error bars.

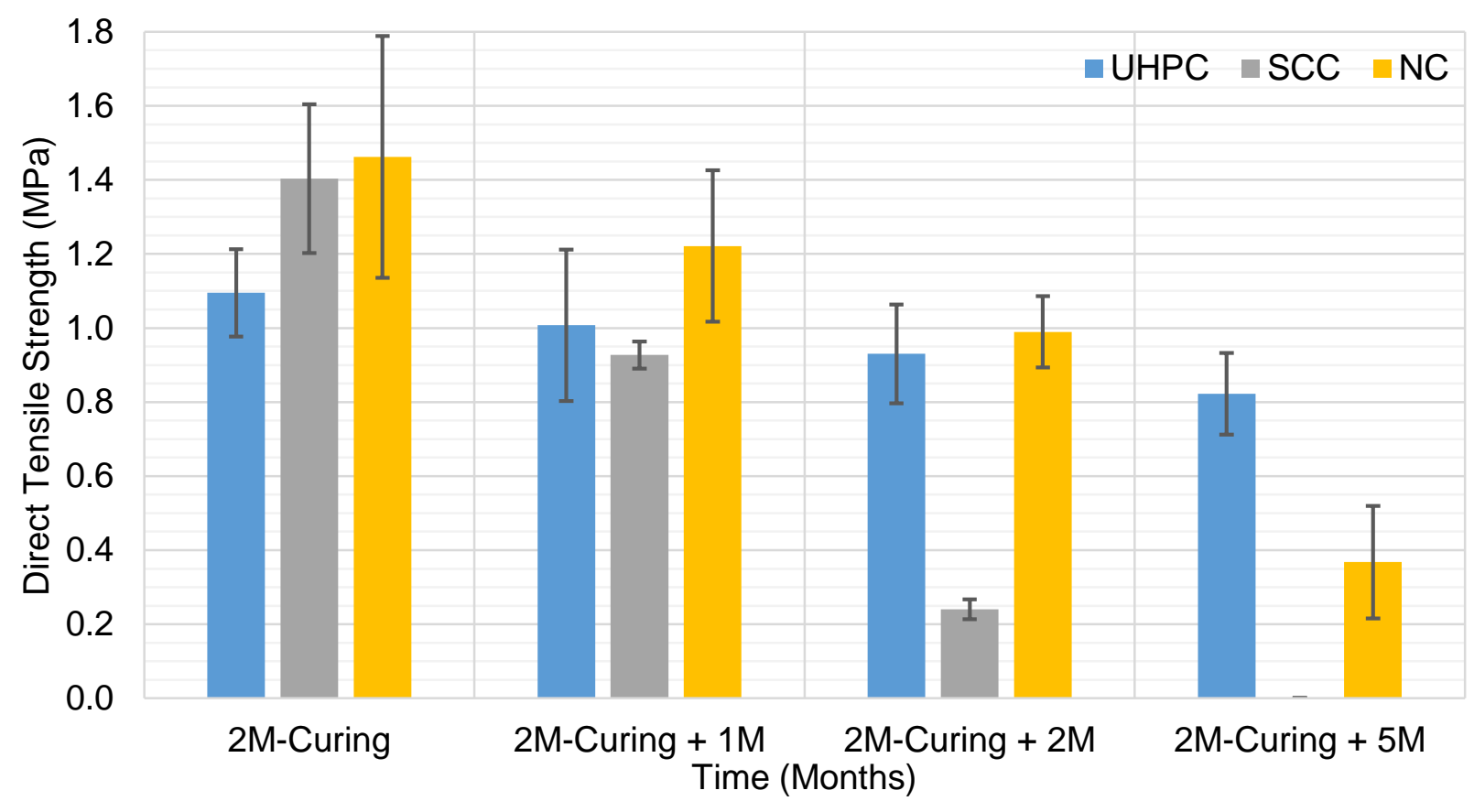

Figure 4-27: Pull-off Test Results for Phase-III

The results of the ECC-Slag were not represented in Figure 4-27 due to the fact that the bond strength of this particular material was measured to be zero even for the initial measurement at 2 months curing (2M-Curing). In fact, the ECC-Slag was started to debond very early. Figure 4-28 demonstrates the cracks right at the bond interface which were observed approximately at 1 month curing (1M-Curing). 

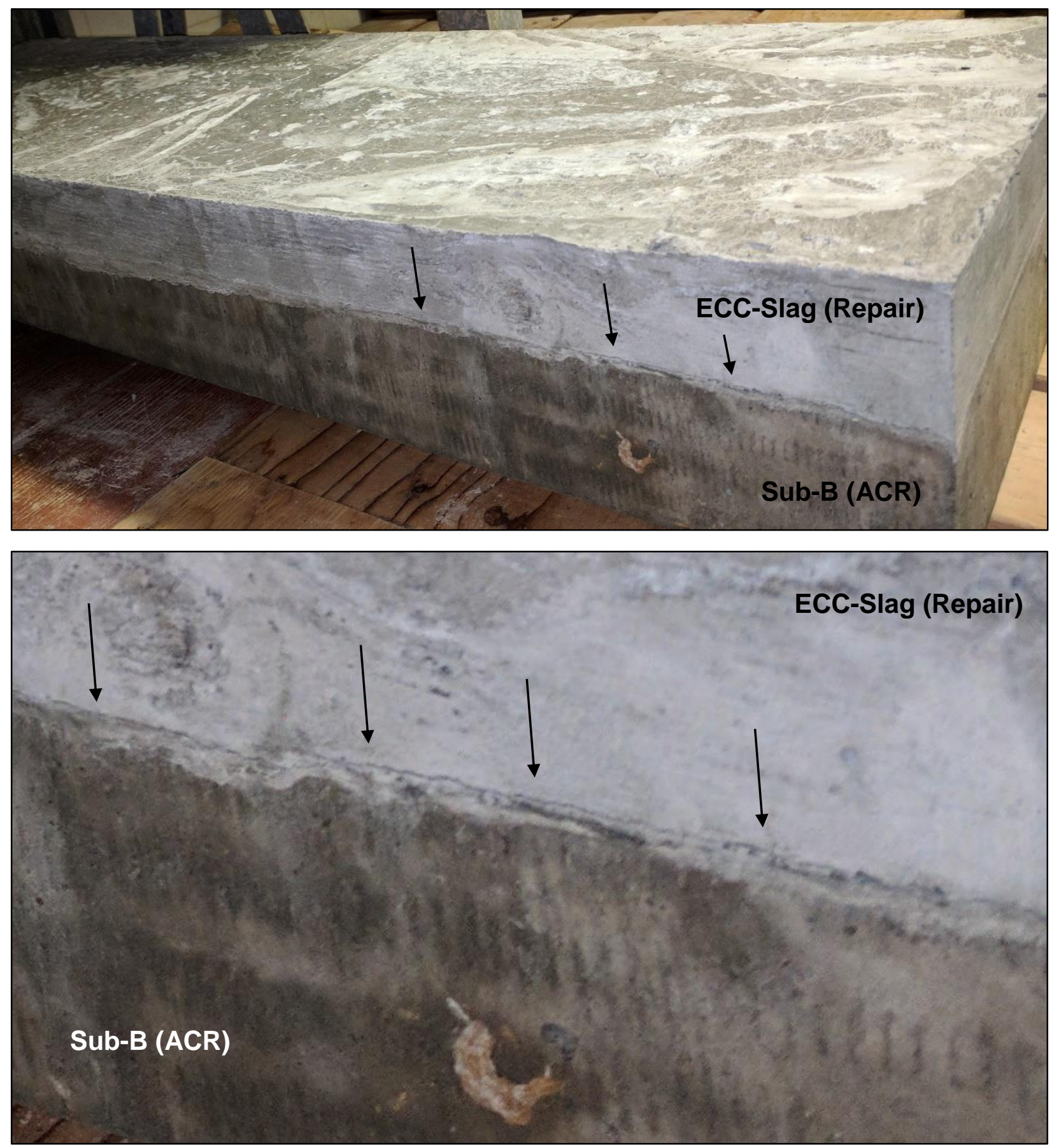

Figure 4-28: Start of Debonding Crack for the ECC-Slag at 1M-Curing

This crack was seen to get completely open (Figure 4-29) after the first coring process for the initial measurement at 2 months curing (2M-Curing). The wide crack opening between ECC-Slag and Sub-B was led to having zero bond strength. The potential reason behind this behaviour of ECC-Slag is explained later (in the following two pages). 

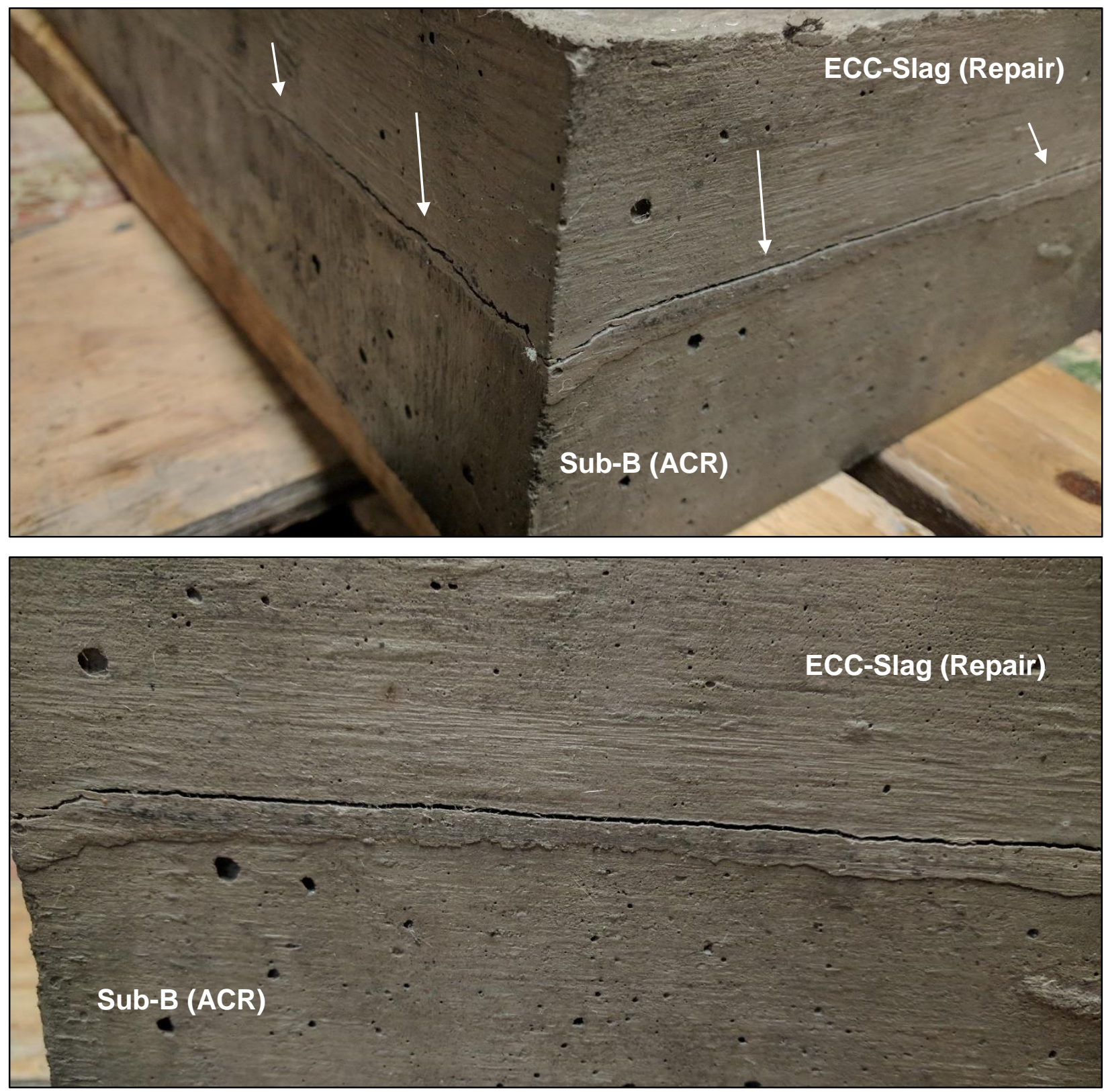

Figure 4-29: Debonding Crack for the ECC-Slag at 2M-Curing

The second complete debonding between the repair products was observed for the SCC during the $2 \mathrm{M}$-Curing $+5 \mathrm{M}$ period. The similar debonding cracks response as the ECCSlag was detected. The first small debonding crack was noted at 2 months curing plus 3 months outside curing room (Figure 4-30). Approximately 2 months after, complete debonding was discovered as it is demonstrated in Figure 4-31 which show the same location of the slab (2M-Curing $+5 \mathrm{M})$. 


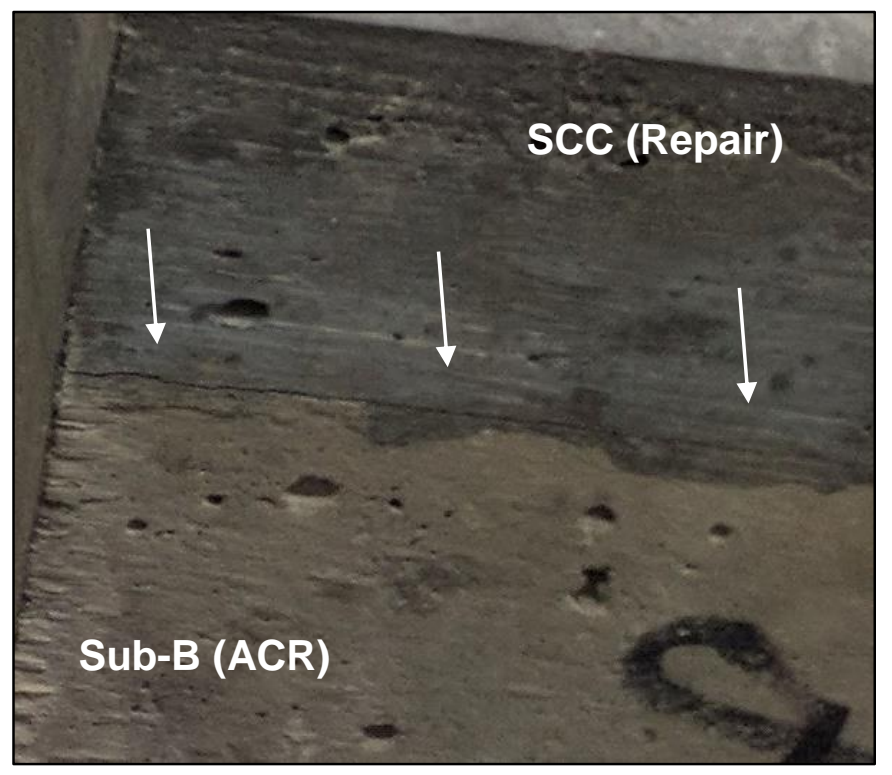

Figure 4-30: Start of Debonding Crack for the SCC at $2 M-$ Curing $+3 M$

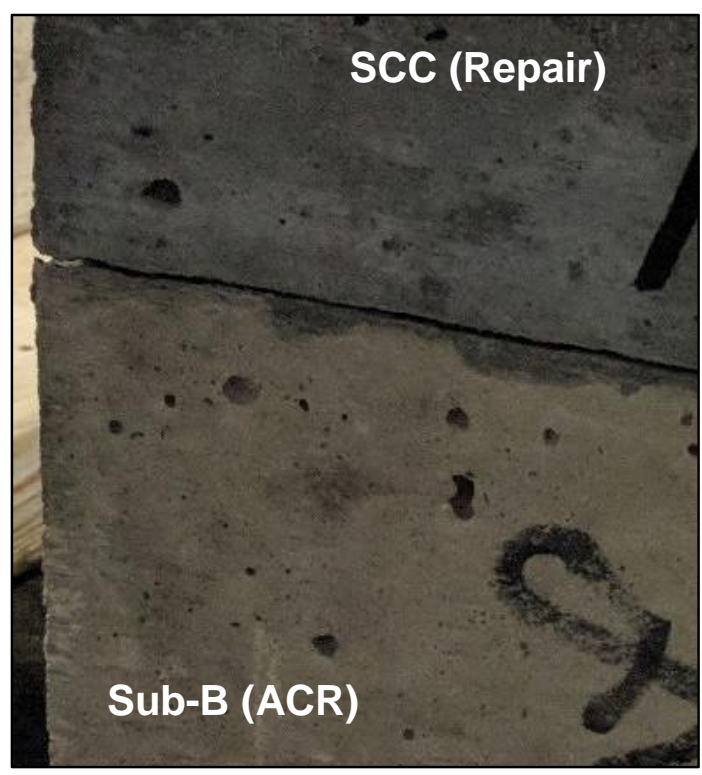

Figure 4-31: Debonding Crack for the SCC at $2 M$-Curing $+5 M$

In addition to Figure 4-27, Table 4-17 provides the stress loss (\%) - which was calculated according to Eq. 4-3 - for each repair products with respect to the 2 months curing (2M Curing). Moreover, the SD and CV values were reported in Table 4-18.

Table 4-17: Stress Loss (\%) for Pull-off Test (Phase-III)

\begin{tabular}{ccccc}
\hline Cycles & UHPC & ECC-Slag & SCC & NC \\
\hline \hline 2M-Curing $+1 \mathrm{M}$ & 8.02 & $\mathrm{n} / \mathrm{a}$ & 33.93 & 16.46 \\
2M-Curing $+2 \mathrm{M}$ & 15.08 & $\mathrm{n} / \mathrm{a}$ & 82.84 & 32.32 \\
2M-Curing $+5 \mathrm{M}$ & 24.91 & $\mathrm{n} / \mathrm{a}$ & 100.00 & 74.85 \\
\hline
\end{tabular}

Table 4-18: SD and CV Results for Pull-off Test (Phase-III)

\begin{tabular}{|c|c|c|c|c|c|c|c|c|}
\hline \multirow[b]{2}{*}{ Cycles } & \multicolumn{2}{|c|}{ UHPC } & \multicolumn{2}{|c|}{ ECC-Slag } & \multicolumn{2}{|c|}{ SCC } & \multicolumn{2}{|c|}{$\mathrm{NC}$} \\
\hline & $\begin{array}{c}\text { SD } \\
\text { (MPa) }\end{array}$ & $\begin{array}{l}\text { CV } \\
(\%) \\
\end{array}$ & $\begin{array}{c}\text { SD } \\
\text { (MPa) }\end{array}$ & $\begin{array}{l}\text { CV } \\
(\%)\end{array}$ & $\begin{array}{c}\text { SD } \\
\text { (MPa) }\end{array}$ & $\begin{array}{l}\text { CV } \\
(\%)\end{array}$ & $\begin{array}{c}\text { SD } \\
\text { (MPa) }\end{array}$ & $\begin{array}{l}\text { CV } \\
(\%)\end{array}$ \\
\hline $2 M-C^{1}$ & 0.12 & 10.77 & 0.00 & 0.00 & 0.20 & 14.32 & 0.33 & 22.35 \\
\hline $2 \mathrm{M}-\mathrm{C}+1 \mathrm{M}$ & 0.20 & 20.28 & 0.00 & 0.00 & 0.04 & 3.91 & 0.20 & 16.72 \\
\hline $2 \mathrm{M}-\mathrm{C}+2 \mathrm{M}$ & 0.13 & 14.38 & 0.00 & 0.00 & 0.03 & 11.11 & 0.10 & 9.74 \\
\hline $2 \mathrm{M}-\mathrm{C}+5 \mathrm{M}$ & 0.11 & 13.38 & 0.00 & 0.00 & $n / a$ & $n / a$ & 0.15 & 41.30 \\
\hline Average & 0.14 & 14.70 & 0.00 & 0.00 & 0.09 & 9.78 & 0.19 & 22.53 \\
\hline
\end{tabular}

$12 \mathrm{M}-\mathrm{C}$ represents $2 \mathrm{M}$-Curing or 2 months curing 
According to the results (Figure 4-27), NC and SCC started with the first and second highest bond strength at initial measurement (2M-Curing) with 1.46 and $1.40 \mathrm{MPa}$, respectively. The bond strength of UHPC was recorded to be the lowest value (1.10 MPa). Having the lowest bond strength for UHPC and complete debonding for ECC-Slag (zero bond strength) at $2 \mathrm{M}$-Curing could be justified by high combined autogenous and drying shrinkage of these two materials (Section 4.1.3) and high expansion of Sub-B at the 2MCuring (Section 4.3.1). In fact, as it was concluded, the UHPC and ECC-Slag continue their shrinkage no matter the type of curing and environmental conditions. Therefore, during the first 2 months, these two materials are shrinking while the Sub-B is expanding. This complete inverse direction of movement for repair materials (UHPC and ECC-Slag) and substrate (Sub-B) creates considerable shear stress at the bond interface. Consequently, it causes significant stress loss for these two repair products.

On the other hand, the NC and SCC - while they were stored in the curing room (for the first 2 months) - revealed almost zero to the minimal expansion (swelling) length change movement which at least aligns with the direction of the Sub-B movement (expansion). Hence, the minimum bond stress loss for NC and SCC in comparison to UHPC and ECCSlag was predicted. The combined consequence of these two characteristics of repair products might describe the higher bond strength of NC and SCC over UHPC at 2 months curing (Figure 4-27).

After moving slabs outside the moist curing room to the typical condition room, the NC and SCC started to shrink as it was presented through Section 4.1.3 (Figure 4-4), Section 4.1.3.1 (Figure 4-5) and discussed in Section 4.2.1. Since the shrinkage of SCC was presented to be much higher than NC, the higher bond loss of the SCC throughout the first 2 months outside the curing room can be confirmed. On the other hand, NC slowly loses its bond strength because of its slow shrinkage compared to other repair products. As it can be seen in Figure 4-27 and Table 4-17, the UHPC showed the best durability (minimum stress loss of $24.91 \%$ ) among other repair products since at the end of $2 \mathrm{M}$ Curing it already experienced most of its shrinkage. However, for NC and SCC the shrinkage is at the starting point right after the $2 \mathrm{M}$-Curing for SCC with the higher rate and NC with the slower rate of shrinkage. 


\section{Chapter 5}

\section{Summary and Discussion}

\subsection{Materials Properties and Compatibility of Repairs with Substrate (Phase-I)}

The results of compressive strength (ASTM C39, 2017), static modulus of elasticity (ASTM C469, 2014), drying shrinkage, and combined autogenous and drying shrinkage (MTO LS-435-R28, 2013) are summarized and discussed in this chapter.

\subsubsection{Compressive Strength}

The compressive strength ratio (repair/substrate) of repair products at different curing period to substrate at 28 days curing (Sub-A for Phase-II and Sub-B for Phase-III) was reported in Table 5-1. This ratio was calculated to better evaluate the compressive strength campatibility of the repair materials with substrate. Although the compressive strength ratios for all the curing periods were provided in Table 5-1, the best curing period for comparison of the compressive strength ratio is the 14 days curing - highlighted in Table 5-1 - which the repair materials were exactly cured in the experimantal program. Consequently, the the compressive strength ratio of one or close to one is an indication of the best compitibility. The results revealed that NC among other repair products demonstrated the best compressive strength compatibility with both Sub-A and Sub-B 
followed by ECC-Slag, SCC, and UHPC. The highest compressive strength compatibility of NC with substrates (Sub-A and Sub-B) was expected since all these materials are having almost the same amount of coarse and fine aggregate, cement content, $\mathrm{W} / \mathrm{C}$ ratio, and they are not containing any SCMs or admixtures in their mix design in comparison to the ECC-Slag, SCC, and UHPC.

Table 5-1: Compressive Strength to Substrate Ratio

\begin{tabular}{|c|c|c|c|c|c|c|c|c|}
\hline \multirow{2}{*}{$\begin{array}{l}\text { Curing } \\
\text { Period }\end{array}$} & \multicolumn{4}{|c|}{ Ratio to Sub-A (Phase-II) } & \multicolumn{4}{|c|}{ Ratio to Sub-B (Phase-III) } \\
\hline & UHPC & ECC-Slag & scc & NC & UHPC & ECC-Slag & scc & NC \\
\hline 1 day & 1.20 & 0.55 & 0.52 & 0.23 & 1.10 & 0.51 & 0.48 & 0.21 \\
\hline 7 days & 2.21 & 1.44 & 1.37 & 0.73 & 2.03 & 1.32 & 1.26 & 0.67 \\
\hline 14 days & 2.44 & 1.64 & 1.69 & 1.00 & 2.24 & 1.50 & 1.55 & 0.92 \\
\hline 28 days & 2.84 & 1.68 & 1.71 & 1.03 & 2.61 & 1.54 & 1.57 & 0.95 \\
\hline 56 days & 3.32 & 1.72 & 1.91 & 1.04 & 3.04 & 1.58 & 1.75 & 0.95 \\
\hline 90 days & 3.40 & 1.77 & 1.92 & 1.05 & 3.12 & 1.62 & 1.76 & 0.96 \\
\hline
\end{tabular}

\subsubsection{Static Modulus of Elasticity}

Concerning the static modulus of elasticity, the ratio of repair products to substrates (Table 5-2) demonstrated that the SCC and NC represented the best compatibility with both Sub-A and Sub-B followed by ECC-Slag and UHPC. In fact, the stress-strain curve (Figure 4-2) of the SCC and NC was found to be very similar to the Sub-A and Sub-B. The similar static modulus of elasticity found for SCC, NC, Sub-A, and Sub-B is mainly due to the fact that these materials implement high amount of coarse aggregate in their mixtures. As discussed in the literature review (Section 2.3.2), one the most influential modulus of elasticity factor is the coarse aggregate and its properties (Mindess et al., 2003; Neville \& Brooks, 2010).

Table 5-2: Static Modulus of Elasticity Ratio of Repairs to Substrates

\begin{tabular}{|c|c|c|c|c|c|c|c|c|}
\hline \multirow{2}{*}{$\begin{array}{l}\text { Curing } \\
\text { Period }\end{array}$} & \multicolumn{4}{|c|}{ Ratio to Sub-A (Phase-II) } & \multicolumn{4}{|c|}{ Ratio to Sub-B (Phase-III) } \\
\hline & UHPC & ECC-Slag & SCC & NC & UHPC & ECC-Slag & Scc & $\mathrm{NC}$ \\
\hline 28 days & 1.34 & 0.70 & 1.07 & 1.11 & 1.27 & 0.66 & 1.02 & 1.05 \\
\hline
\end{tabular}




\subsubsection{Shrinkage}

According to the results presented in the shrinkage section (Section 4.1.3), it could be summarized that NC and UHPC produced the minimum amount of drying shrinkage followed by ECC-Slag and SCC. Consequently, in terms of combined autogenous and drying shrinkage, NC showed the minimum length change movement followed by UHPC, SCC, and the ECC-Slag. The literatures confirm the high amount of autogenous shrinkage for ECC-Slag (S. Wang \& Li, 2005) and UHPC (Meng, Valipour, \& Khayat, 2017), and significantly high drying shrinkage for SCC (Leemann, Lura, \& Loser, 2011) which were found in this research.

Besides, during experimental shrinkage program, it was found that the type and duration of curing have the minimum effect on the length change behaviour of UHPC and ECCSlag since these two materials have a very dense microstructure which makes them almost impermeable. Thus, while evaluating the compatibility of different repair products, it is significantly essential to consider the autogenous shrinkage and drying shrinkage simultaneously (combined autogenous and drying shrinkage defined by the author in this research) particularly for materials with low W/B ratio and high amount of cementitious content (Portland cement and SCMs) for the following reasons:

1. Low W/B ratio and high amount of cementitious materials in the mixture increases the possibility of the autogenous shrinkage specially in the first 28 days.

2. Low W/B ratio and high amount of cementitious materials in the mixture decreases the amount of the drying shrinkage since less amount of water is available inside the element to evaporate and causes the drying shrinkage.

3. Majority of advanced cement-based materials used as repairs are reducing the amount of coarse aggregate (such as SCC) or completely excluding them (like UHPC and ECC) from the mix design by increasing the amount of cementitious materials or generally powders. This characteristic of repair products reduces the restraining force inside the microstructure - which was induced by coarse aggregates - to overcome shrinkage. Therefore, higher amount of shrinkage for these repair products compare to NC is expected. 


\subsection{Repairs under Freeze-Thaw Cycles with De-icing Salt (Phase-II)}

\subsubsection{Length Change of Concrete Prisms Following the Testing Conditions}

The overall results of the conditioning length change (Section 4.2.1, Table 4-4) before the initial bond strength measurement (at 0 -cycle of freezing and thawing with de-icing salt) predicts that the first and second maximum bond stress loss is for ECC-Slag and SCC, respectively. The first maximum bond stress loss estimated for ECC-Slag stays mainly due to its high amount of combined autogenous and drying shrinkage during Period-1 (Curing) and Period-2 (Shrinkage). The second maximum bond stress loss which was predicted to be for SCC is a consequence of having very high drying shrinkage within Period-2 (Shrinkage).

After initial bond strength measurements, the ECC-Slag continued to show the minimum amount of dimensional compatibility with the substrate (Sub-A) throughout the cycles of freezing and thawing (Table 4-4). Therefore, measuring the lowest or zero bond strength for ECC-Slag among other repairs - for two surface textures (rough and smooth) and all the evaluating testing methods including slant shear, splitting tensile, and pull-off test was estimated and later proven to be correct (Section 4.2.2). During the 25-cycles of freezing and thawing with de-icing salt, NC showed the best dimensional compatibility with Sub-A (Table 4-4). Hence, the minimum stress loss or durability of the bond strength was expected and verified by the evaluating testing results to be right (Section 4.2.2).

\subsubsection{Bond Strength Testing Methods}

\subsubsection{Slant Shear and Splitting Tensile Tests}

The results of the slant shear and splitting tensile tests (Sections 4.2.2.1 and 4.2.2.2) revealed that the UHPC started and continued with the higher bond strength during the 25 -cycles of freezing and thawing with de-icing salt. The high bond strength of UHPC is mainly due to its mixture characteristics such as eliminating aggregates larger than 600 $\mu \mathrm{m}$, having low W/B ratio $(\leq 0.2)$, high Portland cement and silica fume content. 
On the other hand, NC showed the best durability performance (minimum stress loss) throughout the 25-cycles for slant shear test under both rough and smooth surface textures. However, the results of splitting tensile test within 25-cycles were not evident enough to identify the best durability performance particularly between SCC and NC. Therefore, based on the linear trend line can be predicted that if the test was implemented for a more extended period of freeze-thaw cycles (for instance 50-cycles), then the NC may show better durability performance than SCC. This behaviour of NC is mainly due to its best dimensional compatibility with Sub-A regarding shrinkage (Section 4.1.3) and length change following the testing conditions (Section 4.2.1).

\subsubsection{Pull-off Test}

The results of the pull-off test (Section 4.2.2.3) did not reveal the higher initial bond strength (0-cycle of freezing and thawing) for UHPC. In fact, the SCC showed the higher bond strength at 0 -cycle and 5-cycles of freezing and thawing with de-icing salt. Several factors simultaneously may cause this behaviour including:

1. The impermeability and very low sorptivity of the UHPC (Prem, Bharatkumar, \& lyer, 2012) may result of having a higher de-icing salt concentration at the bond interface. Therefore, higher deterioration or salt scaling of Sub-A is expected which may lead to higher bond strength loss.

2. A large amount of length change prior to testing (Section 4.2.1) of UHPC particularly during the 14 days curing period (Period-1).

3. Some imperfection (human errors) during casting of the UHPC repair on top of the small slabs - such as not tapping the specimens enough to deplete all the entrapped air - might cause some additional stress loss at the bond interface.

However, NC showed the best durability performance among other repair products throughout the 25 freeze-thaw cycles with de-icing salt although its direct tensile strength (pull-off) was measured to be less than SCC and UHPC at 0-cycle. The same conclusion was made for the slant shear and splitting tensile tests. 


\subsubsection{Surface Roughness Effect}

In terms of the surface roughness effect, it was found that that increasing the surface roughness improves the bond strength no matter what type of repair products were used, the cycles of freezing and thawing, and even the type of testing methods. However, the effect of surface roughness on different testing methods and various repair products were not found to be similar.

\subsubsection{Surface Roughness Effect for Different Testing Methods}

The surface roughness effect under the slant shear test $(121.39 \%)$ was observed to be almost 4 times higher than the splitting tensile test (32.10\%) - according to the overall average stress improvement of all specimens (Table 4-9 and Table 4-14, respectively). The higher surface roughness effect for the slant shear test is primarily due to the type of acting load on the samples. Actually, for slant shear test, the samples are under combined compression and shear stress which enhances the mechanical interlock influence. Hence, higher surface roughness effect for slant shear test was expected.

\subsubsection{Surface Roughness Effect for Different Repair Materials}

The surface roughness effect of slant shear test for different repairs (Table 4-9) was determined to be higher for UHPC followed by ECC-Slag, SCC, and NC. This behaviour may indicate that eliminating coarse aggregate, implementing SCMs specifically silica fume, and reducing the W/B ratio enhance the performance of the repair materials under slant shear test with higher roughness. In fact, the repair materials with higher compressive strength showed better results.

On the other hand, the results for splitting tensile test (Table 4-14) indicated the higher stress improvement due to surface roughness for NC supported by ECC-Slag, UHPC and SCC. This particular behaviour might be due to the material compatibility of the repair products with Sub-A. As a matter of fact, NC demonstrated the best material compatibility with Sub-A in terms of compressive strength (Section 4.1.1), static modulus of elasticity (Section 4.1.2), shrinkage (Section 4.1.3) and length change of concrete prisms following the testing conditions (Section 4.2.1). 


\subsection{Repairs Placed on Expanding Substrate - Suffering ACR (Phase-III)}

\subsubsection{Bond Strength Testing Method}

\subsubsection{Pull-off Test}

The results of the pull-off test for Phase-III (Section 4.3.2.1) showed the complete debonding for ECC-Slag due to its high amount of combined autogenous and drying shrinkage (Section 4.1.3). In fact, during the first 2 months of curing (2M-Curing), while the Sub-B was under the highest rate of expansion, the ECC-Slag experienced the maximum amount of its shrinkage. This complete difference in the direction of the movement between ECC-Slag and Sub-B caused high tensile strength at the bond interface and the complete debonding.

On the other hand, SCC demonstrated the worst durability performance under the expanding deterioration since the drying shrinkage of SCC was recorded to be significantly high. Hence, when SCC moved outside the curing room after the 2M-Curing period (during 2M-Curing period, SCC demonstrated the minimum length change movement), it started to lose bond strength until complete debonding at 5 months (2MCuring $+5 \mathrm{M}$ ) mainly due to its high amount of drying shrinkage.

Interestingly, NC represented the higher bond strength for the first two periods (2M-Curing and $2 \mathrm{M}$-Curing $+1 \mathrm{M}$ ) because basically $\mathrm{NC}$ showed the minimum amount of shrinkage (best dimensional compatibility with Sub-B) while the samples are in curing room and outside curing room.

Finally, the UHPC established the best durability performance due to the fact that this material already experienced the majority of its shrinkage and consequently bond stress loss by the first measurement (2M-Curing). In fact, according to the shrinkage results (Section 4.1.3), UHPC experienced most of its shrinkage - no matter the environmental condition or curing methods - through the first 2 months. Thus, any bond stress loss after the $2 \mathrm{M}$-Curing period is mainly due to the expansion of the Sub-B. 


\subsection{Validation of the Bond Strength Testing Results}

To verify the bond strength results of different repair materials discussed in this section, the most recent literature with similar investigations were considered. However, since the number of articles available in the field of repairs - particularly covering the bond strength under freeze-thaw cycles with de-icing salt (Phase-II) or substrate suffering ACR expansion (Phase-III) - are significantly limited, the initial bond strength measurements for validation of the results were selected. Even without considering the deterioration modes, there are still very limited researches available on the bond strength. Having a reasonable bond strength difference between the stated results in the literature and reported values in this research is acceptable due to the following reasons: (1) It is very unlikely to find articles exact same mix design implemented in this research with the same mechanical properties especially when it comes to the advanced cement-based materials. (2) The mixing conditions at the time of casting such as temperature, relative humidity, speed and even type of mixer (UHPC, ECC-Slag, and SCC) are not the same. (3) It is almost impossible to have substrates with the same level of roughness even though they made with the same method of surface preparation.

In addition to the above common reasons, there is one particular reason which may cause significant bond strength loss for both phases (Phase-II and Phase-III) studied in this research although the initial bond strength was selected as a comparison point:

- For Phase-II at the time of initial measurement (0-cycle), the repair materials were cured for 14 days and experienced shrinkage for 2 months while for all the cited articles measured the bond strength within the curing period (mostly 28 days). Therefore, the 2 months shrinking period causes some bond stress loss for all repair products and more particularly for ECC-Slag and SCC.

- For Phase-III at the time of initial measurement (2M-Curing), the repair products were cured for 2 months. However, the substrate was expanding which again results in some bond stress loss in all materials. It should be mentioned that the author was not able to find any articles considering expanding deterioration modes on the repair materials. 


\subsubsection{Slant Shear Test}

As per investigation was implemented for UHPC at 8 days curing, the slant shear bond strengths stated between 16.1 MPa for smooth (brushed) surface texture to $21.7 \mathrm{MPa}$ for partially rough (sandblasted) texture which is very close to the finding of this research for smooth (21.37 MPa) and rough (28.99 MPa) surface texture (Carbonell Muñoz, Harris, Ahlborn, \& Froster, 2014).

Two recent researches on the ECC-Slag with smooth surface texture at 28 days revealed the bond strength of 24.2 and $24.3 \mathrm{MPa}$ (Sahmaran, Yücel, Yildirim, Al-Emam, \& Lachemi, 2014; Yildirim et al., 2015). The slant shear bond strength for ECC-Slag in this research was reported to be $8.61 \mathrm{MPa}$ for smooth surface texture and $19.46 \mathrm{MPa}$ for rough surface texture.

Regarding SCC, the slant shear bond strength recorded in the range of $11.4 \mathrm{MPa}$ for smooth surface texture (hand brushed) to $15.4 \mathrm{MPa}$ for partially rough surface texture (grooved with $6 \mathrm{~mm}$ width and $6 \mathrm{~mm}$ height) (Diab et al., 2017). In addition, the slant shear bond strength for SCC - provided by its commercial company (Table 3-9) reported to be $20 \mathrm{MPa}$. The literature and reported results were found to be reasonably close to the measured value in this thesis $-13.71 \mathrm{MPa}$ for smooth and $19.53 \mathrm{MPa}$ for rough surface texture.

According to Momayez et al. (2005), the slant shear bond strengths of NC were $8.12 \mathrm{MPa}$ for smooth surface texture (wired brushed with 3 to $4 \mathrm{~mm}$ depth) and $11.13 \mathrm{MPa}$ for rough surface texture (wired brushed with 7 to $8 \mathrm{~mm}$ depth). Another investigation was stated the bond strength of $10.67 \mathrm{MPa}$ for smooth (wired brushed) surface texture and 14.13 MPa for partially rough (sandblasted) surface texture (Júlio, Branco, \& Silva, 2004). The results of this study lied between 12.22 to $18.65 \mathrm{MPa}$ for smooth and rough surface textures, respectively.

The slightly higher slant shear bond strength which was observed for UHPC and NC within both surface texture should be due to eliminating the damages (microcracks) caused by surface roughness preparation methods (Section 2.4.1) which under the slant shear test overcome the negative effect of the shrinkage. 


\subsubsection{Splitting Tensile Test}

For UHPC cured for $\mathbf{2 8 0}$ days the results of splitting tensile bond strength ranges from 3.6 to 4.8 MPa for smooth to rough (grooved) surface texture (Carbonell Muñoz et al., 2014). Throughout this research, the bond strengths were reported to be $2.33 \mathrm{MPa}$ for smooth and $2.85 \mathrm{MPa}$ for rough surface texture.

According to the Sahmaran et al. (2014), the splitting tensile bond strength of the ECCSlag at 28 days curing was stated to be $3.43 \mathrm{MPa}$ for smooth and $3.75 \mathrm{MPa}$ for rough surface texture. The measured splitting tensile bond strengths were 1.42 and $1.63 \mathrm{MPa}$ for smooth and rough textures, respectively.

For SCC the Splitting tensile bond was found to be between 2.6 to $3.4 \mathrm{MPa}$ (Castel, Vidal, \& François, 2010). Therefore, the values for the bond strength should be less. Within this research, the splitting tensile bond strength of the SCC was realized to be $1.89 \mathrm{MPa}$ for smooth and 2.10 MPa for rough surface texture.

The investigation by (Momayez et al., 2005) demonstrated splitting tensile strength of 1.19 to $1.36 \mathrm{MPa}$ for NC. Within this research, the splitting bond strengths for smooth and rough surface texture were recorded to be 1.25 and $1.74 \mathrm{MPa}$, respectively.

The lower splitting tensile bond strength for UHPC, ECC-Slag and SCC with respect to the cited articles was observed. In fact, the influence of eliminating the damages resulted from surface roughness preparations was not enough to overcome the stress loss caused by shrinkage of UHPC, SCC and more particularly ECC-Slag. The difference between the behaviour of slant shear and splitting tensile tests is primarily due to the nature of acting load on specimens. In slant shear test, samples are under combined shear and compression load. Thus, the effect of surface preparation and roughness is more significant.

The slightly higher splitting tensile bond strength for NC reported in this research can be due to the (a) lowest shrinkage of NC among other repairs, (b) influence of the eliminating damages caused by surface preparation, and more probably (c) improvement in the Portland cement chemistry and properties from 2005 till now. 


\subsubsection{Pull-off Test}

For the direct tensile (pull-off) bond strength throughout this research, two bond strengths with only smooth texture - including freeze-thaw cycles with salt (Phase-II) and substrate suffering ACR expansion (Phase-III) - were examined. Therefore, the two measured bond strengths for both phases are compared with the literature values in this subsection.

For UHPC with smooth (brushed) surface texture at 8 days curing, the direct tensile bond strength was stated to be at 2.2 MPa (Carbonell Muñoz et al., 2014). Within this research, the direct tensile bond strengths for UHPC were found to be $0.98 \mathrm{MPa}$ for Phase-II and 1.10 MPa for Phase-III.

As specified by Yildirim et al. (2015), the direct tensile bond strength of ECC-Slag with smooth surface texture was $1.79 \mathrm{MPa}$. Another investigation was performed on the cast in-situ ultra-high toughness cementitious composite (CUHTCC) containing fly ash and $2 \%$ by volume PVA fibers which the CUHTCC mixture was very similar to the ECC blend. the results indicated the direct tensile strength of 0.85 to $1.88 \mathrm{MPa}$ (B. Wang et al., 2016). Throughout this study for ECC-Slag, the direct tensile bond strengths were recorded to be $0.54 \mathrm{MPa}$ for Phase-II and 0.00 MPa for Phase-III.

The direct bond strength of SCC was determined to be $1.72 \mathrm{MPa}$ at 28 days curing for smooth surface texture (Yildirim et al., 2015) which was very close to the reported values in this study - 1.14 MPa for Phase-II and 1.40 MPa for Phase-III.

The direct tensile bond strength of $\mathrm{NC}$ was shown to be in the range of $1.47 \mathrm{MPa}$ for smooth (partially chipped) to $1.92 \mathrm{MPa}$ for partially rough (wire brushed) surface texture (Júlio et al., 2004). Another study by Momayez et al. (2005) demonstrated lower direct tensile bond strength for $\mathrm{NC}$ with smooth $(1.18 \mathrm{MPa})$ and rough (1.32 $\mathrm{MPa}$ ) surface textures. Throughout this thesis, the direct tensile bond strengths were measured to be $0.63 \mathrm{MPa}$ for Phase-II and 1.46 for Phase-III.

Based on the results, Phase-II had the lower direct tensile bond strength in comparison to Phase-III. This could be the result of not casting a continuous layer of repair on top of Sub-A which increases the possibility of imperfection like air voids at the bond interface. 


\subsection{Final Summary}

The advanced cement-based materials including UHPC, ECC-Slag and SCC were implemented in this research to investigate the influence of the high strength provided by these repair products and also examine the effect of fiber content (steel fibers in UHPC or PVA fibers in ECC-Slag) to bridge the microcracks created by two deterioration modes. The results clearly indicated that the high strength or high fiber content alone does not enhance the performance of the repair materials. In fact, the most important influential factor in the designing the repair material mixture is the compatibility of the repair product with a substrate and more particularly dimensional compatibility. Therefore, optimizing a mix design with the minimum amount of combined autogenous and drying shrinkage is the must in the repair industry. Of course, the high strength and proper substrate surface preparation play important roles as well. 


\section{Chapter 6}

\section{Conclusion}

Based on the results of this research the following conclusions can be drawn:

\subsection{Materials Properties and Compatibility of Repairs with Substrate (Phase-I)}

* NC revealed the best material compatibility with both substrates in terms of compressive strength, static modulus of elasticity, and shrinkage.

* The type and duration of curing were proven to have minimum or no effect on the UHPC and ECC-Slag. In other words, the environmental condition does not affect these two materials, particularly during the first 14 days.

\subsection{Repairs under Freeze-Thaw Cycles with De-icing Salt (Phase-II)}

* The best (maximum) and worst (minimum) dimensional compatibility with Sub-A under curing, Shrinkage, and freeze-thaw cycles with de-icing salt were observed for NC and ECC-Slag, respectively.

* For the slant shear test and splitting tensile tests under rough and smooth surface textures through the freeze-thaw cycles with de-icing salt, UHPC represented the highest bond strength, and NC demonstrated the best durability performance (minimum stress loss through the freeze-thaw cycles). 
* For the pull-off test, NC confirmed to have the best durability performance through the cycles of freezing and thawing with de-icing salt. Furthurmore, SCC unexpectedly established the higher bond strength at 0-cycle and 5-cycles among other repair products.

* Increasing the surface roughness was proven to improve the bond strength no matter what type of repair products were used, the cycles of freezing and thawing, and even the type of testing methods.

* The surface roughness effect for slant shear was found to be approximately four times higher than splitting tensile test.

\subsection{Repairs Placed on Expanding Substrate - Suffering ACR (Phase-III)}

* In terms of dimensional compatibility, NC and SCC showed the best compatibility with Sub-B (ACR) during the curing periods, and UHPC was observed to have the best dimensional compatibility with Sub-B after the curing period.

* For the pull-off test under expanding deterioration, the NC represented the higher bond strength at 2 months curing and 2 months curing plus 1 month outside the curing room. Also, UHPC shown the best durability performance.

* ECC-Slag and SCC demonstrated the first and second worst durability performance under the expanding deterioration during the 2 months curing plus 5 months outside the curing room due to their high mount of shrinkage. 


\section{References}

Ahlborn, T. M., Peuse, E. J., \& Misson, D. L. (2008). Ultra-High-Performance-Concrete for Michigan Bridges Material Performance - Phase I. Michigan. Retrieved from https://www.michigan.gov/documents/mdot/MDOT_Research_Report_RC1525_25 7995_7.pdf

Aitcin, P. C. (1998). High Performance Concrete. London and New York: E \& FN Spon, An Imprint of Routledge.

Alkaysi, M., \& El-Tawil, S. (2016). Effects of variations in the mix constituents of ultra high performance concrete (UHPC) on cost and performance. Materials and Structures, 49(10), 4185-4200. https://doi.org/10.1617/s11527-015-0780-6

ASTM C157. (2016). Standard Test Method for Length Change of Hardened HydraulicCement Mortar and Concrete. ASTM International, 08, 1-7. https://doi.org/10.1520/C0157

ASTM C1583. (2013). Standard Test Method for Tensile Strength of Concrete Surfaces and the Bond Strength or Tensile Strength of Concrete Repair and Overlay Materials by Direct Tension (Pull-off Method). ASTM International, 1-4. https://doi.org/10.1520/C1583_C1583M-13

ASTM C1698. (2014). Standard Test Method for Autogenous Strain of Cement Paste and Mortar. ASTM International, 1-8. https://doi.org/10.1520/C1698-09R14 
ASTM C39. (2017). Standard Test Method for Compressive Strength of Cylindrical Concrete Specimens. ASTM International, 1-7. https://doi.org/10.1520/C0039

ASTM C469. (2014). Standard Test Method for Static Modulus of Elasticity and Poisson's Ratio of Concrete in Compression. ASTM International, 1-5. https://doi.org/10.1520/C0469

ASTM C496. (2011). Standard Test Method for Splitting Tensile Strength of Cylindrical Concrete Specimens. ASTM International, 1-5. https://doi.org/10.1520/C0496 ASTM C882. (2013). Standard Test Method for Bond Strength of Epoxy-Resin Systems Used With Concrete by Slant Shear. ASTM International, 1-4. https://doi.org/10.1520/C0882

Austin, S., Robins, P., \& Pan, Y. (1995). Tensile bond testing of concrete repairs. Materials and Structures, 28, 249-259. Retrieved from https://journalsscholarsportal-info.ezproxy.lib.ryerson.ca/pdf/13595997/v28i0005/249_tbtocr.xml

Austin, S., Robins, P., \& Pan, Y. (1999). Shear bond testing of concrete repairs. Cement and Concrete Research, 29(7), 1067-1076. https://doi.org/10.1016/S00088846(99)00088-5

Bache, H. H. (1981). Densified Cement Ultra-Fined Particle-Based Materials. The Second International Conference on Superplasticizers in Concrete. Ottawa.

Bissonnette, B., Courard, L., Beushausen, H., Fowler, D., Trevino, M., \& Vaysburd, A. (2013). Recommendations for the repair, the lining or the strengthening of concrete slabs or pavements with bonded cement-based material overlays. Materials and Structures, 46(3), 481-494. https://doi.org/10.1617/s11527-012-9929-8

Bonaldo, E., Barros, J. A. O., \& Lourenço, P. B. (2005). Bond characterization between concrete substrate and repairing SFRC using pull-off testing. International Journal of Adhesion and Adhesives, 25(6), 463-474.

https://doi.org/10.1016/j.ijadhadh.2005.01.002

Bonen, D., \& Shah, S. P. (2005). Fresh and hardened properties of self-consolidating concrete. Progress in Structural Engineering and Materials, 7(1), 14-26. https://doi.org/10.1002/pse.186

Cai, H., \& Liu, X. (1998). Freeze-Thaw Durability of Concrete: Ice Formation Process in 
Pores. Cement and Concrete Research, 28(9), 1281-1287. Retrieved from https://journals-scholarsportalinfo.ezproxy.lib.ryerson.ca/pdf/00088846/v28i0009/1281_fdocifpip.xml

Carbonell Muñoz, M. A., Harris, D. K., Ahlborn, T. M., \& Froster, D. C. (2014). Bond Performance between Ultrahigh-Performance Concrete and Normal-Strength Concrete. American Society of Civil Engineers, 26(8), 1-9.

https://doi.org/10.1061/(ASCE)MT.1943-5533

Castel, A., Vidal, T., \& François, R. (2010). Bond and cracking properties of selfconsolidating concrete. Construction and Building Materials, 24, 1222-1231. https://doi.org/10.1016/j.conbuildmat.2009.12.017

Cleland, D. J., Naderi, M., \& Long, A. E. (1986). Bond Strength of Patch Repair Mortars for Concrete. In Adhesion between polymers and concrete / Adhésion entre polymères et béton (pp. 235-244). Boston, MA: Springer US. https://doi.org/10.1007/978-1-4899-3454-3_26

CSA A23.1/CSA A23.2. (2014). A23.1-14 Concrete Materials and Methods of Concrete Construction / Test Methods and Standard Practices for Concrete. Mississauga: CSA Group.

Diab, A. M., Abd Elmoaty, A. E. M., \& Tag Eldin, M. R. (2017). Slant shear bond strength between self compacting concrete and old concrete. Construction and Building Materials, 130, 73-82. https://doi.org/10.1016/j.conbuildmat.2016.11.023

Emmons, P. H., Vaysburd, A. M., \& McDonald, J. E. (1993). A Rational Approach to Durable Concrete Repairs. Concrete International, 15(9), 40-45. Retrieved from http://imcyc.com/biblioteca/ArchivosPDF/Reparacion de Estructuras/4 A rational approach to durable concrete repair.pdf

Erhard, D., \& Chorinsky, G. (1986). Repair of Concrete Floors with Polymer Modified Cement Mortars. In Adhesion between polymers and concrete / Adhésion entre polymères et béton (pp. 230-234). Boston, MA: Springer US. https://doi.org/10.1007/978-1-4899-3454-3_25

Espeche, A. D., \& León, J. (2011). Estimation of bond strength envelopes for old-to-new concrete interfaces based on a cylinder splitting test. Construction and Building 


\section{REFERENCES}

Materials, 25(3), 1222-1235. https://doi.org/10.1016/j.conbuildmat.2010.09.032

Fehling, E., Schmidt, M., Walraven, J., Leutbecher, T., \& Fröhlich, S. (2014). Ultra-High Performance Concrete UHPC. Ernst \& Sohn A Wiley Brand. https://doi.org/10.1017/CBO9781107415324.004

Graybeal, B. A. (2006). Material Property Characterization of Ultra-High Performance Concrete. Retrieved from https://www.fhwa.dot.gov/publications/research/infrastructure/structures/06103/061 03.pdf

Hanjari, K. Z., Utgenannt, P., \& Lundgren, K. (2011). Experimental study of the material and bond properties of frost-damaged concrete. Cement and Concrete Research, 41, 244-254. https://doi.org/10.1016/j.cemconres.2010.11.007

Hindo, K. R. (1990). In-Place Bond Testing and Surface Preparation of Concrete. Concrete International, 12(4), 46-48. Retrieved from http://www.germann.org/TestSystems/BOND-TEST/1_hindo.pdf

Hwang, S.-D., \& Khayat, K. H. (2008). Durability characteristics of self-consolidating concrete designated for repair applications. Materials and Structures, 42, 1-14. https://doi.org/10.1617/s11527-008-9362-1

Júlio, E. N. B. S., Branco, F. A. B., \& Silva, V. D. (2004). Concrete-to-concrete bond strength. Influence of the roughness of the substrate surface. Construction and Building Materials, 18(9), 675-681.

https://doi.org/10.1016/j.conbuildmat.2004.04.023

Kapoor, Y. P. (2012). Self Compacting Concrete An Economical Approach.

Masterbuilder, 92-96. Retrieved from

https://www.masterbuilder.co.in/data/edata/Articles/July2012/92.pdf

Khayat, K. H., Ghezal, A., \& Hadriche, M. (1999). Factorial design model for

proportioning self-consolidating concrete. Materials and Structures, 32(9), 679-686.

Retrieved from https://link.springer.com/article/10.1007/BF02481706

Khayat, K. H., Ghezal, A., \& Hadriche, M. S. (2000). Utility of statistical models in proportioning self-consolidating concrete. Materials and Structures, 33(5), 338-344. https://doi.org/10.1007/BF02479705 
Kim, J.-K., Kim, J.-S., Ha, G. J., \& Kim, Y. Y. (2007). Tensile and fiber dispersion performance of ECC (engineered cementitious composites) produced with ground granulated blast furnace slag. Cement and Concrete Research, 37(7), 1096-1105. https://doi.org/10.1016/j.cemconres.2007.04.006

Kong, H. J., Bike, S. G., \& Li, V. C. (2003). Constitutive rheological control to develop a self-consolidating engineered cementitious composite reinforced with hydrophilic poly(vinyl alcohol) fibers. Cement and Concrete Composites, 25(3), 333-341. https://doi.org/10.1016/S0958-9465(02)00056-2

Kosmatka, S. H., Kerkhoff, B., \& Panarese, W. C. (2003). Design and Control Design and Control of Concrete Mixtures. Portland Cement Association (14th Editi, Vol. EB001). Illinois: PCA. https://doi.org/2001007603

Leemann, A., Lura, P., \& Loser, R. (2011). Shrinkage and creep of SCC - The influence of paste volume and binder composition. Construction and Building Materials, 25, 2283-2289. https://doi.org/10.1016/j.conbuildmat.2010.11.019

Lepech, M. D., \& Li, V. C. (2008). Large Scale Processing of Engineered Cementitious Composites. ACI Materials Journal, 105(4), 358-366. https://doi.org/10.1016/j.cemconcomp.2009.07.002

Lepech, M. D., \& Li, V. C. (2009). Water permeability of engineered cementitious composites. Cement and Concrete Composites, 31(10), 744-753. https://doi.org/10.1016/j.cemconcomp.2009.07.002

$\mathrm{Li}, \mathrm{V}$. C. (1993). The Design of Cementitious Composites for Civil Engineering Applications. Structural Eng./Earthquake Eng., 10(2), 37s-48s. Retrieved from https://deepblue.lib.umich.edu/bitstream/handle/2027.42/84735/jsce_paper93.pdf?s equence $=1$ \&isAllowed $=\mathrm{y}$

Li, V. C. (2003). On Engineered Cementitious Composites (ECC) A Review of the Material and Its Applications. Advanced Concrete Technology, 1(3), 215-230. Retrieved from https://www.jstage.jst.go.jp/article/jact/1/3/1_3_215/_pdf/-char/ja Li, V. C. (2006, July). Bendable Composites - Ductile Concrete for Structure. Structure Magazine, 45-48.

Li, V. C. (2007). Engineered Cementitious Composites ( ECC ) - Material , Structural, 
and Durability Performance.

Li, V. C., Fischer, G., Kim, Y., Lepech, M., Qian, M., Weimann, M., \& Wang, S. (2003). Final Report on Durable Link Slabs for Jointless Bridge Decks Based on StrainHardening Cementitious Composites. The Advanced Civil Engineering Material Research Laboratory, MDOT Project Manager: Roger Till. Michigan.

Li, Z. (2011). Advanced Concrete Technology. New Jersey: John Wiley \& Sons, Inc. Retrieved from http://197.14.51.10:81/pmb/ARCHITECTURE/Advanced Concrete Technology.pdf

Lukovic, M., Schlangen, E., Ye, G., \& Savija, B. (2013). Impact of surface roughness onthe debonding mechanism in concrete repairs. Proceedings of the 8 th International Conference on Fracture Mechanics of Concrete and Concrete Structures, FraMCoS 2013, 1-11.

Mehta, P. K., \& Monteiro, P. J. M. (2006). Concrete: microstructure, properties, and materials. The McGraw-Hill Companies (3rd Editio). The McGraw-Hill Companies. https://doi.org/10.1036/0071462899

Meng, W., Valipour, M., \& Khayat, K. H. (2017). Enhancement of microstructure of UHPC View project Economical and Crack-Free High-Performance Concrete for Pavement and Transportation Infrastructure Constructions View project Optimization and performance of cost-effective ultra-high performance concrete. Materials and Structures, 50(29), 1-16. https://doi.org/10.1617/s11527-016-0896-3

Mindess, S., Young, F. J., \& Darwin, D. (2003). Concrete. Prentice Hall (Second Edi). Upper Saddle River, New Jersey: Pearson Education.

Momayez, A., Ehsani, M. R., Ramezanianpour, A. A., \& Rajaie, H. (2005). Comparison of methods for evaluating bond strength between concrete substrate and repair materials. Cement and Concrete Research, 35(4), 748-757. https://doi.org/10.1016/j.cemconres.2004.05.027

Morgan, D. R. (1996). Compatibility of concrete repair materials and systems. Construction and Building Materials, 10(I), 57-67. Retrieved from https://journalsscholarsportal-info.ezproxy.lib.ryerson.ca/pdf/09500618/v10i0001/57_cocrmas.xml MTO LS-412-R17. (1997). Method of Test for Scaling Resistance of Concrete Surfaces 


\section{REFERENCES}

Exposed to Deicing Chemicals. Ministry of Transportation, Ontario (MTO) Laboratory Testing Manual, 1-5.

MTO LS-435-R28. (2013). Method of Test for Linear Shrinkage of Concrete. Ministry of Transportation, Ontario (MTO) Laboratory Testing Manual, 1-3. Retrieved from http://www.roadauthority.com/Standards/Home/FileDownload?standardFileld=6cc0 6fc6-369b-4bd4-b244-696d319aad77

Murthy, N. K., Rao, A. V. N., \& Reddy, I. V. R. (2014). Comparison of Cost Analysis Between Self Compacting Concrete and Normal Vibrated Concrete. International Journal of Civil Engineering and Technology, 5(7), 976-6308. Retrieved from http://www.iaeme.com/MasterAdmin/UploadFolder/20320140507005/20320140507 005.pdf

Neville, A. M. M., \& Brooks, J. J. J. (2010). Concrete Technology. Pearson Education Limited (2nd Editio, Vol. 11). England: Pearson Education Limited. https://doi.org/10.1016/0360-1323(76)90009-3

Okamura, H., \& Ouchi, M. (2003). Self-Compacting Concrete. Journal of Advanced Concrete Technology, 1(1), 5-15. Retrieved from http://kutarr.lib.kochitech.ac.jp/dspace/bitstream/10173/785/3/JACT_1_1_5.pdf

Pai, B. V. B. (2004). How economic is self-compacting concrete. Indian Concrete Journal, (June), 58-59.

Panesar, D. K., Aqel, M., Rhead, D., \& Schell, H. (2017). Effect of cement type and limestone particle size on the durability of steam cured self-consolidating concrete. Cement and Concrete Composites, 80, 175-189.

https://doi.org/10.1016/j.cemconcomp.2017.03.007

Paultre, P., Khayat, K. H., Cusson, D., \& Tremblay, S. (2005). Structural performance of self-consolidating concrete used in confined concrete columns. ACI Structural Journal, 102(4), 560-568. Retrieved from http://irc.nrc-cnrc.gc.ca/ircpubs

Prem, P. R., Bharatkumar, B. H., \& lyer, N. R. (2012). Mechanical Properties of Ultra High Performance Concrete. International Journal of Civil and Environmental Engineering, 6(0), 676-685. Retrieved from scholar.waset.org/1307-6892/230 Redon, C., Li, V. C., Wu, C., Hoshiro, H., Saito, T., \& Ogawa, A. (2001). Measuring and 
modifying interface properties of PVA fibers in ECC matrix. Journal of Materials in Civil Engineering, 13(6), 399-406.

Richard, P., \& Cheyrezy, M. (1995). Composition of reactive powder concretes. Cement and Concrete Research, 25(7), 1501-1511. https://doi.org/10.1016/00088846(95)00144-2

Sahmaran, M., Yücel, H. E., Yildirim, G., Al-Emam, M., \& Lachemi, M. (2014). Investigation of the Bond between Concrete Substrate and ECC Overlays. Journal of Materials in Civil Engineering, 26(1), 167-174.

https://doi.org/10.1061/(ASCE)MT.1943-5533.0000805

Saucier, F., Bastien, J., Pigeon, M., \& Fafard, M. (1991). A Combined ShearCompression Device to Measure Concrete-to- Concrete Bonding. Experimental Techniques, 50-55.

Scrivener, K. L., Crumbie, A. K., \& Laugesen, P. (2004). The interfacial transition zone (ITZ) between cement paste and aggregate in concrete. Interface Science, 12(4), 411-421. https://doi.org/10.1023/B:INTS.0000042339.92990.4c

Shehata, M. H., Jagdat, S., Rogers, C., \& Lachemi, M. (2017). Long-term effects of different cementing blends on alkali-carbonate reaction. ACI Materials Journal, 114(4), 661-672. https://doi.org/10.14359/51689897

Sherir, M. A. A., Hossain, K. M. A., \& Lachemi, M. (2015). Structural performance of polymer fiber reinforced engineered cementitious composites subjected to static and fatigue flexural loading. Polymers, 7(7), 1299-1330.

https://doi.org/10.3390/polym7071299

Shin, H.-C., \& Wan, Z. (2010). Interfacial Properties between New and Old Concretes. In Second International Conference on Sustainable Construction Materials and Technologies.

Tayeh, B. A., Bakar, B. H. A., Johari, M. A. M., \& Ratnam, M. M. (2013). The relationship between substrate roughness parameters and bond strength of ultra high-performance fiber concrete. Journal of Adhesion Science and Technology, 27(16), 1790-1810. https://doi.org/10.1080/01694243.2012.761543

Tragardh, J. (1999). Microstructural features and related properties of self-compacting 


\section{REFERENCES}

concrete. 1st International Rilem Symposium on Self Compacting Concrete, 7(June), 175-186.

Tsivilis, S., Batis, G., Chaniotakis, E., Grigoriadis, G., \& Theodossis, D. (2000). Properties and behavior of limestone cement concrete and mortar. Cement and Concrete Research, 30(10), 1679-1683. https://doi.org/10.1016/S00088846(00)00372-0

Vavrik, W. R., Huber, G., Pine, W. J., Carpenter, S. H., \& Bailey, R. (2002). Bailey Method for Gradation Selection in Hot-Mix Asphalt Mixture Design. Transportation Research CIRCULAR, E-C044(October), 34.

Wang, B., Xu, S., \& Liu, F. (2016). Evaluation of tensile bonding strength between UHTCC repair materials and concrete substrate. Construction and Building Materials, 112, 595-606. https://doi.org/10.1016/j.conbuildmat.2016.02.149

Wang, K., Jansen, D. C., Shah, S. P., \& Karr, A. F. (1997). Permeability study of cracked concrete. Cement and Concrete Research, 27(3), 381-393. https://doi.org/10.1016/S0008-8846(97)00031-8

Wang, S., \& Li, V. C. (2005). Polyvinyl alcohol fiber reinforced engineered cementitious composites: material design and performances. International RILEM Workshop on High Performance Fiber Reinforced Cementitious Composites (HPFRCC) in Structural Applications, 65-73. Retrieved from http://citeseerx.ist.psu.edu/viewdoc/download?doi=10.1.1.67.4523\&rep=rep1\&type $=\mathrm{pdf}$

Wang, S., \& Li, V. C. (2008). Engineered Cementitious Composites with High-Volume Fly Ash, (104), 233-241.

Wille, K., \& Boisvert-Cotulio, C. (2015). Material efficiency in the design of ultra-high performance concrete. Construction and Building Materials, 86, 33-43. https://doi.org/10.1016/j.conbuildmat.2015.03.087

Wille, K., Naman, A. E., \& Parra-Montesinos, G. J. (2011). Ultra - High Performance Concrete with Compressive Strength Exceeding $150 \mathrm{MPa}$ (22ksi) : A Simpler Way. ACI Materials Journal, 108(1), 46-53. https://doi.org/10.14359/51664215

Yan, P., \& Yu, C. (2009). Application of Self-Consolidating Concrete In Beijing. Second 


\section{REFERENCES}

International Symposium on Design, Performance and Use of Self-Consolidating Concrete SCC, 817-822. Retrieved from http://demo.webdefy.com/rilem-new/wpcontent/uploads/2016/10/pro065-086.pdf

Yang, E.-H., Wang, S., Yang, Y., \& Li, V. C. (2008). Fiber-Bridging Constitutive Law of Engineered Cementitious Composites. Journal of Advanced Concrete Technology, 6(1), 181-193. https://doi.org/10.3151/jact.6.181

Yildirim, G., Şahmaran, M., Al-Emam, M. K. M., Hameed, R. K. H., Al-Najjar, Y., \& Lachemi, M. (2015). Effects of compressive strength, autogenous shrinkage, and testing methods on bond behavior of high-early- strength engineered cementitious composites. ACI Materials Journal, 112(3), 409-418.

https://doi.org/10.14359/51687188

Zdeb, T. (2013). Ultra-high performance concrete - properties and technology. Bulletin of the Polish Academy of Sciences Technical Sciences, 61(1), 183-193. https://doi.org/10.2478/bpasts-2013-0017

Zhang, S. Q., Hughes, D., Jeknavorian, A. A., Nishimura, T., \& Yang, K. (2009). SelfCompacting Concrete, Worldwide Experience. Second International Symposium on Design, Performance and Use of Self-Consolidating Concrete SCC, 831-840.

Retrieved from http://demo.webdefy.com/rilem-new/wpcontent/uploads/2016/10/pro065-088.pdf

Zhou, J., Qian, S., Sierra Beltran, M. G., Ye, G., van Breugel, K., \& Li, V. C. (2010). Development of engineered cementitious composites with limestone powder and blast furnace slag. Materials and Structures, 43(6), 803-814. https://doi.org/10.1617/s11527-009-9549-0

Zhu, W., \& Bartos, P. J. (2005). Microstructure and Properties Of Interfacial Transition Zone In Scc. In First International Symposium on Design Performance and Use of Self-Consolidating Concrete (pp. 319-327). Changsha, Hunan, China: RILEM. https://doi.org/10.1617/2912143624.033 